\title{
Increasing access to reproductive health care through improved service delivery
}

Gul Rashida

Population Council

Iram Kamran

Population Council

Muhammad Khalil

Population Council

Zeba Tasneem

Population Council

Rehan M. Niazi

Population Council

See next page for additional authors

Follow this and additional works at: https://knowledgecommons.popcouncil.org/departments_sbsr-rh

Part of the Demography, Population, and Ecology Commons, Family, Life Course, and Society Commons, International Public Health Commons, Maternal and Child Health Commons, and the Women's Health Commons

How does access to this work benefit you? Let us know!

\section{Recommended Citation}

Rashida, Gul, Iram Kamran, Muhammad Khalil, Zeba Tasneem, Rehan M. Niazi, Mumraiz Khan, and Tahira Parveen. 2017. "Increasing access to reproductive health care through improved service delivery." Islamabad: Population Council. 


\section{Authors}

Gul Rashida, Iram Kamran, Muhammad Khalil, Zeba Tasneem, Rehan M. Niazi, Mumraiz Khan, and Tahira Parveen 


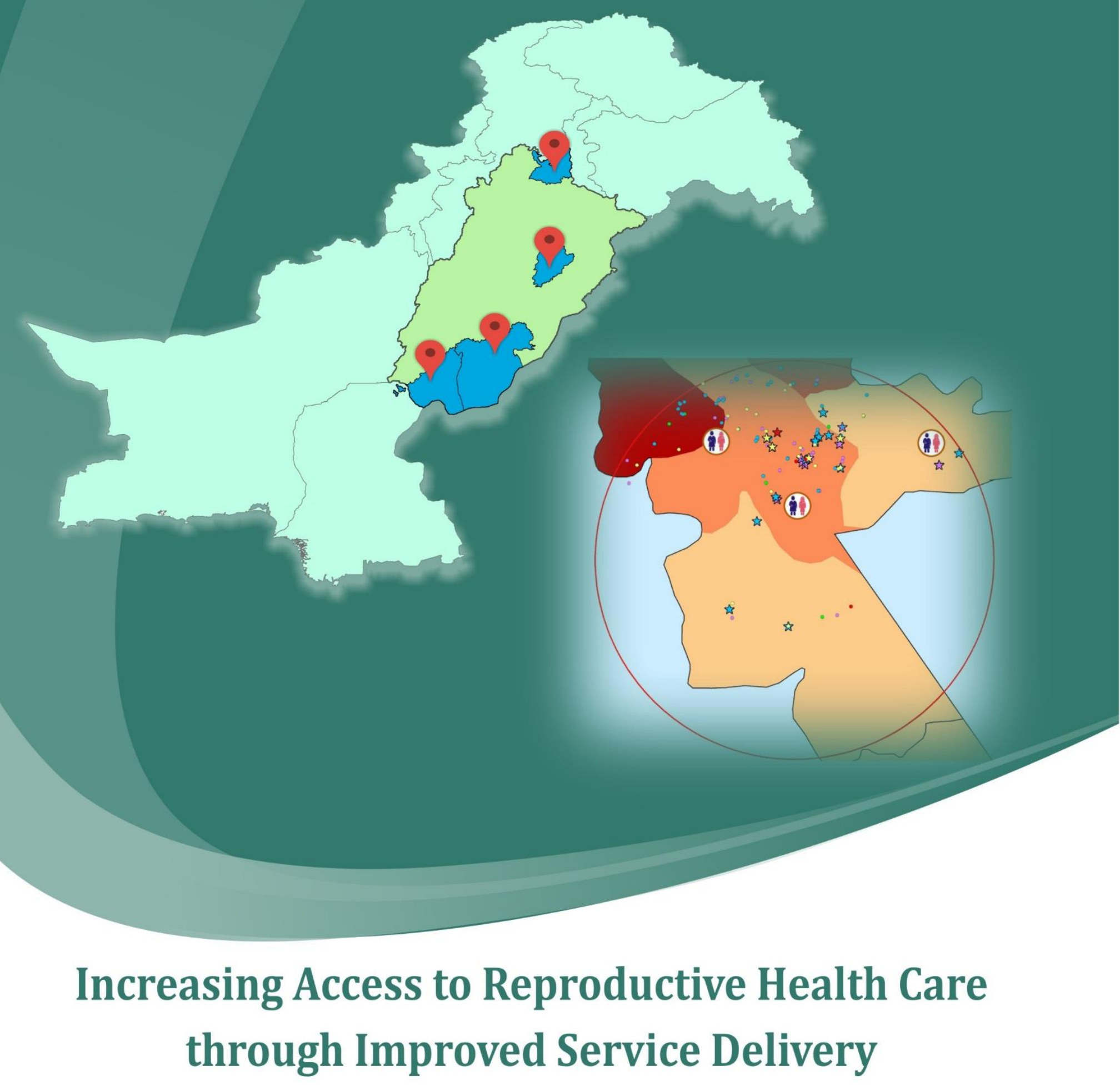

Authors:

Gul Rashida, Iram Kamran, Muhammad Khalil, Zeba Tasneem Rehan Niazi, Mumraiz Khan, Tahira Parveen 



\section{POPULATION \\ 7 COUNCIL \\ Ideas. Evidence. Impact.}

The Population Council confronts critical health and development issues-from stopping the spread of HIV to improving reproductive health and ensuring that young people lead full and productive lives. Through biomedical, social science, and public health research in 50 countries, we work with our partners to deliver solutions that lead to more effective policies, programs, and technologies that improve lives around the world. Established in 1952 and headquartered in New York, the Council is a nongovernmental, nonprofit organization governed by an international board of trustees.

Population Council

3rd Floor, NTC Building (North), Sector F-5/1, Islamabad, Pakistan

Tel: 92519205566

Fax: 92512821401

Email: info.pakistan@popcouncil.org

Web: http://www.popcouncil.org 



\section{Table of Contents}

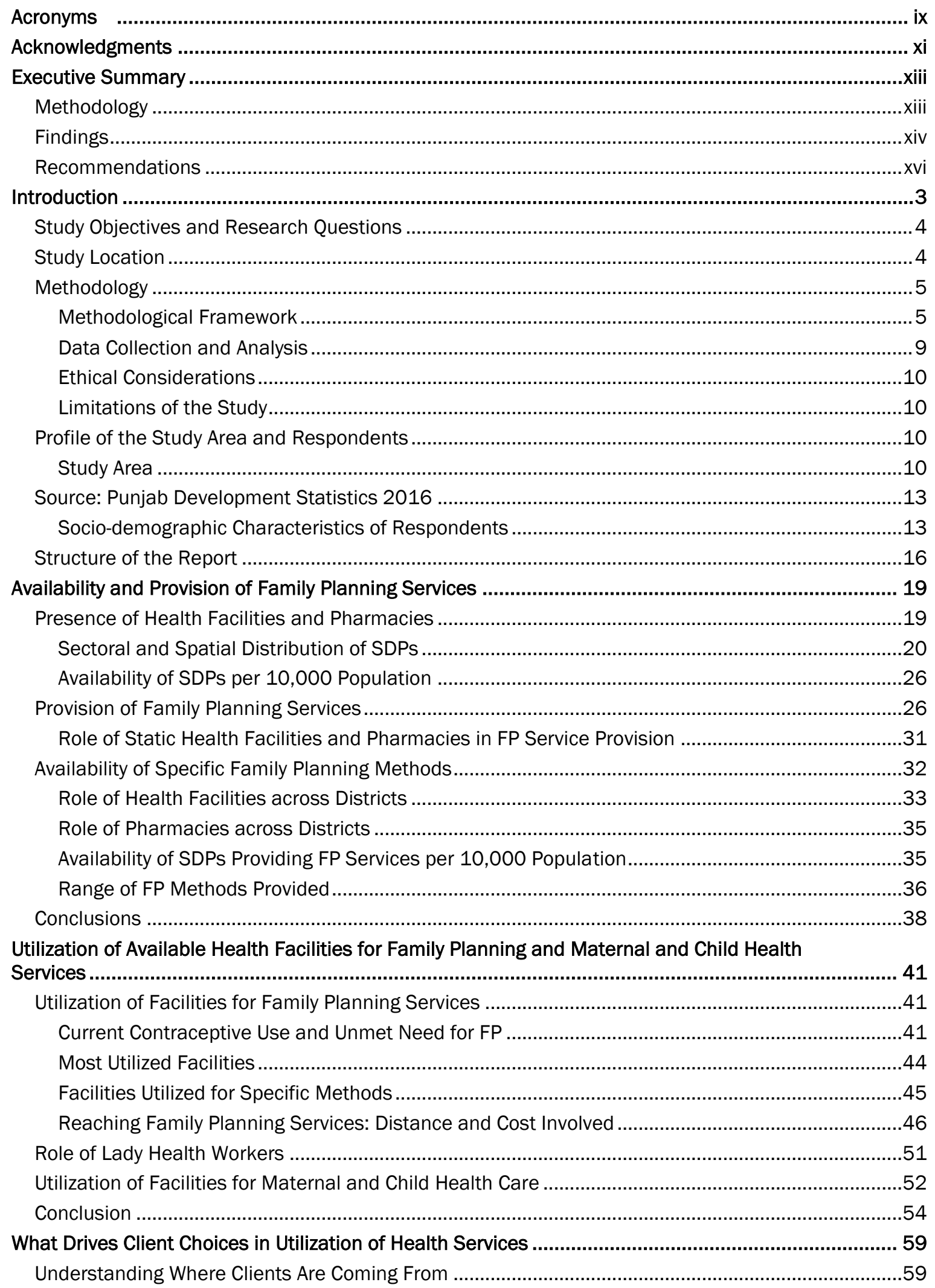




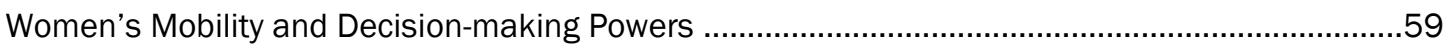

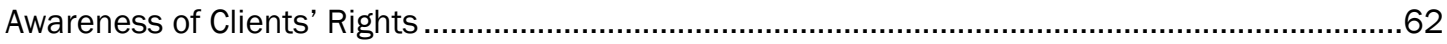

Expectations from Family Planning Service Providers ...................................................................63

Community Structures and Accountability Mechanisms: Existing Support for Utilization of

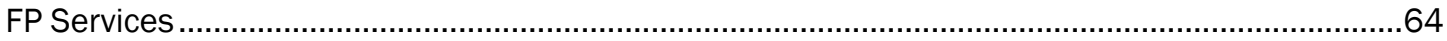

Reasons Clients Give for Their FP Service Utilization Choices ....................................................66

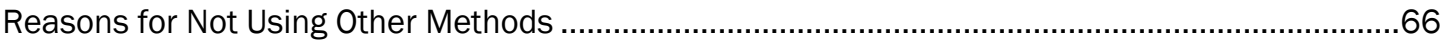

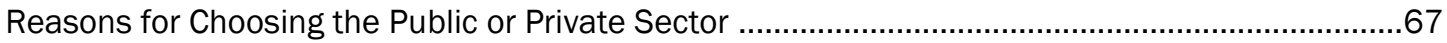

Affordability of FP Services and Willingness to Pay for Specific Methods ......................................71

Preferences of Men and Women about Provision of FP Services .....................................................72

Mobilizing Communities for Improved FP Service Utilization ..........................................................76

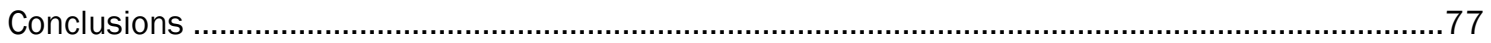

Quality of Care at Health Facilities for Family Planning Services and Missed Opportunities.................. 81

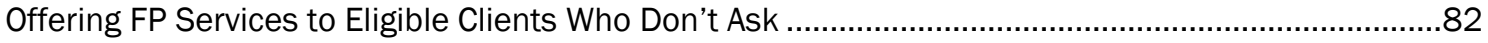

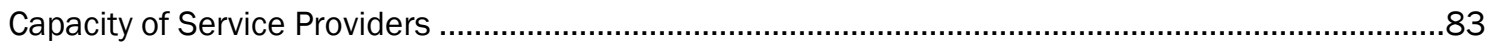

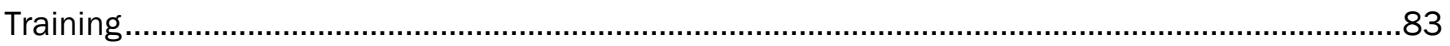

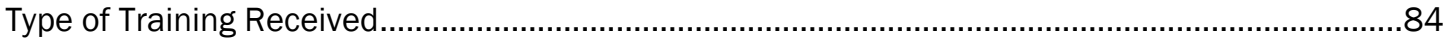

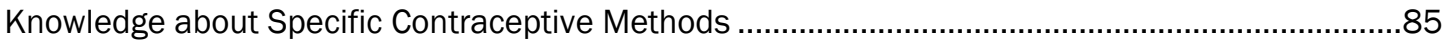

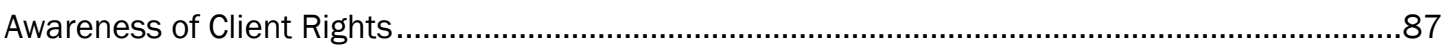

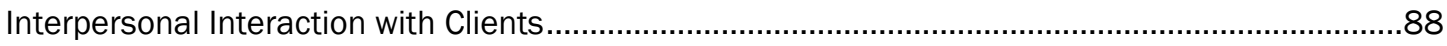

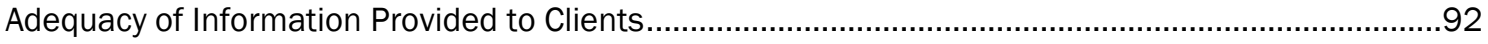

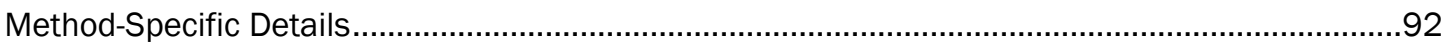

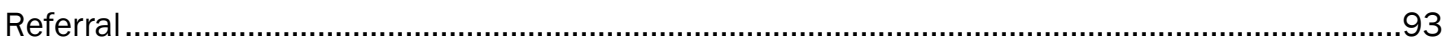

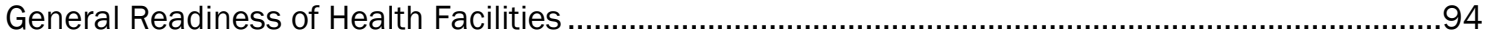

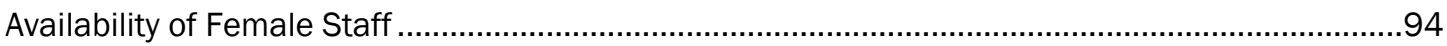

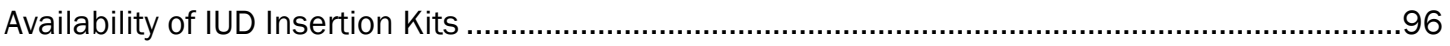

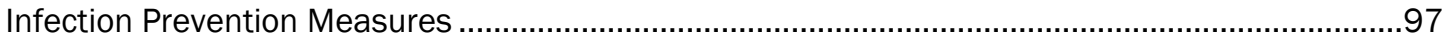

Availability of General Equipment and Arrangements for Privacy .....................................................99

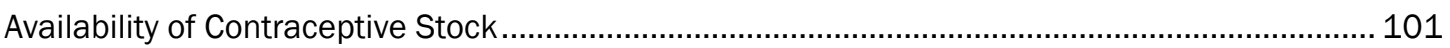

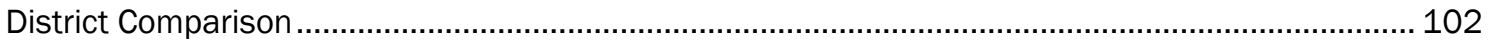

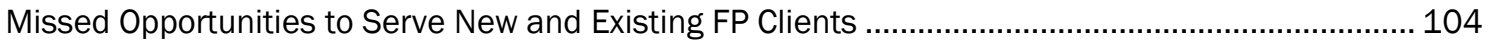

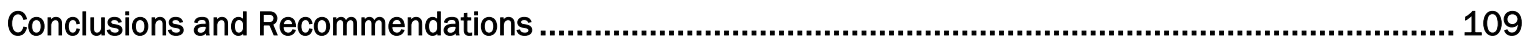

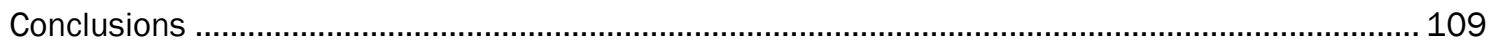

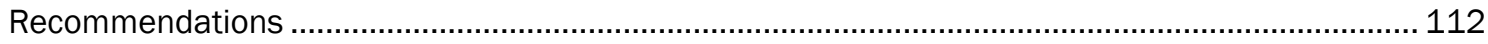

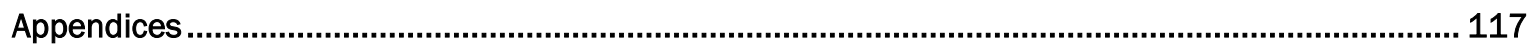

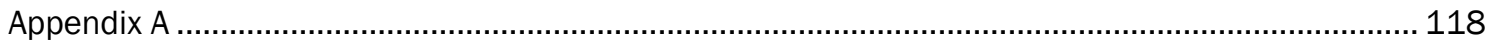

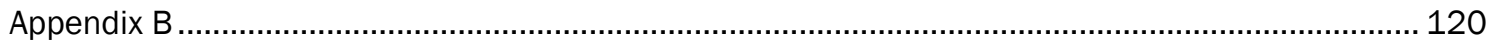

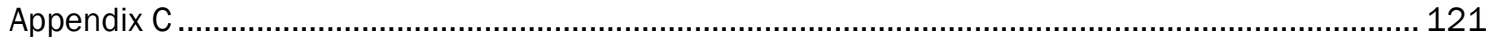

Appendix D

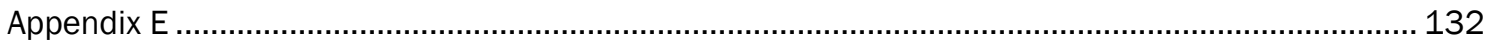




\section{List of Tables}

Table 1.1: Population, Contraceptive Prevalence, and Unmet Need in Study Districts ............................ 11

Table 1.2: Population (in million) of the Study Clusters ..................................................................... 13

Table 1.3: Socio-demographic Characteristics of Service Providers at Static Health Facilities.................. 13

Table 1.4: Socio-demographic Characteristics of Clients........................................................................ 14

Table 1.5: Socio-demographic Characteristics of Household Survey Respondents ................................... 15

Table 2.1: Number of Health Service Delivery Points Present in Study Clusters ......................................... 20

Table 2.2: Number of Public/ Private Health Facilities, LHWs, and Pharmacies per 10,000

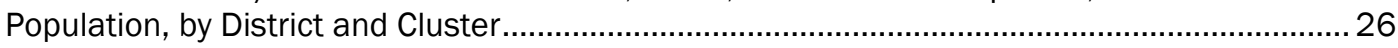

Table 2.3: Proportion of Static Health Facilities and Pharmacies Providing At Least One FP Method in the Study Areas Where They Exist in the Lowest and Highest Numbers, by District ................... 31

Table 2.4: Proportion of Public/ Private Health Facilities, LHWs Providing Specific FP Methods in

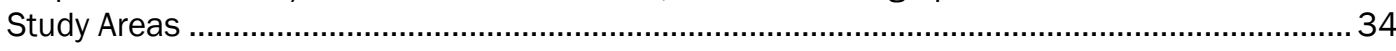

Table 2.5: Number of Static Public/ Private Health Facilities, LHWs, and Pharmacies Providing At Least One FP Method per 10,000 Population, by Cluster ........................................................... 36

Table 3.1: Mean Distances Travelled by Women HHS Respondents to Access Specific Family Planning Methods, $\mathrm{km}$ ( $\mathrm{n}=1,114$ women). 50

Table 3.2: Travel, Method, and Provider Cost Incurred by Women HHS Respondents to Access Specific Family Planning Methods, Pak Rs ( $n=1,114$ women) 50

Table 4.1: Reasons for Utilizing Public and Private Sector for Specific FP Methods among Those who Visit that Type of Facility for that Method, \% of HHS Respondents ( $n=1,114$ women) .............. 68

Table 5.1: Proportion of Service Providers who Gave Correct Answers about IUDs, \% .............................. 85

Table 5.2: Proportion of Service Providers Who Gave Correct Answers about Oral Pills, \%........................ 86

Table 5.3: Proportion of Service Providers Who Gave Correct Answers about Injectables, \% .................... 86

Table 5.4: Proportion of Service Providers Who Observe Specific Elements of Counseling, by Type of Respondent, \% ( $n=125$ service providers, 195 observations, 195 clients). 89

Table 5.5: Availability of At Least One Female Provider in the Morning and Evening Shift, by Type of Facility.

Table 5.6: Availability of Functional Complete and Essential IUD Insertion kits, by Sector and District.....97

Table 5.7: Availability of Functional Infection Prevention Arrangements, by Type of Facility..................... 98

Table 5.8: Availability of Functional Infection Prevention Arrangements, by Sector and District ................ 99

Table 5.9: Availability of Functional General Equipment and Arrangement for Privacy, by Type of

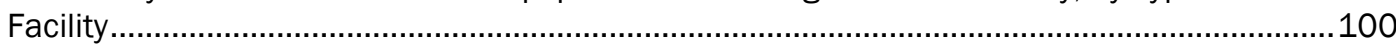

Table 5.10: Proportion of Facilities having Functional General Equipment by Sector and District ...........101

Table 5.11: Ranking of Districts - Capacity of Public Health Facilities to Provide Quality FP Services ....103

Table 5.12: Ranking of Districts - Capacity of Private Health Facilities to Provide Quality FP Services ...104 


\section{List of Figures}

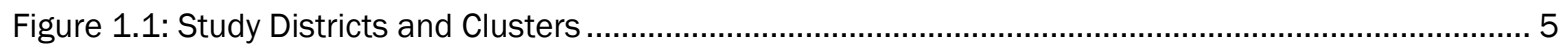

Figure 1.2: Methodological Framework ........................................................................................ 8

Figure 1.3 : Population Density and Cluster Locations in Study Districts ............................................... 12

Figure 2.1: Distribution of Static Public/Private Health Facilities in the Study Areas ................................ 21

Figure 2.2: Distribution of Public/Private Health Facilities, LHWs, and Pharmacies in the Study Areas .... 21

Figure 2.3a: Location of Public/Private Health Facilities, LHWs, and Pharmacies in Rawalpindi ............... 22

Figure 2.3b: Location of Public/Private Health Facilities, LHWs, and Pharmacies in Faisalabad .............. 23

Figure 2.3c: Location of Public/Private Health Facilities, LHWs, and Pharmacies in Bahawalpur.............. 24

Figure 2.3d: Location of Public/Private Health Facilities, LHWs, and Pharmacies in Rahim Yar Khan ...... 25

Figure 2.4a: Location of Public/Private Health Facilities, LHWs, and Pharmacies Providing at Least One FP Method in Rawalpindi......................................................................................... 27

Figure 2.4b: Location of Public/Private Health Facilities, LHWs, and Pharmacies Providing at Least

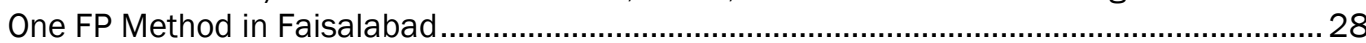

Figure 2.4c: Location of Public/Private Health Facilities, LHWs, and Pharmacies Providing at Least One FP Method in Bahawalpur 29

Figure 2.4d: Location of Public /Private Health Facilities, LHWs, and Pharmacies Providing at Least

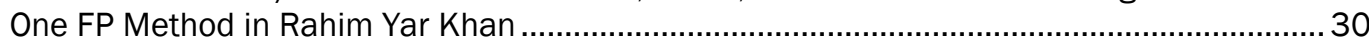

Figure 2.5: Proportion of Health Facilities (by Type) and Pharmacies Providing Any One FP Method in Study Areas.

Figure 2.6: Proportion of Public/ Private Health Facilities, LHW, and Pharmacies Providing Specific Family Planning Methods in Study Areas ........................................................................... 33

Figure 2.7: Proportion of Pharmacies Providing Specific FP Methods in Study Areas $(N=3,133) \ldots \ldots \ldots \ldots . . . .35$

Figure 2.8: Proportion of Public/Private Health Facilities, LHWs, and Pharmacies Providing any 1, at Least 3, and at Least 5 Family Planning Methods in the Study Areas

Figure 3.1: Contraceptive Use Status of HHS Respondents with At Least One Child, \% ( $n=329$ men, 1,114 women)

Figure 3.2: Contraceptive Use Status among Women HHS Respondents with At Least One Child, by District, \% ( $n=1,114$ women).....

Figure 3.3: Unmet Need among Women HHS Respondents with At Least One Child, by District, \% ( $n=1,114$ women).

Figure 3.4: Current Use of Specific Contraceptive Methods among Women HHS Respondents, \% ( $n=$ 1,114 women)

Figure 3.5: Residence and Socioeconomic Status of Current Users of Specific FP Methods among Women HHS Respondents, \% ( $n=1,114$ women).

Figure 3.6: Sources Most Frequently Utilized for FP Services by Women HHS Respondents, by Cluster Type, \% ( $n=1,114$ women)

Figure 3.7: Most Frequently Utilized Sources of Specific FP Methods among Women HHS Respondents, \% ( $n=1,114$ women).

Figure 3.8: Proportion of Women HHS Respondents Reporting Distances Travelled to Access Family Planning Services, by Type of Cluster, \% ( $n=1,114$ women). 
Figure 3.9: Health Facilities and Pharmacies Providing FP Services and Those being Utilized for FP Services by Surveyed Communities in District Head Quarter Cluster in Rawalpindi. 48

Figure 3.10: Health Facilities and Pharmacies Providing FP Services and Those being Utilized for FP Services by Surveyed Communities in Taxila Cluster in Rawalpindi.

Figure 3.11: Sectors Most Frequently Utilized for Maternal and Child Health Services by HHS Respondents, by District, \% ( $n=329$ men, 1,114 women) 53

Figure 3.12: Facilities Most Frequently Utilized by HHS Respondents for Maternal and Child Health Care, by Type of Facility, \% ( $n=329$ men, 1,114 women)

Figure 4.1: Mobility of Women According to HHS Respondents, \% ( $n=329$ men, 1,114 women) 60

Figure 4.2: Percentage of HHS Respondents Reporting a Woman can Seek FP Services When Needed, \% ( $n=329$ men, 1,114 women) .....

Figure 4.3: Percentage of HHS Respondents Reporting a Woman Can Send the Children to School and Seek Health Services Needed for Herself or Her Sick Child, \% ( $n=329$ men, 1,114 women).

Figure 4.4: Percentage of HHS Respondents Reporting a Woman Can Decide to Spend a Part of the Household Income and to Spend on Large Investments, \% ( $\mathrm{n=329}$ men, 1,114 women)....... 61

Figure 4.5: Proportion of HHS Respondents who Perceive They Have Knowledge of Patient Rights and Proportion Who Demonstrate Actual Knowledge of Patient Rights, \% ( $n=329$ men, 1,114 women)

Figure 4.6: Expectations of HHS Respondents When They Seek FP Services at a Health Facility, \% ( $n=329$ men, 1,114 women)

Figure 4.7: Main Reasons for Not Choosing Short-acting Methods at Time of Choosing Current/ Last Method, \% of HHS Respondents, \% ( $n=329$ men, 1,114 women) . 66

Figure 4.8: Reasons for Not Choosing Long-Acting Reversible Contraceptives at Time of Choosing Current/Last Method, \% of HHS Respondents, \% ( $n=329$ men, 1,114 women).

Figure 4.9: Reasons for Utilizing Sources of FP Services Who Utilize that Source Reported by HHS Respondents, \% ( $n=1,114$ women).

Figure 4.10: Main Reasons for Not Using Private Facilities for FP Services among HHS Respondents Frequently Utilizing Public Facilities, \% of respondents ( $n=329$ men, 1,114 women)

Figure 4.11: Main Reasons for Not Using Public Facilities among HHS Respondents Frequently Utilizing Private Facilities, \% of respondents ( $n=329$ men, 1,114 women)

Figure 4.12: Method Specific Actual Median Cost and Willingness to Pay, including Costs of Contraceptive and Travel, Pak Rs. ( $n=1,114$ women)

Figure 4.13: Preferences of Respondents about which Sector should Provide Family Planning Services, \% (Clients $n=406$ women, HHS $n=1,114$ women)

Figure 4.14: Preferences of Respondents about Where Family Planning Services Should be Located, $\%$ (Clients $n=406$ women, HSS n=1,114 women).

Figure 4.15: Preferences of Respondents about Which Provider Cadre Should Provide Family Planning Services, \% (Clients $n=406$ women, HSS n=1,114 women)

Figure 4.16: Preferences of Respondents about Integration of Family Planning Services with Maternal and Child Care or Other Reproductive Health Services, \% (Clients n=406 women, HSS $n=1,114$ women)

Figure 4.17: Profile of HHS Respondents who Prefer Separate Provision of Family Planning Services or Integration with Maternal and Child Care or Other Reproductive Health Services, \% ( $n=1,114$ women) 
Figure 4.18: Reasons Given by Interviewed Clients (in HFA) for Preferring Separate or Integrated Provision of FP Services, \% ( $n=406$ women)

Figure 4.19: Reasons Given by Respondents (HHS) for Preferring Separate or Integrated Provision of FP Services, \% ( $n=1,114$ women)

Figure 5.1: Opportunity Missed Because Providers not Offering FP Counseling/Services to Clients Who don't Ask

Figure 5.2: Proportion of Providers Who Do Not Discuss FP if the Client Comes for Other Needs, by Cadre and Sector, \% $(n=$ public $=638$, private $=592)$

Figure 5.3: Proportion of Service Providers Who had Received Different Types of Training in FP within Last 3 Years, by Cadre, \% $(n=399)$

Figure 5.4: Number of Service Providers Who had Received Different Types of Training in FP $(n=103) \ldots 85$

Figure 5.5: Proportion of Service Providers Who Reported Awareness of Client Rights $(n=399)$ and Those among Them Who Identified at Least One Specific Client Right, \% $(n=304)$, by District.

Figure 5.6: Proportion of Providers Who Reassure Clients that They can Return Anytime as Reported by Cadres of Service Providers and by Observers, \% ( $n=125$ service providers, 195 Observations)

Figure 5.7: Proportion of Service Providers Who Give a Follow-Up Date as Reported by Cadres of Service Providers, Observers, and Clients, \% ( $n=125$ service providers, 195 clients)

Figure 5.8: Proportion of Service Providers Who Ask Clients to Repeat Instructions as Reported by Cadres of Service Providers, Observers, and Clients, \% ( $n=125$ service providers, 195 clients).

Figure 5.9: Proportion of Service Providers Who ASK for Clients' Permission before Conducting Physical Examinations as Reported by Cadres of Providers, Observers, and Clients, \% ( $n=125$ service providers, 195 clients).

Figure 5.10: Proportion of Providers and Clients Reporting that Specific Information was Provided about the FP Method Selected by the Client, \% ( $n=399$ service providers, 416 clients) ....... 93

Figure 5.11: Proportion of Providers Who Give Specific Information to Clients When Referring Them for FP Services, \% ( $n=399)$.

Figure 5.12: Proportion of Facilities with At Least One Female Provider Present in Morning and Evening Shift, by Sector and District, \%.

Figure 5.13: Availability of Functional Essential and Complete IUD Insertion Kits at Public and Private Health Facilities, \% ( $\mathrm{n}=142$ public facilities, 181 private facilities).....

Figure 5.14: Percentage of Facilities Having Stocks of Specific Contraceptive Methods on The Day of Visit, by Sector.

Figure 5.15: Missed Opportunity 106 


\section{Acronyms}

\begin{tabular}{|c|c|}
\hline ANC & Antenatal Care \\
\hline $\mathrm{BHU}$ & Basic Health Unit \\
\hline $\mathrm{BP}$ & Blood Pressure \\
\hline CM & Currently Married \\
\hline CMWRA & Currently Married Women of Reproductive Age \\
\hline CMWs & Community Mid wife Workers \\
\hline CPR & Contraceptive Prevalence Rate \\
\hline CSPro & Census and Survey Processing System \\
\hline DFID & Department for International Development \\
\hline DHQ & District Head Quarter \\
\hline $\mathrm{DoH}$ & Department of Health \\
\hline DPWO & District Population Welfare Officer \\
\hline ECP & Emergency Contraceptive Pills \\
\hline EDO & District Officer-Health \\
\hline FGDs & Focus Group Discussions \\
\hline $\mathrm{FHC}$ & Family Health Center \\
\hline FHT & Female Health Technician \\
\hline FMT & Female Medical Technician \\
\hline FP & Family Planning \\
\hline FWA & Family Welfare Assistant \\
\hline FWC & Family Welfare Centre /Family Welfare Counselor \\
\hline FWW & Family Welfare Worker \\
\hline GYN & Gynecologist \\
\hline HF & Health Facility \\
\hline HFA & Health Facility Assessment \\
\hline HHS & Household Survey \\
\hline IDls & In-depth interviews \\
\hline IRB & Institutional Review Board \\
\hline IUCD & Intrauterine Contraceptive Device \\
\hline LAM & Locational Amenorrhea Method \\
\hline LARCs & Long Acting Reversible Contraceptives \\
\hline LHV & Lady Health Visitor \\
\hline LHW & Lady Health Worker \\
\hline MBBS & Bachelor of Medicine and Surgery \\
\hline $\mathrm{MCH}$ & Maternal and Child Health \\
\hline
\end{tabular}




$\begin{array}{ll}\text { MCHC } & \text { Mother and Child Health Center } \\ \text { MHT } & \text { Male/ Medical Health Technician } \\ \text { MICS } & \text { Multiple Indicator Cluster Surveys } \\ \text { NGO } & \text { Non-Governmental Organization } \\ \text { PC-Landscape } & \text { Population Council's Study “Landscape Analysis of the FP Situation in Pakistan”, 2016 } \\ \text { PDHS } & \text { Pakistan Demographic Health Survey } \\ \text { PNC } & \text { Post Natal Care } \\ \text { PPHI } & \text { Peoples Primary Health Initiative } \\ \text { PRSP } & \text { Punjab Rural Support Program } \\ \text { Pvt } & \text { Private } \\ \text { QoC } & \text { Quality of Care } \\ \text { RH } & \text { Reproductive health } \\ \text { RHC } & \text { Rural Health Center } \\ \text { RHSC-A } & \text { Reproductive Health Services Center-A } \\ \text { SDM } & \text { Standard Days' Method } \\ \text { SDPs } & \text { Service Delivery Points } \\ \text { SP } & \text { Services Provider } \\ \text { SPSS } & \text { Statistical Package for the Social Sciences } \\ \text { THQ } & \text { Tehsil Head Quarter } \\ \text { WRA } & \text { Women of Reproductive Age }\end{array}$




\section{Acknowledgments}

We would like to thank the Department for International Development, UK (DFID) for supporting this study on "Increasing Access through Improving Service Delivery," which identifies key gaps in service delivery and the drivers of client choices in utilization of family planning services in Pakistan's most populous province, Punjab.

We express our gratitude to Dr. Zeba A. Sathar (TI), Country Director, Population Council, Islamabad, for her guidance and invaluable intellectual support from the inception of this study to its completion.

We thank Dr. Ali Mir, Director Programs, Population Council for his guidance and constructive input and support at every step of the study, through planning, implementation, and report development.

We are especially grateful to the provincial Secretaries of the Departments of Population Welfare and Health and their staff for giving their permissions to conduct the study. We also thank the District Officers of Health and Population Welfare in Rawalpindi, Faisalabad, Rahim Yar Khan, and Bahawalpur for their support in carrying out field activities.

A special thanks to those of our team members who carried out the field work for different components for their excellent contribution and dedication. We also thank the data entry staff, who worked overtime to complete their assignment on time.

We are extremely grateful to Ms. Kiren Khan, whose meticulous review, inputs, and editing helped shape this report and greatly ease its finalization.

Thanks are also due to the Administration and Financial Management team at the Population Council Islamabad office, who worked hard to facilitate the implementation of field activities. We also thank Mr. Ali Ammad for his contribution in making this report presentable through formatting and layout.

Finally, we owe a debt of gratitude to all our respondents-including service providers at health facilities, pharmacists, and the men and women of local communities-for sparing their precious time to participate voluntarily in the interviews and discussions conducted for this study. Without their honest and valuable responses, we would not have been able to generate the useful data and insights documented in this report. 



\section{Executive Summary}

With a population of about 208 million that is growing at slightly more than 2 percent a year, Pakistan faces what may legitimately be called a population emergency. Fertility is declining, but not as fast as in most of the rest of South Asia despite high levels of unmet need. Among the provinces, Punjab, where half of the national population resides, has the highest contraceptive prevalence rate (CPR), at 41 percent (PDHS 2012 13). However, of the total 18 million currently married women of reproductive age in the province, 3.2 million are still living with unmet need for family planning (FP), comprising a huge untapped opportunity for reining in population growth. The Punjab provincial government is keen to increase the CPR to 55 percent by 2020, primarily by eliminating existing unmet need.

The study documented in this report examines the provision and utilization of public and private sector maternal and child health services in Punjab, with a focus on family planning services. It is aimed at enabling a better understanding of the specific demand and supply dynamics leading to low contraceptive prevalence despite unmet need, and the opportunities that must be seized to enhance access to quality family planning services. The report is part of a larger project being implemented by the Population Council with the assistance of the Department for International Development, UK (DFID), entitled "Sustaining Focus on Provincial Governments for FP 2020 Goals and Increasing Access to Reproductive Healthcare through Improved Service Delivery."

\section{Methodology}

The study was framed around three key research questions: What factors drive clients' choices when seeking family planning services? What direction can increase accessibility, affordability, and quality of family planning services based on service delivery needs? And what are the existing gaps in service delivery in terms of availability, quality, and missed opportunities to recruit and retain clients?

These questions were explored through a mixed research design comprising three quantitative and two qualitative components. The quantitative components included (1) a census of public and private health facilities, pharmacies and Lady Health Workers (LHWs); (2) an assessment of health facilities; and (3) a household survey of family planning choices, knowledge, and experiences of men and women. The two qualitative assessments concerned (4) community FP care-seeking behavior and perspectives, and (5) the scope for improving community utilization of FP services. These investigations were carried out in four districts with some of the largest populations of women with unmet need, including Rawalpindi from Northern Punjab, Faisalabad from Central Punjab, and Bahawalpur and Rahim Yar Khan from Southern Punjab. This selection reflects the variation in development in Punjab from the more developed north to the least developed south. Four clusters of 10-kilometer radius were randomly selected in each district for data collection, ensuring that one cluster represented all or part of the main city in each district. The population of the four clusters in each district represented 40 percent of the population of Rawalpindi district, 59 percent of the population of Faisalabad district, 37 percent of the population of Bahawalpur, and 35 percent of the population of Rahim Yar Khan (Punjab Development Statistics, 2016).

The census of public and private health facilities, pharmacies and LHWs maps the overall availability of health facilities, LHWs, and pharmacies in the study clusters, as well as provision of FP services and specific FP methods by each. Altogether, 10,578 public and private health facilities, LHWs, and pharmacies are included in the analysis. The assessment of health facilities looks at the readiness of facilities to provide FP services, the capacity of service providers, and the experiences and perspectives of clients at the facilities. About 400 health facilities are included in the assessment. The household survey was conducted in 46 communities in the 16 clusters of study districts, and explores met and unmet demand for FP, choices about FP methods 
and sources, and underlying reasons, constraints, and preferences among current and potential users in the study area based on interviews with 1,114 women and 329 men. Community perspectives on FP careseeking behavior and drivers, and the potential for improving local provision and utilization of FP services are further examined in the two qualitative components which entailed, respectively, 16 focus group discussions (with 81 men and 84 women) and 16 in-depth interviews with service providers and influential community members. The findings of the five components have been triangulated in the analysis.

\section{Findings}

A large proportion of existing health service delivery points (SDPs) are currently not providing family planning services. This untapped potential came to 11 percent of the 329 public static health facilities, 82 percent of the 4,139 private static health facilities, and 26 percent of the 3,133 pharmacies visited in the four study districts. However, all of the 2,977 LHWs located are reportedly providing FP services.

In the study clusters, the average number of SDPs per 10,000 population ranges between 1.8 and 2.6 in the public sector (counting both static facilities and LHWs), and between 3.5 and 4.2 in the private sector (including both health facilities and pharmacies). However, when it comes to FP service provision, these ratios drop to 1.7 to 2.5 in the public sector and 1.2 to 2.1 in the private sector.

Even where FP services are available, the choice of methods is largely limited. The majority of the public health facilities are providing at least one family planning method. However, less than 75 percent of different public sector facilities except BHUs and PWD are providing three family planning methods whereas less than 47 percent of all private facilities are providing three methods. When it comes to providing at least five methods, the proportion of active facilities drops even further to 50 percent or less in public sector and less than 20 percent in private sector, except in the case of mid-level female providers.

Short-acting FP methods are much more commonly available than long-acting reversible contraceptives (LARCs). Condoms, oral pills, and injectables are available at nearly all public health facilities as well as with LHWs, with a slightly lower involvement of DoH facilities. The proportion of private facilities offering a FP method is also highest (about 20\%) for these three methods. ECPs are comparatively less available at health facilities but can be obtained from most pharmacies, which also carry condoms and oral pills, and to a lesser extent, injectables. Although high proportions (about 83\%) of all public health facilities offer intrauterine devices (IUDs), only about 12 percent of private health facilities are providing this method, and its availability at pharmacies is also negligible. Availability of implants is quite low (13\%), and primarily restricted to public sector facilities. Male and female sterilization services available at a handful of health facilities.

In the private sector, some cadres and facility types are more involved in FP service provision than others. Clinics of the mid-level female cadres, i.e., Lady Health Visitors (LHVs), nurses, and midwives, are consistently more active in providing FP services. The other notable types of health facilities in the private sector include hospitals and, to some extent, NGO clinics. A good proportion of female private doctors are providing services, more so in the urban areas. Clinics of male doctors are present in good numbers especially in rural areas but few are providing FP services, leading to a large missed opportunity. Clinics of dispensers and of homeopaths or hakeems are present in far larger numbers than the other types of private facilities, but generally the proportions providing any FP services are quite low.

Both met and unmet demand for family planning is quite high among women with at least one child. Although contraceptive use levels are encouraging-53.3 percent in Rawalpindi and Bahawalpur, 52.3 percent in Rahim Yar Khan, and 50 percent in Faisalabad-unmet need is also quite high, i.e., 23.3 percent in Rawalpindi, 22.9 percent in Bahawalpur, 18 percent in Rahim Yar Khan, and 11.7 percent in Faisalabad. Among women with at least one child, there is no noticeable difference in contraceptive use between the two 
northern districts, Rawalpindi and Faisalabad (51.7\%) and the southern districts (52.7\%). However, the proportion of past users is relatively higher in the south (24.9\%) compared to the north (17.5\%), while never users are present in a larger proportion in the north (30.8\%) than in the south (22.4\%). Unmet need is slightly higher in the south $(20.0 \%)$ than in the north (17.5\%).

The most frequently utilized facilities for family planning services include the LHWs, public static facilities, and pharmacies. The main reason for the popularity of these sources is their presence in the vicinity of users and their affordability. Those who opt for private health facilities primarily do so because public facilities are crowded: they have to wait longer to see the service providers, and the providers have less time to attend to them properly. However, the majority of community respondents are not able to afford private services and some also claim that private providers are not adequately qualified.

FP users are mainly relying on condoms, withdrawal, and female sterilization. Condoms are the main modern reversible method in use (21\%), followed by withdrawal (10\%) and female sterilization (9\%). Use of hormonal methods is quite low, especially among women who are urban and of middle or high socioeconomic status; relatively higher proportions of poor rural women use injectables and intrauterine devices (IUDs). The reliance on male methods appears to imply, both, increased male interest in FP and a rejection of female hormonal methods.

Female respondents recognize that longer acting and permanent methods are more cost-effective and are willing to pay for them. Women feel they are spending too much on condoms, oral pills, and ECP, but are satisfied with the cost of injectables and IUDs. On the other hand, for implants and tubal ligation, they are willing to pay almost double what they are paying now. The mean contraceptive cost is higher in rural than urban areas for all methods except condoms.

Difficulties of access, fear of side effects, and lack of information are main reasons affecting method choices. Women's mobility is restricted outside their communities, and they have to travel 1 to 5 kilometers-often much more in rural areas-to access FP services. On average, men and women need to travel shorter distances for the short-acting methods than they have to for long-acting reversible contraceptives (LARCs) or tubal ligation, especially in rural areas. However, even for the short-acting methods, access may pose a formidable challenge in areas not yet covered by the LHW Programme. Both men and women emphasize the access problem with equal intensity. In addition, fear of side effects (based on past experience or word of mouth) is a main reason why clients do not choose the hormonal methods, especially injectables and IUDs. Women, in particular, are anxious about this risk. Moreover, men and women have limited knowledge about emergency contraceptive pills and implants.

Men want male service providers to provide FP information, counseling and methods to them. Most women cannot practice family planning or choose a method unless their husbands agree, but men typically cannot consult with female providers and do not know where to go for FP information and services except pharmacies, who do not provide information. Men also want providers to be available in the evening so they do not have to choose between work commitments and health needs.

Men and women have limited knowledge of specific client rights-as do service providers-but there is potential to improve accountability through community mobilization. Interviews with service providers and with influential community members suggest that while family planning is not yet a subject of local discussion, potential influencers, such as councilors, teachers, and religious leaders, could be oriented to spread awareness about FP, forge links between local providers and the community, and to provide feedback to the health facilities regarding the quality of services. 
Men and women prefer that FP services be provided locally, via the public sector. There is a strong preference for provision of FP services in their close vicinity or at their doorstep, underscoring the importance of the LHWs. Most men and women want FP services to be integrated with maternal and child health or reproductive health services, however, privacy is a major concern and special arrangements must be ensured in this regard. Men and women prefer qualified doctors to less skilled providers, but generally do not identify any specific aspects of quality of care-other than how the provider interacts with them-as reasons for preferring facilities.

From the foregoing discussion, it can be inferred that gaps in the availability and in the delivery of FP services-both at facility and provider level-are contributing both to the current levels of unmet demand, as well as the low use of oral pills, injectables, and LARCs, which would be more reliable and cost-effective, especially in rural areas.

At the vast majority of health facilities, clients are not offered FP services unless they ask. This study found that 87 percent of clients who visited health facilities with reproductive health needs other than FP were not provided any counseling or information about family planning methods, which is a huge opportunity missed, especially where clients are less educated and rely on providers to make a holistic assessment of their needs.

Service providers are in dire need of refresher trainings in contraceptive technology and client-centered behavior. Only 26 percent have received any type of training related to family planning in the past three years, including only twelve doctors-three male and nine female. Knowledge about specific FP methods is weak, and providers are not clear about basic matters such as where certain methods are contraindicated, the frequency with which they should be administered, and how to manage the associated side effects. There are also weaknesses in provider practices related to communication with clients and ensuring their autonomy and privacy. Most clients leave the health facility with inadequate information about how to use and what to expect while using their chosen contraceptive method.

Facility-level gaps are also contributing to issues in FP service provision. Female providers are not available to cater to female clients at about 60 percent of 323 both public and private facilities in the evenings. This implies additional access difficulties for women who cannot travel in the day time. Most DoH facilities, except teaching hospitals and BHUs, are not giving much weightage to privacy, which is an important concern of clients. Many clients who are referred to other facilities for FP services are also not provided sufficient information to facilitate their access. Availability of contraceptive stocks and necessary equipment, such as IUD insertion kits, also varies considerably.

There is scope for improving contraceptive prevalence as well as the method mix by increasing the proportion of facilities providing FP services, expanding the range of methods available, enhancing the role of male providers, increasing the timings in which female providers are available, and most importantly, by training service providers so they understand the importance of family planning and can confidently help their clients select and sustain use of appropriate contraceptive methods.

\section{Recommendations}

The following measures and approaches are recommended to address unmet need for family planning and the skewed method mix in Punjab.

1. Build solid commitment to family planning across the health sector. The unequivocal commitment to family planning demonstrated by the top leadership in Punjab must be embraced by the health and medical community in the province. Male and female doctors, mid-skilled providers, and community health workers must be made aware of the importance of health timing and spacing of pregnancies (HTSP), and this 
should reflect in the protocols they observe while dealing with clients at health facilities and in communities. Moreover, the institutions involved in health policy making and governance; shaping the health discourse and communications; and educating, training, and organizing health professionals must be fully on board. Champions representing all key institutions shaping Punjab's health and population sectors should be facilitated over the next few years in identifying modifications in Punjab's existing health strategy so that family planning is prioritized at all levels.

2. Tailor specific interventions to local supply and demand realities. The variation observed across districts and urban and rural areas in contraceptive use and unmet need, as well as the coverage, quality, and utilization of health facilities calls for localized strategies based on a sound understanding of indigenous needs and potentials. Thus, while the measures recommended below for improving service delivery and empowering clients are broadly applicable to all settings, the weightage given to each must be calibrated carefully, based on ground realities, in designing interventions for specific areas. Strategies should be designed in consultation with relevant authorities at the district and Union Council (UC) level, which would also ensure that they are practicable and locally supported.

3. Ensure that all public facilities are equipped to provide all FP services in their mandate at all times. It should be ensured that each health facility is providing the full range of family planning services in its mandate, especially emergency contraceptive pills and, to the extent possible, implants, which are especially lacking. Among other measures, this requires a regular and adequate supply of contraceptives to all health facilities. Moreover, all facilities should have a trained female provider present, including during the evening shift at facilities mandated to be open round-the-clock. Availability of necessary equipment for providing FP services, such as blood pressure measurement apparatus and IUD kits, must also be ensured.

4. Train public health service providers and enforce appropriate standards to provide quality FP services. There are large gaps in the knowledge of service providers which must be addressed urgently through training in counseling and all aspects of provision of the specific methods in their mandate, including how to manage any side effects that might arise. Moreover, male and female doctors and Lady Health Visitors should be trained to provide implants to increase availability of this method. Skill-based training should be provided, along with relevant equipment. Providers should also be oriented to the importance of family planning for Healthy Timing and Spacing of Pregnancies and trained to offer FP counseling and information to patients even when they do not ask for it specifically. In addition, they should be oriented to client rights and trained to modify their practices to preserve their rights, even in the busy environment of crowded facilities. Such training should be complemented by appropriate management measures to ensure impact, including supportive supervision at all levels, enforcement of quality standards and checklists, and regular refresher trainings as needed.

5. Reach out actively to clients of public health facilities. All relevant service providers should be officially assigned, as part of their regular duties, to offer FP counsel to clients who visit for other services, and this task should be added in the discharge slip of obstetrics/gynecology in-patients at all levels of public health facilities to ensure that all patients receive FP counseling as a mandatory part of their maternal care.

In addition, separate family planning counseling desks should be set up in each health facility for women and especially men to provide information about specific contraceptives as well as other sources of FP services. Privacy must be ensured, especially at DoH facilities, where they are most lacking. Systems can also be developed for health facilities to send SMS messages to clients to remind them of upcoming resupply/follow-up visits and share information about FP methods. 
6. Increase provision of FP services by private health facilities, especially in less well-served areas. The huge untapped potential of private health facilities must be exploited, especially in areas that are not adequately served by the public health system. This will require training of male and female service providers; their incentivization, for example through vouchers; facilitating supply of contraceptives to private clinics, for example, by linking them with local pharmacies or the public sector supply chain; and quality assurance through registration with the Health Care Commission. In some cases, equipment like IUD insertion kits will also have to be provided by PWD.

The various cadres of private providers should be trained to provide all the methods permitted by their concerned professional associations, Health Care Commission requirements, and the Essential Services Health Package. In addition to the training mentioned above for the public sector provider cadres, dispensers and homeopaths should be trained in counseling and provision of condoms, pills, emergency contraceptive pills, and the second dose of injectables through task shifting/sharing. Moreover, in areas not served by the LHW Programme, tested interventions involving community volunteers and provision of subsidized services should be introduced and rolled out. Conditional cash transfer (voucher) programs targeting the poor should be considered to facilitate access to the nearest available public or private health facilities.

7. Build further on pharmacies' role in provision of contraceptives and information. In areas where private FP service provision needs to be increased, linkages can be built between service providers and pharmacists so the latter can procure methods for providers and refer customers for hormonal methods, especially injectables and LARCs. Such linkages would also encourage more pharmacies to maintain stocks of these methods. Moreover, pharmacists can be trained to serve as the first point of contact to provide men detailed information about specific FP methods. Signboards indicating that FP services are available, and posters encouraging customers to ask the pharmacist about FP methods can support this role. Pictorial leaflets showing the range of contraceptive options can also be placed at pharmacies for interested customers to pick up.

8. Empower users and mobilize communities to increase access to FP services. The increasing potential of mass media and mobile technology should be tapped to disseminate information among men and women about the types of FP services available and where they can be accessed, with a special focus on men's needs. A toll-free or SMS-based helpline for FP related information should be established and widely advertised.

Public awareness should also be built regarding patient rights and the channels of recourse available, such as a toll-free number to call, if these rights are neglected. At the community level, male and female influential residents and village organizations can be sensitized and engaged to increase awareness and utilization of FP services, and contribute to accountability of local providers.

9. Enhance the role of LHWs in increasing access to family planning. LHWs are a major source of contraceptives for users, especially in the southern districts, and an indispensable resource for the large numbers of couples who desire doorstep delivery of FP services. The focus of the LHW Programme must be restored, specifically by prioritizing family planning in their work plans and performance monitoring of LHWs; improving the supply of contraceptives to them; expanding the range of methods in their mandate to include the Standard Days Method (SDM), emergency contraceptive pills, first dose of injectables, and Sayana Press ${ }^{\circledR}$; and training LHWs to not only provide methods, but also to manage their side effects and to counsel clients. The potential of Health technology to facilitate the work of LHWs should also be explored. 

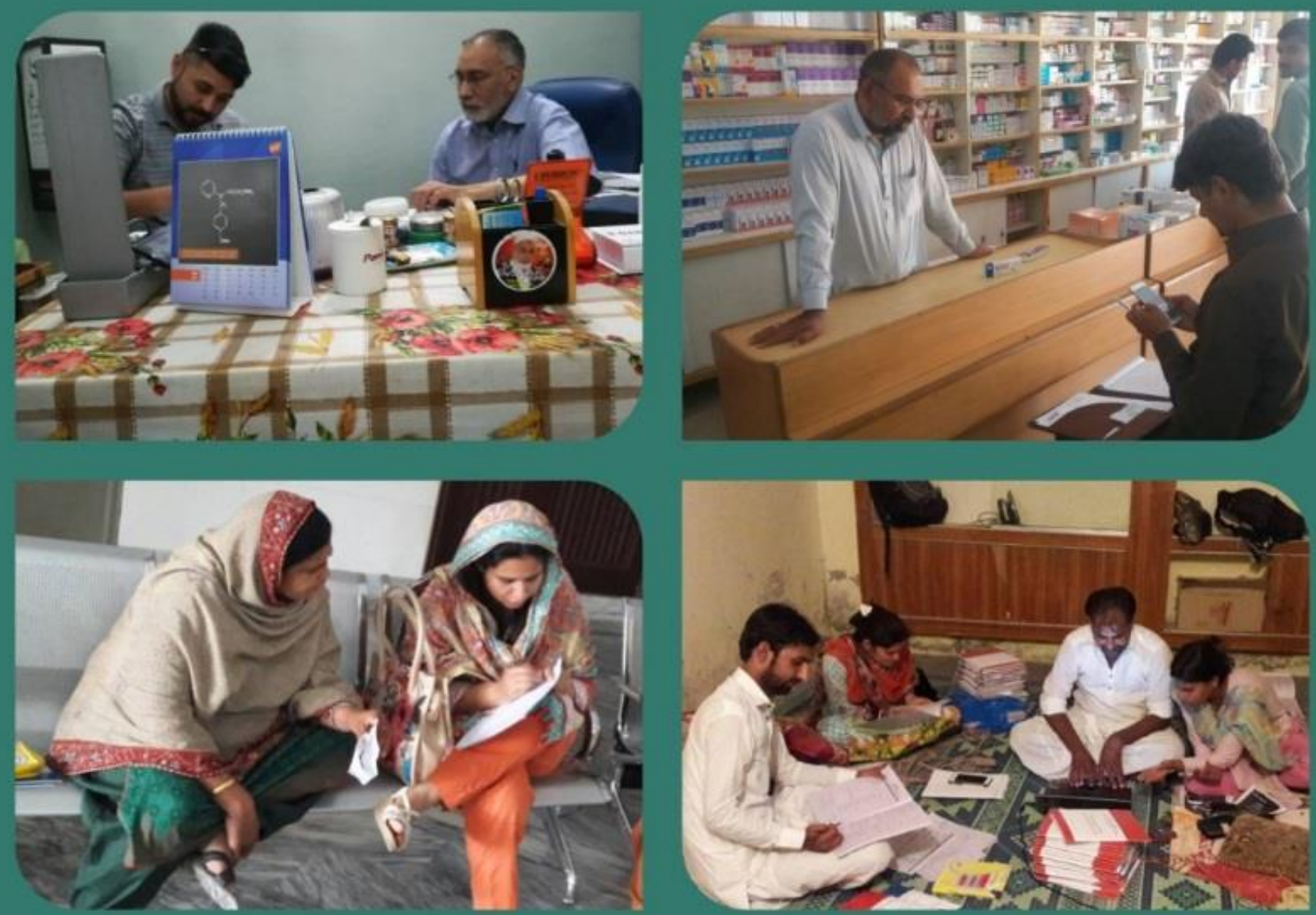

\section{Introduction}

Study Objectives and Research Questions

Study Location

Methodology 



\section{Introduction}

With a population of over 208 million that is growing at slightly more than 2 percent a year, Pakistan faces what may legitimately be called a population emergency. Fertility is declining, but not as fast as in most of the rest of South Asia. The country's current total fertility rate, at 3.8, remains higher than the desired fertility rate of 2.8, signifying that on average every currently married woman of reproductive age (15-49 years) is delivering one more child that she wishes to have. Yet, the national contraceptive prevalence rate (CPR) is only 35.4 percent-even lower (26.1\%) if the less reliable traditional methods are discounted. No less than 20 percent of currently married women of reproductive age (CMWRA) in the country-nearly the same proportion who are already using modern contraceptives-have unmet need for family planning.

However, despite the high level of unmet demand, as well as the well-documented health and economic benefits of family planning, growth in the national CPR has been disappointingly slow. At the landmark National Population Summit 2015, key government and civil society representatives in Pakistan came together for the first time to acknowledge the high health and development costs of the longstanding ambivalence around family planning (FP), and committed to accelerate efforts to ensure universal access to reproductive health services, especially family planning.

To begin with, provincial governments have committed to tackle unmet need for family planning, with the expectation to thereby meet specific CPR targets by 2020. A better understanding is required of why unmet need persists within each province despite couples' desire to space or limit births. Statistics imply it is not a matter of simply increasing outlets. For instance in Punjab, while 18 percent (3.2 million) of the 18 million women with unmet need have never used family planning, the remaining 41 percent do have experience of using a traditional or modern method. Never users with unmet need might be assumed to be held back by personal or household level barriers, or to be living too far away from any source, but the existence of so many past users with unmet need suggests that something is wrong with the way family planning services are being delivered: too many couples or women have tried to obtain family planning services but are so dissatisfied with the experience that they have opted to risk unwanted pregnancy instead. Clearly, accelerating uptake of family planning not only requires making sure women can access the services they need, but also that the quality of those services is conducive to sustained use.

This report examines the demand for and delivery of family planning services in the province of Punjab, where half of Pakistan's population resides and where the government is keen to increase the CPR from the current 41 percent (Pakistan Demographic and Health Survey 2012-13) to 55 percent by 2020. Family planning services are provided in Pakistan by both public and private health facilities, and the report is aimed at assessing client choices between these two sectors in Punjab, and their impact on the uptake of contraception in the province, with a view to better understanding the specific dynamics that are leading to unmet need, and the opportunities that must be seized to enhance access to quality family planning services. The report forms part of a larger project being implemented by the Population Council with the assistance of the Department for International Development, UK (DFID), entitled "Sustaining Focus on Provincial Governments for FP 2020 Goals and Increasing Access to Reproductive Healthcare through Improved Service Delivery." In addition to the current research, the project also includes advocacy and technical assistance components. 


\section{Study Objectives and Research Questions}

- Assess the perspective and healthcare seeking behavior of men and women, including method choices and underlying reasons;

- Identify what drives clients' choices between public and private sources and specific types of providers (e.g., accessibility and quality of care) and examine in depth their need and motivation to use specific facilities as well as their relative satisfaction with services;

- Gauge what combination of services is most effective in recruiting, serving, and retaining clients as satisfied users;

- Identity existing gaps in service delivery in terms of availability, quality, and missed opportunities to recruit new clients;

- Explore the preferences of men and women in availing family planning services, in terms of the public or private sector, location of services, and type of provider; and

- Study community structures, both existing and potential, that can enhance voice and accountability at the service delivery level.

Accordingly, the study was framed around the following key research questions:

- What factors drive clients' choices when seeking family planning services?

- What direction can increase accessibility, affordability, and quality of family planning services based on service delivery exigencies?

- Identity existing gaps in service delivery in terms of availability, quality, and missed opportunities to recruit new clients;

\section{Study Location}

The study locations were carefully selected to represent areas with a large number of women with high unmet need in rural, semi-urban, and urban settings across northern, central, and southern Punjab. Four districts were selected for the study, including Rawalpindi from northern Punjab, Faisalabad from central Punjab, and Bahawalpur and Rahim Yar Khan from southern Punjab.

The key criterion in district selection was extent of unmet need for FP-the selected districts have the largest numbers of women with unmet need in the province. Another consideration was that the selection reflect the disparities in development across Punjab: thus, Rawalpindi and Faisalabad represent the relatively more developed northern and central parts of the province while Bahawalpur and Rahim Yar Khan represent the more deprived southern region. Inclusion of two districts from the south is intended to increase the weightage of perspectives from the poorest communities. Appendix A presents a comparison of these districts with the 28 other districts of Punjab in terms of contraceptive use, demand, and poverty levels.

In each district, four circular clusters of 10-kilometer radius each were randomly selected using GIS maps of the districts, which are shown in Figure 1.1. Cluster 1 in each of the study districts represents the full city area or a portion of it whereas the other three clusters are situated away from the city area. Investigation under all study components was conducted in these 16 clusters. 
Figure 1.1: Study Districts and Clusters

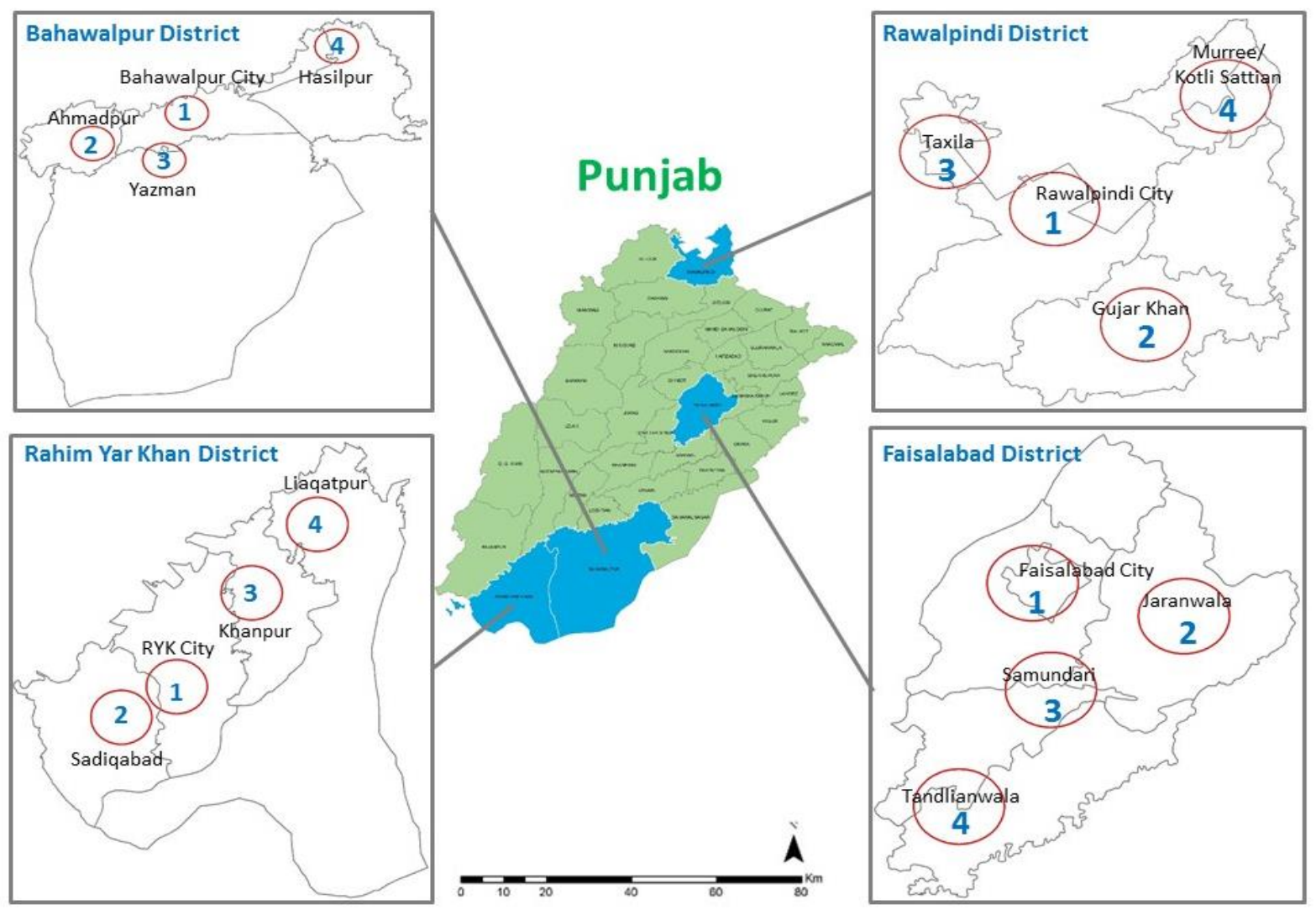

\section{Methodology}

A mixed research design was employed for the study, comprising three quantitative components-including (1) a census of health facilities and pharmacies in the study areas, (2) an assessment of health facilities, and (3) a household survey of family planning choices, knowledge, and experiences of men and women-and two qualitative assessments of (4) community FP care-seeking behavior and perspectives, and (5) the scope for improving community utilization of FP services. This study framework and the methods used to collect and analyze data from each investigation are described below.

\section{Methodological Framework}

The methodological framework of the study is depicted in Figure 1.2, which shows the nature of each of the five study components, the themes explored by each, the tools used and number of interviews and discussions conducted, as well as the number of respondents.

The first quantitative component conducted was the "Census of Health Facilities and Pharmacies" (CFP), which provided a complete overview of the actual and potential service delivery points (SDPs) for provision of family planning methods and services in the study areas. This component was conducted in the 12 clusters in Rawalpindi, Bahawalpur and Rahim Yar Khan but not in Faisalabad, since census data for the 4 clusters in this district was already available with the Population Council from a recent study (PC-Landscape acronym is used in source of CFP tables and figures where Faisalabad data is used). ${ }^{1}$ Altogether, 5,758 health

\footnotetext{
${ }^{1}$ The study, entitled "Landscape Analysis of the Family Planning Situation in Pakistan," was conducted by the Population Council in 2016 with the support of the Bill and Melinda Gates Foundation.
} 
facilities, pharmacies, and Lady Health Workers (LHWs) were mapped during the current study (The LHWs were located but not interviewed). In total, 2,448 SDPs were mapped in Rawalpindi; 1,549 in Bahawalpur; and 1,761 in Rahim Yar Khan. Adding the 4,820 SDPs previously mapped in the Faisalabad clusters, the total number of facilities, LHWs, and pharmacies included in the analysis comes to 10,578. Two paper-based questionnaires were used to collect data of facilities and pharmacies for the CFP. In addition, an Androidbased smaller questionnaire was also filled for each facility and pharmacy interviewed. The district authorities in each district were contacted to help in locating public sector facilities, while a snowball approach was used to locate private health facilities and pharmacies.

Using the lists of different levels of facilities and providers obtained for each cluster from the CFP, 25 health facilities were selected by stratified random sampling from each cluster for the second component, "Assessment of Health Facilities" (HFA). This component gauged facilities' readiness for providing FP services and the quality of care offered based on both provider and client perspectives. In the total sample of about 400 facilities, more private than public facilities were included since a main focus of the study is understanding how potential for private sector provision of FP services may be tapped. Moreover, we wanted the sample to include both types of private health facilities-those providing FP services, and those not providing FP services; this division is not found among public health facilities, as all of them are mandated to provide at least some family planning services. At each health facility assessed, one service provider or incharge was interviewed, one to two client-provider interactions were observed, and some of the same clients interviewed in detail. In addition, short exit interviews were conducted with a larger number of other clients, who were randomly selected, to assess whether opportunities to offer FP services to eligible clients were being captured. In all, we conducted 399 interviews with service providers/facility in-charges, 416 detailed client interviews, 963 brief client exit interviews, and 803 observations of provider-client interactions.

The "Household Survey of FP Choices, Knowledge, and Experiences of Men and Women" (HHS) was conducted in each of the 16 clusters to learn about men's and women's family planning practices and preferences, awareness of client rights, experience of quality of care from the facilities they had frequented, and reasons for their choice of family planning method and source. The sample size for the household survey was calculated to be about 375 interviews per district based on a $5 \%$ margin of error and $95 \%$ confidence level, as the population of the districts is large (over 3 million in each district). In each district, about 300 women and 75 men were interviewed, adding to a total of 1,201 interviews with women and 329 with men. The sample thus included approximately four times as many women as men, reflecting the pattern observed in an earlier study by the Population Council that found 7 out of the average 9 FP clients per week at health facilities to be female (i.e., about 4.5 times as many female as male clients). ${ }^{2}$ In view of the study objectives, a main criterion for selecting respondents was that they have at least one child; this increased the chance that they were utilizing FP services and could provide the information required for the study.

The survey was conducted in a total of 46 communities -3 in each cluster-which were randomly selected using GIS maps of the study clusters to represent a variety of geographic locations and maximize coverage of the survey. A listing of about 900 households was conducted in each of the clusters ( 300 per community)to interview 75 women and 18 men. Facilitation to intervene in the study communities was sought from LHWs of the area in most cases, which may have slightly affected findings about contraceptive use and utilization of health facilities. To extend the study's coverage, it was ensured that the survey sample did not include any communities where discussions for the qualitative assessments (described below) were conducted.

\footnotetext{
${ }^{2}$ M. Haque, P. Miller, and I. Kamran, Role of Private Sector in Delivering Birth Spacing Services in FALAH Districts (Population Council: Islamabad, 2012).
} 
Although 1,201 women were interviewed in total, 87 interviews were excluded from the study during data cleaning and validation due to non-satisfactory quality of the interviews. This left a total of 1,114 interviews with women for the analysis in this report. The numbers of men and women from all four districts whose interviews are included in the analysis are shown in Table 1.5.

The fourth element of the study was a "Qualitative Assessment of Community FP Care-seeking Behavior and Perspectives" in which 16 focus group discussions (FGDs)-two with men and two with women in each district-were conducted to learn about the considerations that shape their choices about which contraceptive method to use and which service provider to consult. The discussions with men also sought to assess existing community structures and potential for enhancing voice and accountability for increasing FP demand and access.

Finally, for the Qualitative Assessment of Scope for Improving Community Utilization of FP Services, 16 indepth interviews (IDIs) were conducted-four in each district-with a total of eight influential community members and eight service providers at health facilities in the vicinity for a better understanding of local communities' social, economic, and political structures, and to identify potential for increasing the demand for and utilization of FP services in the community, including identification of individuals who could serve as a bridge between the community and current and potential FP service providers.

Appendix B provides the numbers of interviews and discussions carried out during the study under each component in each of the four districts. 
Figure 1.2: Methodological Framework

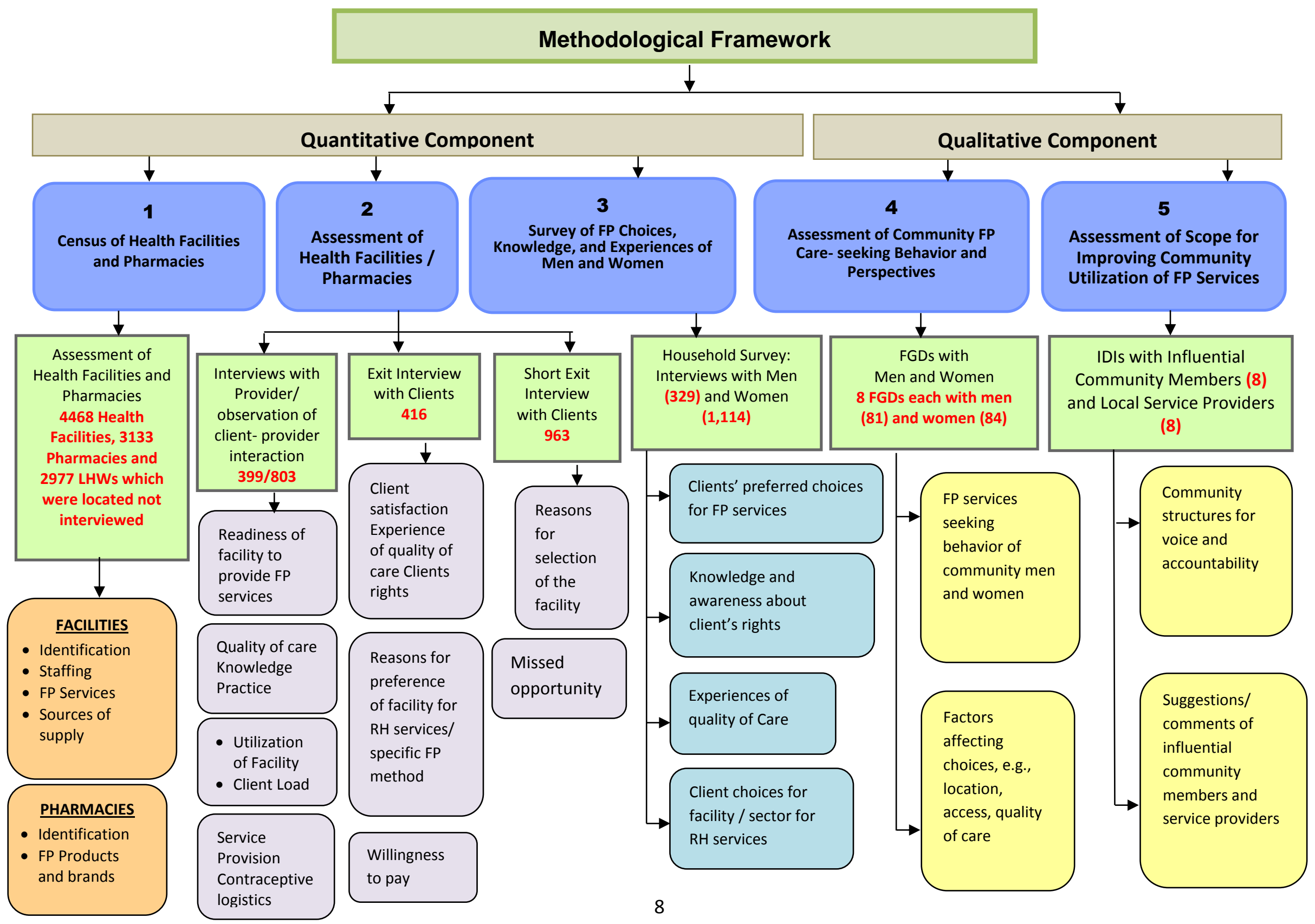




\section{Data Collection and Analysis}

The instruments used to collect data included:

- A structured questionnaire for facility assessment and a short, Android-based questionnaire to collect basic information for the census of health facilities and pharmacies (CFP);

- A structured questionnaire for service providers/facility in-charges, one structured questionnaire for exit interviews with clients, and one short questionnaire for exit interviews with other clients for the assessment of health facilities (HFA);

- $\quad$ Two structured questionnaires-one for interviewing men and the other for interviewing women-for the household survey (HHS);

- $\quad$ Guidelines for FGDs with men and women for the qualitative assessment of community FP careseeking behavior and perspectives; and

- $\quad$ Guidelines for IDIs with local service providers and influential community members for the qualitative assessment of scope for improving community utilization of FP services.

All questionnaires were pre-tested twice, first by the Population Council's research staff in Rawalpindi, and then in Jhelum district, by the data collection team engaged for the study. Data collection for the three quantitative components was carried out in March-April 2017 by 63 experienced male and female interviewers who were recruited and intensively trained for the purpose by senior Population Council staff and closely monitored throughout the process to assure quality. Fieldwork for the qualitative assessments was carried out by the Council's own senior researchers.

During the CFP, data collected through the Android form was uploaded instantly which helped team managers to monitor field teams and also ensured that areas were not left out within the clusters. The paper questionnaires received from the field were checked and verified by a team of experts before being given to the data entry operators. Data entry applications were designed in the latest version of CSPro, in which range, skip, relevance, and other consistency checks were strictly applied to minimize errors during data entry, contributing greatly to data quality. All the health facilities' data was collected, entered, and linked with the data received online, including location of each facility and pharmacy. The files were then exported to SPSS (Statistical Package for the Social Sciences) version 21 and cleaned at the Population Council office. Concurrently, a team prepared spatial data to produce maps and create links with data from other components.

For the health facility assessment and household survey, a data file was initially prepared and tested with all necessary skips and checks to address response inconsistencies. Data from the questionnaires was entered in the latest version of CSPro and analyzed using SPSS. The data manager conducted quality checks to ensure completeness and identify any errors in the data files, and made corrections after verification with study coordinators. Analysis was carried out to obtain descriptive statistics, and this was supplemented by advanced inferential bivariate analysis.

FGD and IDI transcriptions were completed in the field while translation from Urdu to English and data coding in NVivo software were performed at the Council office. After a thorough content analysis, codes were assigned, a matrix developed, and themes identified. Data was sorted based on themes and sub-themes and analyzed to identify factors shaping contraceptive use decisions. 


\section{Ethical Considerations}

As part of its policies and procedures, the Population Council requires all studies involving human subjects to be reviewed by its Institutional Review Board (IRB) before the activity is initiated. Ethical approval for this study was obtained from IRB on January 18, 2017, before the start of field activities. To ensure discharge of obligations to participants, informed consent was obtained in advance from all respondents. The Informed Consent Form, provided in Appendix $\mathrm{C}$, was signed by respondents after the interviewer had explained to them in detail that their participation was completely voluntary; what their rights were during the interview; and the measures that would be taken to ensure confidentiality and prevent any harm.

The structured questionnaires were administered in private. All data collected in each phase of the study was secured ensuring confidentiality and anonymity. The structured questionnaires and IDIs were identified by personal identification numbers rather than participant names. Moreover face-to-face interviews with different stakeholders were conducted in a private setting and were kept as brief as possible.

\section{Limitations of the Study}

Assessment of private health facilities proved an uphill task during this study, with many facilities reluctant to allow interviews with staff or clients and to share data about their client loads. In many cases, special efforts had to be made to contact the owners of the facilities and obtain their permission. Even then, a few facilities $(0.5 \%)$ did not permit interviews with their clients.

A particular issue was obtaining client records from most facilities, especially in the private sector. Many private facilities reported they did not maintain client records and where they did, they usually avoided sharing the records. Moreover, in many facilities, the client load was low and no client visited while the study team was present on the premises. Due to this reason, fewer client exit interviews could be conducted than planned.

\section{Profile of the Study Area and Respondents}

\section{Study Area}

Basic demographic data for the four study districts, drawn from the results of the Sixth Population and Housing Census 2017 and the Multiple Indicator Cluster Survey (MICS) 2014, are presented in Table 1.1. Overall, the data indicate a pattern of higher contraceptive prevalence and lower unmet need for family planning in the more developed northern district (Rawalpindi) and higher levels of unmet need and lower CPR in the southern districts. Maternal health indicators and institutional deliveries are much better for Rawalpindi followed by Faisalabad, Bahawalpur, and Rahim Yar Khan. 
Table 1.1: Population, Contraceptive Prevalence, and Unmet Need in Study Districts

\begin{tabular}{|c|c|c|c|c|}
\hline Socio-demographic features & Rawalpindi & Faisalabad & Bahawalpur & Rahim Yar Khan \\
\hline Total population* & $5,405,633$ & $7,873,910$ & $3,668,106$ & $4,814,006$ \\
\hline Urban Population (\%) & 56 & 42 & 27 & 20 \\
\hline $\begin{array}{l}\text { Proportion of WRA in total } \\
\text { population (\%) }\end{array}$ & 27.08 & 25.82 & 23.65 & 23.28 \\
\hline $\begin{array}{l}\text { Number of WRA (females ages } \\
15-49 \text { years) }\end{array}$ & $1,463,845$ & $2,033,044$ & 867,507 & $1,120,701$ \\
\hline $\begin{array}{l}\text { Proportion of CMWRA in total } \\
\text { population (\%) }\end{array}$ & 16.18 & 15.39 & 15.65 & 14.95 \\
\hline Poverty head count (\%) & 7.5 & 19.4 & 61 & 57 \\
\hline Number of CMWRA & 874,631 & $1,211,795$ & 574,059 & 719,694 \\
\hline $\begin{array}{l}\text { Literacy Rate (10 years and } \\
\text { above) (\%) }\end{array}$ & 74.8 & 56.7 & 34.4 & 35.1 \\
\hline $\begin{array}{l}\text { Literacy Rate (15to } 49 \text { female) } \\
\text { (\%) }\end{array}$ & 75.6 & 59.5 & 29.8 & 27.1 \\
\hline $\begin{array}{l}\text { Percentage of births assisted } \\
\text { by SBA (\%) }\end{array}$ & 80.5 & 64.1 & 54.7 & 42.5 \\
\hline Pre- Natal Consultation (\%) & 94.9 & 78.6 & 78.0 & 78.9 \\
\hline Institutional Deliveries (\%) & 80.6 & 62.9 & 46.0 & 41.7 \\
\hline $\begin{array}{l}\text { Using any traditional method } \\
(\%)\end{array}$ & 8.0 & 6.9 & 2.4 & 2.0 \\
\hline $\begin{array}{l}\text { Using any modern } \\
\text { contraceptive method (\%) }\end{array}$ & 35.3 & 30.7 & 23.3 & 25.9 \\
\hline $\begin{array}{l}\text { Using any contraceptive } \\
\text { method (\%) }\end{array}$ & 43.2 & 37.6 & 25.7 & 27.9 \\
\hline $\begin{array}{l}\text { Unmet need for family planning } \\
(\%)\end{array}$ & 15.8 & 17.6 & 21.5 & 19.5 \\
\hline
\end{tabular}

Source: Sixth Population and Housing Census 2017, MICS (Punjab) 2014.

$\mathrm{CM}=$ currently married, WRA=women of reproductive age.

Government of Pakistan. 2016. Multidimensional Poverty in Pakistan. Planning Commission, Ministry of Planning, Development and Reform. Government of Pakistan. Islamabad.

The spatial distribution and density of population across the four districts and specifically in the 16 study clusters are shown in Figure 1.3. 
Figure 1.3 : Population Density and Cluster Locations in Study Districts
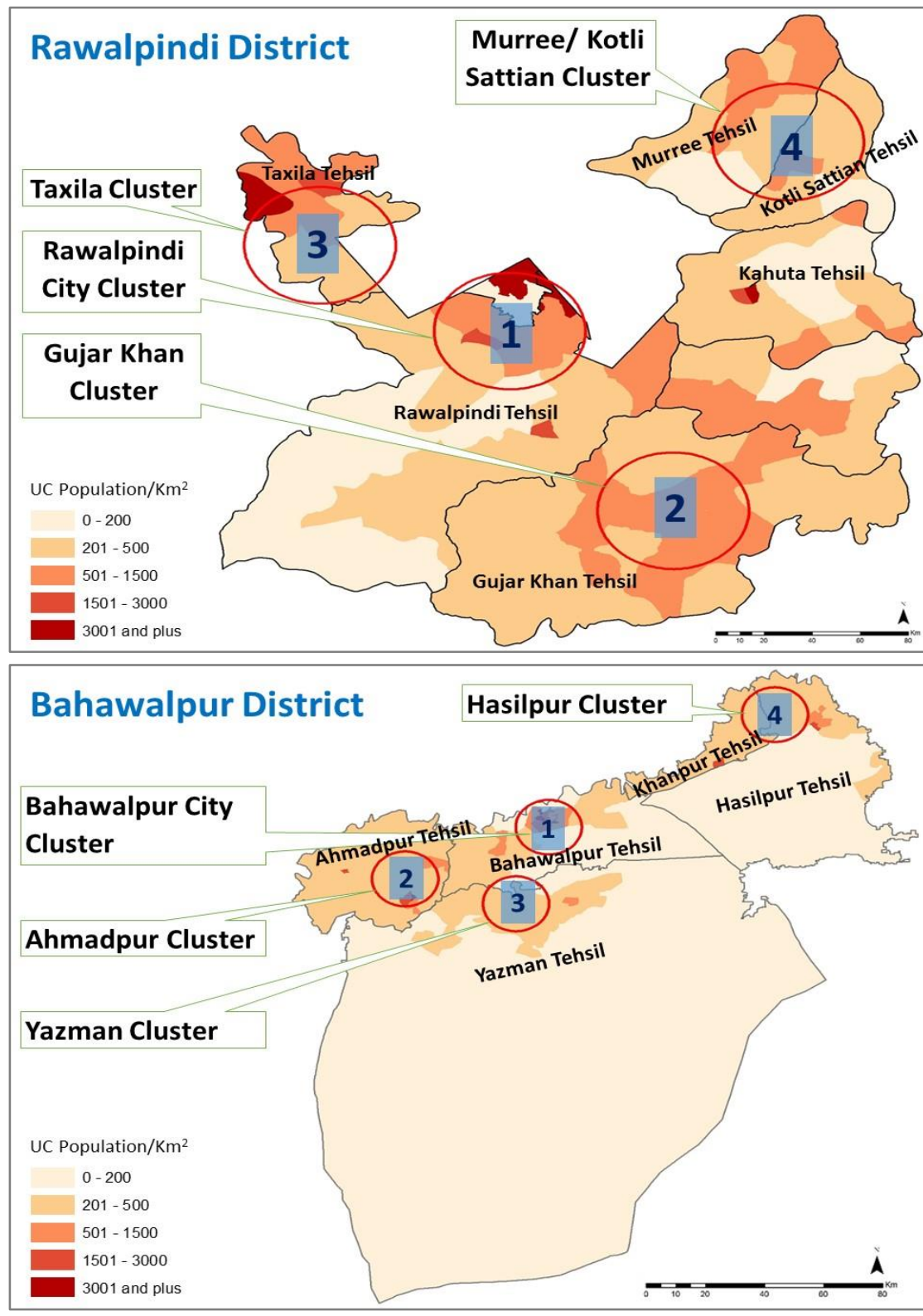
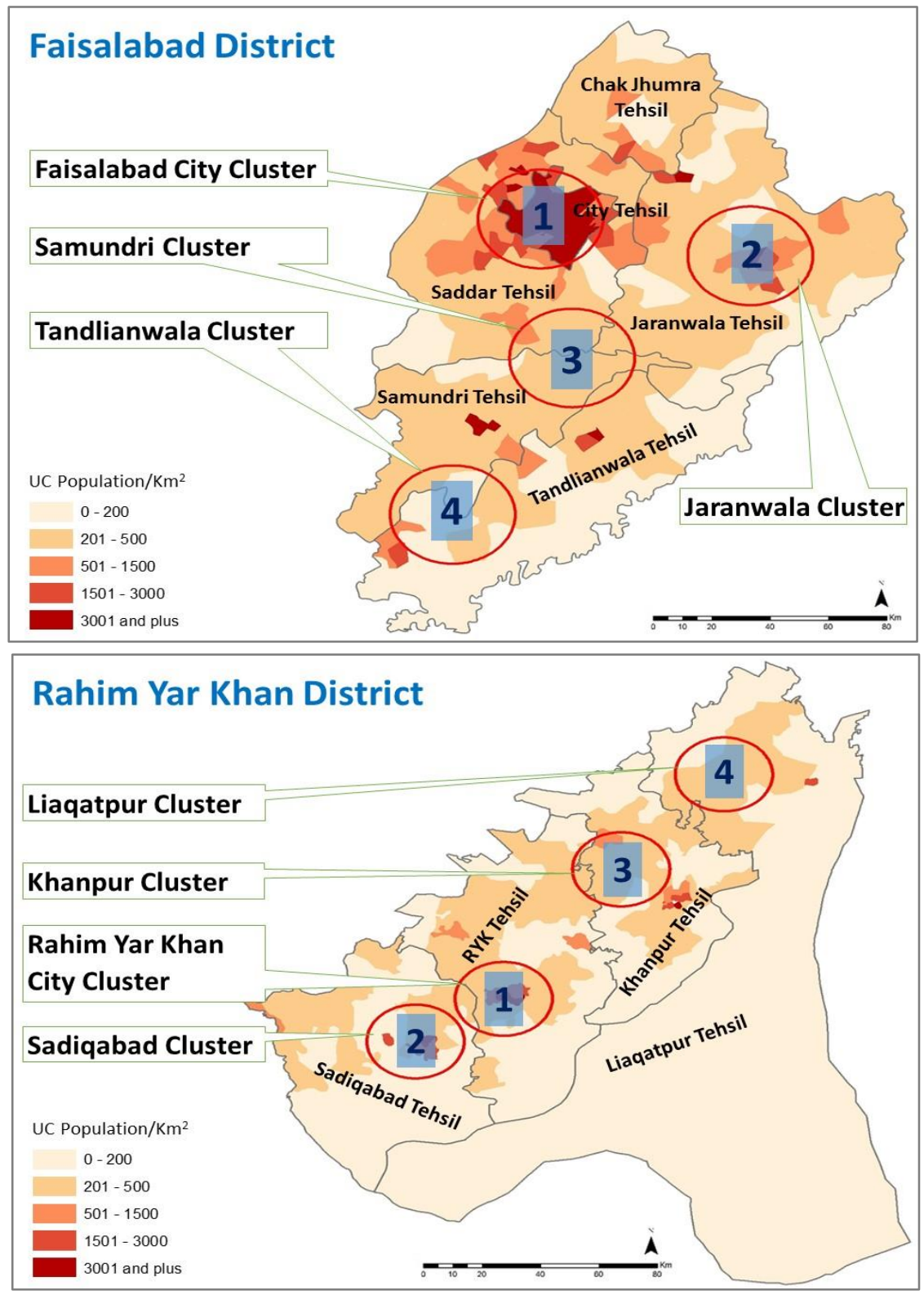
Table 1.2 shows the population of each study district, and the proportion of this population covered in the four clusters of each district. The population of cluster 1 (which is a city cluster) is highest in Faisalabad, followed by Rawalpindi and Bahawalpur. Overall, 40 percent of the district population was covered in Rawalpindi, 59 percent in Faisalabad, 37 percent in Bahawalpur, and 35 percent in Rahim Yar Khan.

Table 1.2: Population (in million) of the Study Clusters

\begin{tabular}{|c|c|c|c|c|c|c|c|}
\hline \multirow[b]{2}{*}{ District } & \multicolumn{4}{|c|}{ Clusters } & \multirow[b]{2}{*}{$\begin{array}{l}\text { Total } \\
\text { Covered }\end{array}$} & \multirow[b]{2}{*}{$\begin{array}{c}\text { District } \\
\text { Population }\end{array}$} & \multirow[b]{2}{*}{$\begin{array}{c}\% \\
\text { Covered }\end{array}$} \\
\hline & Cluster 1 & Cluster 2 & Cluster 3 & Cluster 4 & & & \\
\hline Rawalpindi & $1.3 \mathrm{~m}$ & $0.3 \mathrm{~m}$ & $0.1 \mathrm{~m}$ & $0.1 \mathrm{~m}$ & $1.9 m$ & $4.8 m$ & 40 \\
\hline Faisalabad & $3.2 \mathrm{~m}$ & $0.5 \mathrm{~m}$ & $0.4 \mathrm{~m}$ & $0.3 \mathrm{~m}$ & $4.4 \mathrm{~m}$ & $7.5 \mathrm{~m}$ & 59 \\
\hline Bahawalpur & $0.6 \mathrm{~m}$ & $0.3 \mathrm{~m}$ & $0.2 \mathrm{~m}$ & $0.2 \mathrm{~m}$ & $1.3 m$ & $3.6 \mathrm{~m}$ & 37 \\
\hline Rahim Yar Khan & $0.6 \mathrm{~m}$ & $0.4 \mathrm{~m}$ & $0.3 m$ & $0.3 m$ & $1.6 \mathrm{~m}$ & $4.7 \mathrm{~m}$ & 35 \\
\hline
\end{tabular}

Source: Punjab Development Statistics 2016

\section{Socio-demographic Characteristics of Respondents}

The major groups of respondents in this study included service providers at health facilities, clients at health facilities, and the men and women who participated in the household survey and in the focus group discussions.

\section{Service Providers at Health Facilities}

Table 1.3 summarizes the socio-demographic characteristics of the 399 service providers interviewed. The proportion of male and female providers in the sample was approximately equal. In terms of cadre, about half of the respondents were either mid-level providers (30\%) or male doctors (17\%). About 60 percent of the providers were working in the private sector, 24 percent in the Health Department, 11 percent in the Population Welfare Department, and 5 percent were working at NGOs.

Table 1.3: Socio-demographic Characteristics of Service Providers at Static Health Facilities

\begin{tabular}{|c|c|c|}
\hline & $\%$ & Number of Service Providers \\
\hline \multicolumn{3}{|l|}{ Gender } \\
\hline Male & 52 & 208 \\
\hline Female & 48 & 191 \\
\hline \multicolumn{3}{|l|}{ Type of Provider } \\
\hline Gynecologist & 10 & 40 \\
\hline Male doctor & 17 & 67 \\
\hline Female doctor & 4 & 14 \\
\hline Mid-level provider** & 30 & 120 \\
\hline FWW/FWC/FWA & 11 & 45 \\
\hline CMW & 4 & 16 \\
\hline Dispenser/MHT & 15 & 60 \\
\hline Homeopath/Hakeem & 9 & 37 \\
\hline \multicolumn{3}{|l|}{ Type of Health Facility } \\
\hline Department of Health & 24 & 95 \\
\hline Population Welfare Department & 12 & 47 \\
\hline Private for profit & 60 & 239 \\
\hline NGO & 5 & 18 \\
\hline Mean experience (years) & 15.4 & 399 \\
\hline Total & 100 & 399 \\
\hline
\end{tabular}

Source: HFA

$\mathrm{CMW}=$ Community Midwives, FWA=Family Welfare Assistant, FWC=Family Welfare Councilor, FWW= Family Welfare Worker, MHT= Male Health Technician

** includes Lady Health Visitors (LHVs), nurses, and midwives 


\section{Clients at Health Facilities}

In each of the health facilities assessed, at least one client was interviewed after s/he had consulted with a service provider at the facility for family planning or other reproductive health needs. Table 1.4 outlines the socio-demographic characteristics of these clients. ${ }^{3}$ Of the 416 clients interviewed, only 25 were male.

The majority of the respondents were 25 to 34 years of age; the mean age of the clients was 31 years, while that of their spouses was 35 years (data not shown). Most clients had either 3-5 children (45\%) or 1-2 children (41\%). The mean number of children was 1.6 .

Around 40 percent of clients and their spouses had no schooling, while about 27 percent of clients and 40 percent of spouses had completed secondary or higher education. A large number of women were not involved in any economic activity and reported being housewives (87\%), while among spouses, the main activities mentioned were labor (30\%) followed by self-employment (19\%) and private service (18\%) (data not shown).

\section{Table 1.4: Socio-demographic Characteristics of Clients}

\begin{tabular}{|c|c|c|}
\hline & $\%$ & Number of Clients \\
\hline \multicolumn{3}{|l|}{ Sex } \\
\hline Female & 94 & 391 \\
\hline Male & 6 & 25 \\
\hline \multicolumn{3}{|l|}{ Current age } \\
\hline 17-24 years & 13 & 55 \\
\hline 25-34 years & 58 & 242 \\
\hline $35-44$ years & 25 & 103 \\
\hline $45+$ years & 4 & 16 \\
\hline Mean age & 31 & 416 \\
\hline \multicolumn{3}{|l|}{ Educational attainment } \\
\hline No schooling & 42 & 173 \\
\hline Primary & 20 & 83 \\
\hline Middle & 12 & 48 \\
\hline Secondary & 16 & 66 \\
\hline Higher & 11 & 46 \\
\hline \multicolumn{3}{|c|}{ Spouse's educational attainment } \\
\hline No schooling & 31 & 128 \\
\hline Primary & 17 & 69 \\
\hline Middle & 13 & 54 \\
\hline Secondary & 22 & 91 \\
\hline Higher & 18 & 74 \\
\hline \multicolumn{3}{|l|}{ Number of children } \\
\hline None & 1 & 5 \\
\hline $1-2$ & 41 & 172 \\
\hline $3-5$ & 45 & 187 \\
\hline $6+$ & 13 & 52 \\
\hline Mean number of children & 1.6 & 416 \\
\hline Total & 100 & 416 \\
\hline
\end{tabular}

Source: HFA.

${ }^{3}$ The 963 clients with whom shorter exit interviews were conducted are not included in this profile. 


\section{Participants of Household Survey}

Table 1.5 provides a socio-demographic profile of the 1,114 married women and married 329 men with at least one child who participated in the household survey of family planning choices, knowledge and experiences of men and women in local communities. About half of the total respondents were interviewed from rural areas and slightly more than a quarter each from urban and semi-urban areas. The men and women in the sample were mostly 25 to 34 years of age-the mean age of married men was 33.9 years as against 31.5 years for women. Although the majority of both men and women had 3-5 children, the proportions with 1-2 children were also noticeably high, while the number of high-parity respondents was quite low. This may be because the majority of the study respondents were young. The mean number of children was 1.7 .

Educational attainment among the survey participants reflected the national pattern of much lower attainment among women compared to men, with about one-third of women respondents having no schooling, while men were generally educated. The same pattern was seen in reported educational attainment among spouses.

Table 1.5: Socio-demographic Characteristics of Household Survey Respondents

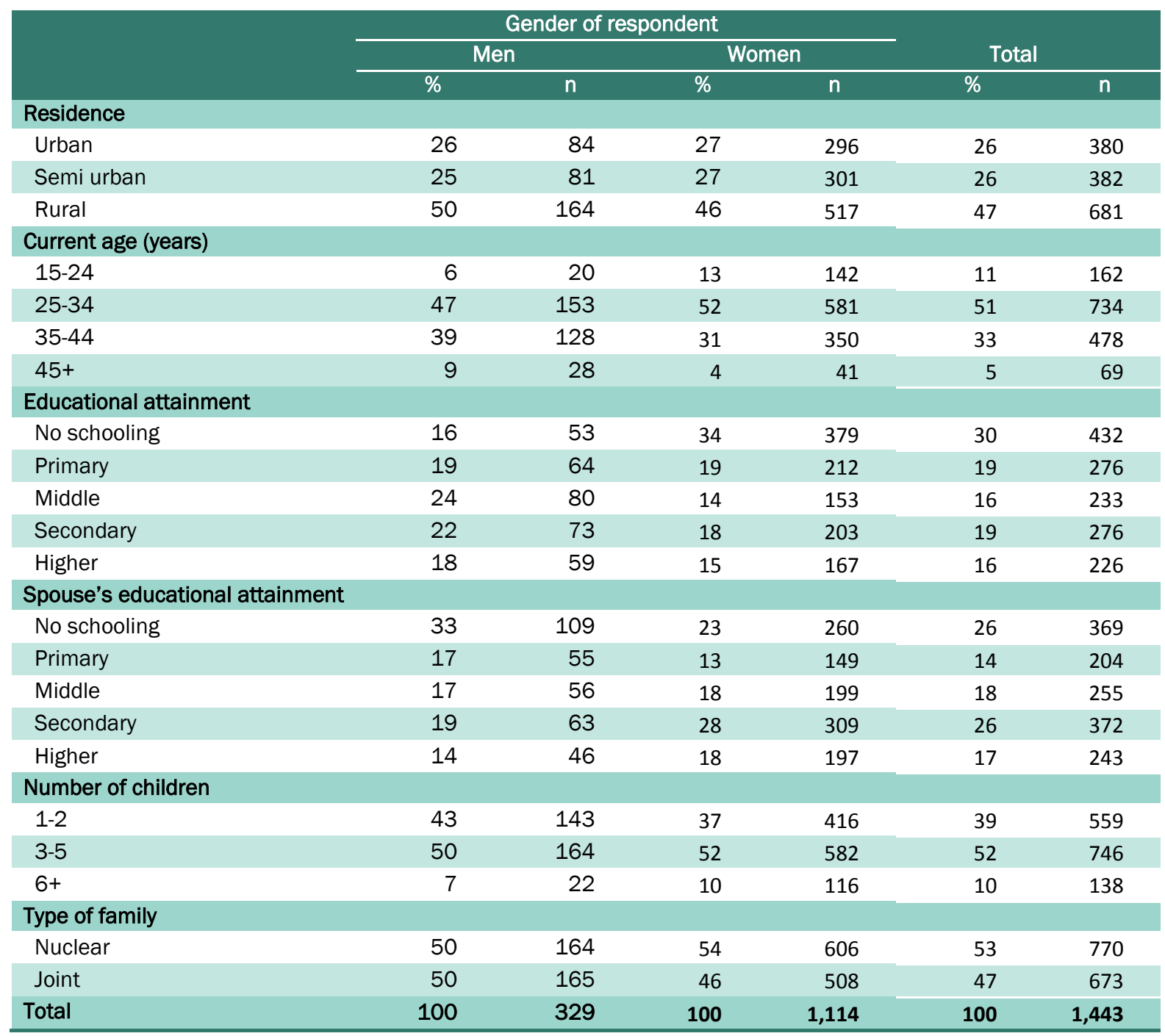

Source: HHS 


\section{Participants of Focus Group Discussions}

Of the total 81 men and 84 women, slightly fewer women participated in FGDs in rural settlements compared to urban settings, although men participated in about the same proportion. The majority of the respondents were 25-34 years old and their mean age was 35 years for men and 33 years for women. More than 80 percent of respondents had two or more children-the mean number of children was 3-and approximately 60 percent reported that their youngest child was $0-3$ years of age.

Nearly a third of women, compared to only 6 percent of men, had no schooling, and while nearly half of the men had secondary or higher education, only about a third of women reported the same. In terms of employment (data not shown), the majority of male respondents were self-employed skilled workers, while a few were employed in the public or private sector. Out of the 84 female respondents, 45 were housewives and the rest were involved in small-scale skilled and unskilled labor. Only a few women were formally employed.

\section{Structure of the Report}

Section $\mathbf{2}$ of this report presents findings about the presence of health facilities and pharmacies, with a focus on provision of family planning services, including specific methods. The roles of the public and private sectors, and of specific cadres within these sectors are reviewed.

The next two sections of the report focus on the demand side of family planning in the study areas. Section 3 describes overall utilization of existing health facilities for maternal and child care as well as for family planning services specifically. Current contraceptive use and unmet need in the study clusters are outlined. The most frequently utilized facilities are identified and the distances and costs entailed in accessing services examined in detail. Spatial patterns of utilization of available family planning services are also illustrated using census data for two clusters.

We then probe the main factors affecting current patterns of health service utilization and contraceptive use in Section 4. The cultural context, specifically women's mobility and role in decision-making, and awareness about rights as clients of health facilities are discussed. Reasons for preferring or avoiding specific providers and methods are examined in detail. Men's and women's conception of the ideal mode of FP service provision are also explored.

Important aspects of the quality of family planning service provision are then described in Section 5, which looks at the readiness of facilities to provide services, provider capacities and practices in FP service provision, and whether all eligible clients are offered FP services. Our primary concern in sections 3 and 5 is to identify the opportunities being missed in the health sector to support and promote use of family planning among clients.

Finally, the conclusions emerging from the study, and recommendations for fully leveraging Punjab's health sector to meet its population's demand for family planning services, with due regard for their constraints and preferences, are presented in Section 6. 

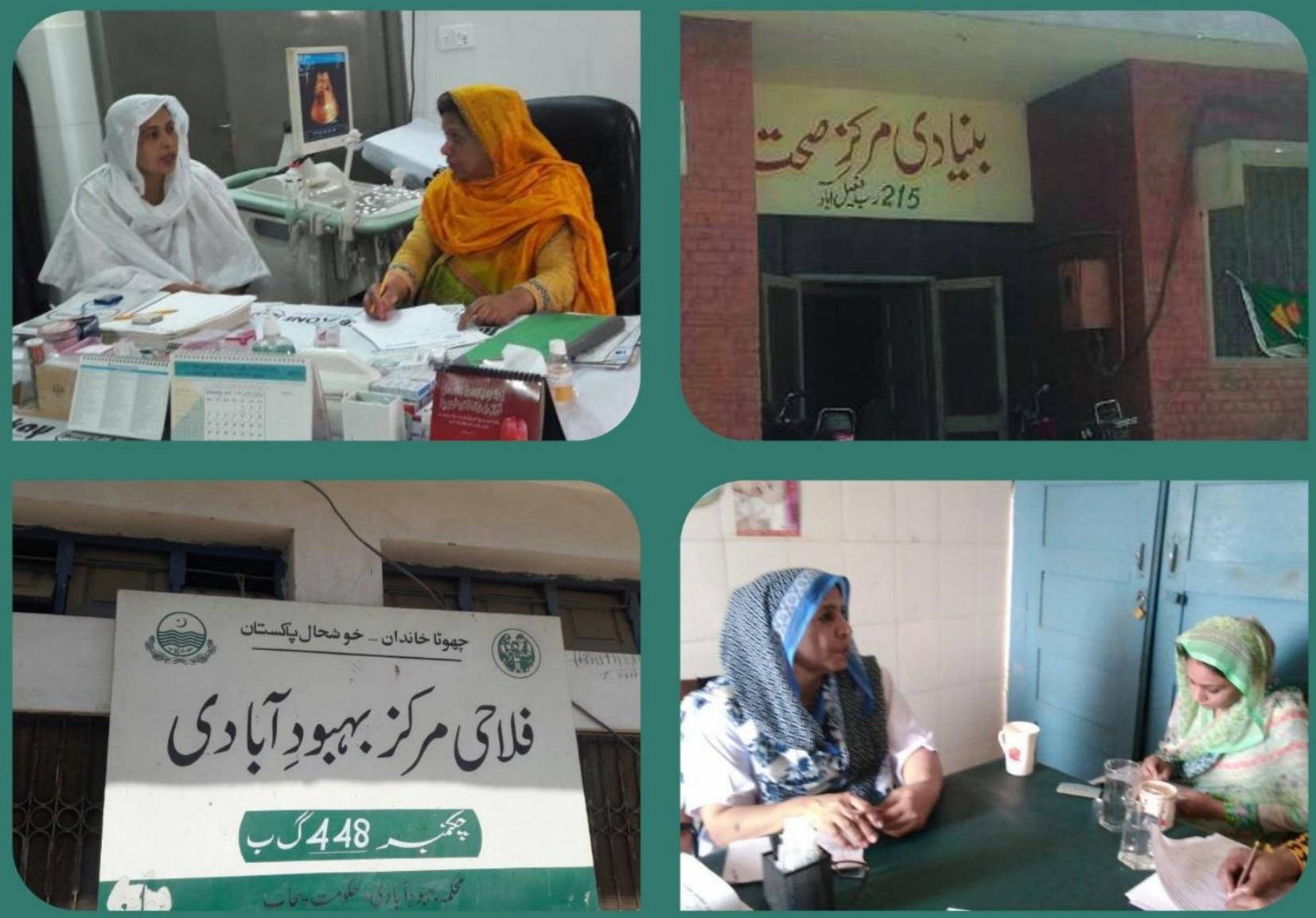

\section{Availability and Provision of Family Planning Services}

Presence of Health Facilities and Pharmacies Sectoral Distribution of Facilities and Pharmacies Provision of Family Planning Services 



\section{Availability and Provision of Family Planning Services}

Public health services are delivered in Punjab mainly by three entities, including the Department of Health $(\mathrm{DoH})$, the Population Welfare Department (PWD), and the Punjab Rural Support Program (PRSP). The Department of Health operates the largest number of facilities, including district and teaching hospitals, which are Category I facilities (more than 50 beds); basic health units (BHUs), maternal and child care centers (MCHs), rural health centers (RHCs), and tehsil hospitals (THQs), which comprise Category II facilities (1-50 beds); and dispensaries, which are Category III facilities (no in-patient services). The Department also manages the Lady Health Worker (LHW) Programme, which greatly extends the reach of its primary healthcare services. A considerable number of BHUs, as well as some RHCs, have been outsourced to the PRSP. Although family planning services are a part of the services provided by the $\mathrm{DoH}$, they comprise the primary mandate of the Department of Population Welfare (PWD), which operates Family Welfare Centers (FWCs), Reproductive Health Services Centers A (RHSC-As) and Family Health Centers (FHCs). PWD also operates a team of community-based workers, known as Family Welfare Workers (FWWs).

Private health facilities may be classified on the basis of their ownership and nature of services into private hospitals; clinics operated by NGOs; clinics of male or female doctors; clinics of mid-level providers (including Lady Health Visitors (LHVs), nurses, or midwives among female providers and dispensers among male providers); and finally, clinics of homeopaths or practitioners of herbal medicine ("hakims"). For the purposes of family planning, pharmacies are also important service delivery points.

In the following discussion, we use CFP and GIS data collected from the 16 study clusters across the four districts to describe the presence of health service delivery points in the clusters, including sectoral shares and geographic location, and compare their numbers to the size of population to be served as a broad gauge for adequacy of coverage. The third part of the discussion, we look at the scale on which opportunities to improve access to family planning are being missed through non-provision by existing facilities. Differences in the roles of specific types of facilities in providing FP services are also examined. Finally, we look at the provision of specific methods of family planning by health facilities and pharmacies.

\section{Presence of Health Facilities and Pharmacies}

Table 2.1 provides the number of public and private facilities and pharmacies surveyed in the study districts. It is immediately apparent that public health facilities are greatly outnumbered by private health facilities, even when the large numbers of LHWs are counted. Within the public sector, there are considerably more DoH facilities (including BHUs) than PWD facilities in all districts except Rahim Yar Khan. The numbers of LHWs are much lower in Rahim Yar Khan and Bahawalpur than in the other two northern districts.

The numbers of private facilities and pharmacies are highest in Faisalabad followed by Rawalpindi. In all districts, there are more than half as many pharmacies as all private health facilities put together, indicating the former's considerable potential for expanding access to FP services through private commercial channels. Further details about the cluster and urban-rural breakdown of health facilities, workers, and pharmacies in each district are provided in Appendix D. 
Table 2.1: Number of Health Service Delivery Points Present in Study Clusters

\begin{tabular}{|c|c|c|c|c|c|}
\hline Sector & Rawalpindi & Faisalabad & Bahawalpur & Rahim Yar Khan & Total \\
\hline \multicolumn{6}{|l|}{ Public sector } \\
\hline BHUs & 30 & 43 & 18 & 28 & 119 \\
\hline PWD facilities* & 20 & 34 & 15 & 32 & 101 \\
\hline DoH facilities ** & 36 & 36 & 19 & 18 & 109 \\
\hline Total public static facilities & 86 & 113 & 52 & 78 & 329 \\
\hline $\begin{array}{l}\text { Lady Health Workers } \\
\text { (LHWs) }\end{array}$ & 848 & 1,186 & 455 & 488 & 2977 \\
\hline Total public sector SDPs & 934 & 1,299 & 507 & 566 & 3306 \\
\hline \multicolumn{6}{|l|}{ Private Sector } \\
\hline $\begin{array}{l}\text { Private health } \\
\text { facilities } * * *\end{array}$ & 801 & 2,106 & 624 & 608 & 4,139 \\
\hline Pharmacies & 713 & 1,415 & 418 & 587 & 3,133 \\
\hline Total private sector SDPs & 1,514 & 3,521 & 1,042 & 1,195 & 7,272 \\
\hline \multicolumn{6}{|l|}{ Source: CFP and PC-Landscape } \\
\hline \multicolumn{6}{|c|}{ DoH=Department of Health, PWD=Population Welfare Department. } \\
\hline \multicolumn{6}{|c|}{ Facilities of PWD include RHSC-A/FHCs and FWCs } \\
\hline \multicolumn{6}{|c|}{ Facilities of DoH include teaching hospitals, DHQs, THQs, RHCs, MCH centers, and dispensaries } \\
\hline \multicolumn{6}{|c|}{$\begin{array}{l}\text { Private Health Facilities include NGO clinics, private hospitals, male doctor clinics, female doctor clinics, LHV/nurse/midwif } \\
\text { clinics, dispenser clinics, and homeopath/hakeem clinics }\end{array}$} \\
\hline
\end{tabular}

\section{Sectoral and Spatial Distribution of SDPs}

The relative proportion of different types of service delivery points (SDPs) in the public sector and the private sector are shown in Figures 2.1 and 2.2, respectively. Figure 2.1 focuses on static health facilities, excluding the huge numbers of LHWs in the public sector and the even larger number of pharmacies from the private sector. These two dominant categories are added in Figure 2.2 to convey the full picture of available SDPs.

As Figure 2.1 shows, BHUs account for the largest share of static facilities in the public sector, followed by PWD and dispensaries. Notably, dispensaries, which are operated by DoH, are shown separately. In the private sector, clinics of hakeems and homeopaths are available in the largest numbers, followed by dispensers' clinics, clinics of male doctors, and private hospitals. Clinics of female doctors; LHVs, midwives and nurses; and NGOs account for a small share of the private sector. 
Figure 2.1: Distribution of Static Public/Private Health Facilities in the Study Areas
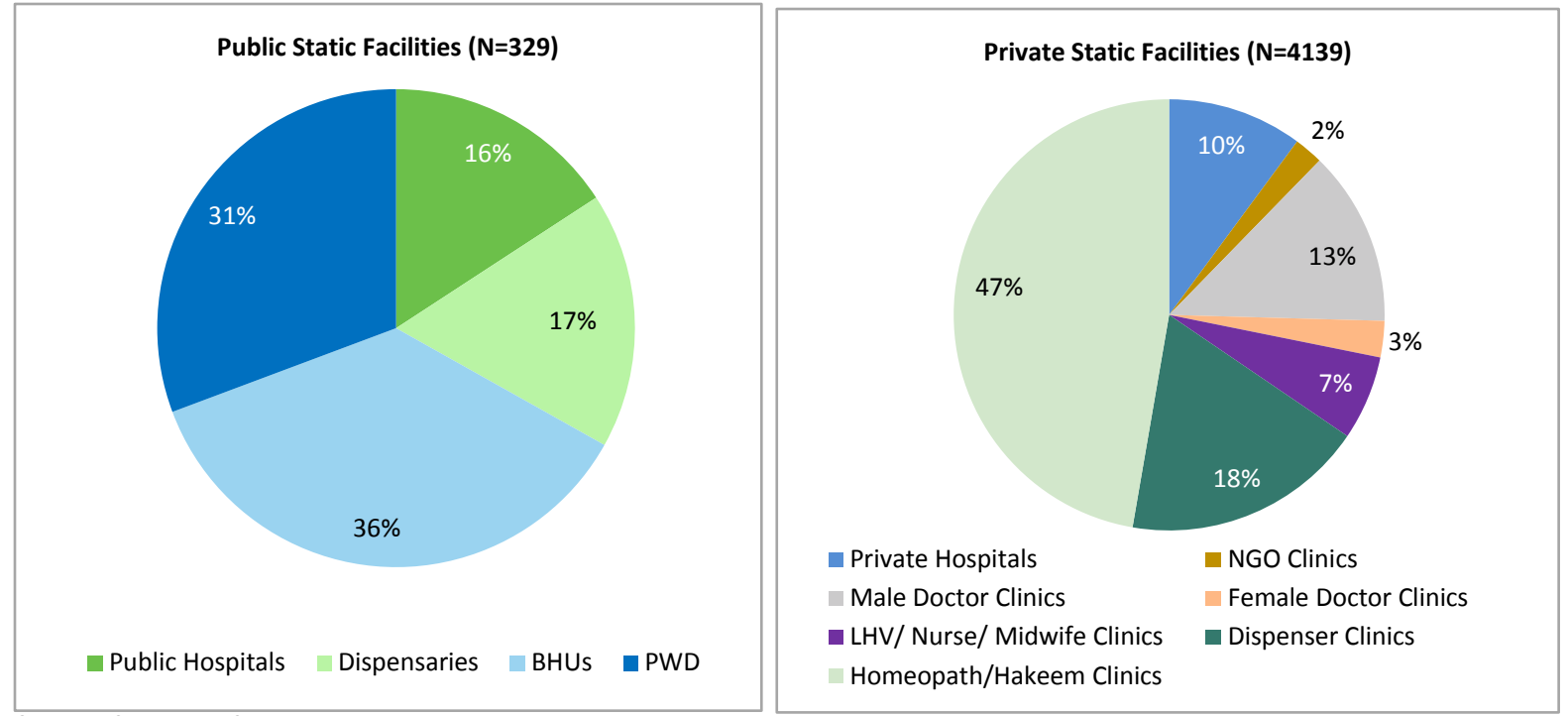

Source: CFP and PC-Landscape

Figure 2.2 shows that LHWs and pharmacies are the largest channels with the potential of providing and dispensing RH services and products, with LHWs comprising 90 percent of public sector SDPs, and pharmacies making up 43 percent of private sector channels.

Figure 2.2: Distribution of Public/Private Health Facilities, LHWs, and Pharmacies in the Study Areas
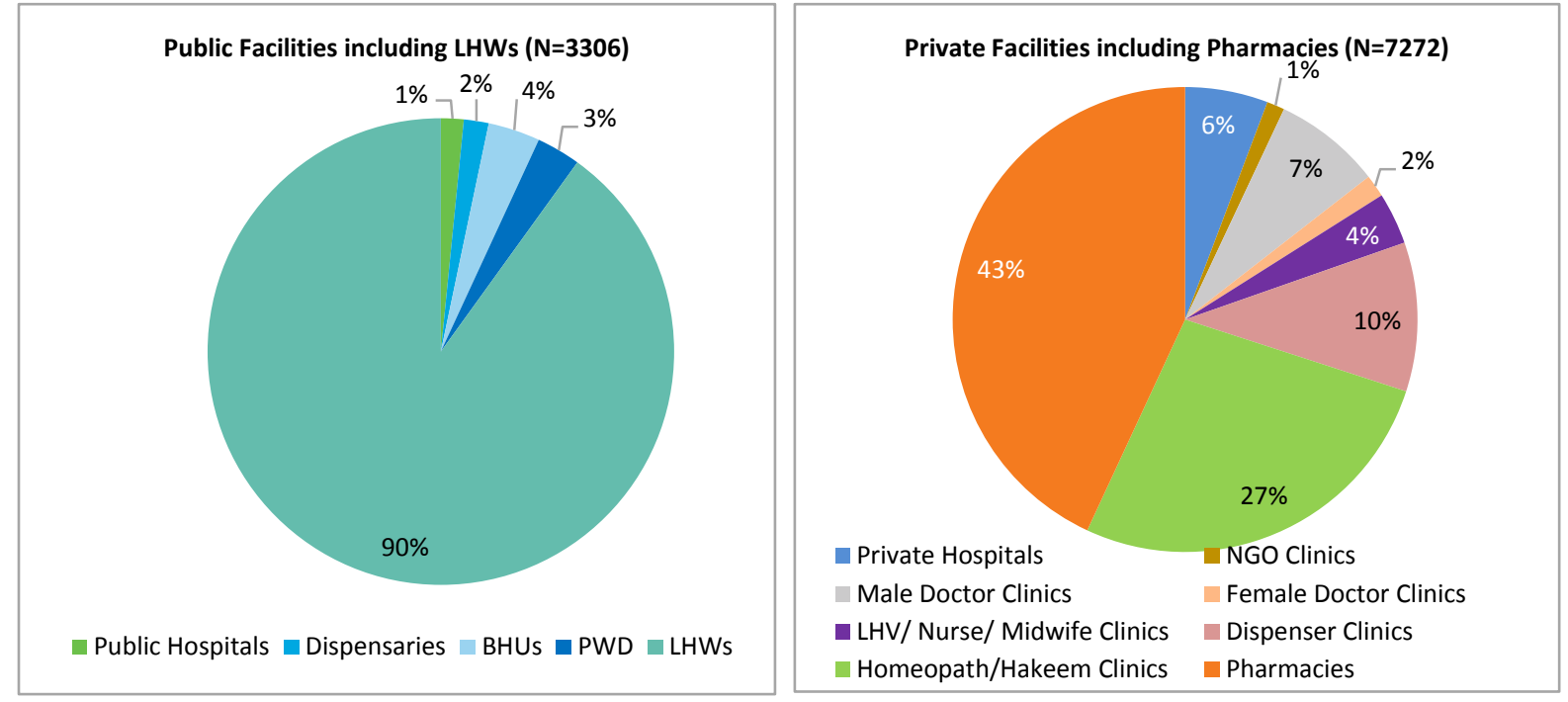

Source: CFP and PC-Landscape

Figures $2.3 a$ to $2.3 \mathrm{~d}$ shows the location of public and private health facilities, LHWs, and pharmacies in the study areas. The overall picture is encouraging, with a wide dispersion of SDPs in the study areas: at least in terms of physical presence, there is potentially a sufficient spread of facilities to provide FP services in the districts, especially when LHWs are taken into account. 
Figure 2.3a: Location of Public/Private Health Facilities, LHWs, and Pharmacies in Rawalpindi
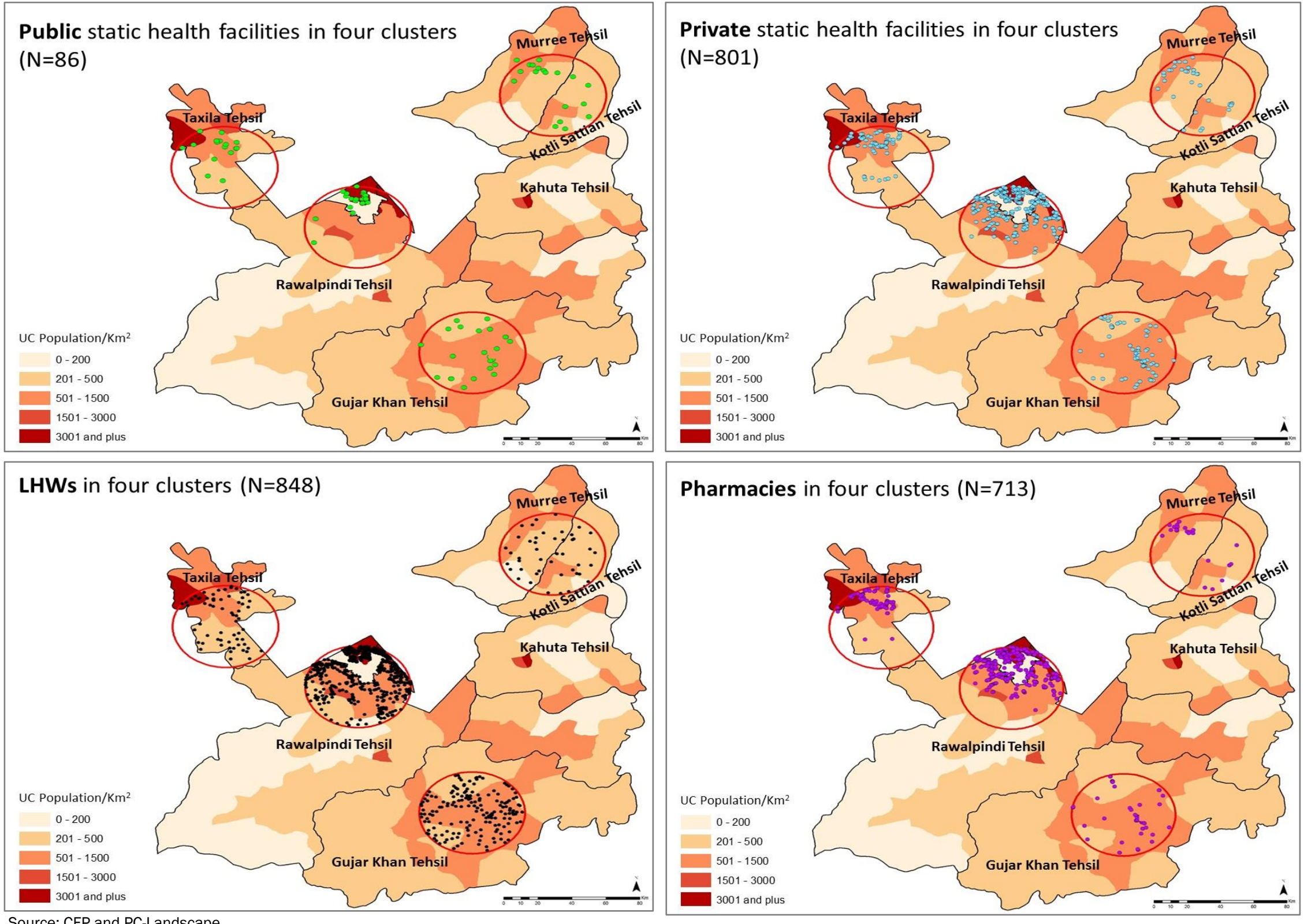

Source: CFP and PC-Landscape 
Figure 2.3b: Location of Public/Private Health Facilities, LHWs, and Pharmacies in Faisalabad
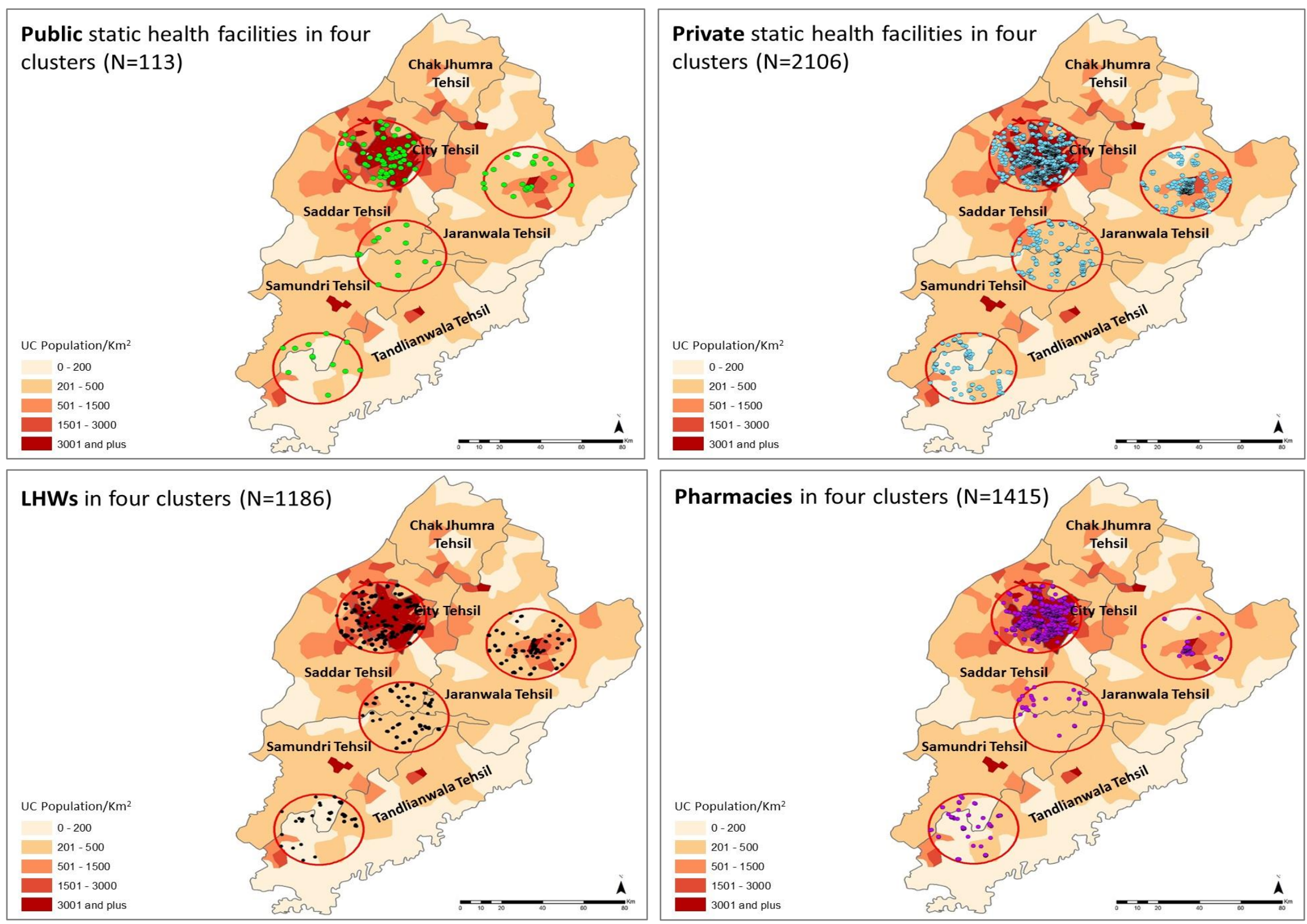

Source: CFP and PC-Landscape 
Figure 2.3c: Location of Public/Private Health Facilities, LHWs, and Pharmacies in Bahawalpur
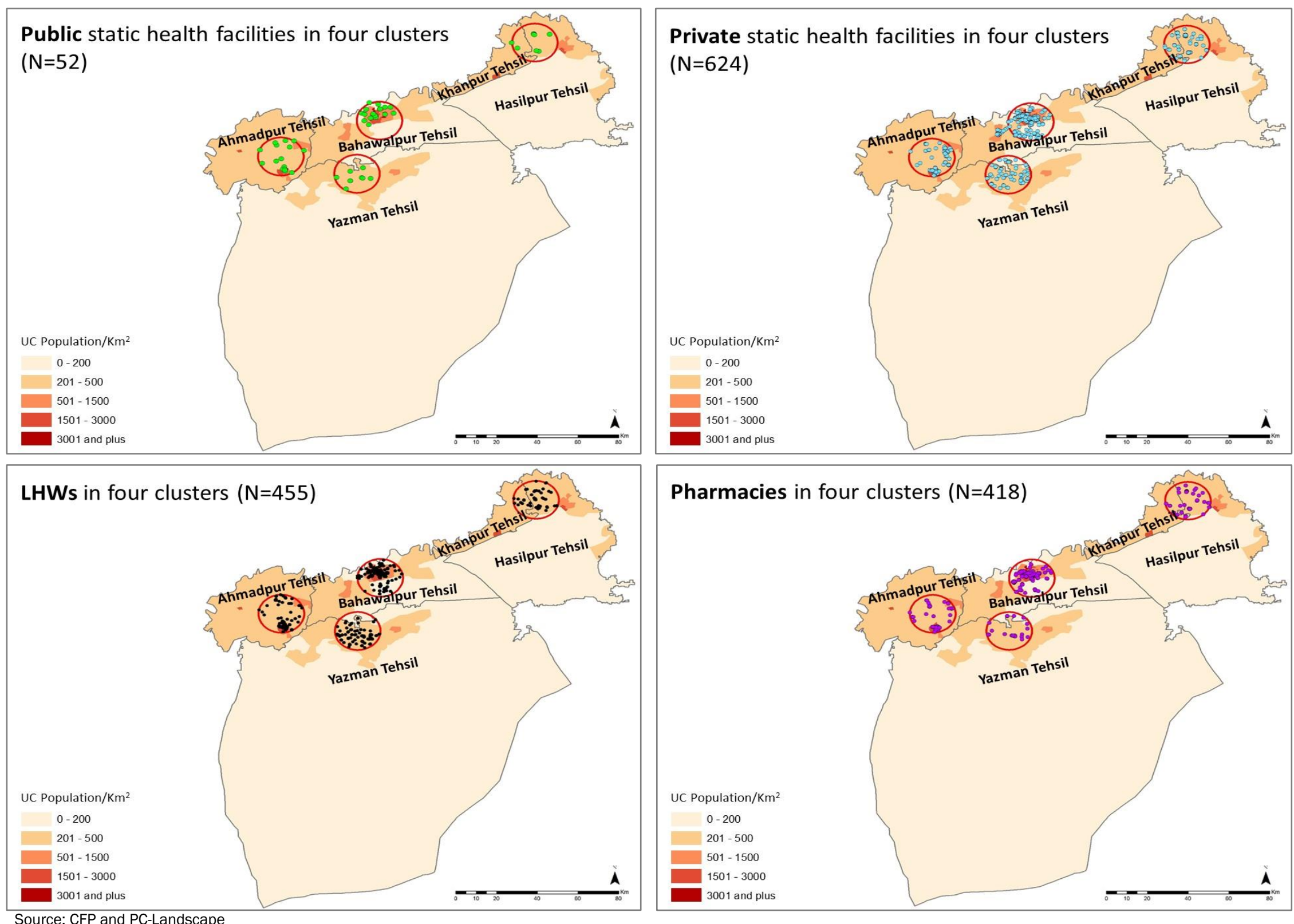
Figure 2.3d: Location of Public/Private Health Facilities, LHWs, and Pharmacies in Rahim Yar Khan
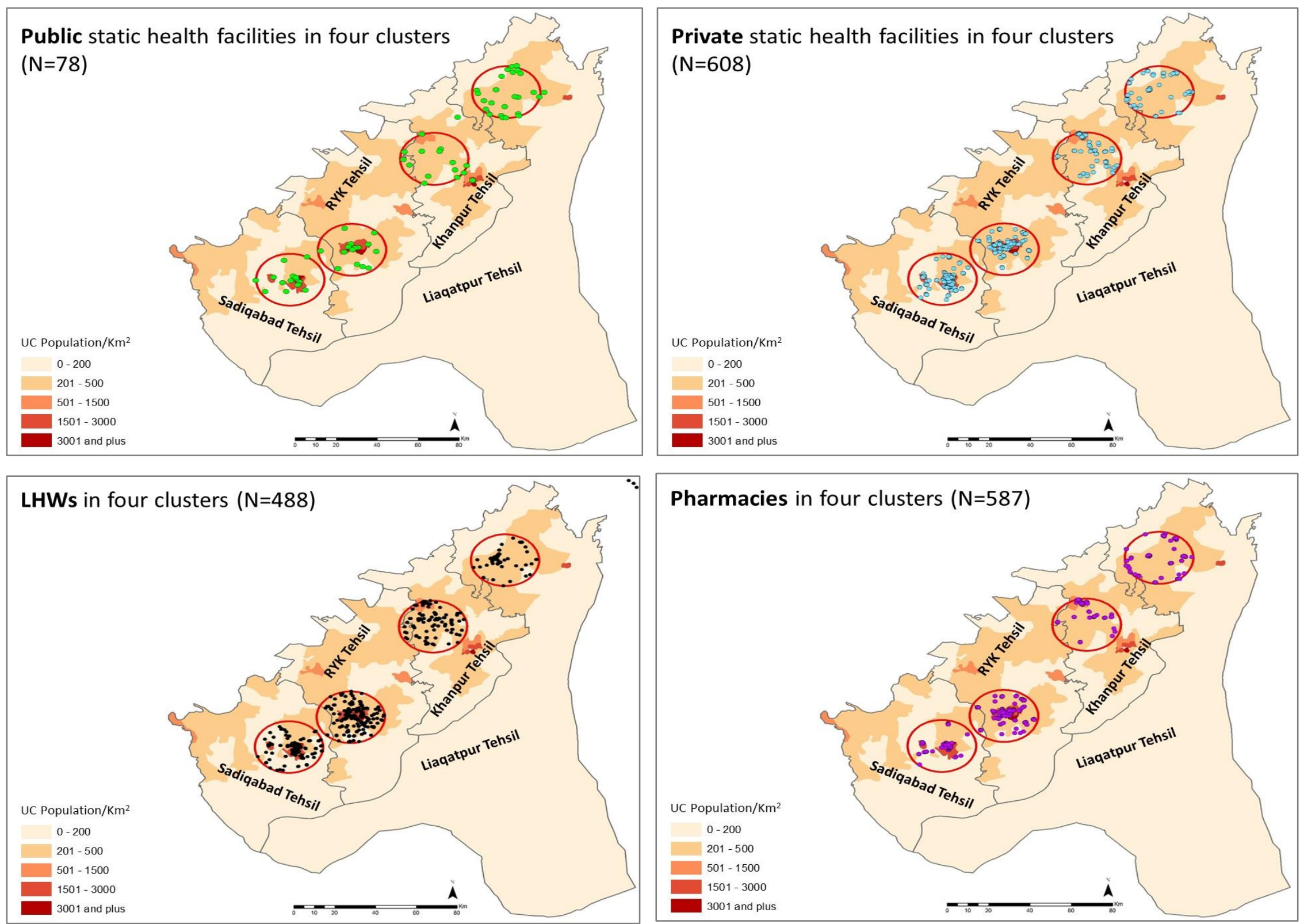


\section{Availability of SDPs per 10,000 Population}

Table 2.2 shows the numbers of static public health facilities, LHWs, private health facilities, and pharmacies per 10,000 population in the study clusters. Overall, the average number of SDPs per 10,000 population ranges between 1.8 and 2.6 in the public sector (counting both static facilities and LHWs), and between 3.5 and 4.2 in the private sector (including both health facilities and pharmacies).

The number of public static facilities varies between 0.2 and 1.4 in the study areas, while the number of LHWs ranges from 2 to 6 . The number of private facilities ranges between 2.3 in Liaqatpur cluster of Rahim Yar Khan and 6.0 in Jaranwala cluster of Faisalabad. The number of pharmacies per 10,000 population ranges from 0.8 in Jaranwala cluster of Faisalabad to 7.4 in Murree/Kotli Sattian cluster of Rawalpindi.

Table 2.2: Number of Public/ Private Health Facilities, LHWs, and Pharmacies per 10,000 Population, by District and Cluster

\begin{tabular}{|c|c|c|c|c|c|c|c|c|c|c|c|c|c|c|c|c|c|c|c|c|}
\hline \multirow[b]{2}{*}{ Facilities } & \multicolumn{4}{|c|}{$\begin{array}{l}\text { Rawalpindi } \\
\text { Cluster* }\end{array}$} & \multicolumn{6}{|c|}{$\begin{array}{l}\text { Faisalabad } \\
\text { Cluster* }\end{array}$} & \multicolumn{5}{|c|}{$\begin{array}{l}\text { Bahawalpur } \\
\text { Cluster* }\end{array}$} & \multicolumn{5}{|c|}{$\begin{array}{c}\text { Rahim Yar Khan } \\
\text { Cluster* }\end{array}$} \\
\hline & 1 & 2 & 3 & 4 & Avg & 1 & 2 & 3 & 4 & Avg & 1 & 2 & 3 & 4 & Avg & 1 & 2 & 3 & 4 & Avg \\
\hline $\begin{array}{l}\text { Public } \\
\text { Facilities }\end{array}$ & 0.2 & 0.9 & 1.2 & 1.4 & 0.9 & 0.2 & 0.4 & 0.3 & 0.5 & 0.4 & 0.3 & 0.4 & 0.4 & 0.6 & 0.4 & 0.3 & 0.4 & 0.4 & 0.9 & 0.5 \\
\hline LHWs & 4.0 & 6.0 & 4.0 & 3.0 & 4.3 & 3.0 & 4.0 & 2.0 & 6.0 & 3.8 & 3.0 & 3.0 & 5.0 & 4.0 & 3.8 & 3.0 & 3.0 & 4.0 & 2.0 & 3.0 \\
\hline $\begin{array}{l}\text { Average } \\
\text { Public }\end{array}$ & 2.1 & 3.5 & 2.6 & 2.2 & 2.6 & 1.6 & 2.2 & 1.2 & 3.3 & 2.1 & 1.7 & 1.7 & 2.7 & 2.3 & 2.1 & 1.7 & 1.7 & 2.2 & 1.5 & 1.8 \\
\hline $\begin{array}{l}\text { Private } \\
\text { Facilities }\end{array}$ & 4.0 & 5.2 & 5.4 & 2.8 & 4.4 & 4.9 & 6.0 & 3.0 & 3.3 & 4.3 & 5.2 & 3.9 & 3.7 & 5.5 & 4.6 & 3.5 & 5.6 & 3.3 & 2.3 & 3.7 \\
\hline Pharmacies & 3.7 & 2.7 & 7.4 & 2.1 & 4.0 & 3.6 & 2.8 & 0.8 & 3.4 & 2.7 & 3.6 & 2.9 & 1.6 & 3.7 & 3.0 & 3.9 & 3.7 & 3.3 & 3.2 & 3.5 \\
\hline $\begin{array}{l}\text { Average } \\
\text { Private }\end{array}$ & 3.9 & 4.0 & 6.4 & 2.5 & 4.2 & 4.3 & 4.4 & 1.9 & 3.4 & 3.5 & 4.4 & 3.4 & 2.7 & 4.6 & 3.8 & 3.7 & 4.7 & 3.3 & 2.8 & 3.6 \\
\hline
\end{tabular}

Source: CFP and PC-Landscape and Population Development Statistics 2016

* Name of the Clusters:

Rawalpindi

$1=$ Rawalpindi City

$2=$ Gujar Khan

$3=$ Taxila

4=Murree/Kotli Sattian

Faisalabad
$\begin{aligned} & \text { = Faisalabad City } \\ & \text { 2=Jaranwala } \\ & 3=\text { Samundri } \\ & \text { ==Tandlianwala }\end{aligned}$

Bahawalpur
1= Bahawalpur City
2=Ahmadpur
3=Yazman
4=Hasilpur

Rahim Yar Khan

1=Rahim Yar Khan City

2=Sadiqabad

3=Khanpur

4=Liaqatpur

\section{Provision of Family Planning Services}

Although the maps in Figures 2.3a to 2.3d, above, convey a promising picture of SDP presence, findings reveal that a considerable proportion of facilities are not providing FP services, especially in the private sector. This gap is evident from the maps in Figures 2.4 a to $2.4 \mathrm{~d}$, which show only those health facilities, LHWs, and pharmacies that offer at least one FP method in each study district. 
Figure 2.4a: Location of Public/Private Health Facilities, LHWs, and Pharmacies Providing at Least One FP Method in Rawalpindi
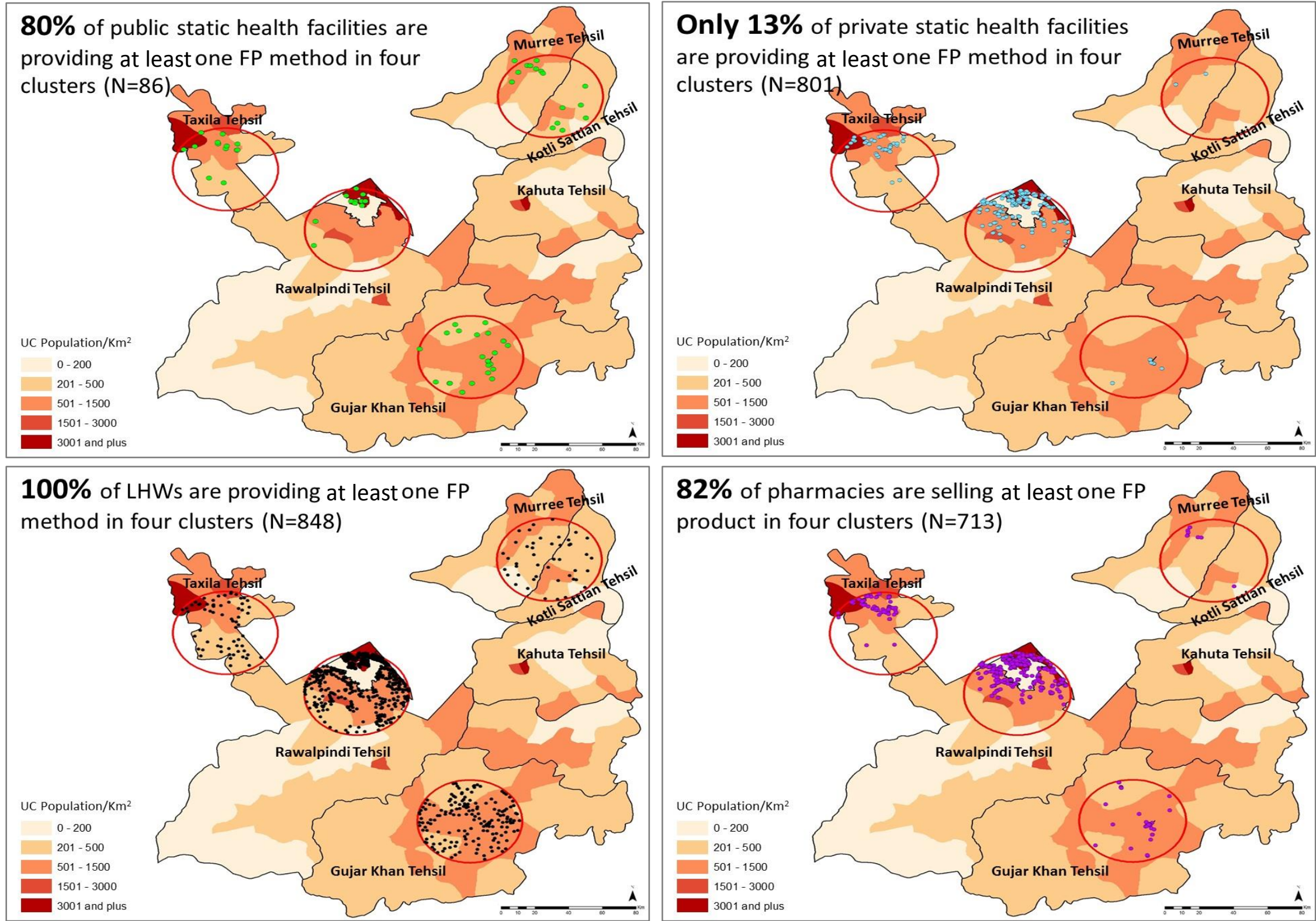

$\mathbf{8 2} \%$ of pharmacies are selling at least one FP product in four clusters $(\mathrm{N}=713)$
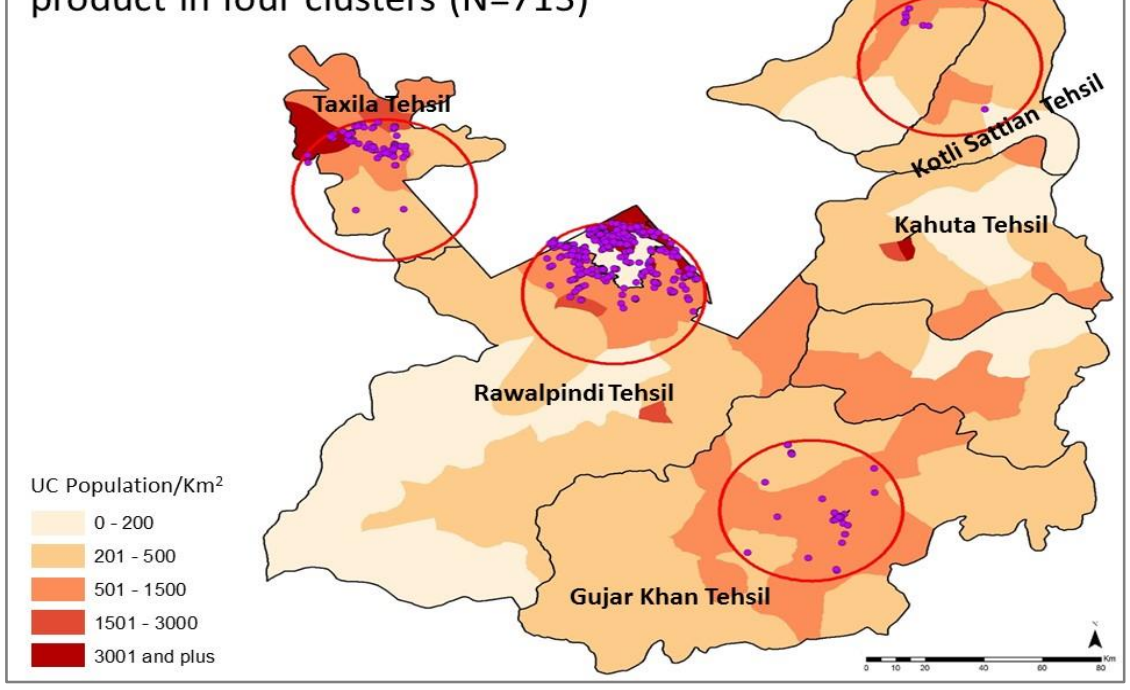
Figure 2.4b: Location of Public/Private Health Facilities, LHWs, and Pharmacies Providing at Least One FP Method in Faisalabad
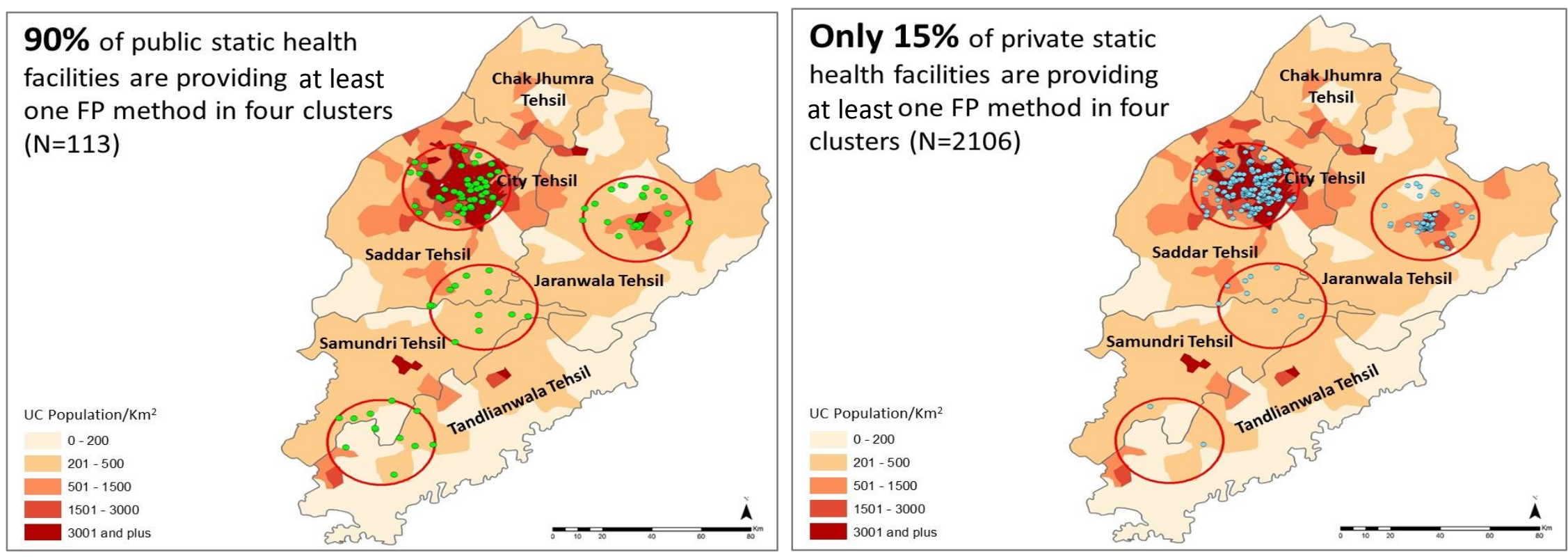

\section{$100 \%$ of LHWs are providing} at least one FP method in four clusters $(\mathrm{N}=1186)$

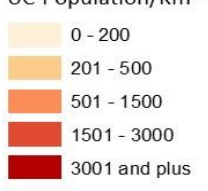

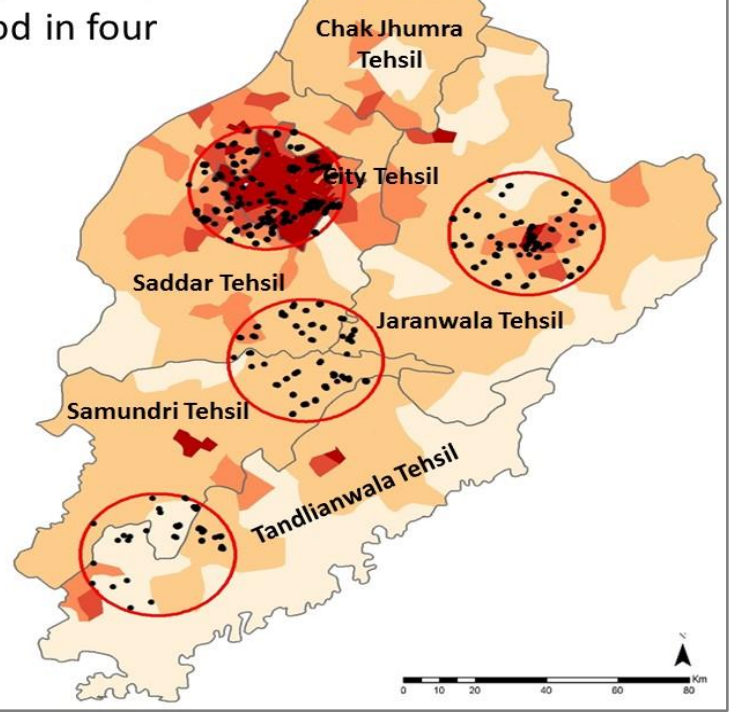

$\mathbf{7 3 \%}$ of pharmacies are selling at leastone FP product in four clusters $(\mathrm{N}=1415)$

UC Population $/ \mathrm{Km}^{2}$ $0-200$

$201-500$

$501-1500$
$1501-3000$

3001 and plus

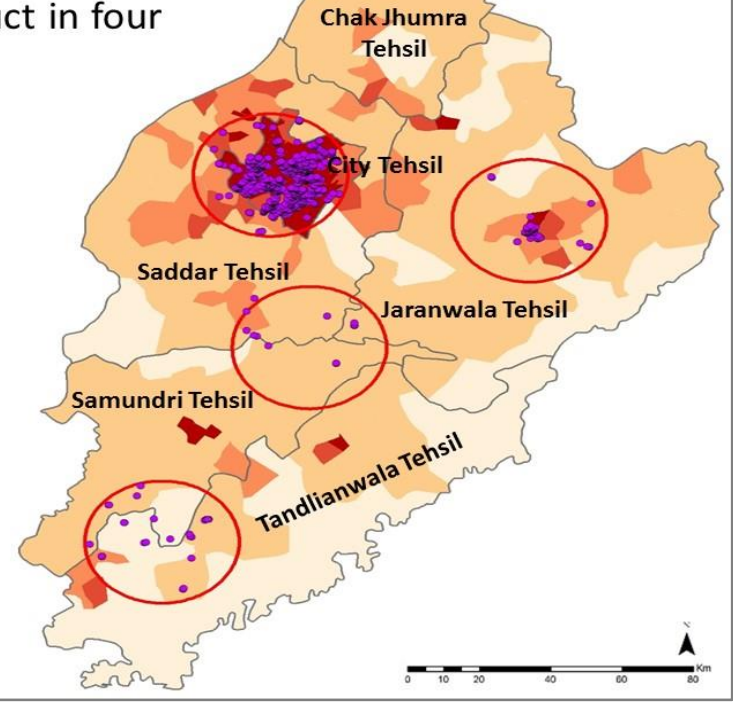

Source: CFP and PC-Landscape 
Figure 2.4c: Location of Public/Private Health Facilities, LHWs, and Pharmacies Providing at Least One FP Method in Bahawalpur

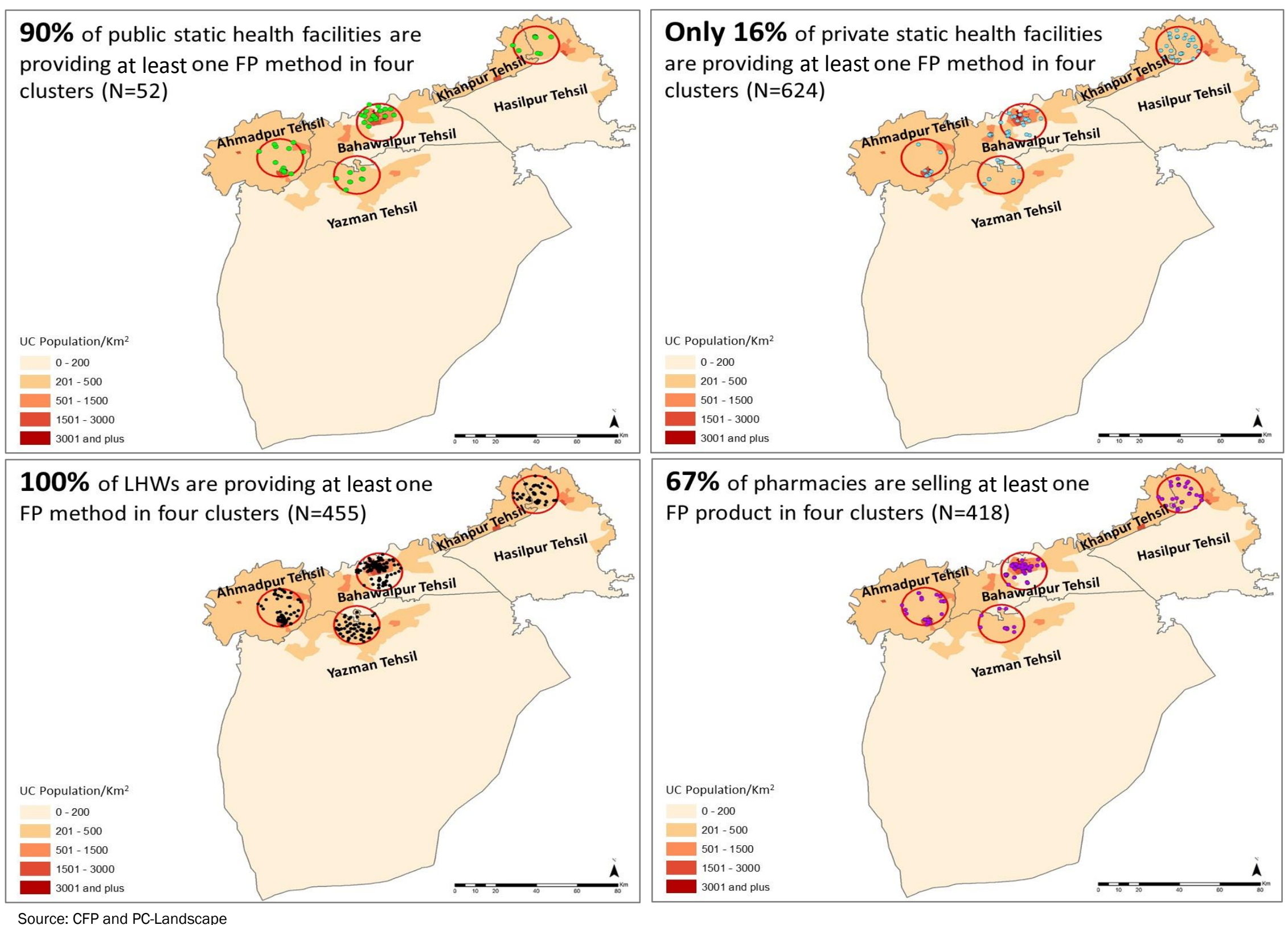


Figure 2.4d: Location of Public /Private Health Facilities, LHWs, and Pharmacies Providing at Least One FP Method in Rahim Yar Khan

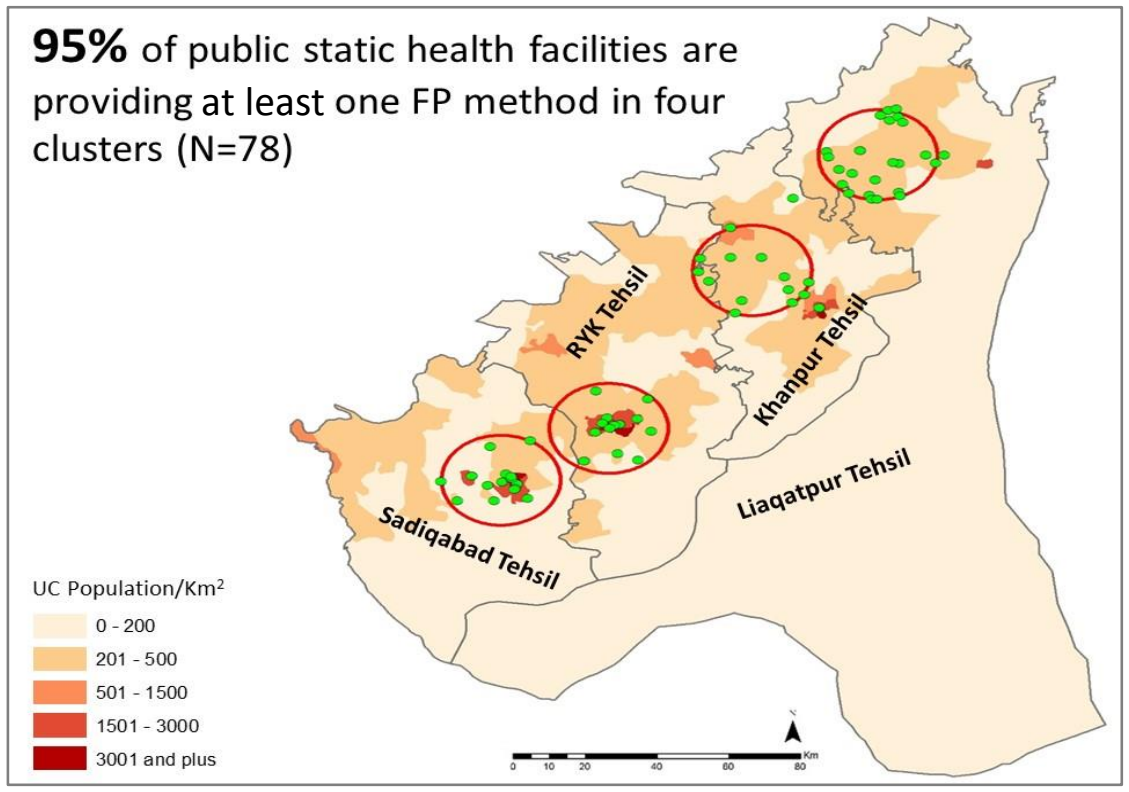

$100 \%$ of LHWs are providing at least one FP method in four clusters $(\mathrm{N}=488)$

UC Population $/ \mathrm{Km}^{2}$ $0-200$

0
$201-500$
$501-1500$

$501-1500$

3001 and plus

Source: CFP and PC-Landscape

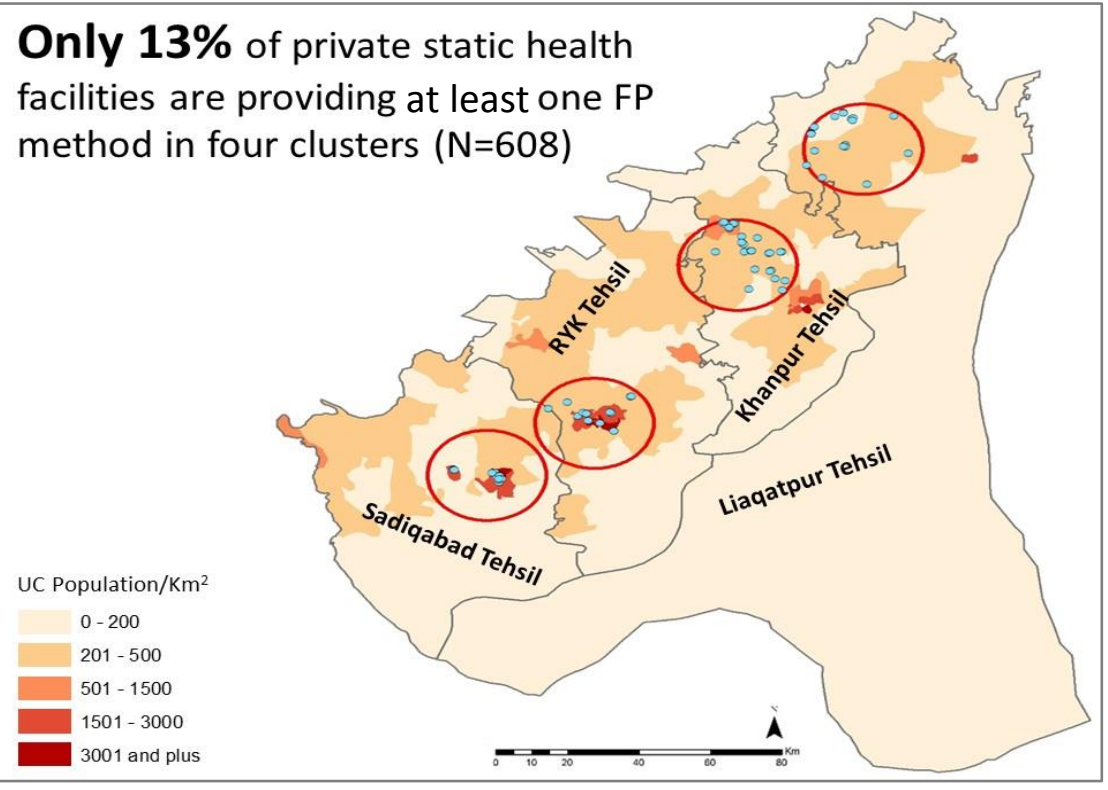

$70 \%$ of pharmacies are selling at least one FP product in four clusters $(\mathrm{N}=587)$

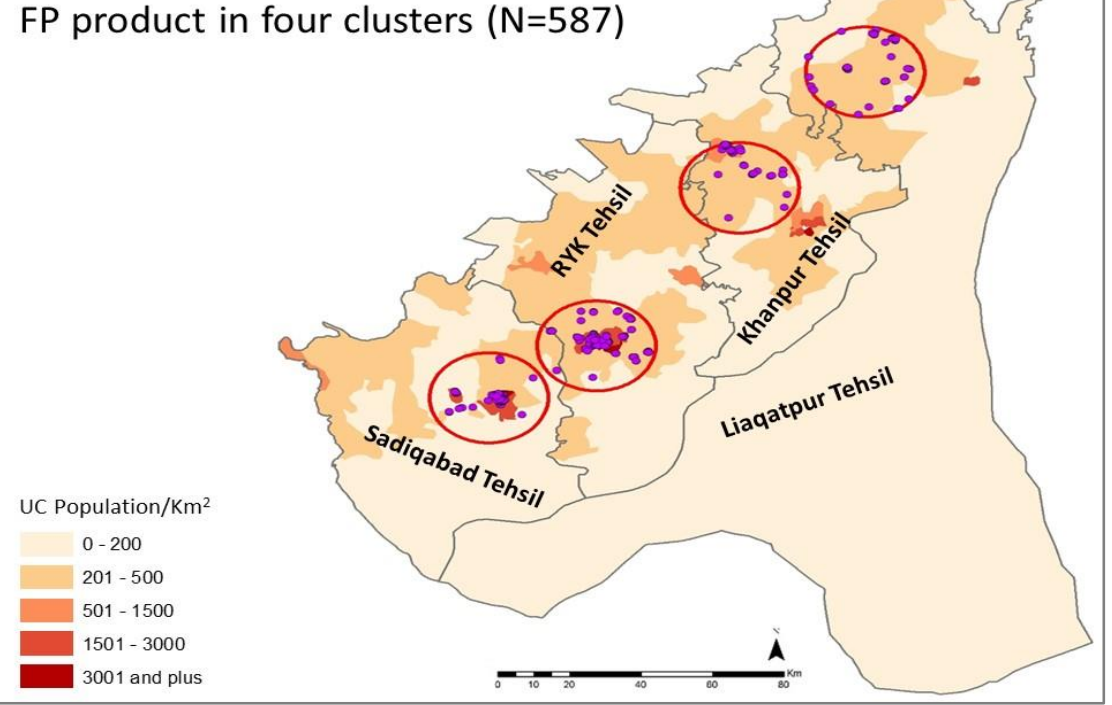




\section{Role of Static Health Facilities and Pharmacies in FP Service Provision}

Overall, of the 329 public static and 4,139 private static health facilities surveyed in the study areas, 89 percent and 18 percent, respectively, are providing family planning services while the rest are not providing even a single method. Among the 3,133 pharmacies visited in the four study districts, 74 percent were selling at least one contraceptive method, mainly in urban areas.

Table 2.3 shows the proportion of health facilities and pharmacies providing FP methods in clusters with the lowest and highest number of SDPs in each district. Most public sector facilities are providing FP services, in the clusters where they are present in the lowest numbers as well as in clusters where they are most concentrated. However, the provision of FP services by private facilities varies from 2 percent to 25 percent in clusters where they are least present and from 6 percent to 37 percent in clusters with the most private health facilities. Pharmacies are mostly selling FP products in both types of clusters.

\section{Table 2.3: Proportion of Static Health Facilities and Pharmacies Providing At Least One FP Method in the Study Areas Where They Exist in the Lowest and Highest Numbers, by District}

\begin{tabular}{|c|c|c|c|c|c|c|c|}
\hline \multirow[b]{2}{*}{ District } & \multirow[b]{2}{*}{ Type of Facility } & \multicolumn{2}{|c|}{$\begin{array}{l}\text { Providing at least one FP } \\
\text { method in cluster with } \\
\text { lowest number of } \\
\text { facilities and pharmacies }\end{array}$} & \multicolumn{2}{|c|}{$\begin{array}{l}\text { Providing at least one FP } \\
\text { method in cluster with } \\
\text { highest number of } \\
\text { facilities and pharmacies }\end{array}$} & \multicolumn{2}{|c|}{$\begin{array}{l}\text { Providing at least one FP } \\
\text { method in all four } \\
\text { clusters of district }\end{array}$} \\
\hline & & $\%$ & $n$ & $\%$ & $n$ & $\%$ & $n$ \\
\hline \multirow{3}{*}{ Rawalpindi } & Public Facilities & 83 & 18 & 92 & 26 & 80 & 86 \\
\hline & Private Facilities & 5 & 38 & 37 & 532 & 31 & 801 \\
\hline & Pharmacies & 39 & 28 & 89 & 497 & 82 & 713 \\
\hline \multirow{3}{*}{ Faisalabad } & Public Facilities & 100 & 12 & 86 & 65 & 90 & 113 \\
\hline & Private Facilities & 2 & 88 & 15 & 1582 & 15 & 2106 \\
\hline & Pharmacies & 42 & 33 & 75 & 1150 & 73 & 1415 \\
\hline \multirow{3}{*}{ Bahawalpur } & Public Facilities & 89 & 9 & 100 & 19 & 90 & 52 \\
\hline & Private Facilities & 13 & 77 & 10 & 328 & 16 & 624 \\
\hline & Pharmacies & 44 & 34 & 64 & 228 & 67 & 418 \\
\hline \multirow{3}{*}{$\begin{array}{l}\text { Rahim Yar } \\
\text { Khan }\end{array}$} & Public Facilities & 91 & 11 & 97 & 31 & 95 & 78 \\
\hline & Private Facilities & 25 & 76 & 6 & 226 & 13 & 608 \\
\hline & Pharmacies & 71 & 95 & 72 & 235 & 70 & 587 \\
\hline \multirow{3}{*}{ Overall } & Public Facilities & 90 & 51 & 85 & 125 & 89 & 329 \\
\hline & Private Facilities & 22 & 290 & 18 & 2653 & 18 & 4139 \\
\hline & Pharmacies & 69 & 270 & 77 & 2110 & 74 & 3133 \\
\hline
\end{tabular}

Source: CFP and PC-Landscape

The proportions of SDPs providing FP services are shown in Figure 2.5, with a closer look at the public channels, the graph shows variation in FP service provision at DoH facilities, which are not being fully utilized. Since the DoH operates the largest number of health facilities in the public health sector, this is a concern. In the private sector, while pharmacies' role in offering at least one FP method is encouraging, the involvement of private health facilities is conspicuously low. 
Figure 2.5: Proportion of Health Facilities (by Type) and Pharmacies Providing Any One FP Method in Study Areas

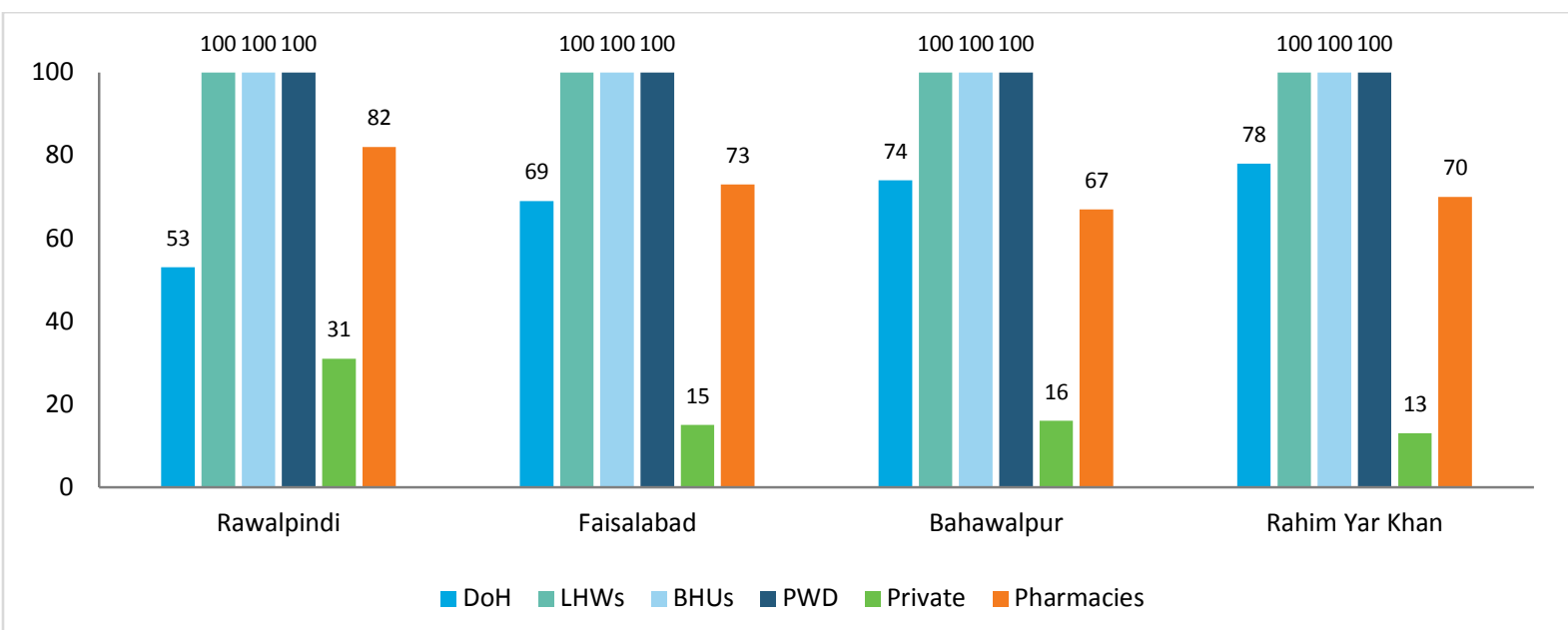

Source: CFP and PC-Landscape

Further details about the role of specific types of facilities and cadres in FP service provision in each district are provided in Appendix E.

\section{Availability of Specific Family Planning Methods}

Offering adequate choice is a crucial element in provision of family planning services. Both short- and longacting methods must be available so that clients can select one that suits their needs, and particularly, so that those who are dissatisfied with one method are able to switch to a more suitable alternative rather than discontinuing family planning use altogether. Being able to choose a preferred method is also an important element of voluntary family planning and rights-based service provision.

Figure 2.6 shows the proportions of health facilities and pharmacies providing specific family planning methods in the study areas.

Among the short-acting methods, condoms, oral pills, and injectables are available at nearly all public health facilities as well as with LHWs, with a slightly lower involvement of DoH facilities. Most pharmacies carry condoms and, to a lesser extent, oral pills, but relatively fewer stock injectables. The proportion of private facilities offering a family planning method is highest for these three methods.

Among the long-acting reversible contraceptives (LARCs), availability of implants is also quite low, and primarily restricted to public sector facilities. Although high proportions of all public health facilities offer intrauterine devices (IUDs), only about 12 percent of private health facilities are providing this method, and its availability at pharmacies is also negligible. Since these methods cannot be used without the services of a skilled provider, it is particularly important that private health facilities be providing these methods. Noninvolvement of private providers may also be a reason why pharmacies are not interested in keeping these methods.

Availability of emergency contraceptive pills (ECPs) is comparatively low at health facilities. Less than half of all types of public health facilities provide this method, even though it could help to reduce the risk of failure associated with condoms, currently the most popular method in the country. Interestingly, however, the majority of the pharmacies are stocking ECPs.

Availability of male and female sterilization services is clearly very low, with only a few DoH facilities providing this method. PWD facilities are playing some role in providing this method. 
Figure 2.6: Proportion of Public/ Private Health Facilities, LHW, and Pharmacies Providing Specific Family Planning Methods in Study Areas

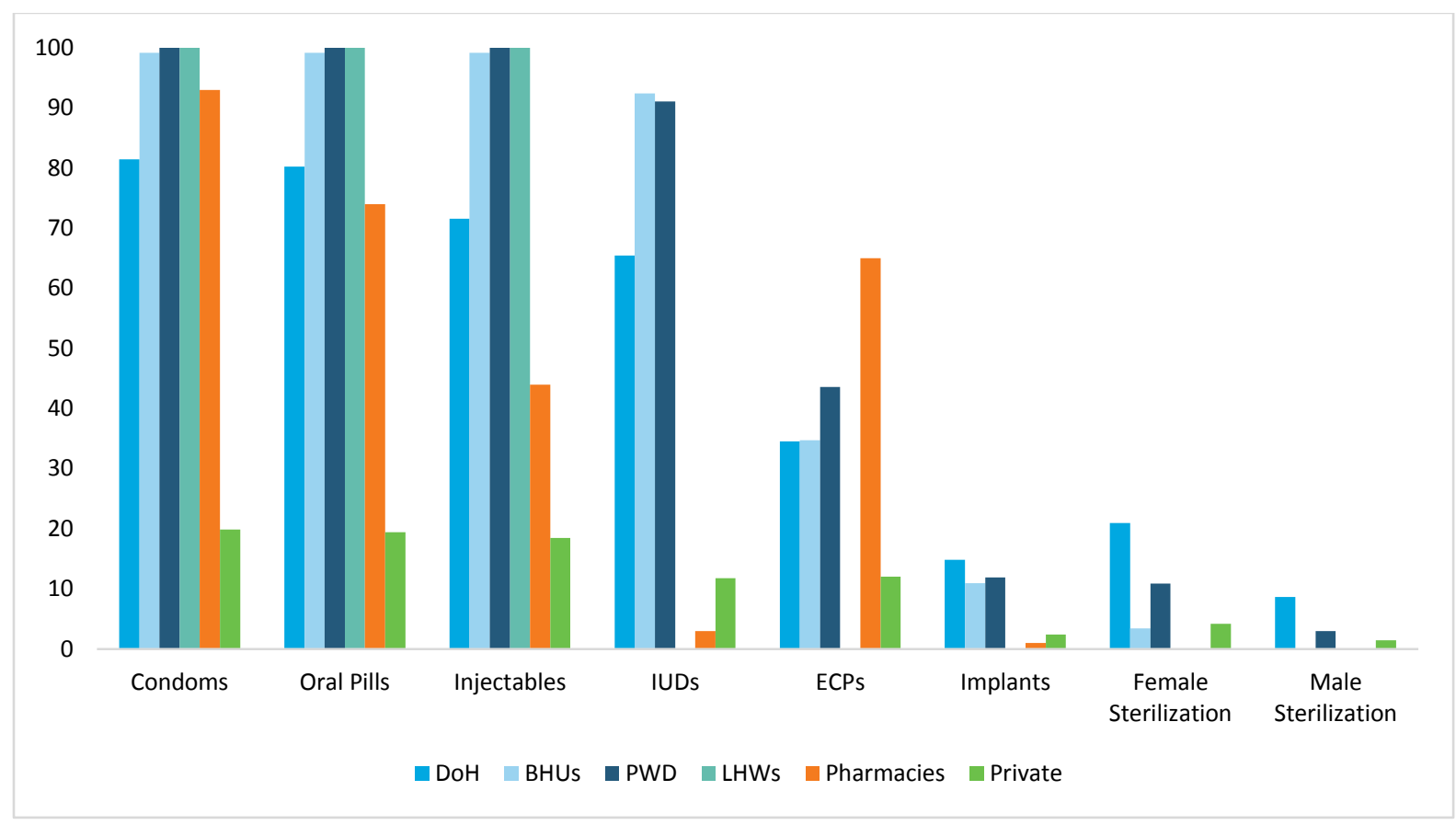

Source: CFP and PC-Landscape

\section{Role of Health Facilities across Districts}

Table 2.4 presents the detailed breakdown of the proportion of health facilities providing different family planning methods in the study areas. It can be observed that DoH facilities are mostly providing condoms, oral pills, injectables, IUDs and ECPs. However, the full potential of these facilities is not being utilized: they can provide more methods. All LHWs are providing three methods they are mandated with, i.e., condoms, oral pills, and subsequent dose of injectables.

The table shows that almost all BHUs are providing condoms, oral pills, injectables, and IUDs. All PWD facilities are also providing condoms, pills, IUDs and injectables. In addition, all PWD facilities in Rawalpindi are providing ECPs followed by Bahawalpur and Faisalabad.

The data shows that most private health facilities are providing condoms, pills, injectables, IUDs and ECPs in all districts except Faisalabad, where their provision of family planning services is very low. Provision of implants and female sterilization services by private providers is generally very low, except in Rawalpindi and Rahim Yar Khan. 
Table 2.4: Proportion of Public/ Private Health Facilities, LHWs Providing Specific FP Methods in Study Areas

\begin{tabular}{|c|c|c|c|c|c|c|c|c|c|c|c|c|c|c|c|c|c|c|c|c|}
\hline & \multicolumn{5}{|c|}{$\begin{array}{l}\text { Rawalpindi } \\
\text { Public } N=86 \\
\text { LHWs } \mathbf{N}=\mathbf{8 4 8} \\
\text { Private } N=801\end{array}$} & \multicolumn{5}{|c|}{$\begin{array}{c}\text { Faisalabad } \\
\text { Public } N=113 \\
\text { LHWs } N=1,186 \\
\text { Private } N=2,106\end{array}$} & \multicolumn{5}{|c|}{$\begin{array}{l}\text { Bahawalpur } \\
\text { Public N= } 52 \\
\text { LHWs N= } 455 \\
\text { Private N= } 624\end{array}$} & \multicolumn{5}{|c|}{ 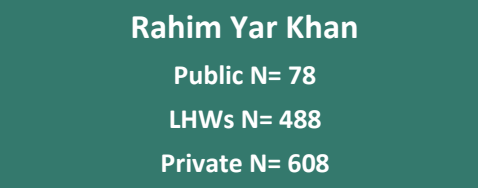 } \\
\hline & DoH & BHUs & LHWs & PWD & Private & DoH & BHUs & LHWs & PWD & Private & DoH & BHUs & LHWs & PWD & Private & DoH & BHUs & LHWs & PWD & Private \\
\hline & $\%$ & $\%$ & $\%$ & $\%$ & $\%$ & $\%$ & $\%$ & $\%$ & $\%$ & $\%$ & $\%$ & $\%$ & $\%$ & $\%$ & $\%$ & $\%$ & $\%$ & $\%$ & $\%$ & $\%$ \\
\hline Condoms & 100 & 100 & 100 & 100 & 69 & 59 & 98 & 100 & 100 & 9 & 93 & 100 & 100 & 100 & 85 & 100 & 100 & 100 & 100 & 79 \\
\hline Oral Pills & 100 & 100 & 100 & 100 & 65 & 59 & 98 & 100 & 100 & 9 & 86 & 100 & 100 & 100 & 82 & 100 & 100 & 100 & 100 & 86 \\
\hline Injectables* & 95 & 100 & 100 & 100 & 62 & 59 & 98 & 100 & 100 & 9 & 79 & 100 & 100 & 100 & 74 & 64 & 100 & 100 & 100 & 73 \\
\hline IUDs & 89 & 83 & - & 100 & 38 & 53 & 95 & - & 74 & 8 & 64 & 89 & - & 100 & 21 & 64 & 100 & - & 100 & 27 \\
\hline Implants & 37 & 7 & - & 30 & 13 & 6 & 5 & - & 3 & 1 & 21 & 39 & - & 27 & 8 & 0 & 7 & - & 3 & 9 \\
\hline ECPs & 79 & 50 & - & 100 & 59 & 18 & 26 & - & 32 & 3 & 29 & 56 & - & 40 & 55 & 21 & 19 & - & 22 & 51 \\
\hline $\begin{array}{l}\text { Female } \\
\text { Sterilization }\end{array}$ & 47 & 10 & - & 40 & 21 & 9 & 2 & - & 3 & 1 & 14 & 0 & - & 0 & 6 & 21 & 0 & - & 6 & 22 \\
\hline $\begin{array}{l}\text { Male } \\
\text { Sterilization }\end{array}$ & 26 & 0 & - & 5 & 8 & 3 & 0 & - & 3 & 0 & 7 & 0 & - & 7 & 1 & 0 & 0 & - & 0 & 11 \\
\hline
\end{tabular}

Source: CFP and PC-Landscape

* LHWs are currently mandated to provide second and subsequent doses of injectables. 


\section{Role of Pharmacies across Districts}

Figure 2.7 shows the role of pharmacies in providing specific FP methods in study areas. Condoms are provided by the largest proportions of pharmacies in all districts; the next most commonly stocked methods are oral pills and ECPs, respectively. Injectables are sold by relatively fewer pharmacies in all districts, except Rawalpindi where more pharmacies carry this method. Provision of IUDs and implants is negligible in all districts

Among the districts, Rawalpindi consistently has the highest proportion of pharmacies providing each method, while Faisalabad generally has the lowest provision (except for condoms). Rahim Yar Khan has the second highest proportion of pharmacies providing each method, except for condoms.

Figure 2.7: Proportion of Pharmacies Providing Specific FP Methods in Study Areas $(\mathbf{N}=3,133)$

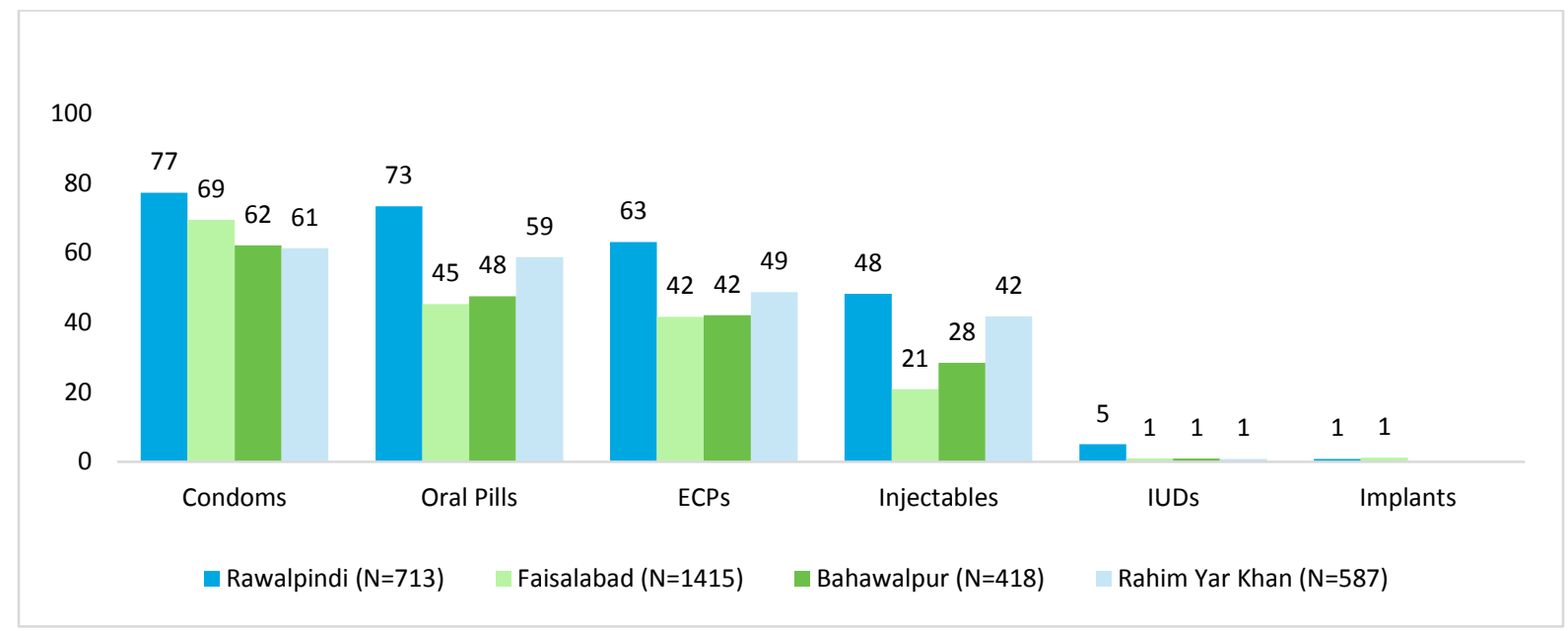

Source: CFP and PC-Landscape

In terms of the contraceptive choices for clients, availability of condoms, oral pills, injectables and IUDs is quite impressive in the public sector. Facilities of PWD and BHUs are fully engaged in providing these four methods. However, a relatively limited number of PWD facilities is providing ECPs.

The role of private health facilities is very limited; a small proportion are providing condoms, oral pills and injectables. These methods, as well as ECPs, are widely available at pharmacies, although injectables are carried by relatively fewer outlets.

LARCs are currently being provided almost entirely through public health facilities, and even there, while IUDs are widely available, implants are offered by very few facilities. Private health facilities are playing a conspicuously small role in providing these methods.

\section{Availability of SDPs Providing FP Services per 10,000 Population}

The impact of sub-optimal provision of FP services by existing facilities on access to FP services is clearly evident in Table 2.5, which provides the number of public static facilities, LHWs, private health facilities, and pharmacies providing family planning services per 10,000 population in each of the study clusters. The ratios are noticeably lower than those presented in Table 2.2, above, for all facilities except LHWs. The number of public static facilities per 10,000 population ranges from 0.1 in Rawalpindi city cluster to 1.1 in Murree/Kotli Sattian cluster of Rawalpindi. Among LHWs, the range of 2 to 6 per 10,000 population is retained. Availability of private facilities providing at least one FP method varies between 0.1 in Murree/Kotli Sattian cluster of Rawalpindi to 2.6 in Taxila cluster of Rawalpindi and Liaqatpur cluster of Bahawalpur. 
The number of pharmacies selling FP products per 10,000 population varies between 0.3 in Samundri cluster of Faisalabad and 6.1 in Taxlia cluster of Rawalpindi. The average number of public facilities providing family planning services per 10,000 population are highest in the Rawalpindi (2.5) while lowest in the Rahim Yar Khan (1.7).

Across the study clusters, the average number of SDPs providing FP services per 10,000 population ranges between 1.7 and 2.5 in the public sector (counting both static facilities and LHWs), and between 1.2 and 2.1 in the private sector (including both health facilities and pharmacies). Thus there is considerable variation within districts and across districts in terms of number of SDPs providing FP services per 10,000 population.

Table 2.5: Number of Static Public/ Private Health Facilities, LHWs, and Pharmacies Providing At Least One FP Method per 10,000 Population, by Cluster

\begin{tabular}{|c|c|c|c|c|c|c|c|c|c|c|c|c|c|c|c|c|c|c|c|c|}
\hline \multirow[b]{2}{*}{ Facilities } & \multicolumn{5}{|c|}{$\begin{array}{l}\text { Rawalpindi } \\
\text { Cluster* }\end{array}$} & \multicolumn{5}{|c|}{$\begin{array}{l}\text { Faisalabad } \\
\text { Cluster* }\end{array}$} & \multicolumn{5}{|c|}{$\begin{array}{l}\text { Bahawalpur } \\
\text { Cluster* }\end{array}$} & \multicolumn{5}{|c|}{$\begin{array}{c}\text { Rahim Yar Khan } \\
\text { Cluster* }\end{array}$} \\
\hline & 1 & 2 & 3 & 4 & Avg & 1 & 2 & 3 & 4 & Avg & 1 & 2 & 3 & 4 & Avg & 1 & 2 & 3 & 4 & Avg \\
\hline $\begin{array}{l}\text { Public } \\
\text { Facilities }\end{array}$ & 0.1 & 0.8 & 1.0 & 1.1 & 0.7 & 0.2 & 0.4 & 0.3 & 0.5 & 0.4 & 0.3 & 0.3 & 0.4 & 0.6 & 0.4 & 0.3 & 0.4 & 0.3 & 0.7 & 0.4 \\
\hline LHWs & 4.0 & 6.0 & 4.0 & 3.0 & 4.3 & 3.0 & 4.0 & 2.0 & 6.0 & 3.8 & 3.0 & 3.0 & 5.0 & 4.0 & 3.8 & 3.0 & 3.0 & 4.0 & 2.0 & 3.0 \\
\hline $\begin{array}{l}\text { Average } \\
\text { Public }\end{array}$ & 2.1 & 3.4 & 2.5 & 2.1 & 2.5 & 1.6 & 2.2 & 1.2 & 3.3 & 2.1 & 1.7 & 1.7 & 2.7 & 2.3 & 2.1 & 1.7 & 1.7 & 2.2 & 1.4 & 1.7 \\
\hline $\begin{array}{l}\text { Private } \\
\text { Facilities }\end{array}$ & 1.5 & 0.4 & 2.6 & 0.1 & 1.2 & 0.7 & 1.2 & 0.2 & 0.1 & 0.6 & 0.5 & 0.3 & 0.5 & 2.6 & 1.0 & 0.2 & 0.3 & 1.2 & 0.6 & 0.6 \\
\hline Pharmacies & 3.3 & 1.4 & 6.1 & 0.8 & 2.9 & 2.7 & 2.1 & 0.3 & 1.7 & 1.7 & 2.3 & 2.0 & 0.7 & 3.2 & 2.1 & 2.8 & 2.8 & 2.3 & 1.9 & 2.5 \\
\hline $\begin{array}{l}\text { Average } \\
\text { Private }\end{array}$ & 2.4 & 0.9 & 4.4 & 0.5 & 2.1 & 1.7 & 1.7 & 0.3 & 0.9 & 1.2 & 1.4 & 1.2 & 0.6 & 2.9 & 1.6 & 1.5 & 1.6 & 1.8 & 1.3 & 1.6 \\
\hline
\end{tabular}

Source: CFP and PC-Landscape and Population Development Statistics 2016

* Name of the Clusters:

\section{Rawalpindi}

1 = Rawalpindi City

2=Gujar Khan

3=Taxila

4=Murree/Kotli Sattian

Faisalabad
1 = Faisalabad City
2=Jaranwala
3=Samundri
4=Tandlianwala

\section{Faisalabad}

$2=$ Jaranwala

4=Tandlianwala

Bahawalpur
1= Bahawalpur City
2=Ahmadpur
3=Yazman
4=Hasilpur

\section{Bahawalpur}

2=Ahmadpur

3=Yazman

\section{Rahim Yar Khan}

1=Rahim Yar Khan City

2=Sadiqabad

3=Khanpur

4=Liaqatpur

\section{Range of FP Methods Provided}

Figure 2.8 shows the proportions of various types of public and private health facilities and LHWs providing at least one, at least three, and at least five family planning methods. The majority of public health facilities are providing at least one family planning method. Among private facilities, the male and alternative cadres have a very low role, while mid-level female providers are playing the greatest role. The second graph shows that lower proportions of SDPs are offering at least three methods; this applies to all types of channels except LHWs, and FHCs. When it comes to providing at least five methods, the proportion of active facilities drops even further, except in the case of mid-level female providers. The majority of pharmacies (74\%) are stocking at least one family planning product and 46 percent of the pharmacies are stocking at least three family planning products. 
Figure 2.8: Proportion of Public/Private Health Facilities, LHWs, and Pharmacies Providing any 1, at Least 3, and at Least 5 Family Planning Methods in the Study Areas
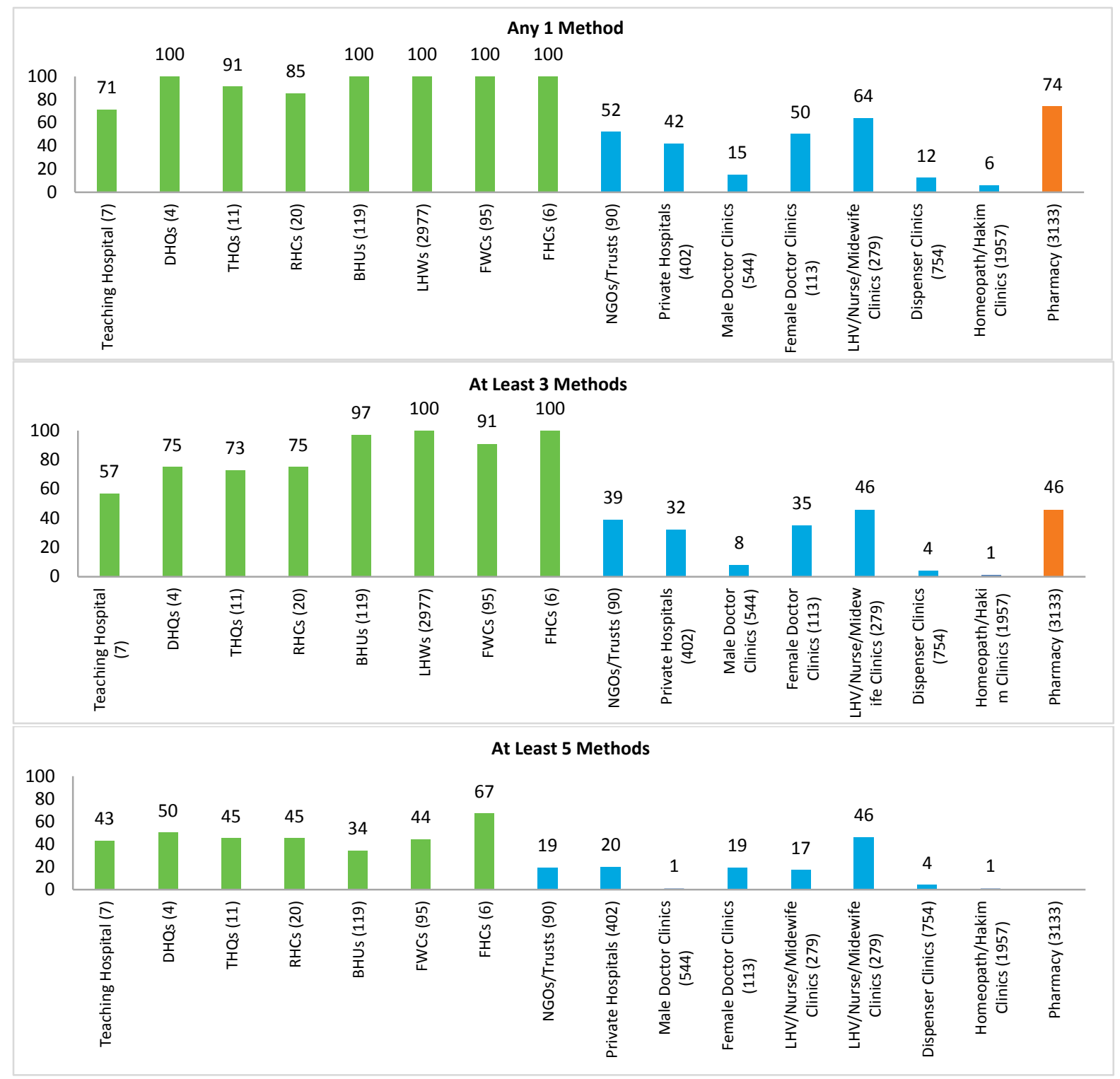

Public Facilities

Private Facilities

Pharmacies

Source: CFP and PC-Landscape 


\section{Conclusions}

While the numbers and distribution of major health facilities in the public and private sector is quite impressive, the full potential of these facilities is not being utilized to deliver family planning services, especially in the private sector, where the majority of health facilities are not providing even a single contraceptive method. The public sector, which has the explicit mandate to provide FP services, is generally active in this role in both urban and rural areas, although some gaps are seen among the static facilities of the Department of Health.

Private health facilities outnumber public facilities, but are considerably less involved in providing family planning services. However, pharmacies are playing an important role in this sector, with over three quarters selling contraceptives in urban areas, and more than half in rural areas. Short-acting contraceptive methods are much more available than LARCs and sterilization services. Condoms, oral pills and injectables are widely available through public health facilities, the LHWs, and pharmacies. IUDs are mainly available through the public sector, but implants are offered at very few SDPs. Emergency contraceptive pills are less available at health facilities but frequently available at pharmacies. 

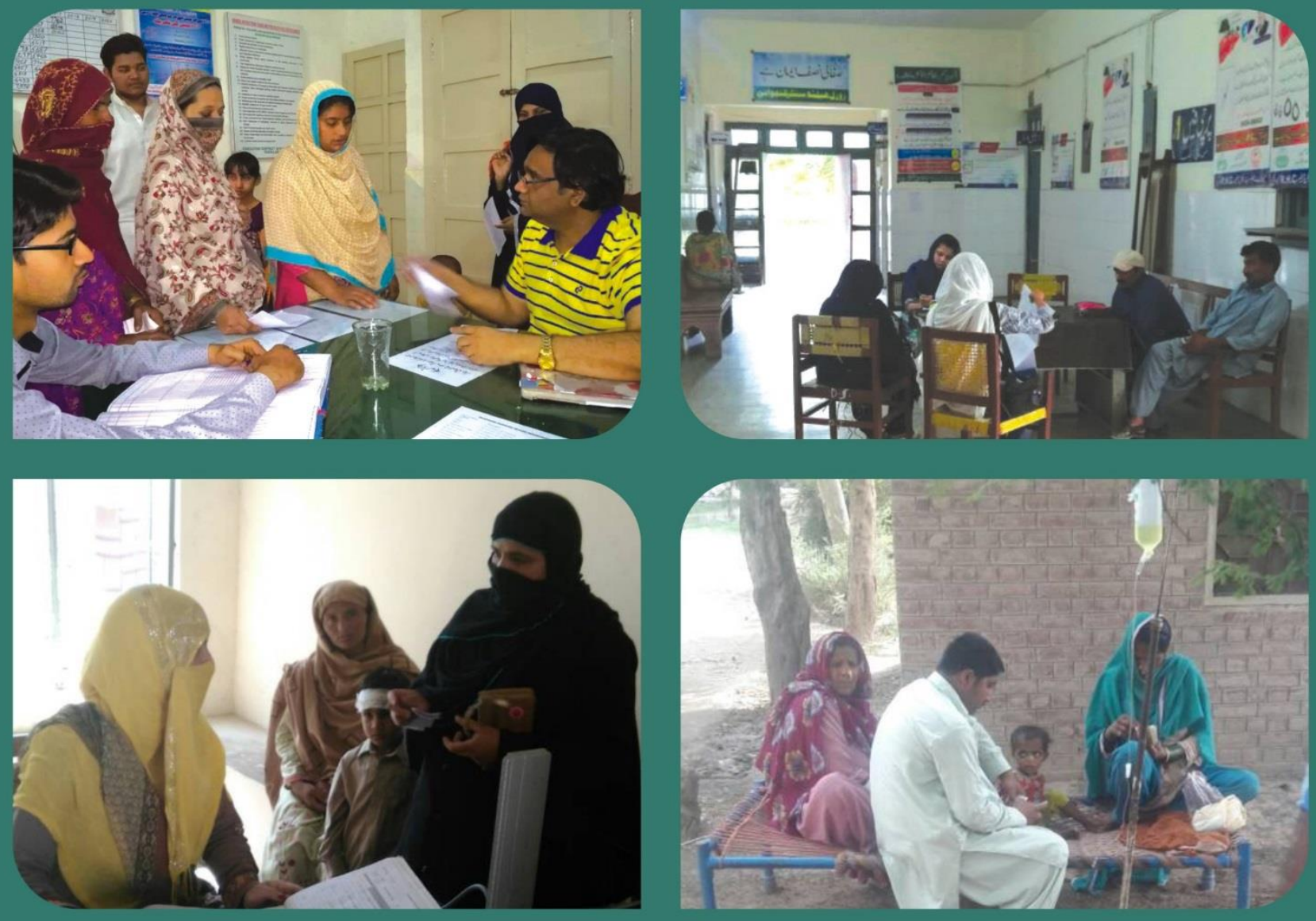

\section{Utilization of Available Health Facilities for Family Planning and Maternal and Child Health Services}

Utilization of Facilities for Family Planning Services

LHW is the most utilized source for FP services Utilization of Facilities for Maternal and Child Health Care 



\section{Utilization of Available Health Facilities for Family Planning and Maternal and Child Health Services}

The previous section provided a detailed picture of the availability of health service delivery points, whether or not they are providing family planning services, and the specific methods available. In the current section, we turn our attention to how these facilities are being utilized by men and women in the surrounding communities. An overview is provided of the most frequently utilized sectors, types of facilities, and cadres of providers for FP and $\mathrm{MCH}$ services based on data from the household survey (HHS) and focus group discussions conducted during this study. With respect to utilization of family planning services, the distances clients travel and the costs they bear to access services are also assessed. We further look at which methods are being utilized more frequently, and from which facilities. In addition, illustrative maps of two clusters are presented showing both availability of health services and their utilization by communities surveyed in the vicinity.

The patterns of utilization that emerge in this section raise many important questions about why clients choose-and also why they elect not to choose-certain sectors, facilities, providers, and FP methods to meet their health needs. These reasons are probed in detail, through an examination of clients' circumstances, reasons, and preferences, in Section 4.

\section{Utilization of Facilities for Family Planning Services}

Before describing the most frequently utilized facilities and methods for family planning, this section looks at the levels of current contraceptive use and unmet need for family planning among respondents of the HHS. Since having at least one child was a criterion of the household survey, both Contraceptive Prevalence Rate and unmet need presents the picture of women with at least one child.

\section{Current Contraceptive Use and Unmet Need for FP}

To understand the situation and trends in demand for FP in each district, it is imperative to look at the contraceptive use status of respondents. As shown in Figure 3.1, in the HHS, more women than men reported current use and past use, while never use was reported by more men than women. This could indicate that either some women are using contraceptives without the knowledge of their husbands, or that men report lower levels of use of contraceptives. 
Figure 3.1: Contraceptive Use Status of HHS Respondents with At Least One Child, \% (n=329 men, 1,114 women)

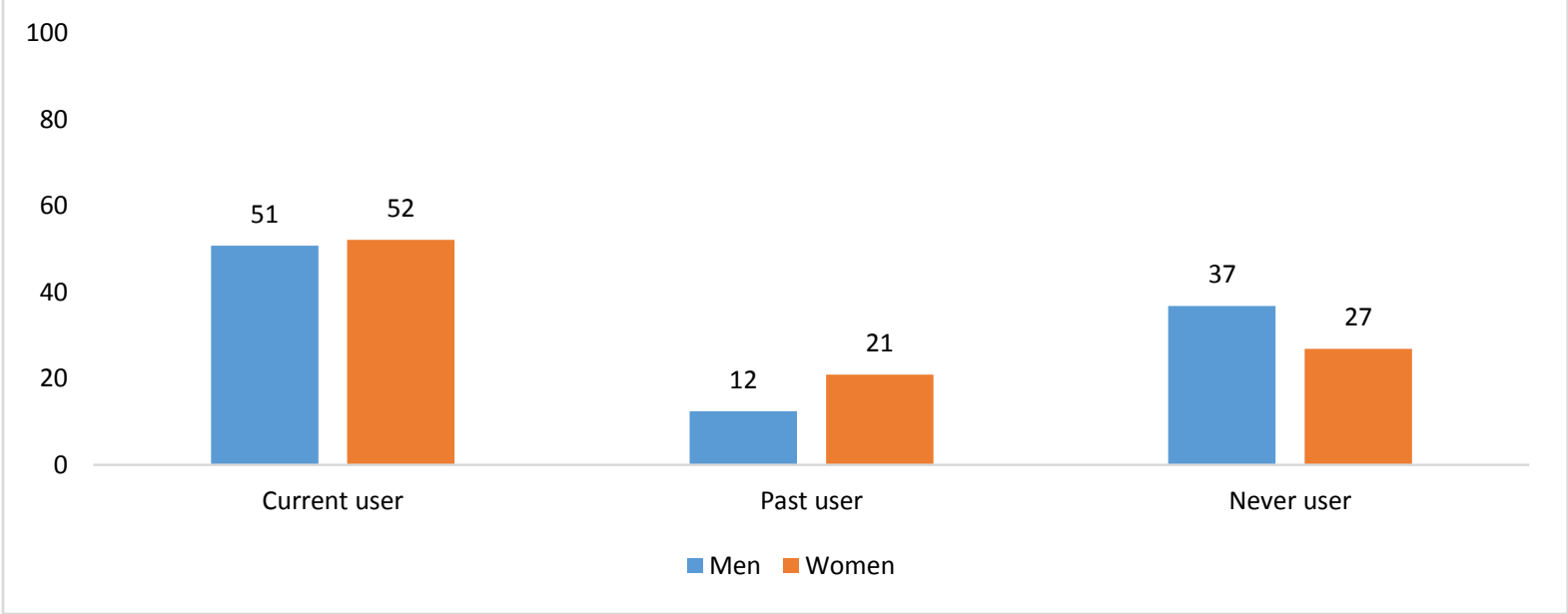

Source: HHS

Note: Having at least one child was a criterion of the HHS.

Figure 3.2 shows the contraceptive use status of the HHS respondents with at least one child. The picture is encouraging, with at least half the respondents from each district reporting current use of family planning. The CPR is highest in Rawalpindi and Bahawalpur (53.3\%), followed by Rahim Yar Khan. Past use is highest in the two southern districts-Bahawalpur and Rahim Yar Khan-whereas never use is reported frequently from the northern and central districts, especially Faisalabad, which seems to depict lower demand for family planning in general.

Figure 3.2: Contraceptive Use Status among Women HHS Respondents with At Least One Child, by District, \% ( $n=1,114$ women)

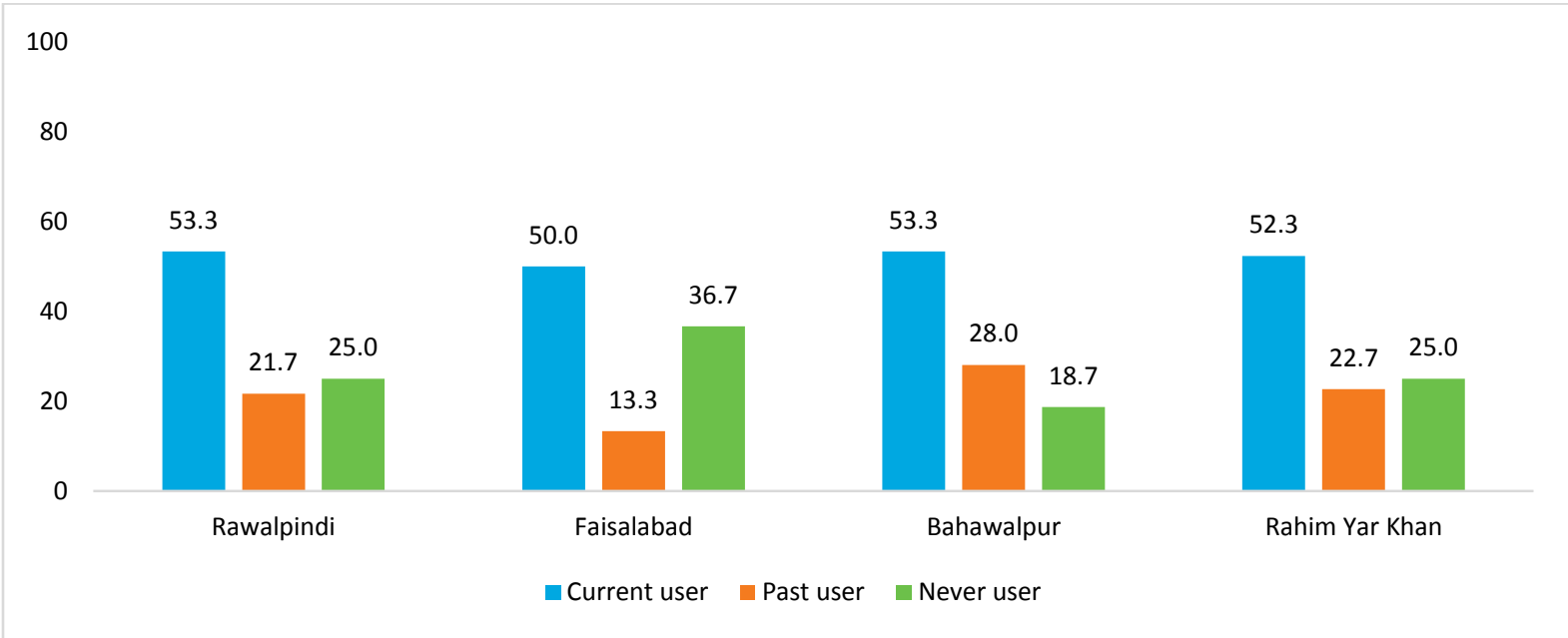

Source: HHS

Note: Having at least one child was a criterion of the household survey.

Unmet need for FP is also an important indicator of the adequacy of current FP services for local needs, and the potential for increasing contraceptive prevalence. An increase in unmet need over time could signal deterioration of existing services, decreasing utilization of services, or-more positively-an increase in demand for family planning. Sub-regional estimates of unmet need are useful for identifying specifically where efforts to increase contraceptive uptake are likely to be fruitful. 
Figure 3.3 shows the overall levels of unmet need for family planning in the four districts among women who have at least one child. However, among the districts, unmet need is highest in Rawalpindi and Bahawalpur, implying a clear inclination towards contraceptive use combined with either inability to access FP services or dissatisfaction with quality of care.

Figure 3.3: Unmet Need among Women HHS Respondents with At Least One Child, by District, \% (n=1,114 women)

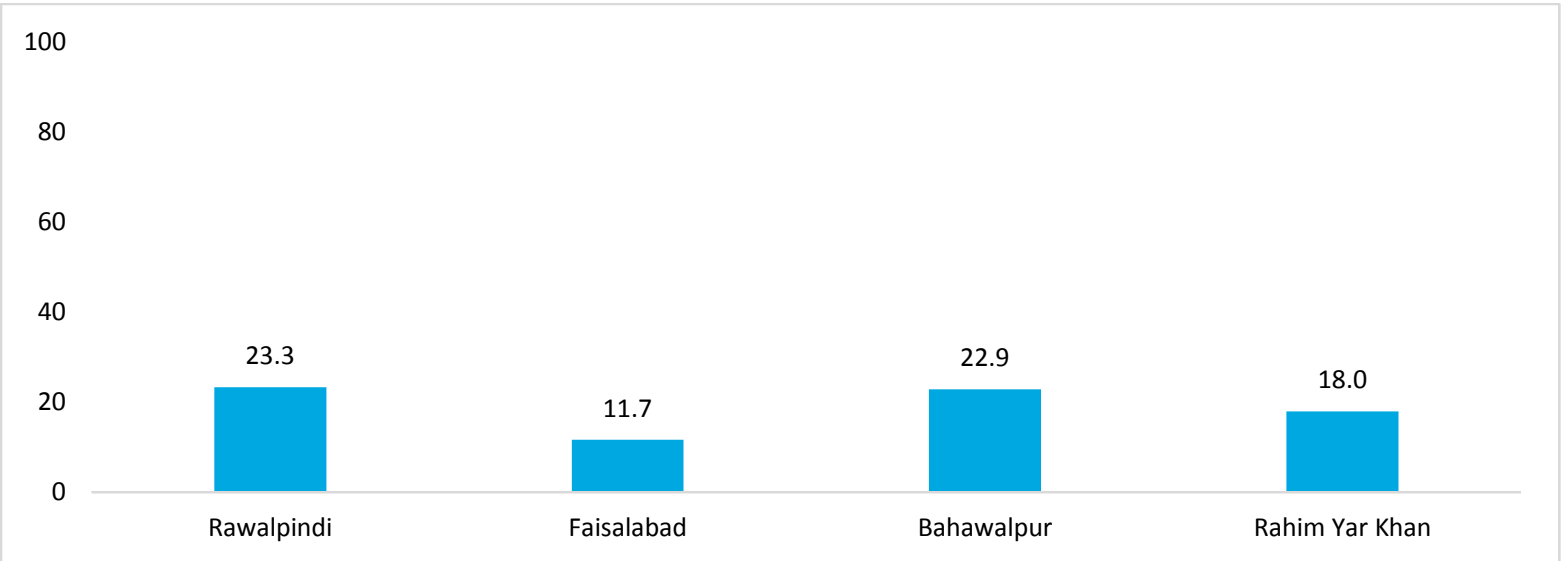

Source: HHS

Note: Having at least one child was a criterion of the household survey.

Women who reported current use of family planning were asked which method they were using. The responses, depicted in Figure 3.4, show three clear favorites-condoms, withdrawal, and female sterilizationwhile use of the other methods is quite low. Among the long-acting reversible contraceptives (LARCs), IUDs are being used by 3.9 percent of respondents, while implants were reported by only six respondents, which is not surprising considering the low availability of this method indicated in Section 2. Vasectomy was reported by only three respondents.

Figure 3.4: Current Use of Specific Contraceptive Methods among Women HHS Respondents, \% (n = 1,114 women)

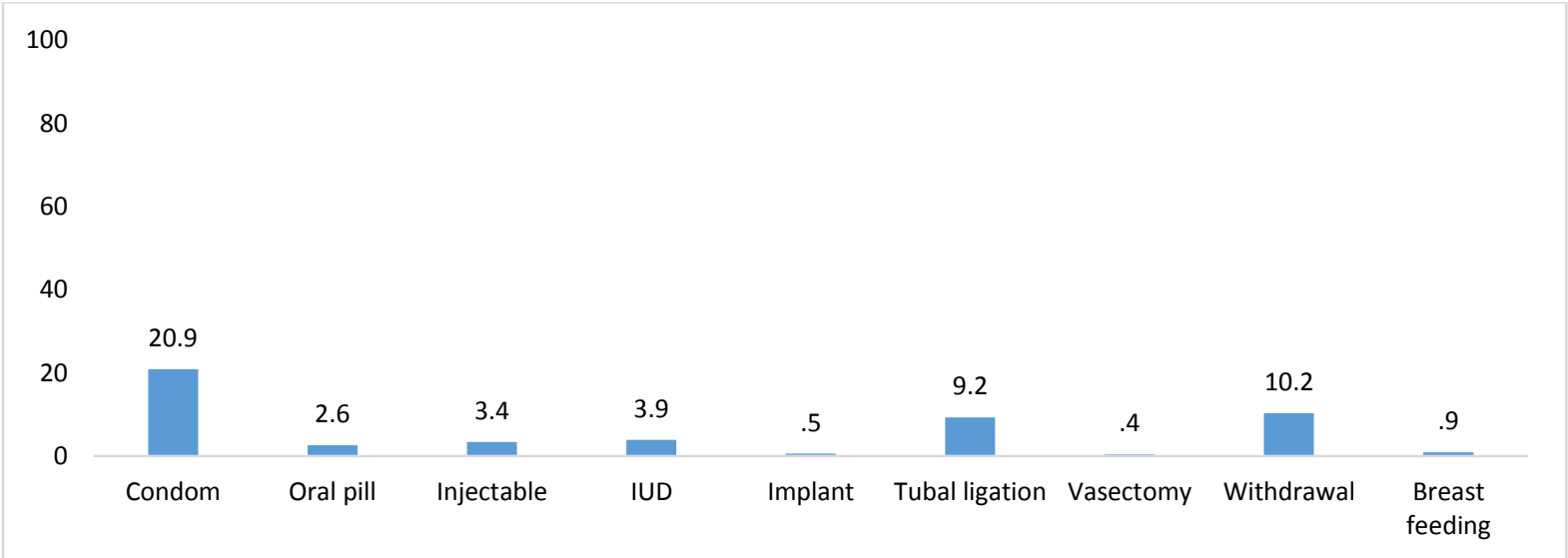

Source: HHS

Note: Having at least one child was a criterion of the household survey.

Although the overall levels of contraceptive use are quite encouraging, it is a concern that most men and women are relying on only three methods-one, a permanent method (tubal ligation), and the other two shortacting (condoms and withdrawal) and relatively less reliable. LARCs, pills and injectables are not only more reliable methods for preventing unwanted pregnancy, but also require fewer resupply visits, which can save 
time and travel costs. Why, then, are men and women limiting their choice to mainly three methods? This is an important question to which further dimensions are explored below, as well as in Section 4 .

A look at the profile of users of specific methods (Figure 3.5) shows that both of the male methods, i.e., condoms and withdrawal, are reported more commonly by urban than rural residents. On the contrary, injectable and IUD users mainly belong to rural areas. However, tubal ligation is used by both urban and rural women, with a slight tilt in favor of urban users. Moreover, injectables are mainly used by women of low socioeconomic status (SES) whereas condoms, tubal ligation, and withdrawal are reported more commonly by women of medium and high SES.

Figure 3.5: Residence and Socioeconomic Status of Current Users of Specific FP Methods among Women HHS Respondents, \% ( $n=1,114$ women)

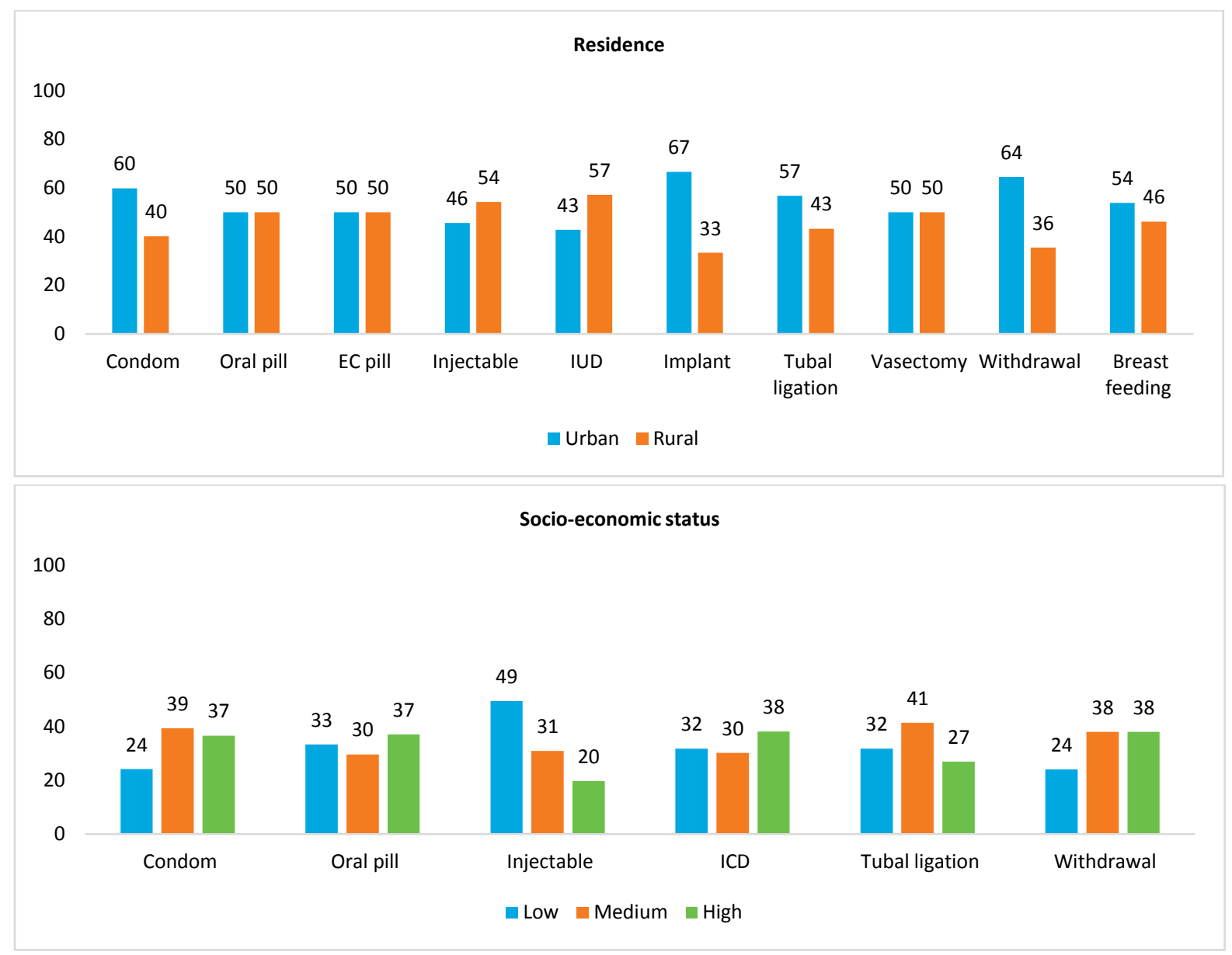

Source: HHS

\section{Most Utilized Facilities}

According to HHS respondents, the most frequently utilized sources of FP services in both district head quarter cluster and other clusters are public static health facilities and the Lady Health Workers (LHWs); the latter provide three methods-condoms, oral pills, and injectables-at women's doorsteps. Private sources are utilized by roughly a third of men and women in district head quarter cluster as well as other clusters. The most commonly used facilities are pharmacies or shops, followed by private hospitals. 
Figure 3.6: Sources Most Frequently Utilized for FP Services by Women HHS Respondents, by Cluster Type, \% (n = 1,114 women)

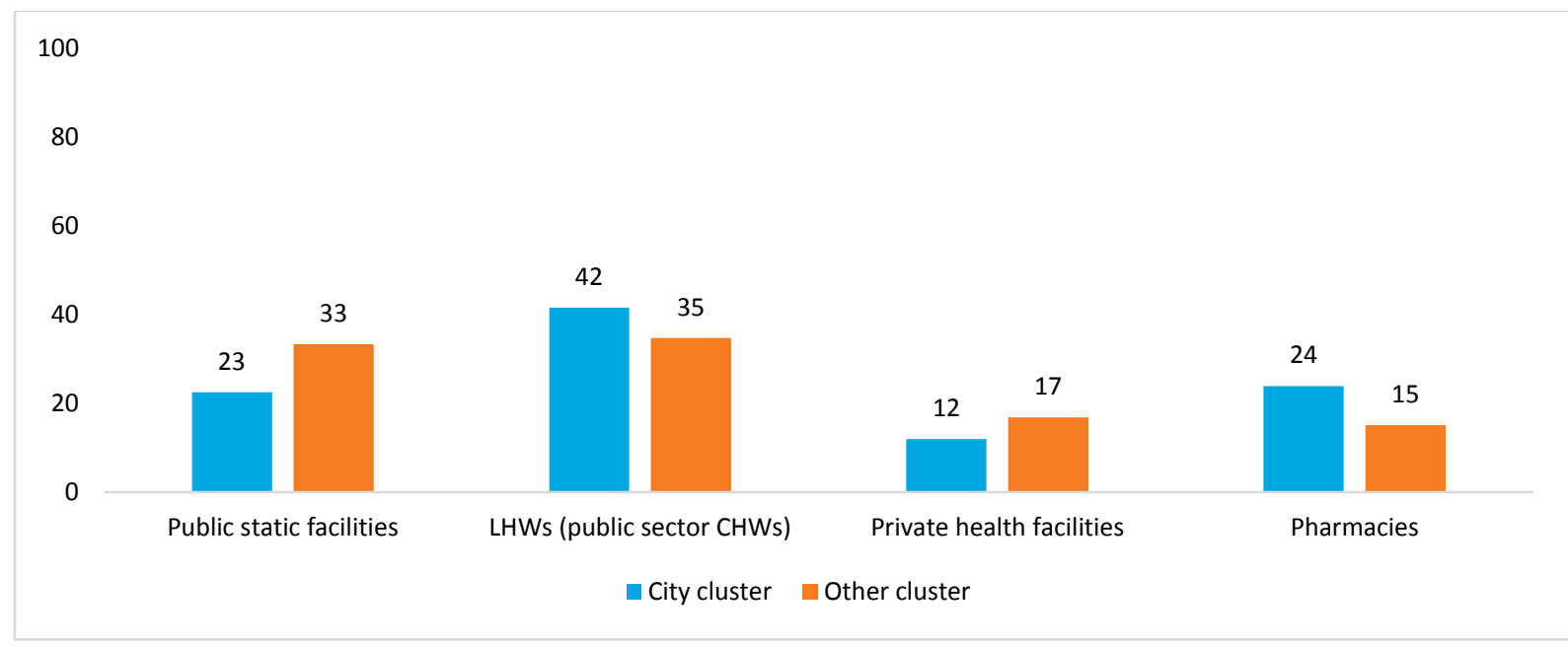

Source: HHS

CHWs $=$ Community Health Workers

\section{Facilities Utilized for Specific Methods}

With regard to sources of specific methods, Figure 3.7 shows clearly that, for condoms, LHWs are a major source, delivering the method at couples' doorsteps. Pharmacies are the second largest source. For pills and injectables, public health facilities and especially LHWs comprise the major source. In addition to being a significantly bigger source of oral pills and injectables than the private sector, the public sector is also the larger source of IUDs and implants. However, interestingly, about the same proportions of women utilize public and private facilities for tubal ligation. Overall, the figure suggests that public sector facilities are most frequently being utilized for all short- and long-acting reversible contraceptives while the private sector is mainly utilized for condoms and tubal ligation services. It is probable that tubal ligation provision in the private sector occurs concurrently with C-sections.

Figure 3.7: Most Frequently Utilized Sources of Specific FP Methods among Women HHS Respondents, \% (n = 1,114 women)

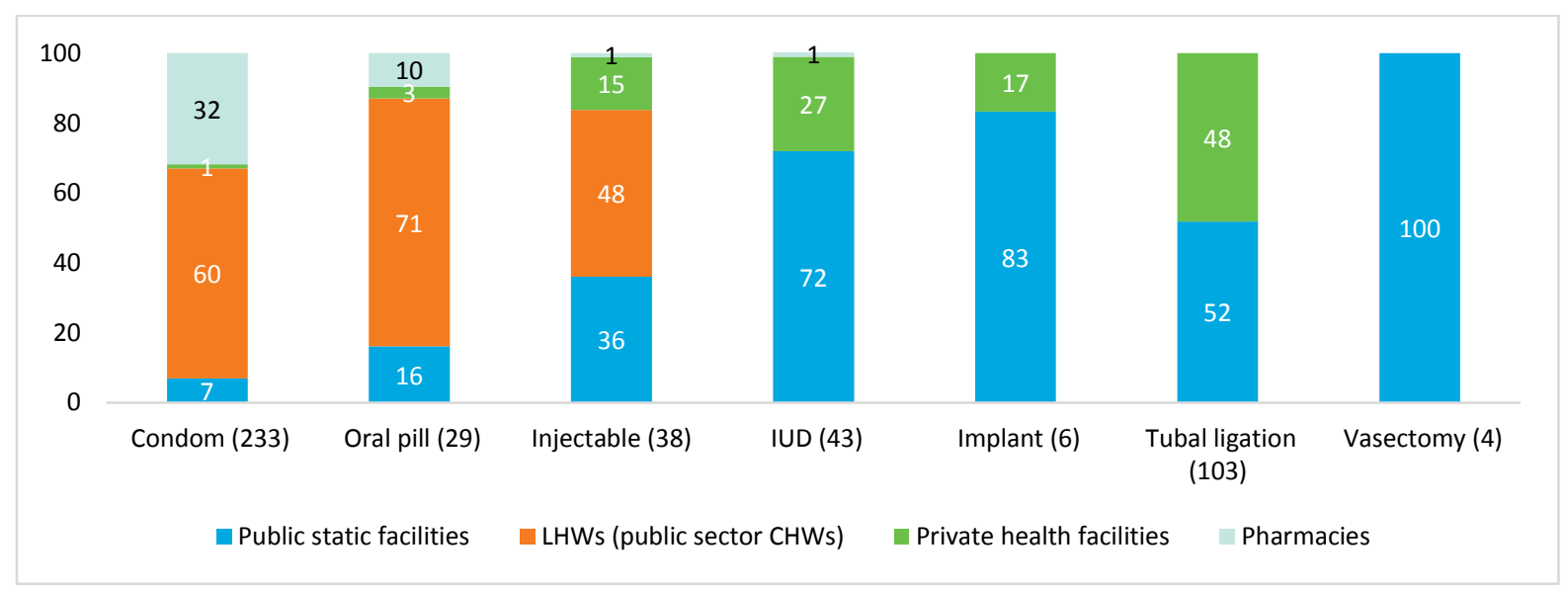

Source: HHS

Findings from the focus group discussions support the above findings. Overall, the majority of FGD participants said that people from their communities mostly visit public health facilities for FP services. 
Moreover, in areas that are served by LHWs, the community workers are the main providers and people are comparatively less dependent on private facilities. The LHWs provide available methods to the communities or refer them to a nearby public facility.

"BHUs are providing all the facilities which the government has intended for us. There is a Lady Health Visitor (LHV) working at every BHU. Apart from the LHV, there are LHWs working in every village, who provide door to door services." FGD, Rural men, Bahawalpur

"In the adjacent Islami colony, there is a center (public) which provides family planning, services." FGD, Urban women, Faisalabad

"Four LHVs are appointed at the BHU, of those, two live at the facility. Dr. Nazish, who works at the BHU, is very good. She has displayed her contact numbers at many places in the BHU so if someone has any issue, they can complain. The staff is also very good." FGD, Urban women, Rawalpindi

In rural communities where an LHW is not appointed, the majority of FGD respondents reported that people in their community depend on private service providers because public facilities are not available at an accessible distance. Due to restricted mobility among women, mostly men visit pharmacies for FP methods. This limits the contraceptive methods used in these communities to mainly condoms and oral pills.

\section{Reaching Family Planning Services: Distance and Cost Involved}

The HHS respondents were asked how far they usually travel for FP services and what types of facilities these are. Figure 3.8 indicates that the majority of respondents from all clusters travel 1-5 kilometers to reach health services. Respondents from district head quarter clusters generally have to travel less than those in other clusters to access FP services.

Some of the men and women also have to travel 16 or more kilometers to access services. The most common facilities where this is the case are dispensaries in district head quarter clusters, and private hospitals and doctors' clinics in the other clusters (data not shown).

Figure 3.8: Proportion of Women HHS Respondents Reporting Distances Travelled to Access Family Planning Services, by Type of Cluster, $\%$ ( $n=1,114$ women)

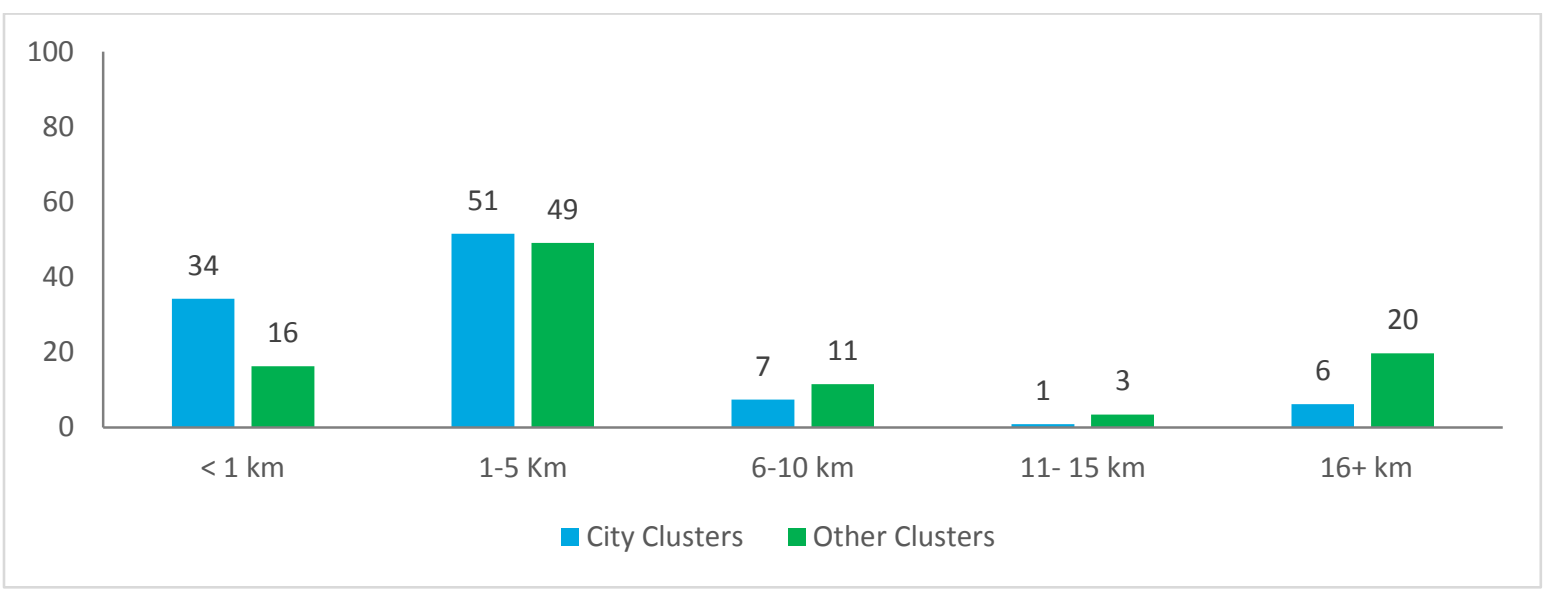

Source: HHS

The following figures present maps of two clusters in Rawalpindi-one in the main district head quarter cluster (Figure 3.9) and one in Taxila (Figure 3.10) -showing the situation of the communities where the HHS was 
conducted, as well as all health facilities and pharmacies providing family planning services. The service delivery points being utilized by communities are highlighted with a star in each of the categories.

From the map of the main district head quarter cluster (Rawalpindi central) (Figure 3.9), it is apparent that individual communities are utilizing only a small number of SDPs, mostly those present in their close vicinity. Mostly, communities are utilizing health facilities and pharmacies for condoms and injectables. Although there are facilities providing LARCs, they are mostly not utilized by the surveyed communities. The mean distance from communities or households to health facilities and pharmacies is 1 kilometer.

Similarly, in the Taxila cluster (Figure 3.10), it is apparent that individual communities are utilizing only a small number of SDPs present in their close vicinity. Mostly, they are going to health facilities and pharmacies for condoms and injectables. Compared to the main district head quarter cluster, there are fewer facilities providing LARCs. The mean distance from communities or households to health facilities and pharmacies is 2 to 4 kilometers. Census data about communities' utilization of available service delivery points in the other 14 study clusters present approximately the same picture. 
Figure 3.9: Health Facilities and Pharmacies Providing FP Services and Those being Utilized for FP Services by Surveyed Communities in District Head Quarter Cluster in Rawalpindi

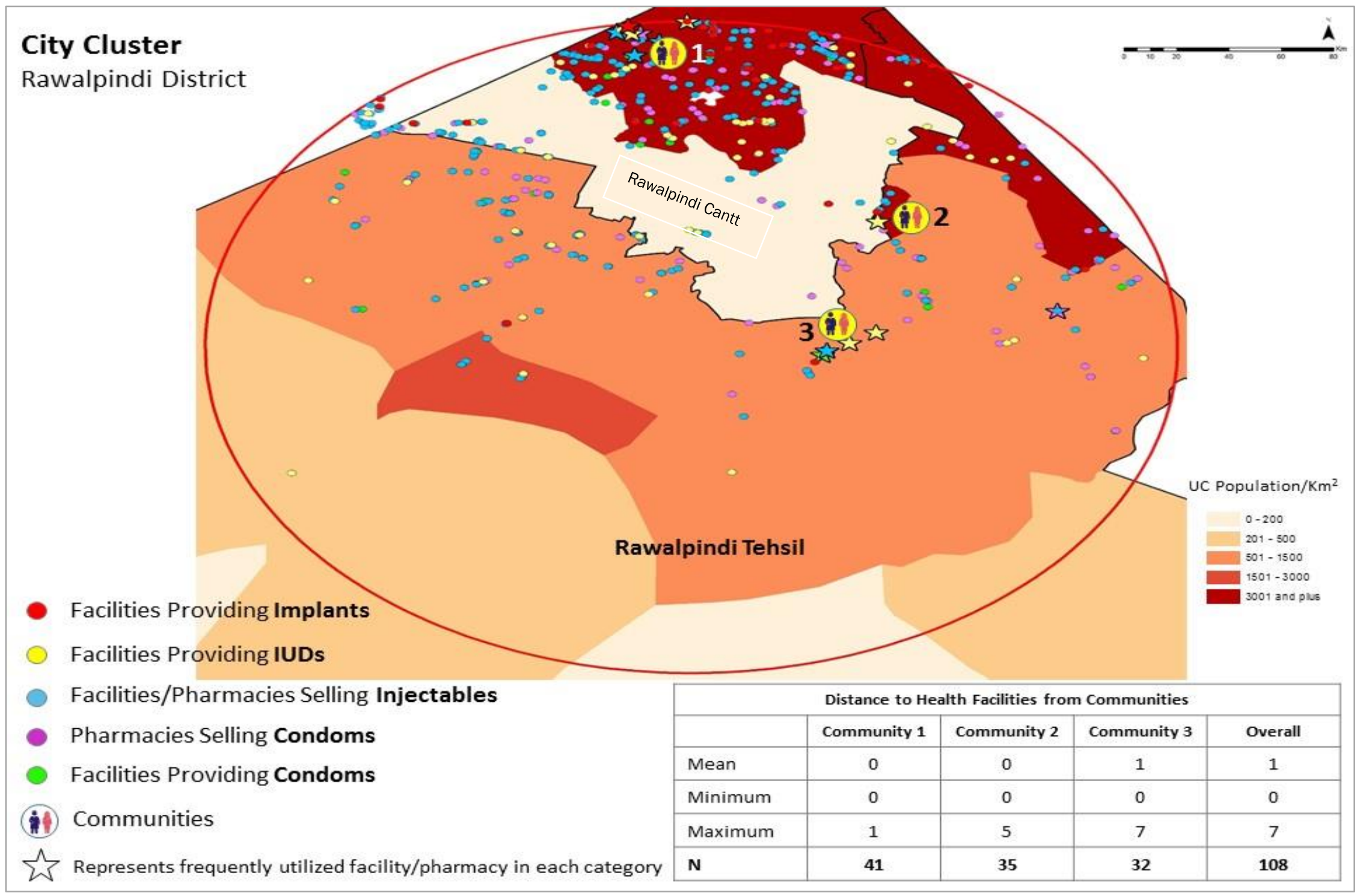

Source: CFP and HHS 
Figure 3.10: Health Facilities and Pharmacies Providing FP Services and Those being Utilized for FP Services by Surveyed Communities in Taxila Cluster in Rawalpindi

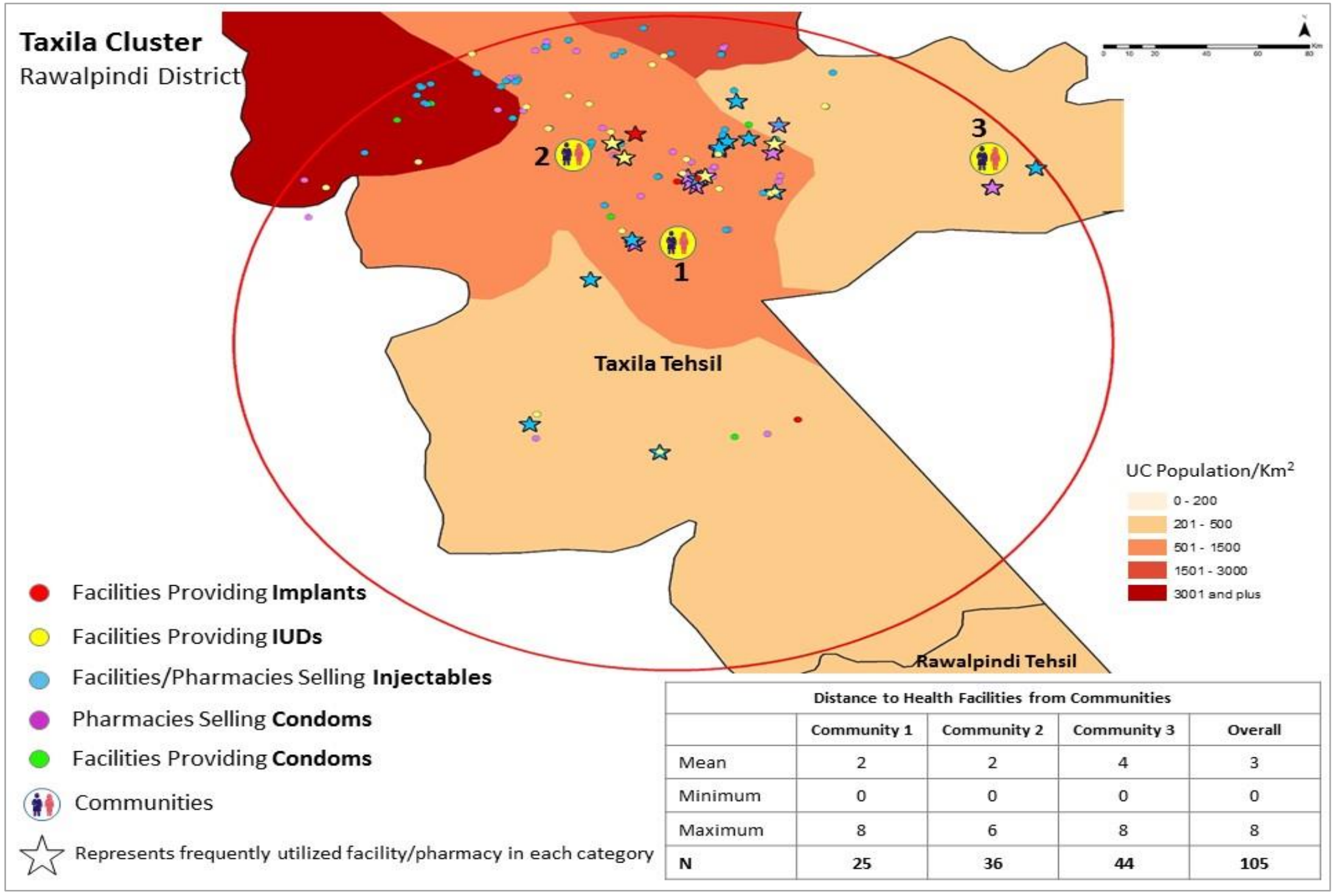

Source: CFP and HHS 


\section{Distances Travelled for Specific FP Methods}

Table 3.1 presents the mean and median distances travelled by women respondents of HHS to access specific FP methods. In the four main district head quarter clusters, the mean distance is $1 \mathrm{~km}$ for condoms; 2-3 km for injectables and IUDs; and $9 \mathrm{~km}$ for tubal ligation. In the other clusters, the mean distances are 1 $\mathrm{km}$ for condoms and pills, 2-10 km for injectables and IUDs, and $21 \mathrm{~km}$ for tubal ligation.

Table 3.1: Mean Distances Travelled by Women HHS Respondents to Access Specific Family Planning Methods, km ( $n=1,114$ women)

\begin{tabular}{|c|c|c|c|c|c|c|c|c|c|c|c|}
\hline & & \multicolumn{2}{|c|}{ Condoms } & \multicolumn{2}{|c|}{ Pills } & \multicolumn{2}{|c|}{ Injectables } & \multicolumn{2}{|c|}{ IUDs } & \multicolumn{2}{|c|}{ Tubal Ligation } \\
\hline & & $\begin{array}{l}\text { City } \\
\text { cluster }\end{array}$ & $\begin{array}{l}\text { Other } \\
\text { cluster }\end{array}$ & $\begin{array}{l}\text { City } \\
\text { cluster }\end{array}$ & $\begin{array}{l}\text { Other } \\
\text { cluster }\end{array}$ & $\begin{array}{l}\text { City } \\
\text { cluster }\end{array}$ & $\begin{array}{l}\text { Other } \\
\text { cluster }\end{array}$ & $\begin{array}{l}\text { City } \\
\text { cluster }\end{array}$ & $\begin{array}{l}\text { Other } \\
\text { cluster }\end{array}$ & $\begin{array}{l}\text { City } \\
\text { cluster }\end{array}$ & $\begin{array}{l}\text { Other } \\
\text { cluster }\end{array}$ \\
\hline \multirow{3}{*}{ Rawalpindi } & Mean & 1 & 3 & 0 & 2 & 0 & 10 & 3 & 14 & 8 & 28 \\
\hline & Median & 0 & 0 & 0 & 0 & 0 & 0 & 0 & 10 & 5 & 15 \\
\hline & $\mathrm{n}$ & 47 & 33 & 4 & 4 & 3 & 13 & 7 & 11 & 6 & 6 \\
\hline \multirow{3}{*}{ Faisalabad } & Mean & 1 & 1 & 0 & 1 & 0 & 10 & 2 & 5 & 10 & 17 \\
\hline & Median & 0 & 0 & 0 & 1 & 0 & 10 & 1 & 2 & 4 & 5 \\
\hline & $\mathrm{n}$ & 36 & 15 & 1 & 2 & 2 & 1 & 3 & 6 & 21 & 12 \\
\hline \multirow{3}{*}{ Bahawalpur } & Mean & 0 & 0 & 0 & 0 & 0 & 0 & 3 & 16 & 10 & 17 \\
\hline & Median & 0 & 0 & 0 & 0 & 0 & 0 & 3 & 2 & 2 & 11 \\
\hline & $\mathrm{n}$ & 31 & 23 & 7 & 6 & 2 & 8 & 5 & 5 & 18 & 23 \\
\hline \multirow{3}{*}{$\begin{array}{l}\text { Rahim Yar } \\
\text { Khan }\end{array}$} & Mean & 3 & 1 & 0 & 3 & 4 & 1 & 3 & 4 & 5 & 30 \\
\hline & Median & 0 & 0 & 0 & 0 & 0 & 0 & 3 & 3 & 6 & 23 \\
\hline & $\mathrm{n}$ & 39 & 24 & 4 & 6 & 10 & 6 & 2 & 8 & 14 & 11 \\
\hline \multirow{3}{*}{ Overall } & Mean & 1 & 1 & 0 & 1 & 2 & 5 & 3 & 10 & 9 & 21 \\
\hline & Median & 0 & 0 & 0 & 0 & 0 & 0 & 1 & 4 & 4 & 12 \\
\hline & $\mathrm{n}$ & 153 & 95 & 16 & 18 & 17 & 28 & 17 & 30 & 59 & 52 \\
\hline
\end{tabular}

Source: HHS

* No users of EC pills were interviewed in the other clusters.

\section{Cost Incurred for Specific FP Methods}

HHS respondents were further asked about the costs they typically incurred to access FP services from the facilities they usually visited.

Table 3.2 shows the costs reported by women respondents. Overall, the mean travel cost is more in other clusters than in the district head quarter clusters for all methods. The mean contraceptive cost is also higher in other clusters than district head quarter clusters for pills and IUDs as well as for tubal ligation, the cost of which doubles in rural areas relative to urban areas. On the other hand, mean provider fees are much higher for IUDs and tubal ligation in district head quarter clusters, and for injectables in other clusters.

Table 3.2: Travel, Method, and Provider Cost Incurred by Women HHS Respondents to Access Specific Family Planning Methods, Pak Rs ( $=1,114$ women)

\begin{tabular}{|c|c|c|c|c|c|c|c|c|c|c|c|}
\hline & & \multicolumn{2}{|c|}{ Condom } & \multicolumn{2}{|c|}{ Pills } & \multicolumn{2}{|c|}{ Injectables } & \multicolumn{2}{|c|}{ IUD } & \multicolumn{2}{|c|}{ Tubal Ligation } \\
\hline & & $\begin{array}{c}\text { City } \\
\text { Cluster }\end{array}$ & $\begin{array}{l}\text { Other } \\
\text { cluster }\end{array}$ & $\begin{array}{c}\text { City } \\
\text { Cluster }\end{array}$ & $\begin{array}{l}\text { Other } \\
\text { cluster }\end{array}$ & $\begin{array}{c}\text { City } \\
\text { Cluster }\end{array}$ & $\begin{array}{l}\text { Other } \\
\text { cluster }\end{array}$ & $\begin{array}{c}\text { City } \\
\text { Cluster }\end{array}$ & $\begin{array}{l}\text { Other } \\
\text { cluster }\end{array}$ & $\begin{array}{c}\text { City } \\
\text { Cluster }\end{array}$ & $\begin{array}{l}\text { Other } \\
\text { cluster }\end{array}$ \\
\hline \multirow{3}{*}{$\begin{array}{l}\text { Travel } \\
\text { cost }\end{array}$} & Mean & 6 & 17 & 0 & 32 & 10 & 95 & 56 & 143 & 203 & 474 \\
\hline & Median & 0 & 0 & 0 & 0 & 0 & 0 & 50 & 50 & 100 & 200 \\
\hline & $n$ & 153 & 95 & 16 & 18 & 17 & 28 & 17 & 30 & 59 & 52 \\
\hline \multirow{3}{*}{$\begin{array}{l}\text { Method } \\
\text { cost }\end{array}$} & Mean & 17 & 11 & 2 & 24 & 53 & 15 & 63 & 156 & 320 & 729 \\
\hline & Median & 0 & 0 & 0 & 0 & 0 & 0 & 0 & 0 & 0 & 0 \\
\hline & $n$ & 153 & 95 & 16 & 18 & 17 & 28 & 17 & 30 & 59 & 52 \\
\hline \multirow{3}{*}{$\begin{array}{l}\text { Provider's } \\
\text { fee }\end{array}$} & Mean & 1 & 0 & 0 & 0 & 0 & 11 & 54 & 22 & 179 & 126 \\
\hline & Median & 0 & 0 & 0 & 0 & 0 & 0 & 0 & 0 & 0 & 0 \\
\hline & $n$ & 153 & 95 & 16 & 18 & 17 & 28 & 17 & 30 & 59 & 52 \\
\hline \multirow{3}{*}{ Total cost } & Mean & 24 & 29 & 2 & 56 & 63 & 121 & 173 & 321 & 609 & 1054 \\
\hline & MEDIAN & 0 & 0 & 0 & 0 & 0 & 0 & 80 & 115 & 100 & 225 \\
\hline & $\mathbf{n}$ & 153 & 95 & 16 & 18 & 17 & 28 & 17 & 30 & 59 & 52 \\
\hline
\end{tabular}

Source: HHS 


\section{Role of Lady Health Workers}

Doorstep delivery of family planning services is a core element of the LHWs' mandate. Present in far larger numbers than static health facilities, LHWs are crucial sources of family planning services for women with unmet need, especially in underserved communities. The maps of Faisalabad in Figure 3.11 show how dramatically the presence of LHWs increases available public sector health SDPs.

HHS data indicates that 42 percent of women with at least one child in the city clusters and 37 percent of women in the same category in the other clusters most frequently avail FP services from LHWs. As indicated in Figure 3.7 above, among women in this category, LHWs are the most frequently utilized sources of all three of the methods they are mandated to provide, i.e., condoms, oral pills, and injectables.

FGD findings support these data. In LHW-served areas, most FGD participants reported that LHWs were the main-and sometimes the only-source of FP information and services, and people were comparatively less dependent on other facilities. It was reported that LHWs either provide available methods to the women or refer them to a nearby public facility.

"There are LHWs who work in the area. They tell our women about family planning. LHWs give all information as here. There is no special facility. There are LHWs who visit door to door. They also provide family planning facilities to people. LHWs are local from our village and all people are satisfied with them. LHWs also work hard and they provide everything to people." FGD, Rural women, Rawalpindi

"People here mostly consult the LHW for family planning because she is available at village level. If she does not have the method, she refers or accompanies them to a hospital when needed." FGD, Rural men, Bahawalpur

"LHW visits door to door and provides us information at our homes. The LHW is the only main source of information." FGD, Rural women, Rawalpindi

In communities where an LHW was not appointed or had retired, FGD respondents reported that people depended on private service providers because public facilities were not available at an accessible distance.

"There is neither any government facility nor any LHW. There should be LHWs at community level who visit door to door and tells us that we are having too many children and should use family planning methods, etc." FGD, Rural women, Rahim Yar Khan

"Previously an LHW was appointed in our community, and she was resolving our all family planning related issues. Now, she has retired and we are facing difficulties. My husband says that we cannot purchase condoms from nearby medical stores because he is modest. He has to buy condoms from a pharmacy far from the community where nobody knows him." FGD, Urban women, Faisalabad

As indicated above, in remote communities with restricted mobility, accessing health services entails heavy travel costs that are doubled when a woman has to be accompanied by someone. Among poorer users, as well as women who do not want their husbands to know about their contraceptive use, this limits the choice of contraceptive methods to those available within the community. The latter situation was specifically mentioned during an FGD.

"Mostly, when the LHW, Baji Bushra, visits, we discuss child related things with her and our issues with her. Women use the method at home after thinking about it. If a husband or motherin-law says they may not use any contraceptive method, the women secretly go to the LHW and get pills or an injection. The LHW keeps this confidential and just notes down their name on her register and provides the methods for use. We will have no knowledge until she gives us awareness." FGD, Urban women, Rahim Yar Khan 
Among reasons for utilizing LHWs, the fact that they provide doorstep services was a major reason mentioned by almost all HHS respondents at community level. In addition, about 32 percent of respondents cited the fact that LHWs provide services free of cost.

However, some respondents noted that LHWs were too busy with other tasks, especially polio eradication activities, and not paying sufficient attention to their family planning role.
"LHW is available in our area but mostly she does polio work. She does not provide information about family planning. The LHW should visit each home and give information to people. It will help people who want to use family planning methods and even people who don't want to use will at least get information." MFGD, Rural man, Faisalabad
"Every person depends upon LHWs like for polio, mother and child health, and for other health problems. I think their workload should be reduced, so they can perform their duty properly at the community level. Their work will suffer if they are assigned multiple tasks simultaneously." IDI, Rural services provider, Rawalpindi

Many recent studies have identified the same issue, attributing it to low prioritization of family planning in the LHWs' work schedule ${ }^{4,5}$, and the burden of too many additional tasks, especially polio eradication work $6,7,8)$. Interruptions in the supply of contraceptives to the workers ${ }^{9}$ and the narrow range of methods in their mandate also limit their role in increasing contraceptive uptake ${ }^{10}$.

\section{Utilization of Facilities for Maternal and Child Health Care}

The study also looked at which sector and facilities are being visited by the same respondents for maternal and child health care services to identify differences and similarities in the pattern of utilization. Figure 3.11 shows the proportions of household survey respondents, including both men and women, who utilize public and private health facilities for $\mathrm{MCH}$ services. Some differences can be seen across districts as well as the nature of services sought. For maternal health care, the majority of users in Rawalpindi and Bahawalpur visit public sector facilities, while private facilities are preferred by respondents in Faisalabad and Rahim Yar Khan (especially women in Faisalabad and men in Rahim Yar Khan). However, for child health services, most men and women in Rawalpindi, Faisalabad and Rahim Yar Khan use private facilities; in Bahawalpur, equal proportions avail the public and private sector.

\footnotetext{
${ }^{4}$ Population Council. 2015. Low use and High Discontinuation of Modern Contraceptives in Pakistan: Reasons and Policy Recommendations. Population Council Islamabad.

${ }^{5}$ Khan, A., and Khan, A. 2012. "The Contribution of Lady Health Workers towards Family Planning in Pakistan." Research and Development Solutions, Policy Briefs Series No. 15. N.p.: USAID.

${ }^{6}$ Hafeez, A., Mohamud, B. K., Shiekh, M. R., Shah, S. A. I., \& Jooma, R. (2011). Lady health workers programme in Pakistan: challenges, achievements and the way forward. JPMA-Journal of the Pakistan Medical Association, 61(3), pp210-215.

${ }^{7}$ Oxford Policy Management (2009b). Lady Health Worker Programme: External Evaluation of the National Programme for Family Planning and Primary Health Care; Punjab Report. Oxford Policy Management; 2009.

8 Kamran, I., Tasneem, Z., Parveen, T., and Zaidi, Y. (2015). Investigating the low patterns of modern contraceptive use in Pakistan. Islamabad: Population Council.

${ }^{9}$ Gul, R., Kamran, I., Muhammad, K., Niazi, R., and Parveen, T. (2015). The Availability and Quality of Family Planning Services across Eight Districts in Pakistan: The Potential and the Constraints. Islamabad: Population Council.

10 Population Council. 2016. Landscape Analysis of the Family Planning Situation in Pakistan. Islamabad.
} 
Figure 3.11: Sectors Most Frequently Utilized for Maternal and Child Health Services by HHS Respondents, by District, \% (n=329 men, 1,114 women)

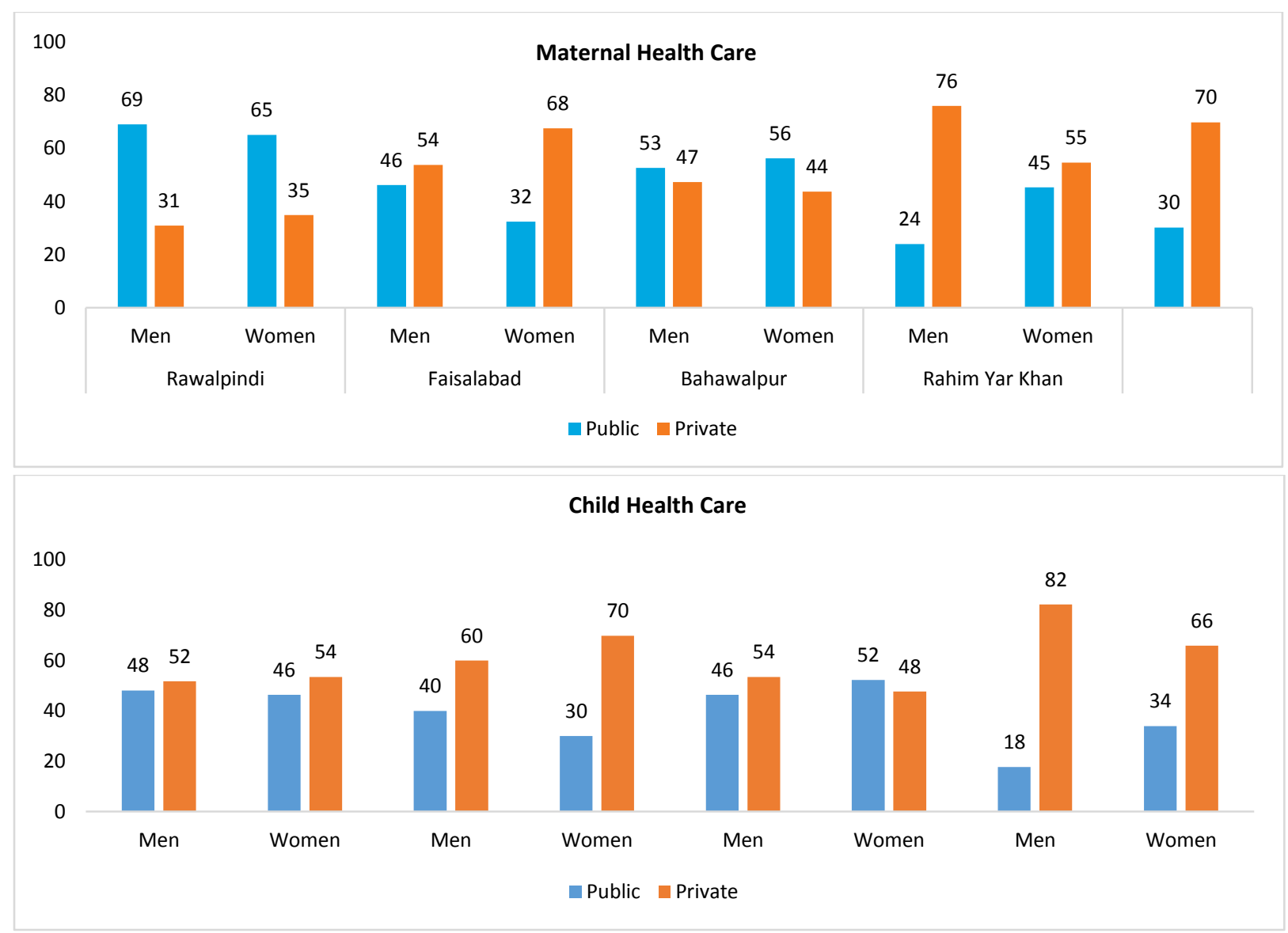

Source: HHS

Figure 3.12 shows the utilization of different types of facilities for maternal and child health care services by men and women. The most commonly reported types of public and private facilities are shown. For maternal health care, the respondents who utilize public sector facilities mainly visit DHQs and BHUs with no noticeable variance between responses of men and women. On the other side, those who utilize private sector facilities mainly go to private hospitals according to women and to doctors' clinic as reported by men. Within private sector, dispenser clinics are also being utilized for maternal health care.

For child health care, as the previous figure (3.11) has shown, the private sector is more frequently utilized. Figure 3.12 further reveals that both men and women report that private doctors' clinics are the most utilized facility for child health care. Among the less used public sector facilities, it is again mainly DHQs and BHUs that are visited for child health services. 
Figure 3.12: Facilities Most Frequently Utilized by HHS Respondents for Maternal and Child Health Care, by Type of Facility, \% (n=329 men, 1,114 women)

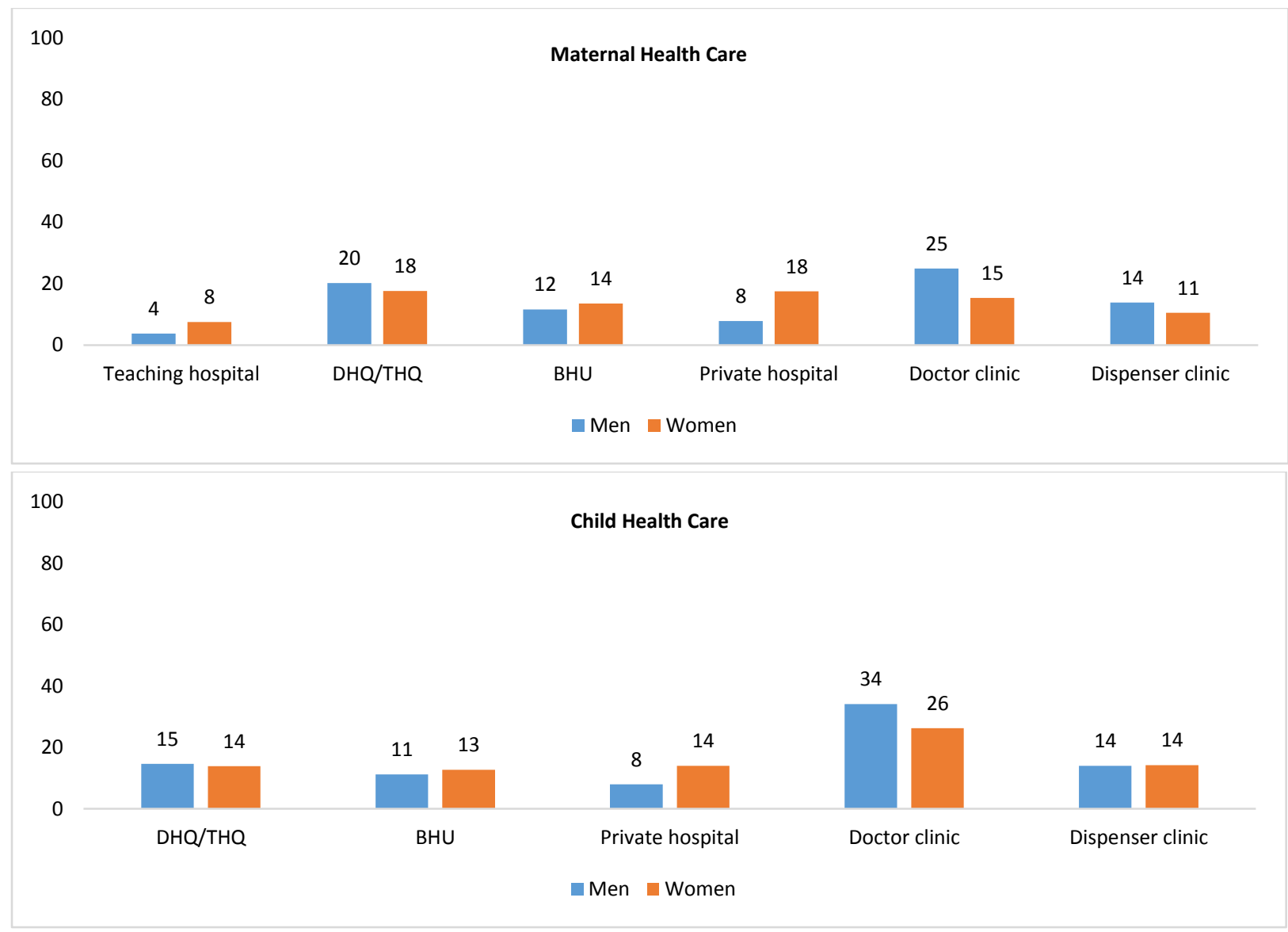

Source: HHS

Overall, looking at the utilization pattern of FP services, and maternal and child health care, variation is seen for all three types of services. Overall, for FP services, the majority of respondents mentioned utilization of public sector facilities whereas for maternal health care, they utilize both public static and private sector facilities and for child health care majority utilize private health sector facilities.

\section{Conclusion}

Demand for family planning is quite high among women with at least one child in the study districts. However, there is still a high need of family planning that remains unmet. The highest unmet need amongst the study districts is found to be in Rawalpindi (23.3\%), followed by Bahawalpur (22.9), Rahim Yar Khan (18\%), and Faisalabad (11.7\%).

Furthermore, method choice is skewed with high dependence on condoms and withdrawal. The three main methods being used for family planning include condoms (20.9), withdrawal (10.2), and female sterilization (9.2) Condoms are the predominant modern reversible method in use, with oral pills, injectables, IUDs and implants making up very small portions of the method mix.

Currently, the most frequently utilized facilities for family planning services include the LHWs, public static facilities, and pharmacies. The findings also show that this is linked with wider availability of method through 
pharmacies, LHWs, and public static facilities. For pills and injectables, public health facilities and especially LHWs comprise the major source. In addition, the public sector is also the larger source of IUDs and implants. However, interestingly, about the same proportions of women utilize public and private facilities for tubal ligation.

The median distance women have to travel to facilities offering family planning services is 1-5 kilometers, shorter for district head quarter cluster than other clusters. The mean contraceptive cost and distance is higher in rural than urban areas for all methods except condoms. In the case of tubal ligation especially, the cost in rural areas is double that in urban areas, this possess difficulties in accessing methods that are not locally available.

There is variation in the pattern of utilization of FP, maternal and child health care services. For FP services, the majority of respondents mentioned utilization of public sector facilities whereas for maternal health care, they utilize both public static and private sector facilities and for child health care majority utilize private health sector facilities.

As mentioned above, LHWs, where available, are the most utilized facility for three methods- condoms, oral pills and injectable. They are mainly utilized because they provide free of cost services at the door step of FP clients addressing their FP needs even in mobility restricted setting and if an LHW is not available, the community is at a loss for availing family planning services. Though she is main player in FP service provision at community level however, she is not fully functional yet, because of certain challenges - she is permitted to provide a limited range of methods; faces contraceptives stock outs and she is assigned numerous additional tasks which had diverted her focus from FP as priority. Her full potential needs to be revitalize by addressing her needs and challenges. 


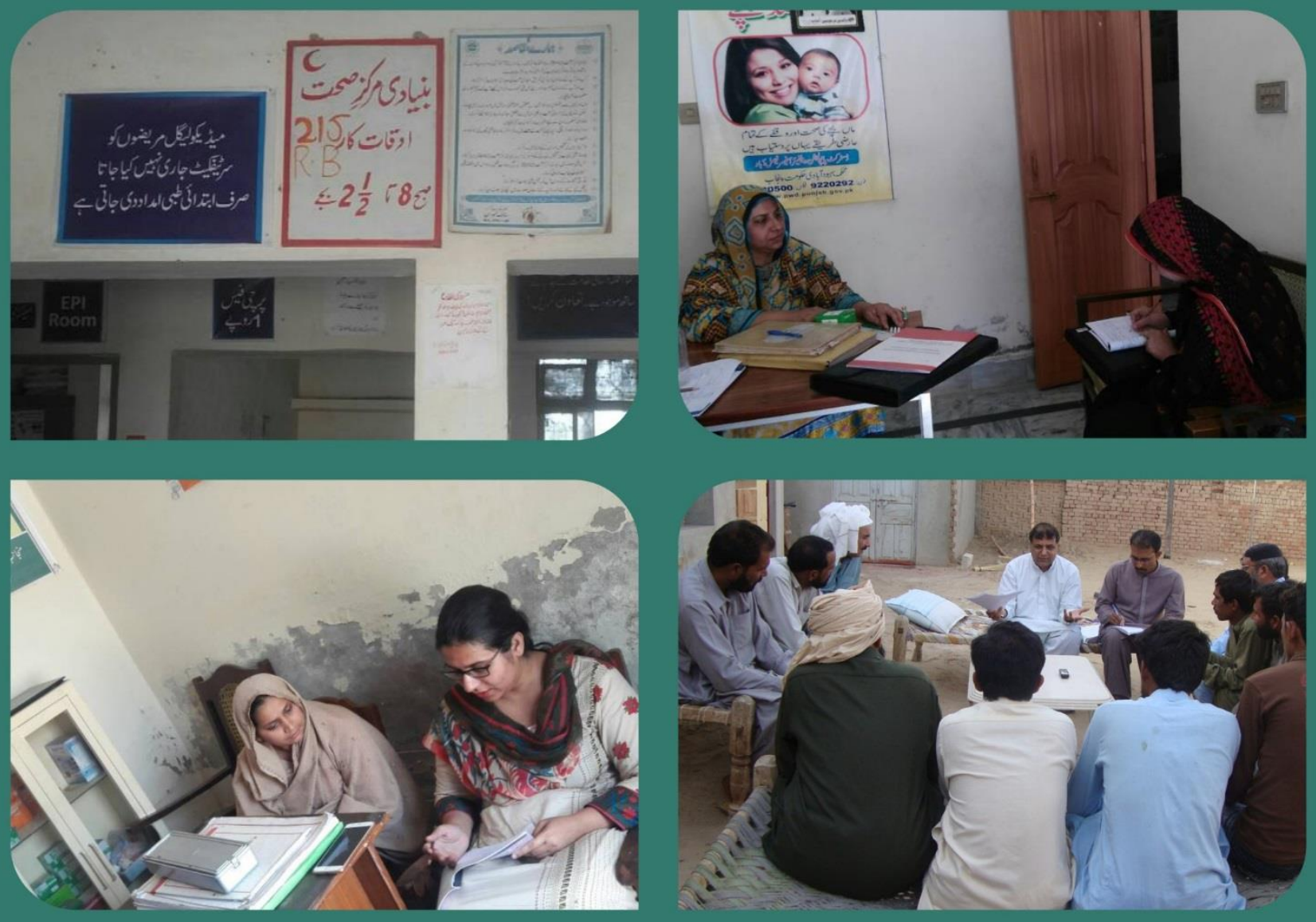

\section{What Drives Client Choices in Utilization of Health Services}

Understanding Where Clients Are Coming From

Reasons Clients Give for Their FP Service Utilization Choices Preferences of Men and Women about Provision of FP Services 



\section{What Drives Client Choices in Utilization of Health Services}

Several factors affect the choices of men and women in their utilization of health services, that is, whether they turn to the public or private sector, the types of facilities and cadres of providers they visit, and in the context of family planning, the specific contraceptive methods they adopt. Some of these factors are external, pertaining to aspects of availability and quality of services covered in Sections 2 and 5 of this report. Others are related to the clients' own circumstances, such as how well they recognize their need for healthcare, their financial means, and whether they discern what constitutes a reasonable quality of care. The patterns of health facility utilization described in Section 3 of this report are a function of the interplay of these supplyside and demand-side factors.

In the current section, we attempt to better understand and identify the key drivers of clients' health care choices, with a focus on family planning services. First outlined are the study's findings about the circumstances affecting clients' own agency-specifically, women's mobility and their say in decisions about seeking healthcare, clients' awareness about patient rights, and the expectations men and women have from health service providers. In this context, we also briefly examine existing community power structures, and the presence of any local initiatives to support utilization of FP services.

We then present a detailed analysis of the reasons men and women gave in the HHS for choosing the public or private sector and specific facilities and providers for family planning services. In particular, the reasons underlying users' narrow focus on condoms, withdrawal and tubal ligation as the main contraceptive method choices are examined. We also describe where the preferences of men and women lie regarding where and how family planning services should be provided. Finally, the views of community members and service providers are presented regarding how community support may be built to improve access to and utilization of FP services.

\section{Understanding Where Clients Are Coming From}

The socio-demographic profile of the current and potential users interviewed in this study, including clients at health facilities and men and women interviewed in the household survey, are presented in Section 1. Further findings about the men and women are outlined below.

\section{Women's Mobility and Decision-making Powers}

The mobility of women plays an important role in where and how they seek health care. HHS respondents were asked where women in their community could go, and whether they were required to have somebody's permission or be accompanied. Figure 4.1 shows the responses of HHS respondents including both men and women. Among the respondents, more than 50 percent of women said that they can go out within the community, either with or without permission. Outside the community, they usually have to be accompanied by someone. The responses of men and women broadly concurred. 
Figure 4.1: Mobility of Women According to HHS Respondents, \% (n=329 men, 1,114 women)

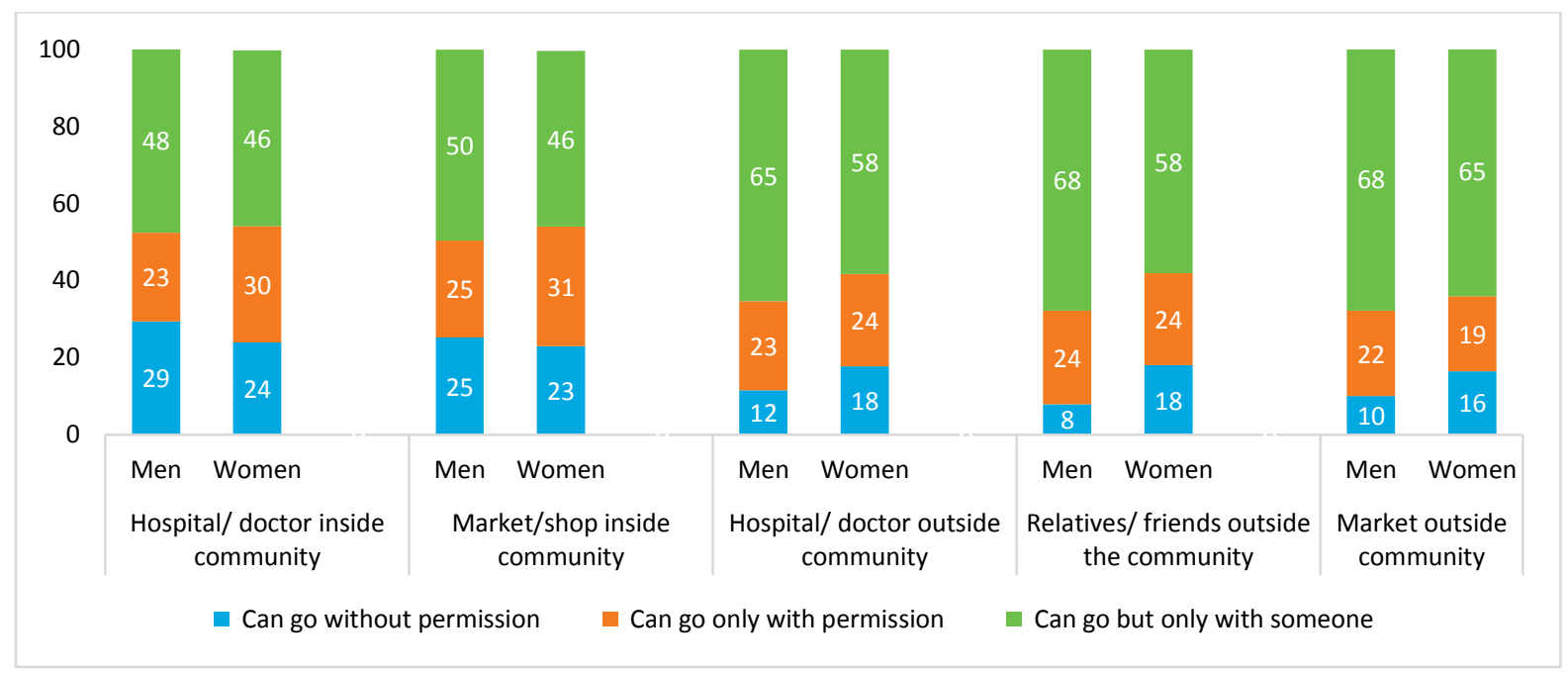

Source: HHS

Mobility restrictions imply that women must be accompanied by someone to access services situated far away, doubling travel costs. Among poorer users, as well as women who do not want their husbands to know about their contraceptive use, this would serve to limit the choice of contraceptive methods to those available within the community. The latter situation was specifically mentioned during an FGD.

“Some women want to go to Faisalabad for sterilization but their men don't allow them. They can go secretly if this facility is available in the village. It would be the great for women if facilities were available within the village. Some men take their women to get this method, but some feel bad about it." FGD, Rural women, Faisalabad

In the HHS, men and women were asked a number of questions to assess wives' decision-making power in various household matters, particularly in relation to use of family planning and seeking maternal and child healthcare. The vast majority of men and women agree that FP decisions can be made by the wife only after consulting her husband, although about one fifth of women said they can decide on their own - Figure 4.2.

Figure 4.2: Percentage of HHS Respondents Reporting a Woman can Seek FP Services When Needed, \% $(n=329$ men, 1,114 women)

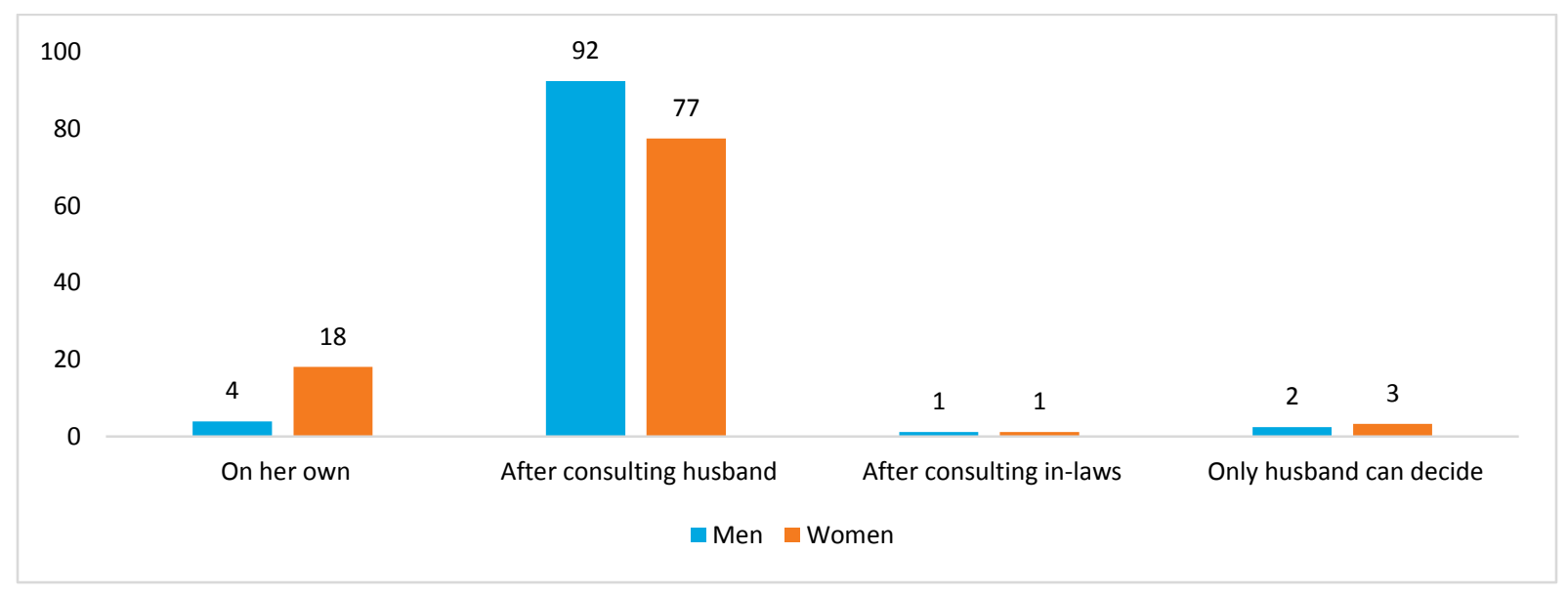

Source: HHS 
There is a similar pattern in responses to the question whether women can make decisions about sending children to school and about seeking health services for their children or their own selves (Figure 4.3). Nearly 90 percent of men and about 70 percent of women say the decisions are based on the couple's mutual consultation, but 21 percent of women report that she can make these decisions independently. The figure suggest that a lot of women are more autonomous than what men think. In contrast, very low proportions of men say these matters are decided solely by the husband. The role of in-laws is negligible in all decisions, and overall, the responses suggest an encouraging picture of good spousal concurrence.

Figure 4.3: Percentage of HHS Respondents Reporting a Woman Can Send the Children to School and Seek Health Services Needed for Herself or Her Sick Child, \% ( $n=329$ men, 1,114 women)

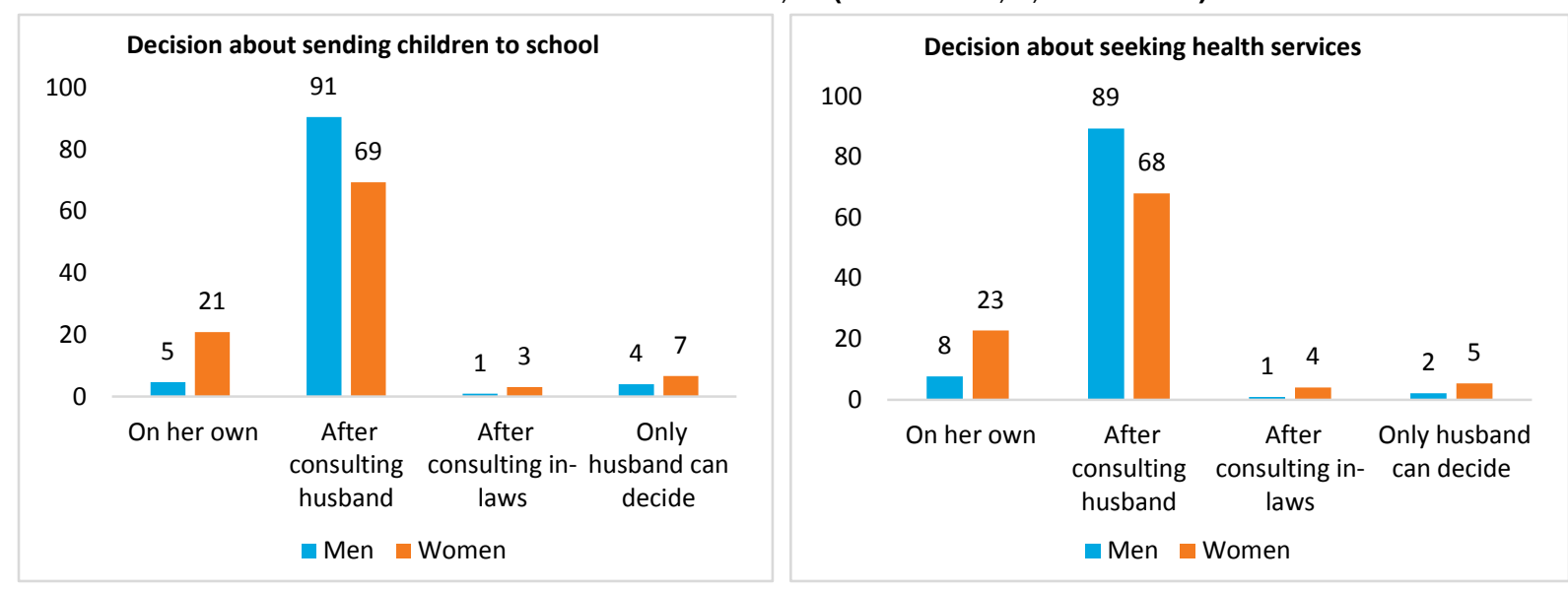

Source: HHS

When it comes to financial decision-making, the responses of husbands and wives show greater disparity in Figure 4.4. More women than men think that they can make independent decisions about spending a portion of the household income, while more men than women think the decision is made after consultation with the husband. Surprisingly, the role of in-laws remains negligible in this matter and it is encouraging that very few men and women report sole decision-making by husbands.

However, with respect to large investments, men and women concur that women do not make decisions on their own (Figure 4.4). While the majority of both sexes still say such decisions can be made by the woman after consulting her husband, reported sole decision-making by the husband is highest on this question.

Figure 4.4: Percentage of HHS Respondents Reporting a Woman Can Decide to Spend a Part of the Household Income and to Spend on Large Investments, \% ( $n=329$ men, 1,114 women)

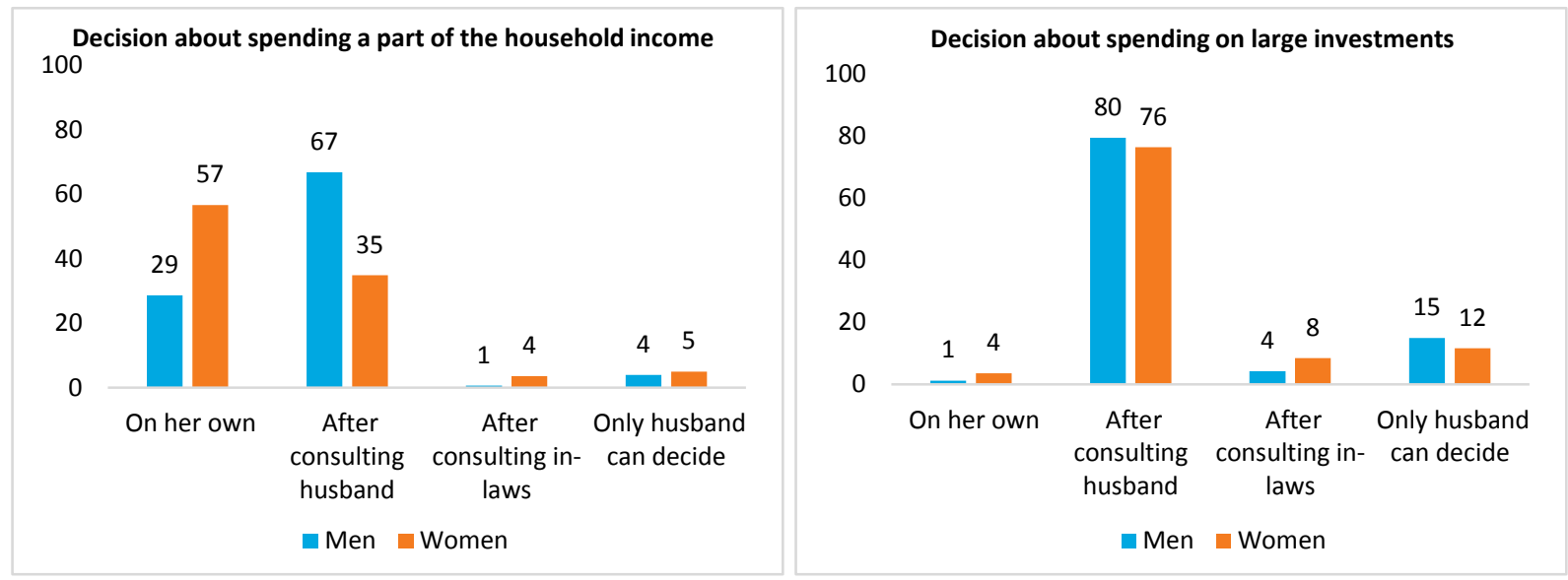

Source: HHS 


\section{Awareness of Clients' Rights}

Apart from the availability of health services, their perceived quality can influence which sources clients utilize. Clients' perceptions of quality, in turn, depend greatly on what they think should expect at the health facilities they visit. During the HHS, men and women were asked if they knew what their rights are as patients and also what they expect from providers. Respondents' knowledge of specific client rights was also assessed.

Figure 4.5 compares the proportion of respondents who said they were aware of clients' rights and those who were able to list at least two of the actual rights (list mentioned in Section 5). The graph shows both overall and district specific results. Generally, very low percentages of men said they were aware of rights, while about one third of women reported that they were aware of clients' rights. However, actual knowledge of at least two rights was far more limited, especially among men. No obvious differences are seen in this pattern across the four districts.

Among the survey respondents who claimed awareness of client rights, about a third mentioned that the doctor should check the client carefully and give advice, and nearly half the clients said the provider should behave well with clients. However, very few mentioned the rights to privacy and respect (data not shown). This low awareness of patient/client rights among men and women could contribute to low expectations and therefore higher tolerance of poor practices among service providers.

Figure 4.5: Proportion of HHS Respondents who Perceive They Have Knowledge of Patient Rights and Proportion Who Demonstrate Actual Knowledge of Patient Rights, \% (n=329 men, 1,114 women)

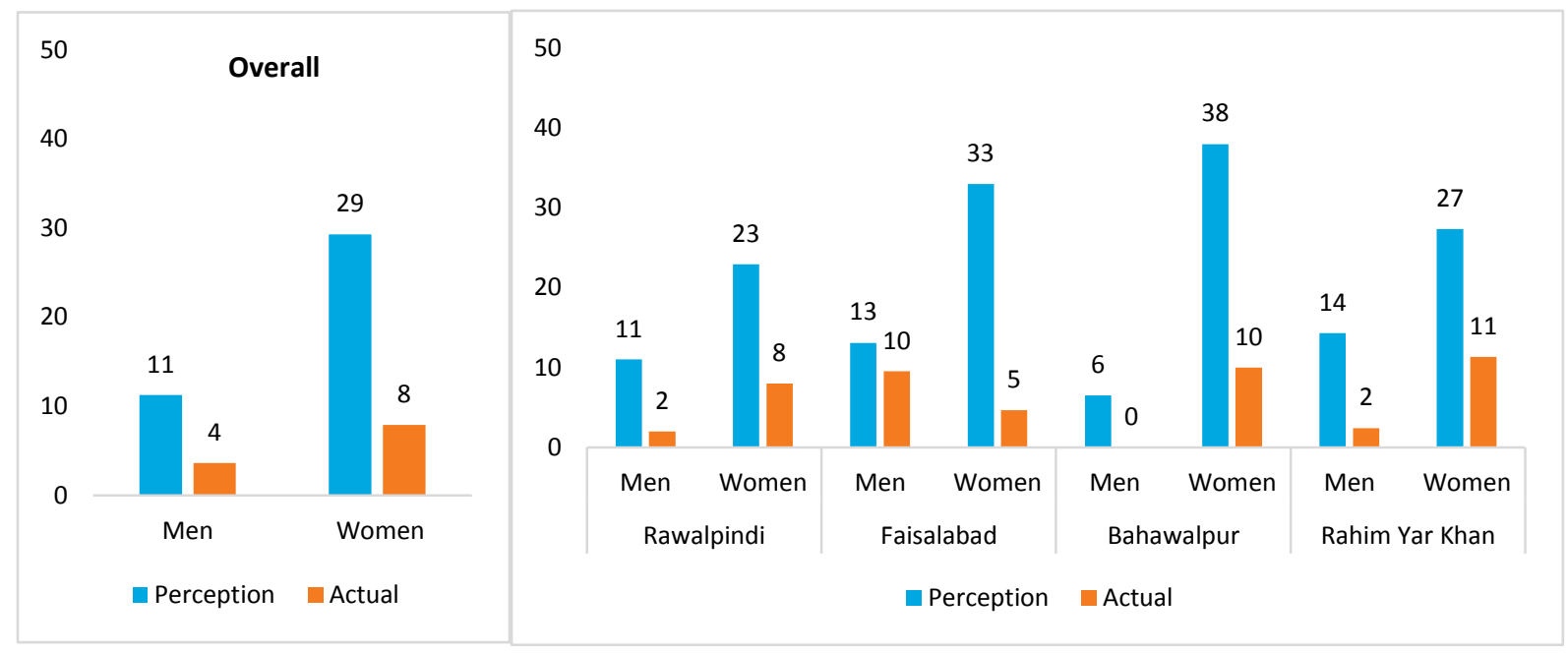

Source: HHS

Further dimensions to this issue were revealed during focus group discussions with men and women in the study districts. Respondents from both urban and rural communities admitted that the majority of people were largely unaware of client rights. A few respondents mentioned that a small proportion of men and women in their community were aware of the rights of a client, but they never asserted these rights.

"People know about their rights but there is no fulfillment of their rights. Like I know about my rights, but when an influential person will come, he breaks the queue to get his work done." FGD, Rural women, Bahawalpur

Some respondents explained that while they had never been exposed to any formal discourse of client rights, they intuitively perceive that a client deserves certain safeguards when seeking FP and other health services. 
In some remarks, respondents hinted that the absence of functional accountability systems were leading to non-observance of rights.

"We know there are certain rights of the client. We have read that if they charge you extra or misbehave with you, you can complain against them. But nothing like that happens. There is written (on the board in the hospital) that don't pay for anything and you can complain if the staff doesn't cooperate with you." FGD, Urban men, Rahim Yar Khan

"I also work at a government institution as a government servant. Nobody ever said that these people have any rights and you are here to serve these people. Nobody said that you have to take care of your clients. There is no awareness that we are paid from the taxes that the community pays and we have to serve them. They tell us that they are the officers, and the more they make it hard for others, the higher their office!" FGD, Urban men, Faisalabad

"We never read about it but we know that patients also have some rights. A sick person needs to get examined. Medicines should be available to patients and they should be treated with affection and care. These are the rights of a patient... Doctors should talk to them in a good manner, provide them medicines and perform laboratory tests, if needed." FGD, Rural women, Bahawalpur

"Their (The providers') behavior should be good; they should treat us well when we go to avail family planning services. They should talk to us with concern. They should give good suggestions, and give proper information that this is good for you and this is not." FGD, Rural men, Bahawalpur

The above findings suggest that men and women have low awareness of specific client rights, although some of them do perceive that they know these rights. Addressing this gap is crucial for enabling clients to expect and demand basic quality of care, and to strengthen accountability in service provision.

\section{Expectations from Family Planning Service Providers}

Whether or not they are aware of their rights, clients bring certain expectations to their interactions with service providers. Men and women were asked about their expectations from providers of family planning services in the household survey. Their responses, shown in Figure 4.6, indicate that their expectations are largely related to easily observable features of the interaction, and not to any technical aspects such as provision of method specific details, information about follow-up visit, possible side effects and their management. Their expectations are mainly divided into three areas: availability of male and female providers; behavior and competence of the service provider; and availability and quality of contraceptives.

The most important expectations, expressed by the majority of the respondents, are related to qualities they expect in service providers. Respondents, especially men, shared that the provider should attend properly to them. Only half of the men and women question the competence of their provider. Furthermore, they expect that the behavior of the provider be polite and he or she should be cooperative with clients-significantly more women than men expect this.

The second important expectation is that male and female service providers be available for men and women at the time of visit, respectively. It is very important to note that more than a third of men expect a male provider to be available for them, underscoring their need for a male provider, particularly to meet their FP needs.

Much lower proportions of respondents said they expected to be provided quality medicines, contraceptives, effective medicine, or free or low-cost services. However, noticeably more women than men state that the 
prescribed contraceptives should be effective, perhaps signifying female clients' greater awareness of the chances of method failure or side effects. Overall, the data show that respondents' expectations are related more to the behavior and attitudes of providers, than to other quality aspects of the services they receive from a facility.

Figure 4.6: Expectations of HHS Respondents When They Seek FP Services at a Health Facility, \% (n=329 men, 1,114 women)

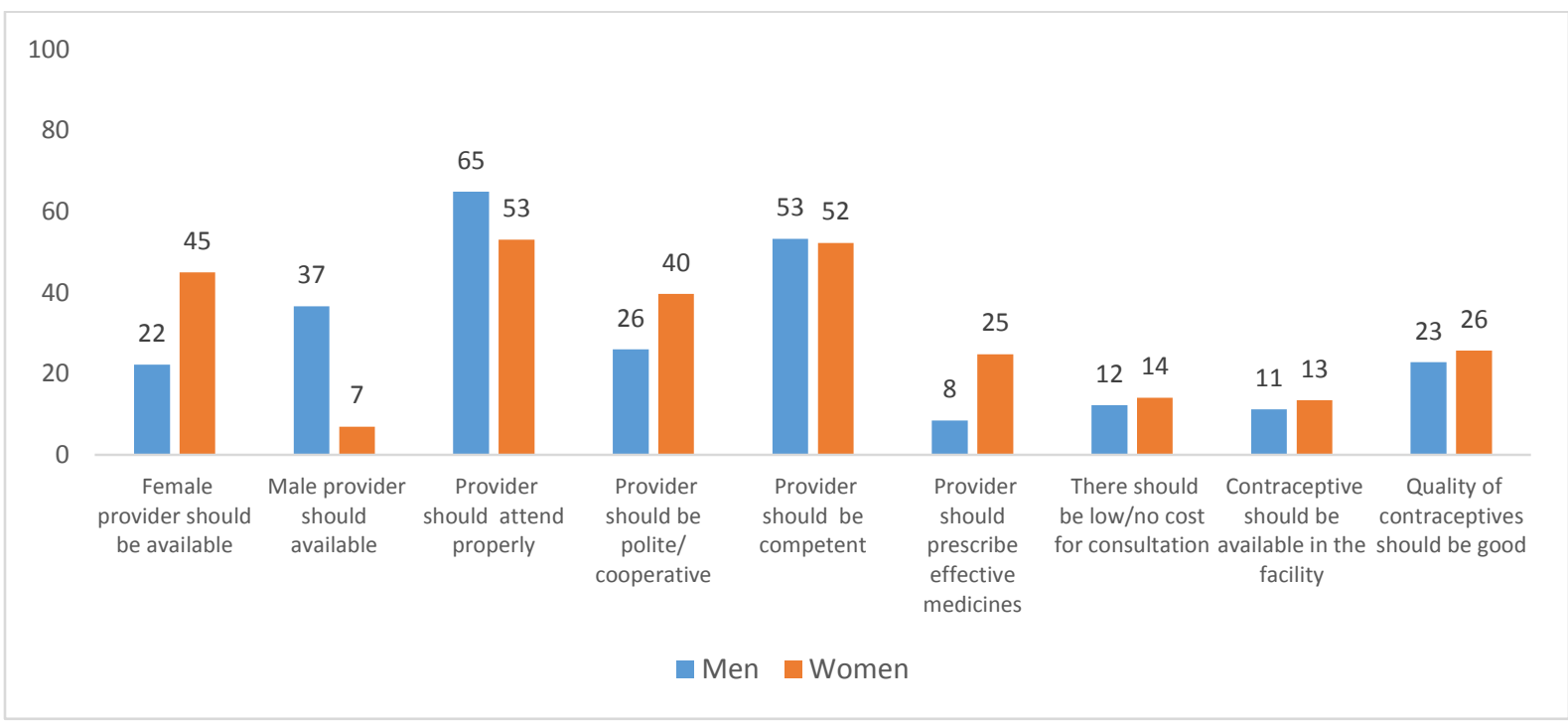

Source: HHS

\section{Community Structures and Accountability Mechanisms: Existing Support for Utilization of FP Services}

As mentioned in Section 1, in-depth interviews were conducted with influential community members and local service providers in eight communities for a better understanding of local social, economic and political structures, and to identify the potential for increasing the demand for and utilization of FP services in the community, including identification of individuals who could serve as a bridge between the community and current and potential FP service providers. Some of the FGD questions were also aimed at collecting this information.

\section{Potential Influencers}

When asked who in their community could play a role in facilitating utilization of FP services, most respondents were able to list locally prominent individuals who were already involved in some form of social activity in the community, such as mediation in social issues, arrangement of community development activities at village or neighborhood level, and utilization of public funds in community development. Most of these were retired individuals or owners of community-based businesses who could spare the time to participate in development activities. Respondents suggested that schoolteachers, religious leaders, local health professionals, or volunteers could work as activists, although people employed in other public or private sector work would be unsuitable as they would not have the time.

"LHWs and LHVs in government dispensaries could be helpful for this purpose. Doctors who provide health services, they can also play their role in support groups very well. There is no specific person against family planning, and such women should be included in support groups who talk to other women informally about family planning in their homes." IDI, Urban service provider, Bahawalpur 
"I think religious leader plays a key role in it. Religious leader, teachers or worker of health department should be there who can create awareness about different methods of family planning among people." IDI, Rural service provider, Rahim Yar Khan

Opinion on the role of councilors and political leaders was mixed. Some respondents were concerned that they would have political biases. However, others felt that councilors and political leaders would be wellplaced to effectively link communities with the relevant government departments. Moreover, as they were already involved in community development activities, their interventions were likely to be more acceptable. In rural communities, it was stressed that development activities are not possible without the approval of local landlords (like the Chaudhary or Vadera), who were playing a positive role already in some cases. In urban communities, any credible person could serve as a mobilizer.

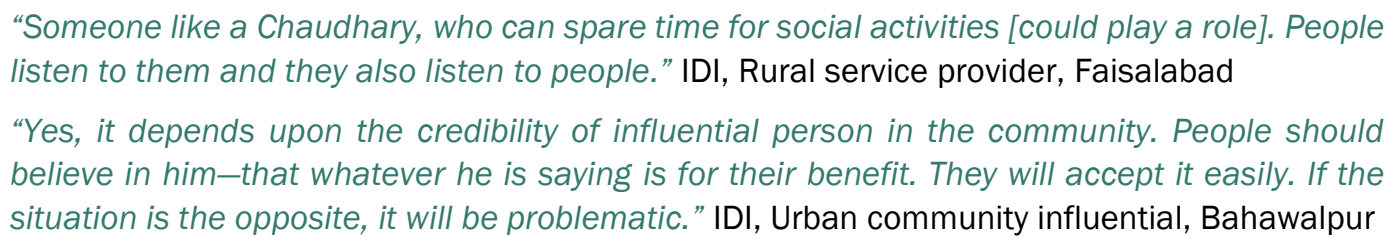

In two communities, respondents pointed out that village committees or organizations were already helping to implement health and water supply projects. These had been formed through external initiatives of concerned departments with the consensus of the communities. One of these, a health committee set up by the PRSP in a rural community in Faisalabad, was especially mentioned as a success story. Respondents said it was successfully contributing in resolving local health issues. Monthly meetings are held where issues and suggestions from both community representatives and service providers are discussed. Achievements of such village organizations include endorsement of demands from communities to improve health services, fundraising for the purchase of medicines that were not supplied by the health department, and accountability of both service providers and communities.

"We have a social organizer who arranges a meeting every month. It was initiated by PRSP. We have a proforma on which people sign in every meeting. Members regularly attend meetings and discuss problems. They give money to needy people. There are two or three Chaudharieslike Chaudhary Younas helped in ceiling work during construction and he also used to do charity." IDI, Rural service provider, Faisalabad

Although the majority of the respondents suggested that community organizations or support groups were a comparatively effective option for mobilizing communities, some respondents felt it would be challenging to bring all people together to adopt a common position and individual leaders support might be more effective.

"IIn the] sardari (feudal) system, there is no aptitude for collective social work." IDI, Rural service provider, Faisalabad

\section{Current Role in Supporting Family Planning}

Despite the existence of some health committees, no system for the support and accountability of family planning programs specifically was found to exist in any of the eight communities sampled for this component. This may partly be attributed to the limited availability of FP services-the Population Welfare Department's Family Welfare Centers were accessible to only two of the communities, while the Department of Health's LHWs were appointed in seven. More importantly, a common perception prevails that these facilities are for women's use only; men have very limited interaction with them. This was confirmed by service providers, who said men had less contact with them and rarely accompanied women on visits. According to community respondents, men's low involvement in utilization of FP services is a key reason why influential men in the community are not working in this sphere. 


\section{Reasons Clients Give for Their FP Service Utilization Choices}

Section 3 has shown that men and women in the study area are generally using a very narrow range of family planning methods. The two most popular are both male methods-condoms and withdrawal-while the third is female sterilization. It was also noted that the three most frequently used sources of family planning services for clients are static health facilities of the public sector, the Lady Health Workers (also public sector sources), and pharmacies. Among private health facilities, private hospitals are playing a larger role than clinics of doctors and less skilled providers.

Below, we take stock of the reasons men and women gave about why they prefer the facilities and methods they use, when asked during the household survey.

\section{Reasons for Not Using Other Methods}

Both men and women, including current and past users of contraceptives, were asked which method they were using or had last used, and why they had not chosen other methods at the time they adopted it. Figures 4.7 and 4.8 summarize and compare the main reasons given by men and women for not choosing the shortacting and long-acting reversible contraceptives, respectively.

With regard to why they did not choose oral pills, both men and women mainly mentioned access issues. Further, a quarter of men and about one-third of women said that it was difficult to take the pills daily because women often forgot due to housework, and also that they were afraid of side effects. Interestingly, fear of side effects is reported more by women than men, implying that women might be more aware of the risks compared to men.

In the case of emergency contraceptive pills, a surprising reason reported by half of the women respondents and 40 percent of men was that they do not know about the method. This is a serious concern as it limits choices for clients. The other main reason was access problems, which could also include lack of knowledge about sources for the method.

The majority of respondents mentioned mainly two important reasons for not choosing injectables: problems in accessing the method, which were reported as a major reason by both men and women, and fear of side effects, which was cited by nearly half of the women but, again, fewer men.

Figure 4.7: Main Reasons for Not Choosing Short-acting Methods at Time of Choosing Current/ Last Method, \% of HHS Respondents, \% ( $n=329$ men, 1,114 women)

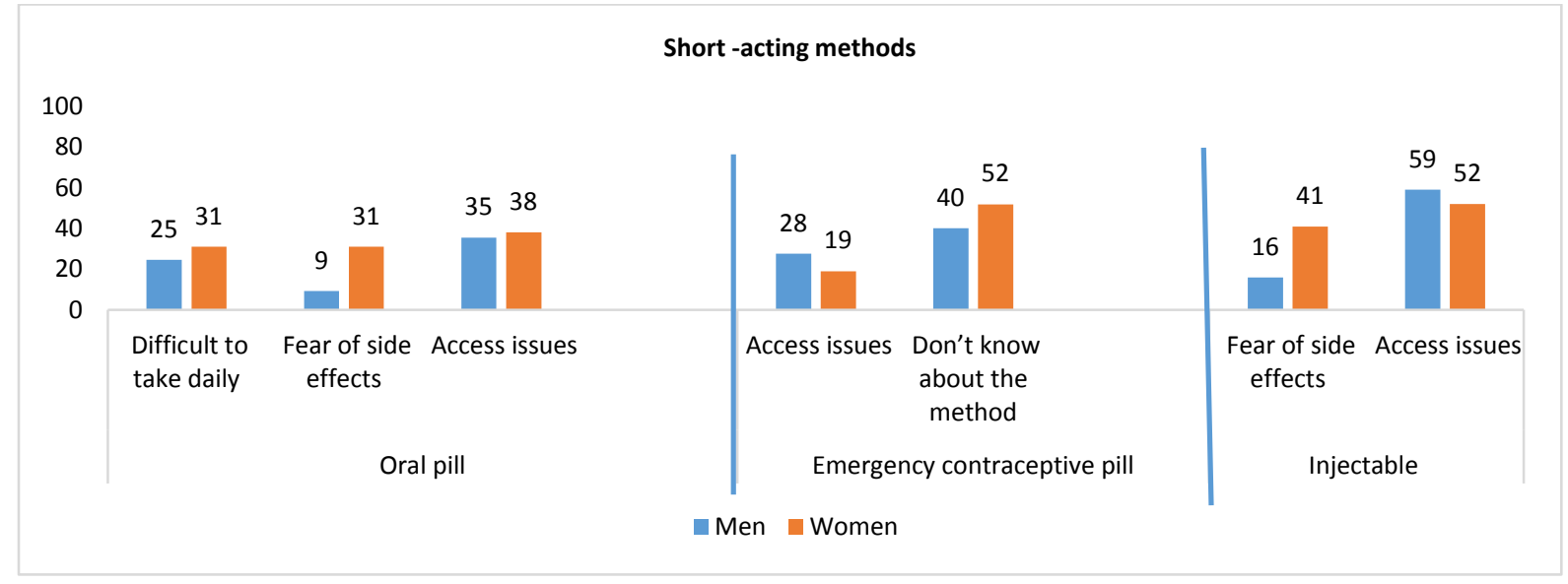

Source: HHS 
With regard to not using IUDs, the reason mentioned most frequently by respondents was access difficulties, which was cited slightly more by men than women. About 32 percent of women also attributed their avoidance to fear of side effects.

Surprisingly, for implants, nearly half of the respondents, including 45 percent of men and 47 percent of women, mentioned access as a major issue: they did not know where the services were available. Many respondents (34\% men and $40 \%$ women) also reported ignorance of the method, implying that providers are not providing sufficient support for FP clients to make a fully informed choice.

\section{Figure 4.8: Reasons for Not Choosing Long-Acting Reversible Contraceptives at Time of Choosing Current/Last Method, \% of HHS Respondents, \% ( $n=329$ men, 1,114 women)}

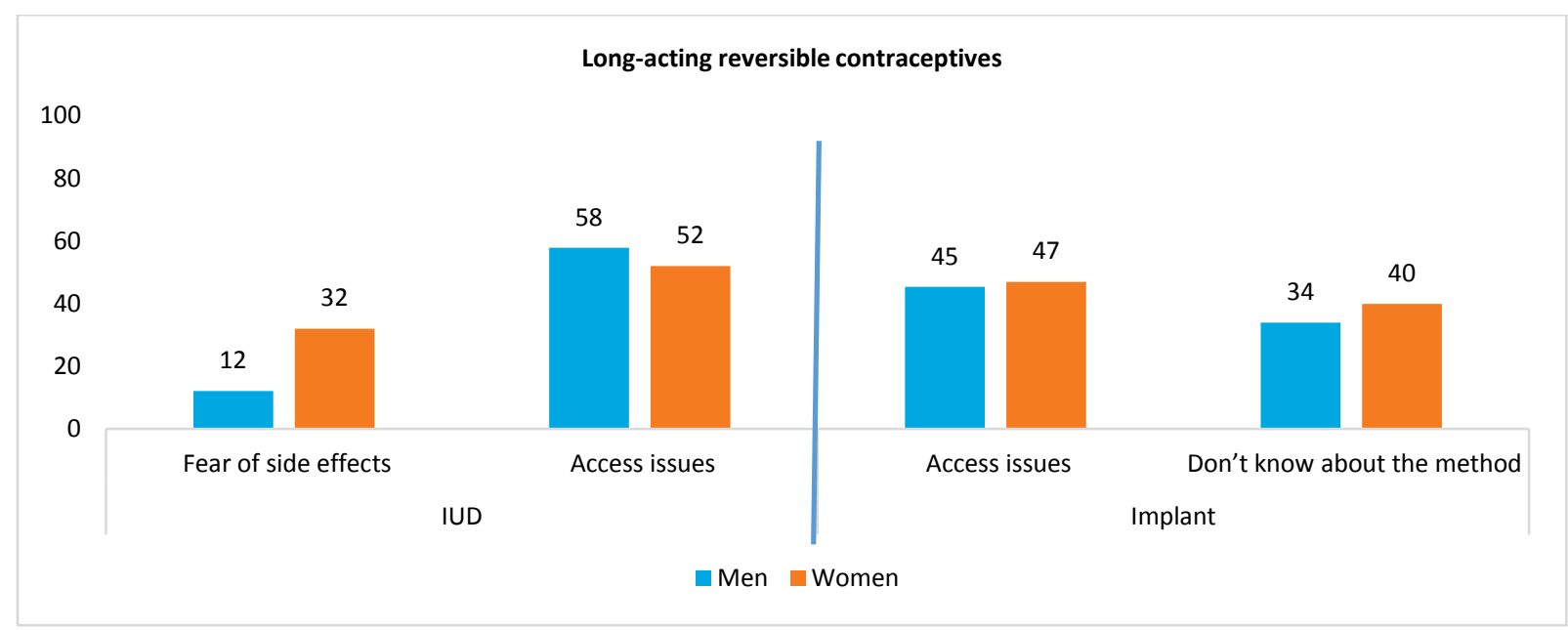

Source: HHS

Overall, among respondents interviewed, the main problems were access issues due to limited availability of services and fear or experience of side effects. Access as a major issue is cited more by men than women, while fear of side effects is more a concern of women than men. Notably, while certain side effects can arise from use of pills, injectables, and IUDs, they can be reduced if clients are properly counseled, the provider is competent in providing the method, aseptic measures are observed, and the provider properly manages side effects if they occur.

\section{Reasons for Choosing the Public or Private Sector}

In the household survey and focus group discussions, women were asked why they typically chose to use public or private facilities, pharmacies, or LHWs for FP services. Figure 4.9 shows the main reasons given by women for utilizing the public or private sector for FP services. For public static health facilities, the major reasons were free services and close location of facilities. In the case of LHWs, the fact that they provide doorstep services was a major reason that was mentioned by almost all respondents. Similarly, the main reason for using pharmacies was their location in the vicinity; these facilities were mostly catering to condom users. Utilization of the private sector is mainly due to the perception that it provides better quality services. Overall, Figure 4.9 suggests that availability in the close vicinity matters a lot to FP clients. 
Figure 4.9: Reasons for Utilizing Sources of FP Services Who Utilize that Source Reported by HHS Respondents, \% ( $n=1,114$ women)

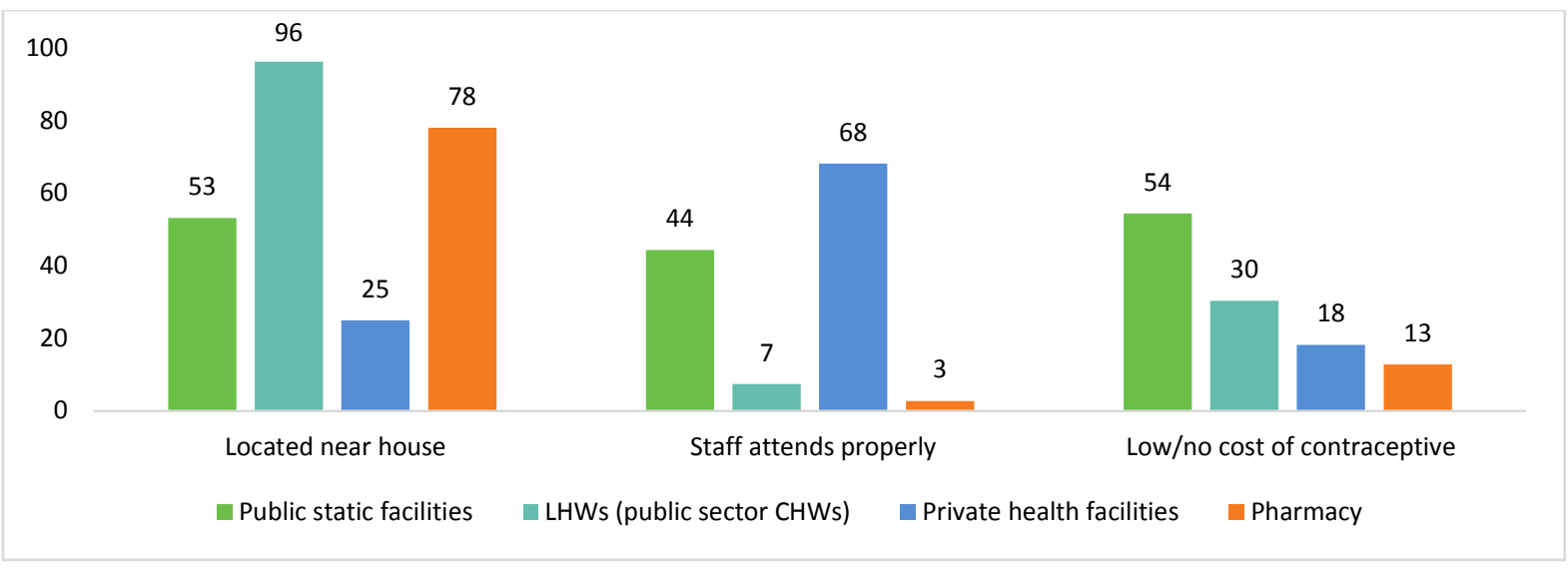

Source: HHS

As Table 4.1 explains, for both short- and long-acting reversible contraceptives most of the respondents preferred to use public facilities because these were located in their vicinity and providing contraceptives free of cost. The other important consideration was that the staff attends properly. Reasons for utilizing public and private facilities for tubal ligation are slightly different from other methods. The main reason for utilizing public facilities are provider's competence and free services. However, in the private sector, the main reason is that the staff attends to them properly, followed by availability of a combination of services at one placemost of the clients who sought tubal ligation at private facilities did so at the time of a delivery through Csection.

Table 4.1: Reasons for Utilizing Public and Private Sector for Specific FP Methods among Those who Visit that Type of Facility for that Method, \% of HHS Respondents ( $n=1,114$ women)

\begin{tabular}{|c|c|c|c|c|c|c|c|c|c|c|}
\hline & \multicolumn{2}{|c|}{ Condom } & \multicolumn{2}{|c|}{ Pill } & \multicolumn{2}{|c|}{ Injection } & \multicolumn{2}{|c|}{ IUD } & \multicolumn{2}{|c|}{ Tubal Ligation } \\
\hline & Public & Private & Public & Private & Public & Private & Public & Private & Public & Private \\
\hline Located near house & 96 & 80 & 92 & 38 & 79 & 57 & 56 & 29 & 27 & 16 \\
\hline $\begin{array}{l}\text { Other facility far from } \\
\text { house }\end{array}$ & 2 & 8 & 2 & 0 & 4 & 7 & 2 & 0 & 6 & 4 \\
\hline Staff attends properly & 9 & 1 & 11 & 38 & 12 & 43 & 48 & 46 & 55 & 88 \\
\hline $\begin{array}{l}\text { Suitable facility } \\
\text { Timings }\end{array}$ & 2 & 2 & 2 & 13 & 5 & 0 & 6 & 8 & 10 & 7 \\
\hline $\begin{array}{l}\text { Female provider } \\
\text { available }\end{array}$ & 15 & 1 & 16 & 0 & 26 & 14 & 18 & 21 & 15 & 14 \\
\hline $\begin{array}{l}\text { COntraceptives } \\
\text { available }\end{array}$ & 7 & 13 & 6 & 50 & 5 & 0 & 12 & 25 & 22 & 29 \\
\hline $\begin{array}{l}\text { Low/no cost of } \\
\text { contraceptive }\end{array}$ & 29 & 12 & 33 & 0 & 40 & 14 & 64 & 21 & 54 & 7 \\
\hline Family doctor/ trust & 5 & 1 & 10 & 13 & 5 & 14 & 6 & 21 & 13 & 27 \\
\hline $\begin{array}{l}\text { Combination of } \\
\text { services available }\end{array}$ & 0 & 1 & 3 & 0 & 1 & 0 & 2 & 4 & 21 & 36 \\
\hline Total & 266 & 152 & 63 & 8 & 77 & 14 & 50 & 24 & 67 & 56 \\
\hline
\end{tabular}

Source: HHS

The majority of FGD participants said that people from their communities generally visit public facilities for FP services, although a considerable proportion visit private facilities as well. Various reasons were mentioned by the respondents as to why they avail a facility for family planning methods. The main reasons 
mentioned were availability of the source in the close vicinity, affordability of services, quality of services or service providers, professional skills and attitudes of service providers, and awareness about the existence of the facilities.

\section{Reasons for Using Public Facilities}

To assess whether men and women who were using public facilities preferred these to private facilities, or were compelled by personal or external circumstances, HHS respondents were asked whether private facilities were available in their area offering the same services and, if so, why they did not opt for them. Figure 4.10 shows that the main reasons given by a substantial number of both men and women respondents were the high cost of contraceptives (52\% men and $45 \%$ women). This is the main reason mentioned by men while women also cited high consultation fees (44\%). A few women also said that providers at private facilities were not competent and contraceptives were not available.

\section{Figure 4.10: Main Reasons for Not Using Private Facilities for FP Services among HHS Respondents Frequently Utilizing Public Facilities, \% of respondents ( $n=329$ men, 1,114 women)}

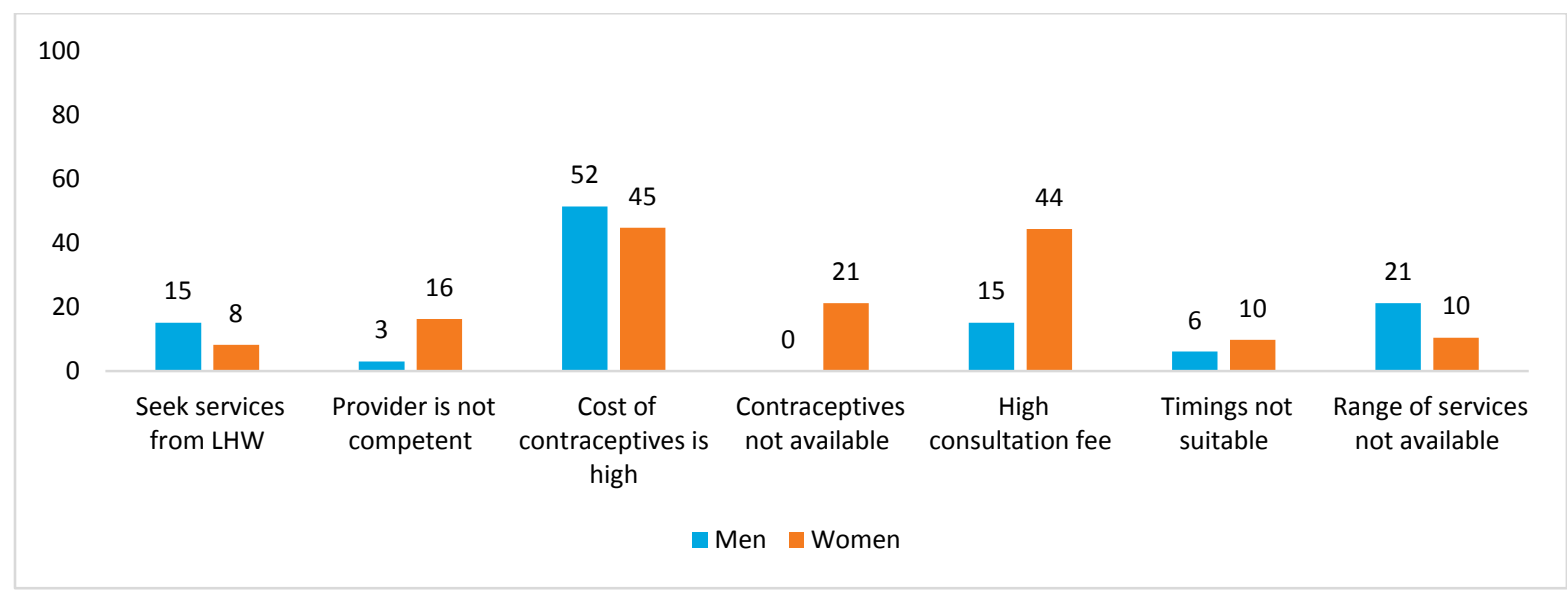

Source: HHS

The main reason given by clients for utilizing public facilities for FP services was that the contraceptives were available for little or no cost. This was the case in all four districts. Information from FGDs reinforces this finding.
“It doesn't take time if we visit public facilities for family planning because there is a separate arrangement for family planning services. Service providers of the facilities take care for their clients. They don't charge at all for contraceptives. They only charge a token fee, while private facilities charge from 200 to 250 rupees." FGD, Rural women, Bahawalpur
"Government facilities are better for family planning services because private facilities are out of reach for people with low income." FGD, Rural men, Rahim Yar Khan
“The government facility is better for family planning facilities; we can't afford others (private) because of less income." FGD, Urban women, Bahawalpur

During FGDs, men and women drew attention to the fact that many private providers were not qualified to provide services.

"There are experienced doctors in government hospitals, which is beneficial. There are difficulties in government facilities but there are well qualified doctors, which is helpful." FGD, Urban women, Faisalabad 
"There are two to three private service providers in each community but they are not doctors but masons. They work with a doctor for a year and start working as doctors." FGD, Rural men, Faisalabad

"Actually, in private facilities, service providers are less qualified. They sit with doctors as compounders for some time and later on they establish their private clinic to earn money. They provide tablets and injections for family planning. In the government facility, doctors are qualified and experienced." FGD, Rural women, Bahawalpur

\section{Reasons for Using Private Facilities}

Figure 4.11 shows that among HHS respondents using private facilities for family planning services, the most frequently cited reason was that the private facility was situated closer to their home. In addition, women said that providers at public facilities do not attend properly, or are not competent, or the complete range of services is not available. For men, the main reasons after distance were and inadequate range of services and unsuitable timings at public health facilities. The issue of limited timings exacerbates access issues for clients who cannot go to facilities in the morning due to household chores or engagement in economic activities.

Figure 4.11: Main Reasons for Not Using Public Facilities among HHS Respondents Frequently Utilizing Private Facilities, \% of respondents ( $n=329$ men, 1,114 women)

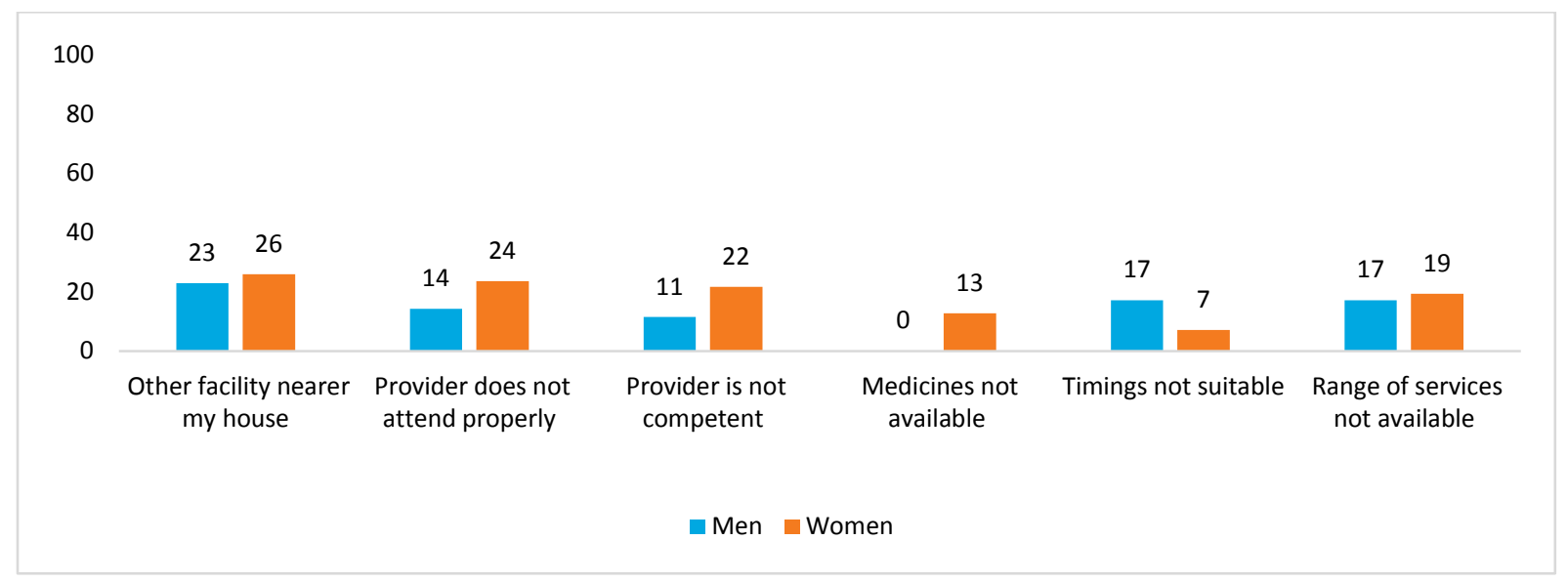

Source: HHS

In FGDs, the main reasons given for visiting private service providers were that it was time saving and that better quality services are provided compared to the public facilities.

"Rich people don't have time so they don't go to the public sector. They seek services of the private sector to save their time, although it is expensive." FGD, Urban men, Bahawalpur

“There is a rush at government facilities due to which we don't like to go there. We get medicines from private facilities and are done in a short time. Although services are also available at the government level, we have to wait for a long time in the queue there." FGD, Rural men Bahawalpur

"We visit private facilities for family planning services because there is no rush and hustle like in government hospitals; they go to private facilities and get free early." FGD, Urban women, Bahawalpur 
FGD respondents also noted that the heavy client load at public facilities made providers less available and attentive, and led to inadequate counseling.

"Nobody cares at government hospitals even if you are waiting for hours. There are only a few doctors appointed, who mostly remain absent." FGD, Rural women, Bahawalpur

"Obviously they get proper checkup and counseling from a private sector service provider. At the government facility, they just insert the IUD and send you home with some medicines, but at private facilities, they counsel patients properly and talk nicely and Reassure us." FGD, Urban women, Rahim Yar Khan

\section{Affordability of FP Services and Willingness to Pay for Specific Methods}

Figure 4.9 and Table 4.1, above, show that a major reason for utilization of public sector facilities is that services are provided free of cost. Clearly, affordability is a main determining factor in men's and women's decisions regarding which source of FP services to utilize. To probe this issue, respondents of the household survey were asked about their willingness to pay for each of the contraceptive methods. Figure 4.12 compares the actual cost that respondents have paid to seek FP services with the amount they are willing to pay. The graph shows that for condoms, pills and emergency contraceptive pills, women want to pay less than what they are actually paying, whereas for injectables and IUDs, the cost they are willing to pay is the same as what they actually paid, indicating that they find these methods affordable.

Interestingly, for implants and tubal ligation, women are willing to pay almost double the amount they are paying currently. In the case of tubal ligation, it could be that they value the transaction in terms of paying once for final termination of child bearing.

Figure 4.12: Method Specific Actual Median Cost and Willingness to Pay, including Costs of Contraceptive and Travel, Pak Rs. ( $n=1,114$ women)

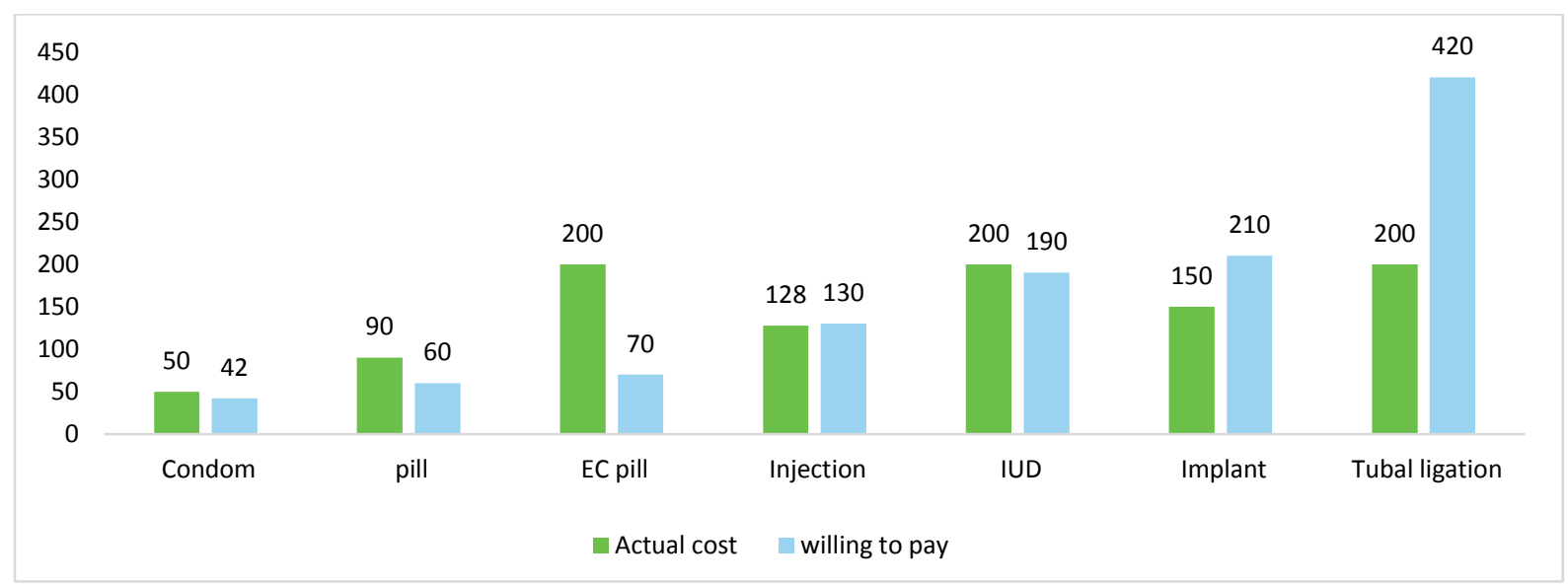

Source: HHS 


\section{Preferences of Men and Women about Provision of}

\section{FP Services}

Respondents of the HHS and HFA (Exit interviews with clients) were asked what their preferred combination of family planning services would be in terms of sector, location, cadre of provider, and whether the services should be integrated with $\mathrm{MCH}$ services or provided separately. Their responses are outlined below.

\section{Preferred Sector}

Figure 4.13 shows that well over half of both categories of respondents prefer that family planning services be provided by the public sector. In addition, about a quarter of female and a third of male respondents want both the public and the private sector to provide FP services. Very few respondents expect services only from the private sector.

Preference for the public sector can be seen in the patterns of utilization discussed in Section 3. Likewise, the reasons for this preference echo those outlined above: public facilities are preferred because they cost much less, while private facilities are preferred for better quality (checkups and attention) and less waiting time (data not shown).

\section{Figure 4.13: Preferences of Respondents about which Sector should Provide Family Planning Services, \% (Clients n=406 women, HHS $n=1,114$ women)}

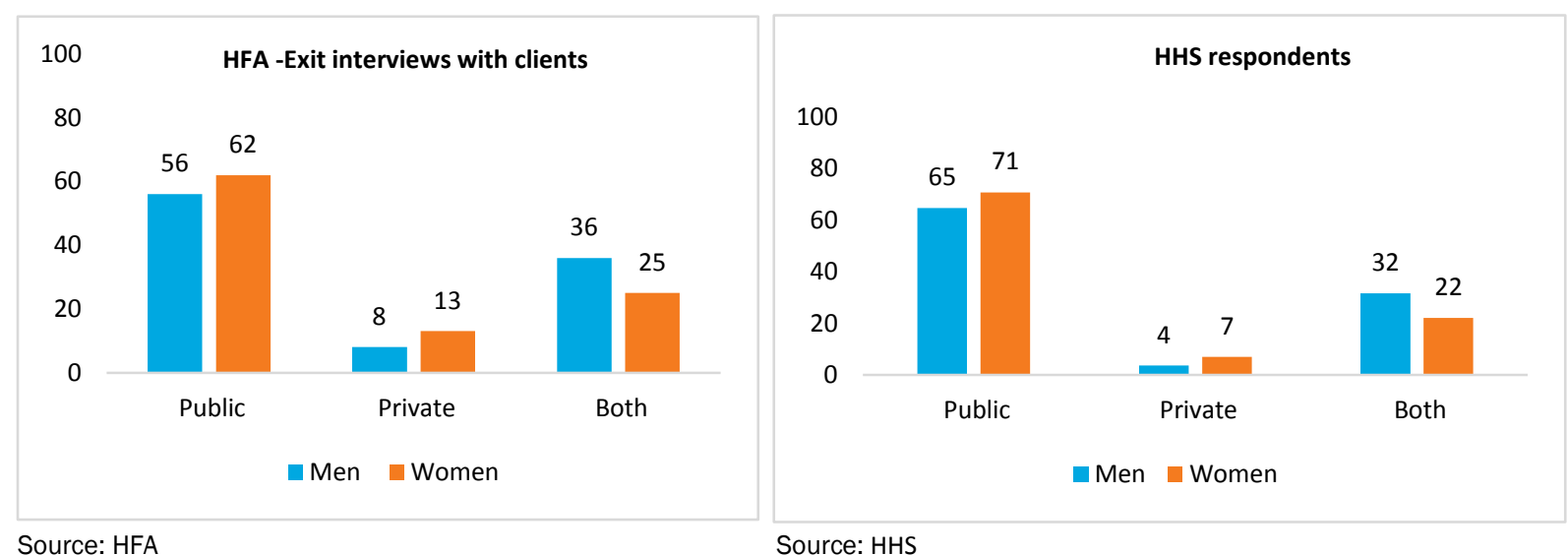

\section{Preferred Location}

The location of FP services is an important consideration because of the limited mobility of women, and its influence on travel costs and time spent away from home. Figure 4.14 shows that the vast majority respondents of both the HHS and HFA-the client interviews preferred that FP services be delivered at their doorstep or provided within their communities.

Notably, preferences about where FP services should be located have implications for the method choices of men and women. For those who prefer that services be delivered at their doorstep, the obvious source is an LHW. However, she only provides injectables, oral pills, and condoms. Likewise, the preference for services within the local community could explain the popularity of pharmacies, which mainly offer the same three methods as LHWs. Given that women find it difficult to remember to take the daily pill, and are afraid of the side effects of injectables (Figure 4.7), their method choice becomes largely restricted to condoms and traditional methods. 
Figure 4.14: Preferences of Respondents about Where Family Planning Services Should be Located, \% (Clients $\mathrm{n}=406$ women, HSS $\mathrm{n}=\mathbf{1 , 1 1 4}$ women)

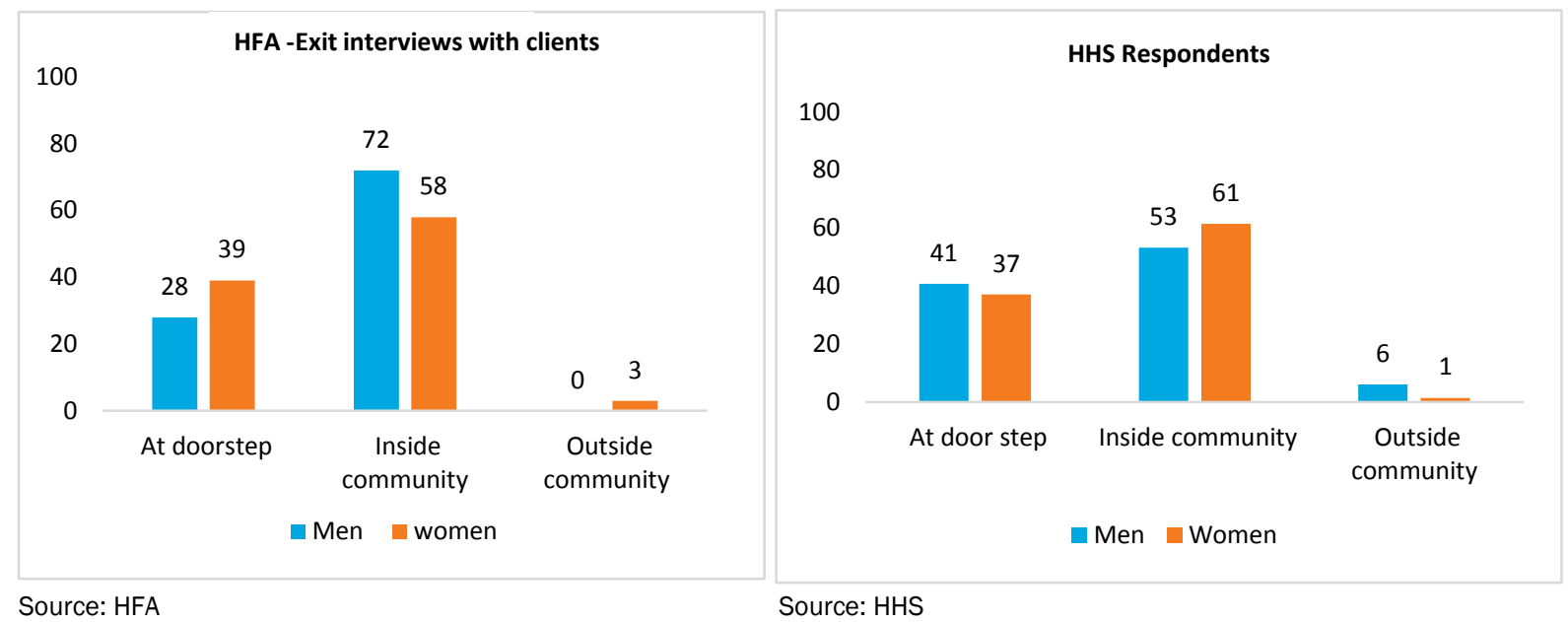

\section{Preferred Cadre}

With regard to which cadre of providers should provide family planning services, Figure 4.15 shows that female doctors are the most frequently mentioned preference of female respondents, followed by LHWs and community midwives (CMWs).

Female doctors are also one of the most commonly mentioned preferred source among male respondents, but men also show a far greater preference compared to women for both male and female doctors, as well as for male doctors only, reflecting their need for direct access to FP information, counseling, and methods.

The data indicate that clients, especially women, prefer to avail family planning services from more qualified providers (doctors) if there is a choice but are also likely to accept LHVs.

Figure 4.15: Preferences of Respondents about Which Provider Cadre Should Provide Family Planning Services, \% (Clients n=406 women, HSS n=1,114 women)

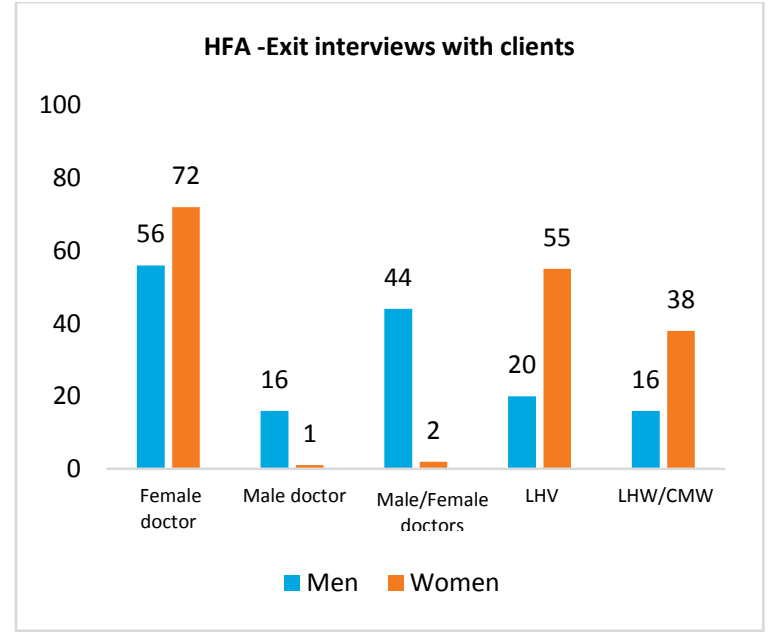

Source: HFA

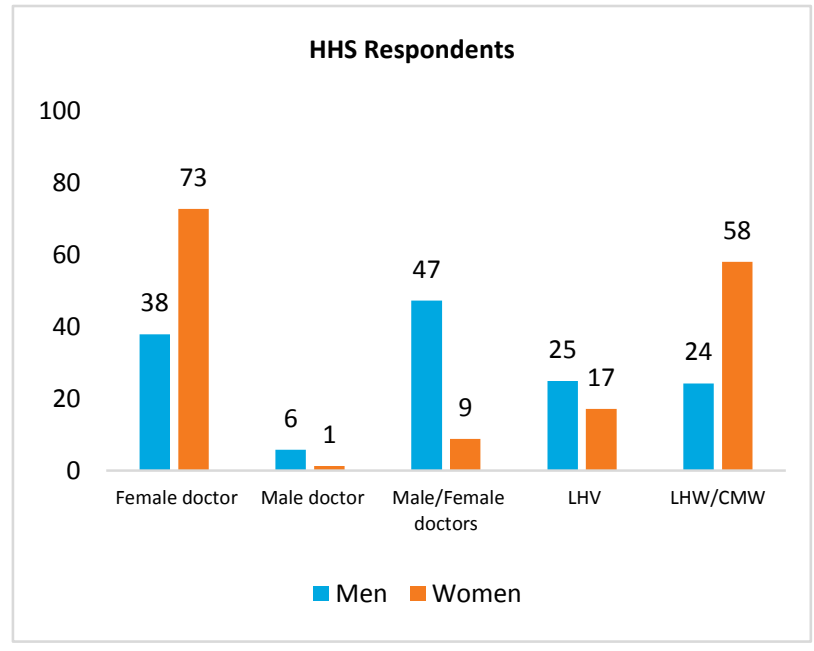

Source: HHS 


\section{Separate or Integrated Service Provision}

Men and women were asked whether they preferred that FP services be provided separately or at the same facilities where other reproductive health $(\mathrm{RH})$ services or maternal and child health services were being provided. They were also asked the reason for their preference. Figure 4.16 shows that more than 50 percent of both male and female respondents of both components preferred that FP services be integrated with maternal and child care services. However, the interest in separate FP facilities is also notable: among clients, more men (44\%) than women (29\%) preferred this option, as did about a third of HHS respondents, both male and female.

Figure 4.16: Preferences of Respondents about Integration of Family Planning Services with Maternal and Child Care or Other Reproductive Health Services, \% (Clients $n=406$ women, HSS $n=1,114$ women)

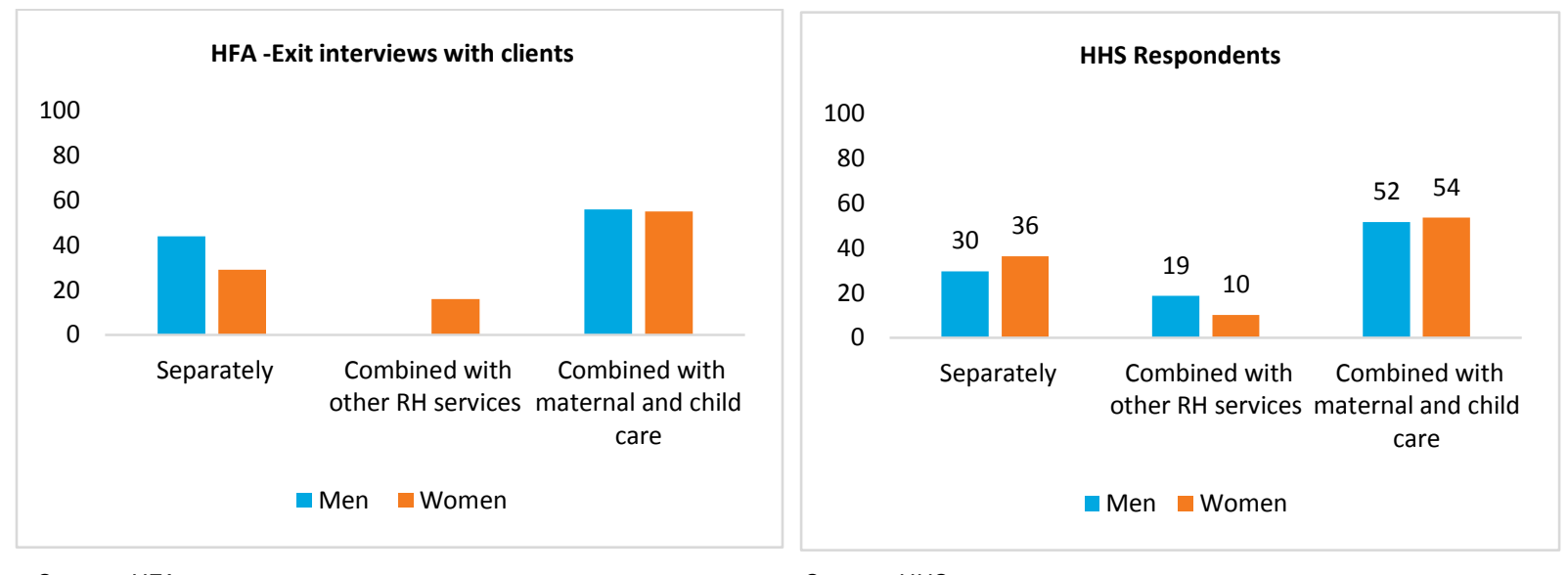

Source: HFA

Source: HHS

Figure 4.17 below compares the profiles of women who prefer integration of FP services with other RH and $\mathrm{MCH}$ services and those who prefer that FP services be provided separately. More than half the urban women prefer separate services, while over half of the rural women prefer combined services; this difference likely reflects the greater access issues of rural women, who are therefore more keen that all family health services be available at one location. Among women of low socioeconomic status, more prefer combined services, while among women of middle and high SES, a relatively higher proportion prefer separate FP services, again suggesting that integrated service provision is linked with the saving of time, travel expenses, and affordability for poorer users.

Figure 4.17: Profile of HHS Respondents who Prefer Separate Provision of Family Planning Services or Integration with Maternal and Child Care or Other Reproductive Health Services, \% ( $n=1,114$ women)

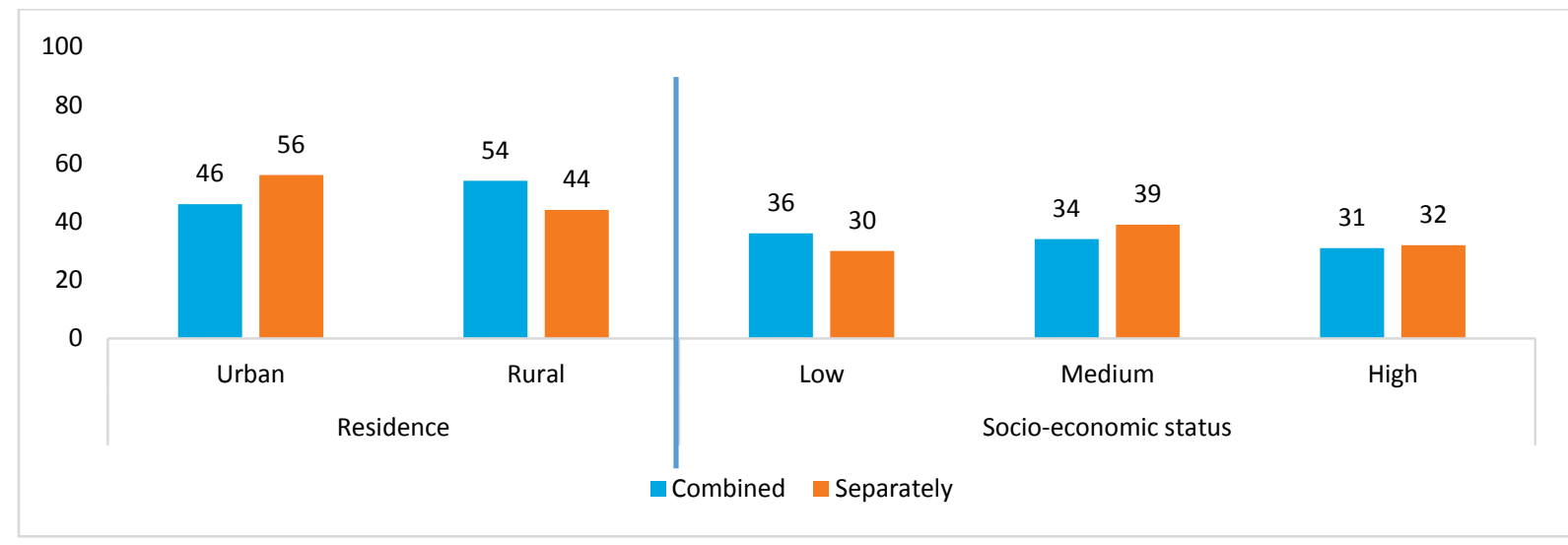

Source: HHS 
The reasons respondents gave for their preferred model of service provision are shown in Figure 4.18, for interviewed clients, and in Figure 4.19, for HHS respondents. The most common reason given for combining FP services with $\mathrm{RH}$ or $\mathrm{MCH}$ services was that all facilities would be available under one roof and families could avail all required services in one visit, thereby reducing their travel cost and time.

The main reason given for preferring separate facilities for FP was that it would protect clients' privacy in this personal matter. A few respondents also pointed out that it would reduce waiting time.

Figure 4.18: Reasons Given by Interviewed Clients (in HFA) for Preferring Separate or Integrated Provision of FP Services, $\%$ ( $n=406$ women)

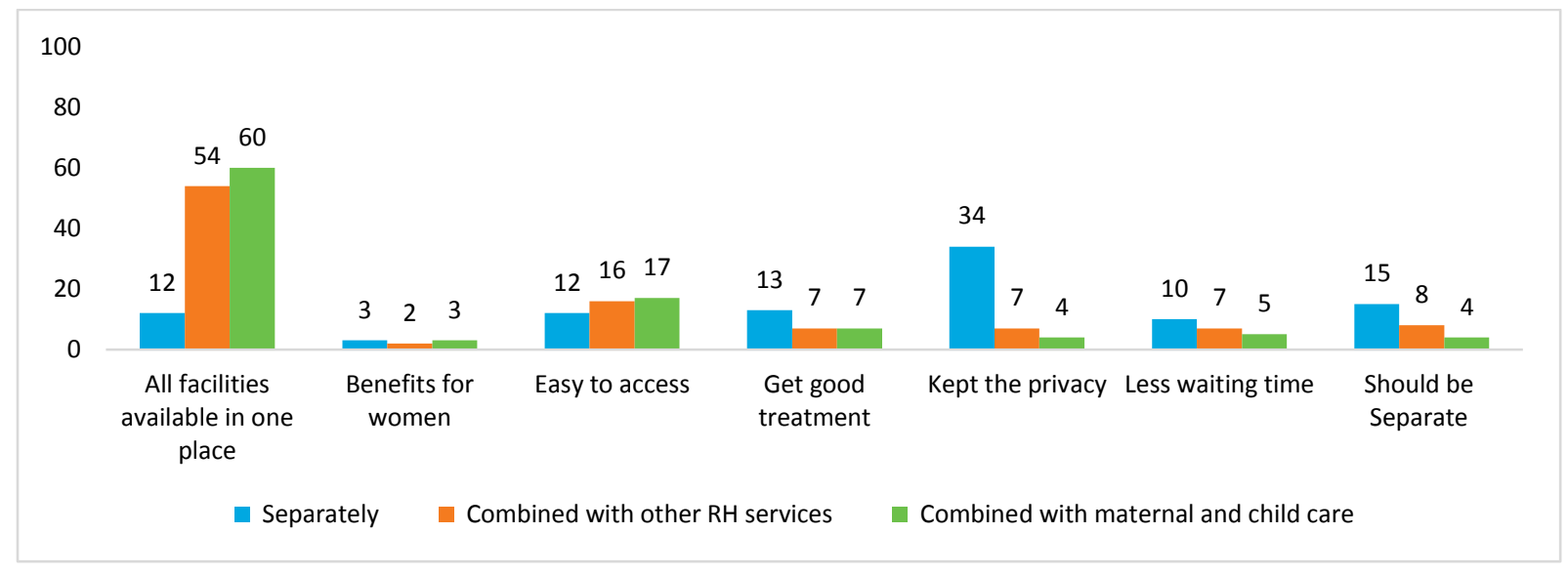

Source: HFA

Figure 4.19: Reasons Given by Respondents (HHS) for Preferring Separate or Integrated Provision of FP Services, $\%(n=1,114$ women $)$

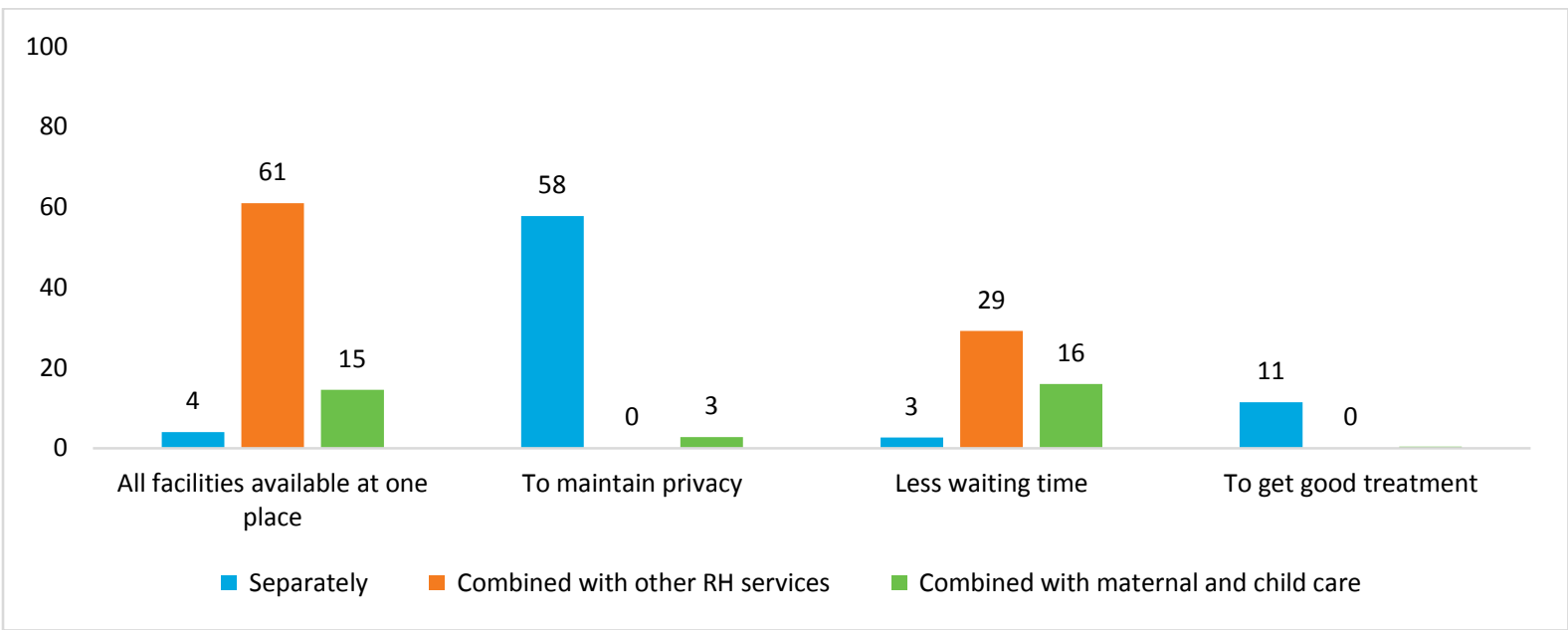

Source: HHS

With regard to privacy, it may be pointed out that some FGD respondents felt that separate FP services would actually make it harder to maintain privacy:

"I think some hesitation will remain if there are separate centers for family planning. If someone sees a women going to seek family planning services, people will say, what did she go there for? People will look at the man strangely too. So it should be combined." FGD, Urban men, Rahim Yar Khan 
There was generally a mixed response on this question among FGD respondents. The majority of men and women favored separate facilities for family planning to avoid long waiting periods and to get the full attention of service providers.

"We can get these (FP) facilities easily if there is a separate department for them. People would know that there are family planning facilities available and this is not like a common hospital." FGD, Rural men, Rawalpindi

"We would need to wait for a short time if family planning facilities are provided at a separate facility. Otherwise, there will be a huge rush if these facilities are available combined with other health services." FGD, Rural women, Rawalpindi

However, others pointed out that having all needed family health services under one roof would be convenient.

"A hospital may be small but there should be all facilities available. There should be medicines for fever, delivery facilities, and family planning facilities." FGD, Rural women, Rahim Yar Khan

\section{Mobilizing Communities for Improved FP Service Utilization}

In Section 4.1.4 above, it was noted that family planning does not currently figure as a concern in any local initiatives discussed during interviews with influential community members and local service providers. However, this does not imply that the potential does not exist: community respondents reported that people do not generally disapprove of family planning and unmet need exists. The main hurdles in use of family planning include low availability, poor quality, and lack of awareness of available services. If they could be persuaded to participate, influential persons could enhance awareness and acceptance of family planning in the community-because they have a greater influence than service providers in this respect-and help improve provision and utilization of family planning services in collaboration with the health or population welfare departments.

"Yes, the demand and use of family planning will be increased if a committee is established at community level. When awareness is created among people, then demand will increase. People who feel shy and hesitate will also use family planning." IDI, Rural service provider, Rawalpindi

The service providers interviewed said that the involvement of communities would be a positive development and could help facilitate family planning initiatives at the community level. If communities were willing to play a positive role in family planning programs, no one would object to their role in improving accountability.

"We will not mind if a responsible person like a Haji sahib (respected pious man), teacher, or Moulana sahib (religious person) comes to the clinic and asks us about checks and balances, we would say you are right [to ask], as you are a member of this committee." IDI, Urban service provider, Faisalabad

During interviews, a number of practical suggestions were put forward regarding the practical mechanism whereby influential local residents could facilitate improvements in FP service utilization and provision. As a first step, many respondents said the influential individuals would need to be persuaded to play a role in improving family planning, and counseled and trained for this work. Moreover, there should be formal engagement with the concerned government department, which should contact and brief them about the program, the mechanism for their engagement, and their specific responsibilities. 
"You will guide them first and then they will convince people further. Those people don't know about this (Family Planning) so they need to be trained first." IDI, Rural service provider, Faisalabad

Most respondents were of the view that community organizations would be the best platform for mobilizing local stakeholders. Separate organizations were recommended for men and women, and awareness building was emphasized as a primary role.

"There should a committee for males and females that organizes meeting at least once a month. People on the committee will create awareness among people about the use of family planning." IDI, Rural community influential, Rawalpindi

It was also suggested that in communities where village organizations were already established and working on other issues, the same organizations could be involved in supporting family planning programs.

"We have a Health Council committee and a Food and Nutrition committee. All these things are interrelated, so information about mother and child health can be given in the monthly meeting. We are already running three committees." IDI, Rural service provider, Rawalpindi

Some respondents stressed that involvement of the relevant government departments along with community representatives was necessary for effective accountability. Involvement of service providers was also stressed.

"We will establish such an organization but there should be monitoring of the government office for it to work properly. This organization will work better if they create awareness among people." IDI, Urban service provider, Rahim Yar Khan

"Meetings and seminars should be organized within 2-3 months where people can convey their problems to higher authorities. Then the technical people will handle these problems in a good way." IDI, Urban community influential, Bahawalpur

\section{Conclusions}

Currently, the most frequently utilized facilities for family planning services include the LHWs, public static facilities, and pharmacies. The main reason for the popularity of these sources is their presence in the vicinity of users and their affordability. Those who opt for private health facilities primarily do so because public facilities are crowded, and the providers have less time to attend to them properly.

Though a limited proportion of men and women claim they are aware of their rights as clients of health facilities (11\% and $29 \%$ respectively), their knowledge of specific rights is quite low ( $4 \%$ men and $8 \%$ women).

While access issues comprise one of the main reasons for not using oral pills, emergency contraceptive pills, and injectables, they are a major reason for non-use of IUDs and implants. Apart from difficulties in access, fear of side effects (based on past experience or word of mouth) and lack of knowledge are also important reasons for not using other methods. Fear of side effects is a main reason why clients do not choose the hormonal methods, especially injectables and IUDs. These fears are not entirely unfounded given the gaps in the training and knowledge of service providers, and the resulting lack of capacity to counsel and reassure clients and manage the possible side effects of these methods. Men and women also have limited knowledge about emergency contraceptive pills and implants; the latter method is available at very few facilities.

Affordability of FP services is a main concern of men and women in deciding which sector and facilities to utilize and what method to choose. The mean contraceptive cost is higher in rural than urban areas for all 
methods except condoms. In the case of tubal ligation especially, the cost in rural areas is double that in urban areas.

Women are willing to pay more for implants and tubal ligation, but want to spend less on condoms, oral pills, and emergency contraceptive pills. Although lower costs are a main reason for preferring public health facilities, female respondents in this study clearly recognized that longer acting and permanent methods would be more cost-effective over time. They felt they were spending too much on condoms, oral pills, and ECP, but were satisfied with the cost of injectables and IUDs. On the other hand, for implants and tubal ligation, they are willing to pay almost double what they are paying now.

The majority of men and women want FP services to be provided via the public sector, in their close vicinity, and alongside maternal and child health services. Around a third of men and women desire that FP services be delivered at their doorstep or within the community, underscoring the importance of the LHWs. More than half of both male and female respondents preferred that FP services be integrated with maternal and child care services to avail all required services in one visit, thereby reducing their travel cost and time. However, there is a notable interest in separate FP facilities, primarily to maintain privacy.

Men have a pronounced preference for including male providers in FP service provision, reflecting their need for direct access to FP information, counseling, and methods. It is important to meet this need: most women cannot practice family planning or choose a method unless their husbands agree, but men typically cannot consult with female providers and do not know where to go for FP information and services except pharmacies. 

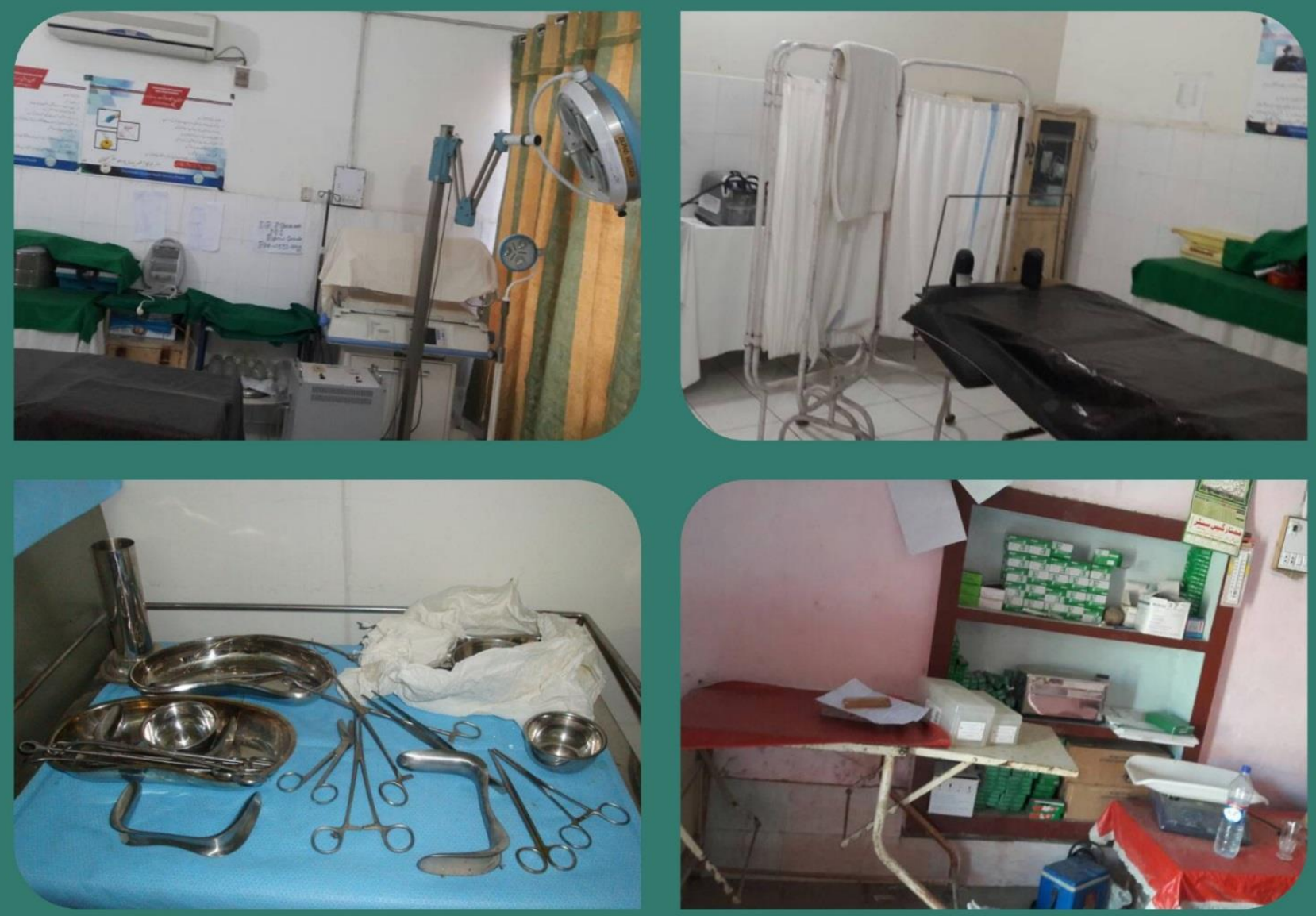

\section{Quality of Care at Health Facilities for Family Planning Services and Missed Opportunities}

Offering FP Services to Eligible Clients Who Don't Ask

Capacity of Service Providers

General Readiness of Health Facilities 



\section{Quality of Care at Health Facilities for Family Planning Services and Missed Opportunities}

In Section 2, we have seen that significant proportions of service delivery points, especially in the private sector, are not offering any family planning services. Moreover, even where they do offer family planning, many facilities offer only a limited range of methods. These gaps comprise the early tiers of missed opportunities to provide family planning services to clients in the health sector. However, even beyond this level, there are multiple ways-broadly related to quality of care-in which health facilities may be letting clients down. In this section, we draw on our CFP as well as assessment of 399 health facilities (HFA) in the study districts to complete the analysis of missed opportunities to recruit and support FP clients, focusing this time on gaps in the quality of services.

In the context of family planning service provision, Judith Bruce identifies six main elements of quality of care, 11 including choice of methods, technical competence of the provider, information provided to the client, interpersonal interaction with the client, mechanism of continuity and follow-up of services, and appropriate constellation of services. If these elements are in good order, the client is more likely to be satisfied, and increase in contraceptive use can be expected with fewer cases of dropouts. Recent years have seen increased emphasis on a rights-based approach to family planning, adding further dimensions to the concept of quality care, such as non-discrimination, equity, autonomy, empowerment, and accountability. ${ }^{12}$

Additionally, with well over half the clients interviewed having no or little schooling (Section 1), making them less likely to ask questions. It is particularly important for service providers at health facilities in Punjab to proactively assess their clients' need for family planning-even if they have not asked for these services-and to advise them accordingly. Failure to do so comprises an important missed opportunity to increase contraceptive use.

In the following discussion, we first assess the extent to which clients who visit for other health services, such as maternal or pediatric care, are offered family planning services. Next, we then look at how ready service providers are to provide FP services, in terms of having the relevant knowledge and training, awareness of basic client rights, and demonstrating the interpersonal skills necessary to ensure that clients know what to do, participate fully in decisions, and enjoy privacy. We also examine whether adequate information is provided to clients at the time they adopt a new method or are referred to another facility. We then look at some general aspects of facility readiness, including availability of a female provider, basic equipment, amenities and contraceptive stock, as these are linked with the capacity of facilities to provide reliable services, which is essential for ensuring safe and continued use of FP methods among clients. Following the analysis, the four study districts are compared and ranked in terms of quality of care offered.

At the end of the section, we take stock of the study's overall findings about the availability and quality of FP services to identify the key ways in which health service delivery points in Punjab are missing opportunities to serve existing and new users of contraceptives.

\footnotetext{
11 Judith Bruce Studies in Family Planning Vol. 21, No. 2 (Mar. - Apr., 1990), pp. $61-91$

12 Kumar, Jan and Karen Hardee. 2015. “Rights-Based Family Planning: 10 Resources to Guide Programming," Resource Guide. Washington, DC: Population Council, The Evidence Project
} 


\section{Offering FP Services to Eligible Clients Who Don't Ask}

Of the total 1,379 clients who were interviewed at health facilities, 1,230-i.e., 89 percent-had come to the facility for needs other than family planning. All of these clients were currently married and of reproductive age. ${ }^{13}$

When they were asked whether the service provider they consulted had raised the subject of family planning with them, 87 percent of these clients said their family planning needs were not discussed or assessed. As the numbers of clients in Figure 5.1 indicate, this signifies a huge missed opportunity.

Figure 5.1: Opportunity Missed Because Providers not Offering FP Counseling/Services to Clients Who don't Ask

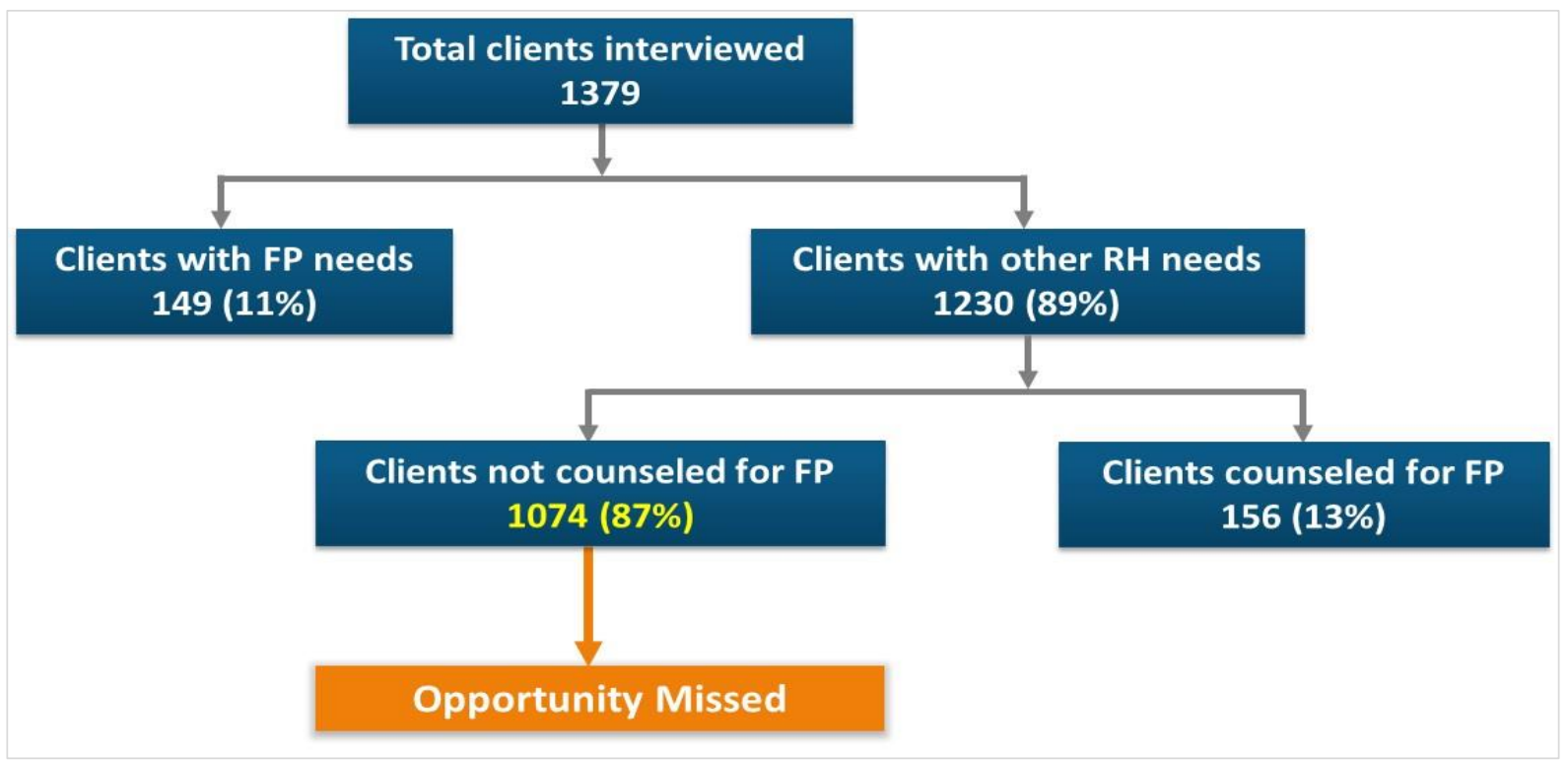

Source: HFA

Of these clients, 638 were interviewed at public health facilities and 592 at private facilities. As shown in Figure 5.2, overall, 84 percent of public providers and 91 percent of private providers did not discuss family planning with clients who visited for needs other than FP. The figure also shows that there is not much difference in the performance of the various cadres in this regard, except that relatively lower proportions of FWWs/FWCs are omitting to inquire about family planning needs. Given that family planning is the core mandate of the PWD cadres and they are expected to counsel all clients in this regard, the fact that only 63 percent are not asking about family planning needs is surprising.

\footnotetext{
13 In total, 1,354 female and 25 male clients were interviewed, of whom 1,207 female and 23 male clients were at the facility for services other than family planning.
} 
Figure 5.2: Proportion of Providers Who Do Not Discuss FP if the Client Comes for Other Needs, by Cadre and Sector, $\%(n=$ public $=638$, private $=592)$

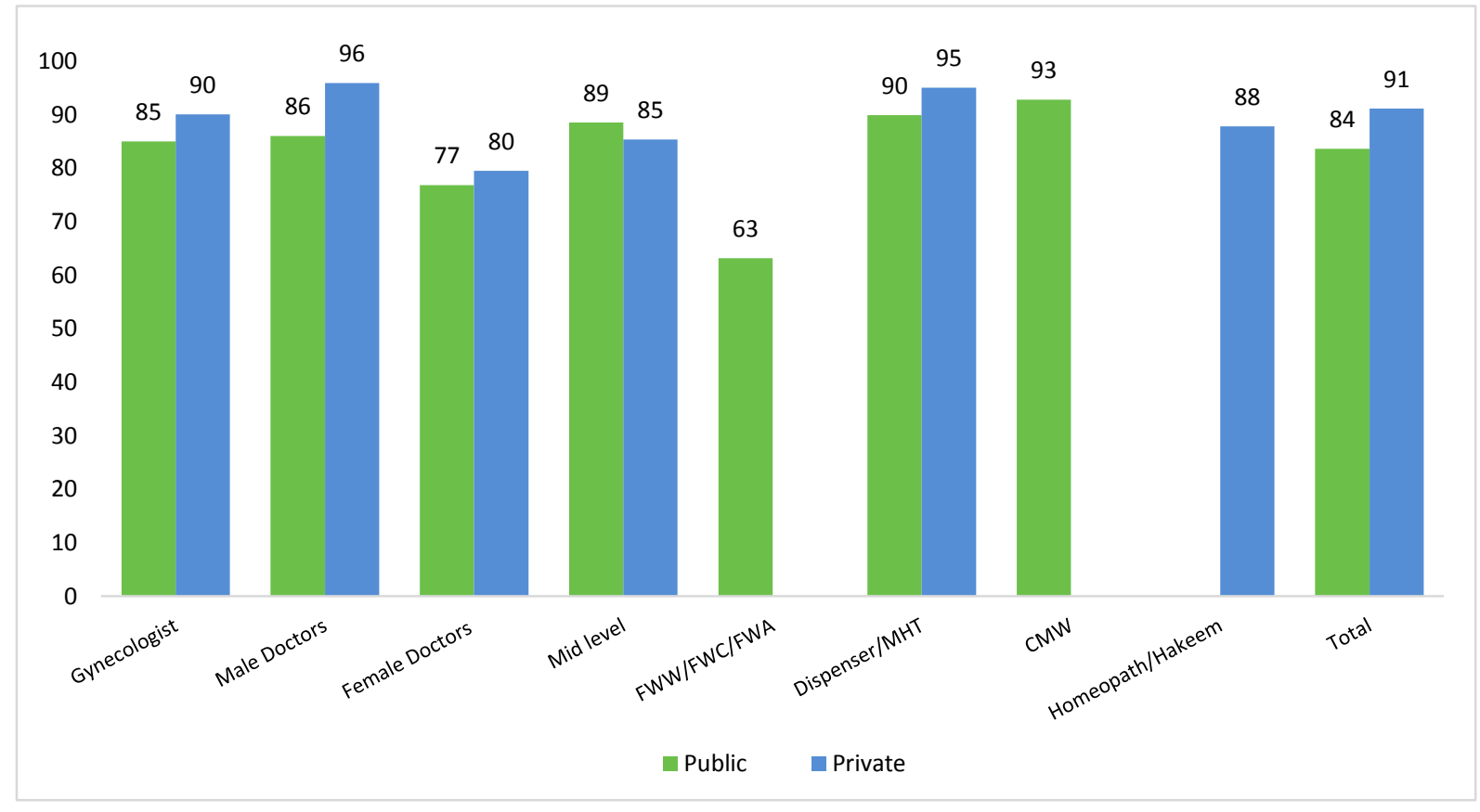

Source: HFA

\section{Capacity of Service Providers}

The capacity of service providers to provide quality FP services was assessed in this study primarily on the basis of their technical knowledge about different contraceptive methods and the relevant training they had received, as well as their actual practices in service provision, specifically how they communicated with clients, and ensured their autonomy and privacy. We also explored whether providers provide complete necessary information to clients when they are adopting a new contraceptive method or being referred to another source for FP services. In addition, we examined providers' awareness of client rights and whether they were safeguarding these rights in their practices.

\section{Training}

To provide quality FP services, providers must be trained in contraceptive technology ${ }^{14}$, counseling, and client-centered service provision. This technical knowledge is crucial for providers to be able to propose and provide suitable methods for their clients. In addition, counseling is a necessary skill as it is the means by which a provider facilitates clients in deciding to use contraceptives and choosing the right method. The skill is also vital for allaying the fears among clients that lead to non-use, due to misinformation or misperceptions, and for supporting clients in continuing use or switching to a different method according to changing needs. These capacities must be complemented with client-centered behavior, which providers must be taught. As seen in Section 4, client's expectations from the providers of family planning services are largely related to behavior and attitude, with lesser mention of other aspects of quality.

However, the study's findings indicate that most service providers are working without the benefit of training in these areas. Figure 5.3 shows that only about one fourth (103/399) of the interviewed service providers

\footnotetext{
14 Training in contraceptive technology includes indications and contraindication of the method, its advantages and disadvantages, how to use the method, duration of use, efficacy, side effects, warning signs, and management of side effects.
} 
had received training related to family planning in the last three years. Of these, the highest proportion (71\%) were from the Population Welfare Department. Mid-level providers had the second highest proportion of recently trained professionals (43\%). Very few male providers-only three doctors and two dispensers-had been trained in this period.

\section{Figure 5.3: Proportion of Service Providers Who had Received Different Types of Training in FP within Last 3 Years, by Cadre, \% (n=399)}

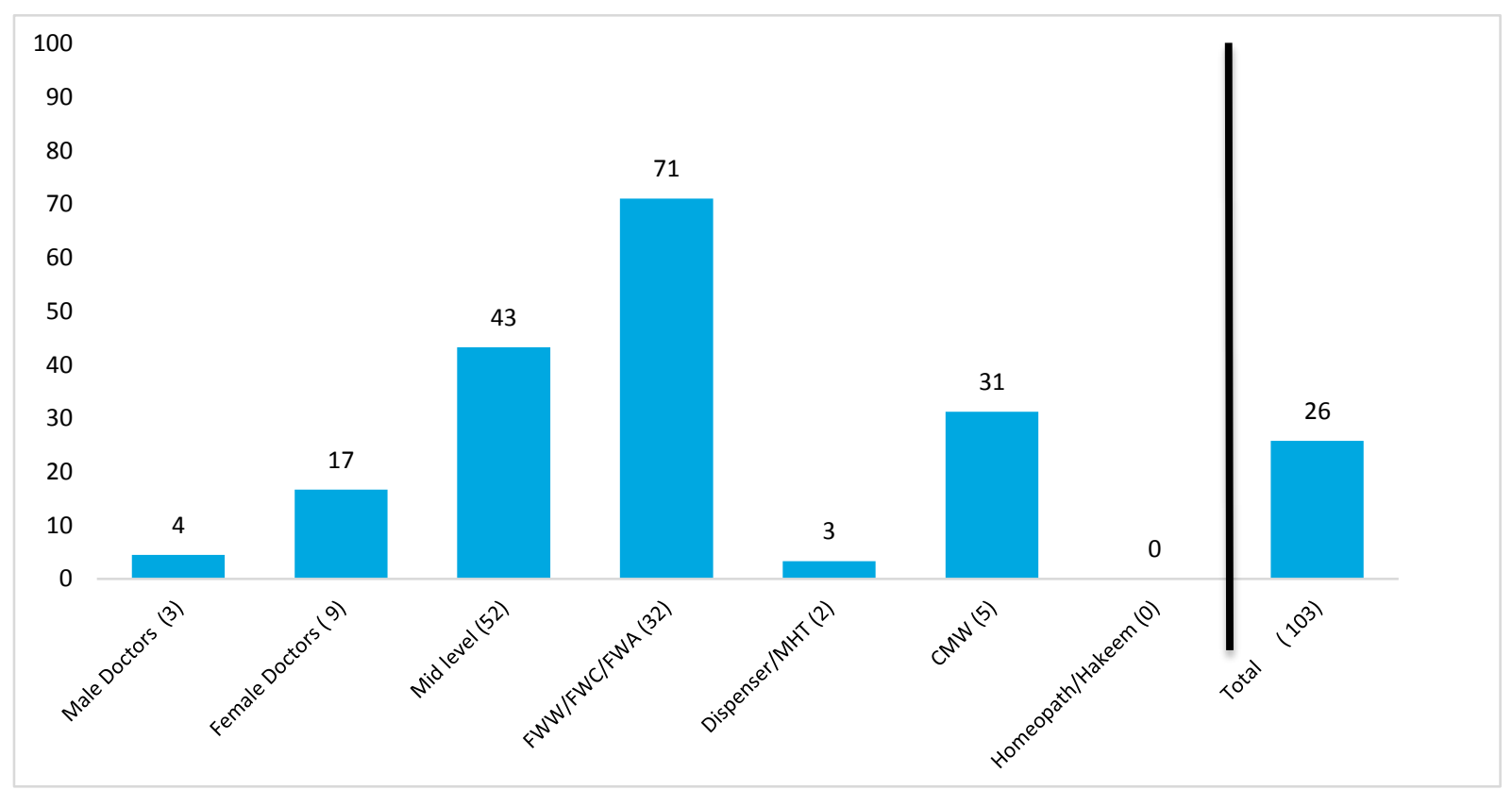

Source: HFA

\section{Type of Training Received}

The 103 providers who had received FP-related training in the past three years were asked about the nature and type of training they had received. Training in contraceptive technology was reported by only about half of the providers, mainly mid-level providers (25), FWWs (18), and (4) community midwives (CMWs). Surprisingly only three female doctors, and one male doctor had received this training. Training in IUD insertion and removal was also reported by about half of the providers, mainly mid-level providers and CMWs. Only five female doctors had received this training.

Training in counseling on FP was reported by 17 of PWD staff (i.e., FWWs and FWCs) and only 8 of mid-level female providers; none of the male or female doctors had been trained in this area. Trainings in clientcentered FP services were reported by only 3 mid-level providers, and training about the rights of clientswhich is a relatively less known concept among providers as discussed later in this section-was reported by only one female doctor and 13 percent of PWD staff (Figure 5.4). 
Figure 5.4: Number of Service Providers Who had Received Different Types of Training in FP ( $n=103)$

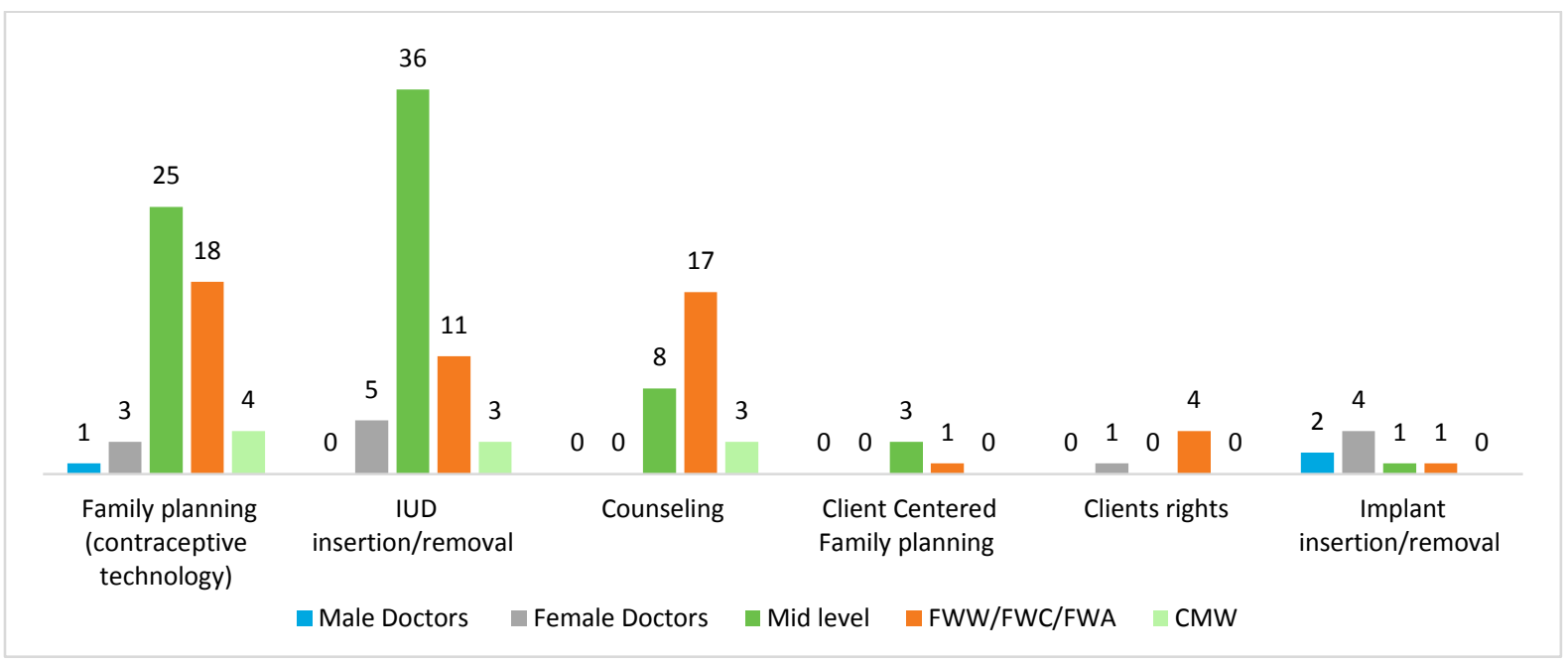

Source: HFA

\section{Knowledge about Specific Contraceptive Methods}

To assess the knowledge of providers about different contraceptive methods, they were asked a number of method-specific and general questions regarding family planning. As Table 5.1 shows, female service providers have much better knowledge about IUDs than male providers, which is expected, since this method is primarily provided by female providers. Male dispensers and hakeems/homeopaths, in particular, are neither mandated nor allowed to provide this method. However, the data show that almost all service providers, both male and female, have incorrect information regarding when the copper T380a type of IUD should be replaced, which is a serious concern. About half of the PWD staff did give the correct answer, but even this is a low score. Knowledge regarding indication of IUD in nulliparous and diabetic women is also weak across all cadres and could be a source of very strong provider bias against provision of IUDs even when clients want this method.

Table 5.1: Proportion of Service Providers who Gave Correct Answers about IUDs, \%

\begin{tabular}{lc|c|c|c|c|c|c|} 
& $\begin{array}{c}\text { Qualified } \\
\text { Gynecologist }\end{array}$ & $\begin{array}{c}\text { Male } \\
\text { doctors }\end{array}$ & $\begin{array}{c}\text { Female } \\
\text { doctors }\end{array}$ & $\begin{array}{c}\text { Mid- } \\
\text { level* }\end{array}$ & $\begin{array}{c}\text { FWW/FWC/ } \\
\text { FWA }\end{array}$ & $\begin{array}{c}\text { CMW } \\
\text { Overall } \\
\%\end{array}$ \\
\hline $\begin{array}{l}\text { Contraindication of IUD } \\
\text { Side effects of IUD }\end{array}$ & 73 & 52 & 93 & 78 & 73 & 63 & 65 \\
$\begin{array}{l}\text { Nulliparous woman can use } \\
\text { IUD }\end{array}$ & 65 & 48 & 36 & 44 & 36 & 56 & 48 \\
$\begin{array}{l}\text { Diabetic woman can use an } \\
\text { IUD }\end{array}$ & 55 & 46 & 57 & 38 & 38 & 19 & 41 \\
$\begin{array}{l}\text { When copper T380a need to } \\
\text { be replaced }\end{array}$ & 15 & 7 & 7 & 18 & 51 & 13 & 17 \\
\hline \begin{tabular}{l} 
Overall n \\
\hline
\end{tabular}
\end{tabular}

Source: HFA

*Mid-level Providers = including LHV, Nurse, Midwife

With regard to oral pills and emergency contraceptive pills, Table 5.2 shows that, overall, more female than male service providers gave correct answers. Most gynecologists (more than $75 \%$ ) had good knowledge of contraindications and indications of oral pills except for use of progestin-only pills by breastfeeding women, where a very low proportion gave the correct answer. Surprisingly, about 50 percent of male doctors had 
correct knowledge of pill use by breastfeeding women. However, knowledge about emergency contraception was generally low among all cadres except gynecologists (63\%).

Table 5.2: Proportion of Service Providers Who Gave Correct Answers about Oral Pills, \%

\begin{tabular}{|c|c|c|c|c|c|c|c|}
\hline & $\begin{array}{c}\text { Qualified } \\
\text { Gynecologist }\end{array}$ & $\begin{array}{c}\text { Male } \\
\text { doctors }\end{array}$ & $\begin{array}{l}\text { Female } \\
\text { doctors }\end{array}$ & Mid level & $\begin{array}{c}\text { FWW/ } \\
\text { FWC/FWA }\end{array}$ & CMW & $\begin{array}{c}\text { Overall } \\
\%\end{array}$ \\
\hline $\begin{array}{l}\text { Contraindication of } \\
\text { oral pills }\end{array}$ & 83 & 61 & 71 & 76 & 62 & 75 & 71 \\
\hline $\begin{array}{l}\text { Nulliparous } \\
\text { women can take } \\
\text { oral pills }\end{array}$ & 78 & 51 & 64 & 58 & 49 & 56 & 58 \\
\hline $\begin{array}{l}\text { Breastfeeding } \\
\text { woman can take } \\
\text { progestin-only pills }\end{array}$ & 8 & 48 & 43 & 34 & 16 & 38 & 31 \\
\hline $\begin{array}{l}\text { Progestin-only pills } \\
\text { can be used as } \\
\text { emergency } \\
\text { contraception }\end{array}$ & 80 & 46 & 71 & 57 & 69 & 44 & 59 \\
\hline $\begin{array}{l}\text { True about } \\
\text { emergency } \\
\text { contraception }\end{array}$ & 63 & 28 & 36 & 36 & 27 & 31 & 36 \\
\hline Overall $n$ & 40 & 67 & 14 & 120 & 45 & 16 & 302 \\
\hline
\end{tabular}

Source: HFA

Five main questions were asked to test service providers' knowledge about injectables, as listed in Table 5.3. Overall, female providers had better knowledge than male providers. Among them, more mid-level and PWD providers had correct information regarding all five questions. Over 80 percent of providers, including even dispensers and homeopaths/hakeems, were aware that the needle of used syringes should be bent to prevent reuse. However, there is clearly a great need to improve providers' knowledge about indication of injectables, infection prevention practices, and management of side effects.

Table 5.3: Proportion of Service Providers Who Gave Correct Answers about Injectables, \%

\begin{tabular}{|c|c|c|c|c|c|c|c|}
\hline & $\begin{array}{c}\text { Qualified } \\
\text { Gynecologist }\end{array}$ & $\begin{array}{c}\text { Male } \\
\text { doctors }\end{array}$ & $\begin{array}{l}\text { Female } \\
\text { doctors }\end{array}$ & $\begin{array}{l}\text { Mid } \\
\text { level }\end{array}$ & $\begin{array}{c}\text { FWW/FWC } \\
\text { /FWA }\end{array}$ & CMW & $\begin{array}{l}\text { Overall } \\
\%\end{array}$ \\
\hline $\begin{array}{l}\text { Injection Norigest needed for } \\
\text { continuous protection from } \\
\text { pregnancy }\end{array}$ & 33 & 33 & 29 & 57 & 60 & 44 & 47 \\
\hline $\begin{array}{l}\text { Always bend needle of } \\
\text { disposable syringe to prevent } \\
\text { reuse }\end{array}$ & 88 & 87 & 86 & 83 & 89 & 94 & 86 \\
\hline $\begin{array}{l}\text { Decontaminate the needle and } \\
\text { syringe before destroying in } \\
\text { destruclip }\end{array}$ & 38 & 40 & 43 & 64 & 51 & 50 & 52 \\
\hline $\begin{array}{l}\text { Effective strength } \\
\text { decontamination is } 0.1 \% \\
\text { Chlorine }\end{array}$ & 83 & 63 & 71 & 51 & 73 & 31 & 61 \\
\hline $\begin{array}{l}\text { Injection depo-provera, Client } \\
\text { comes one week later than } \\
\text { schedule, second injection can } \\
\text { be given }\end{array}$ & 80 & 60 & 64 & 69 & 76 & 69 & 69 \\
\hline Overall $n$ & 40 & 67 & 14 & 120 & 45 & 16 & 302 \\
\hline
\end{tabular}

Source: HFA 
Surprisingly, there was no difference in knowledge levels of public and private providers for all the above mentioned contraceptive methods (data not shown).

From the above data, it can be concluded that no cadre of providers has complete correct knowledge about any contraceptive method. This is a serious gap which implies that most providers do not have the capacity to accurately and comprehensively counsel their clients in safely adopting an appropriate method. The knowledge gaps also indicate low capacity among service providers to manage any side effects experienced by clients in using specific methods, or to counsel clients faced with this difficulty, which may be contributing to discontinuation of contraceptive use.

Moreover, gaps in providers' knowledge are also likely to lead to biases in method provision, and this is confirmed by findings from FGDs: at times, clients voluntarily choose and ask for a method, but are denied that method by the provider because of the latter's misconception that it is unsuitable.

"I had 3 children and I was not working at that time. I started stitching to cope with my financial circumstances. My condition was not good and it was difficult to manage more children. I used many methods before my third pregnancy but failed. After my third child, finally, I decided to have an operation (sterilization) but the service providers refused to operate, saying that they don't operate on women of 27 years and that they only operate after a woman has four children. They said, if your husband divorced you in the future and took custody of your children too, what would you do? I said I did not think this would happen but they did not agree, and I left without taking any method". FGD, Urban women, Faisalabad

"I decided to use Norplant for 5 to 10 years of birth spacing after the birth of my third child on the advice of a lady doctor. I went to get the implant to the family health center. The female service provider told me that it was very expensive, and also that once the implant was inserted, I would not be able to have it removed before its expiry, even if I experienced side effects. I said I wanted a permanent method, but the service provider discouraged me with various undesirable scenarios. Then I decided to use withdrawal for birth spacing." FGD, Urban women, Faisalabad

\section{Awareness of Client Rights}

Observance of patients' rights is part of ensuring high quality health care, and contributes to more effective treatment as well as client satisfaction. Although the precise delineations of client rights vary in different contexts, all descriptions include the following basic rights:

- To be treated with respect, consideration and dignity, and without discrimination

- To privacy and confidentiality

- To be informed about all the services available at the center

- To be entitled to make voluntary use of services

- To receive accurate information

- To ask about reasonable alternatives to care at outside facilities

- To receive services that comply with appropriate standards of professionalism, competency and accountability

- To receive a second professional opinion regarding care and treatment 
- To be given a full explanation or information on any research that the client may be requested to participate in

- To receive a copy of own medical record upon request and written authorization

- To file a complaint with the facility management regarding any concerns related to privacy, confidentiality, or security of medical records.

All interviewed service providers were asked whether they were aware of the basic rights of clients when seeking health or FP services. Although the majority in all districts reported they had heard of client rights, especially in Rawalpindi and Faisalabad, much lower proportions were able to support this claim by listing any specific client right when asked. The discrepancy between providers' perception of their knowledge of client rights and their actual knowledge of these rights is illustrated in Figure 5.5.

\section{Figure 5.5: Proportion of Service Providers Who Reported Awareness of Client Rights (n=399) and Those among} Them Who Identified at Least One Specific Client Right, \% $(n=304)$, by District

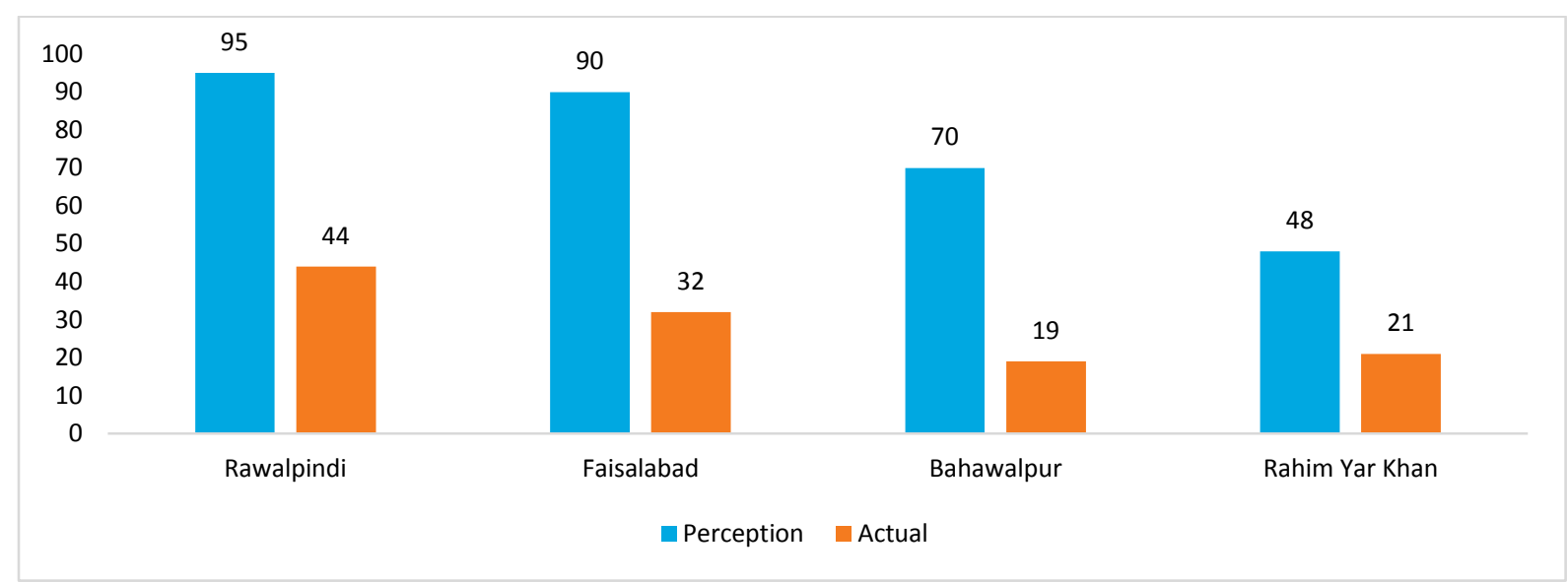

Source: HFA

\section{Interpersonal Interaction with Clients}

Providers' practices, specifically interpersonal interactions with clients, were probed with a focus on 12 elements related to how they communicated with clients and assured their autonomy and privacy during consultations.

The practices related to communication, autonomy and privacy, listed in Table 5.4, were examined from three perspectives-reports of service providers, reports of clients at health facilities, and observations of clientprovider interactions at health facilities.

As shown in Table 5.4, consistently high proportions of service providers report observing the 12 practices while observations of the study team and interviews with clients indicate a number of gaps. The gaps are particularly large in the case of some practices, such as asking the client to repeat the instructions provided, asking for the client's permission before examination, and giving a date for follow-up. 
Table 5.4: Proportion of Service Providers Who Observe Specific Elements of Counseling, by Type of Respondent, \% ( $n=125$ service providers, 195 observations, 195 clients)

\begin{tabular}{|c|c|c|c|}
\hline & Services provider & Observer & Client \\
\hline & $\%$ & $\%$ & $\%$ \\
\hline \multicolumn{4}{|l|}{ Communication } \\
\hline Treat with respect & 100 & 99 & 98 \\
\hline Listen carefully & 100 & 96 & 96 \\
\hline Explain things in a way understand & 100 & 90 & 95 \\
\hline Give sufficient time to discuss & 99 & 88 & 92 \\
\hline Give time to questions about the health problems/ treatment & 98 & 79 & 85 \\
\hline Give a date for a follow-up visit & 98 & 57 & 48 \\
\hline Reassure could return any time & 95 & 63 & 0 \\
\hline Ask to repeat instructions & 86 & 20 & 14 \\
\hline \multicolumn{4}{|l|}{ Autonomy } \\
\hline Involve deciding about FP method & 98 & 83 & 86 \\
\hline Ask permission before starting the examination & 91 & 40 & 19 \\
\hline \multicolumn{4}{|l|}{ Privacy } \\
\hline Physically examine and treat in a way privacy was respected & 99 & 95 & 87 \\
\hline Talk with the client in privacy & 100 & 85 & 68 \\
\hline
\end{tabular}

Source: HFA

\section{Communication}

In the context of communication practices, almost all service providers (more than 90 percent) reported that they assured their clients that they could return any time if they had any problem, but interviewers observed that only 67 percent of the doctors, FWWs and FWCs and lower proportions of other mid-level providers observed this practice, as shown in Figure 5.6. (This question was not asked of clients.)

Figure 5.6: Proportion of Providers Who Reassure Clients that They can Return Anytime as Reported by Cadres of Service Providers and by Observers, \% (n=125 service providers, 195 Observations)

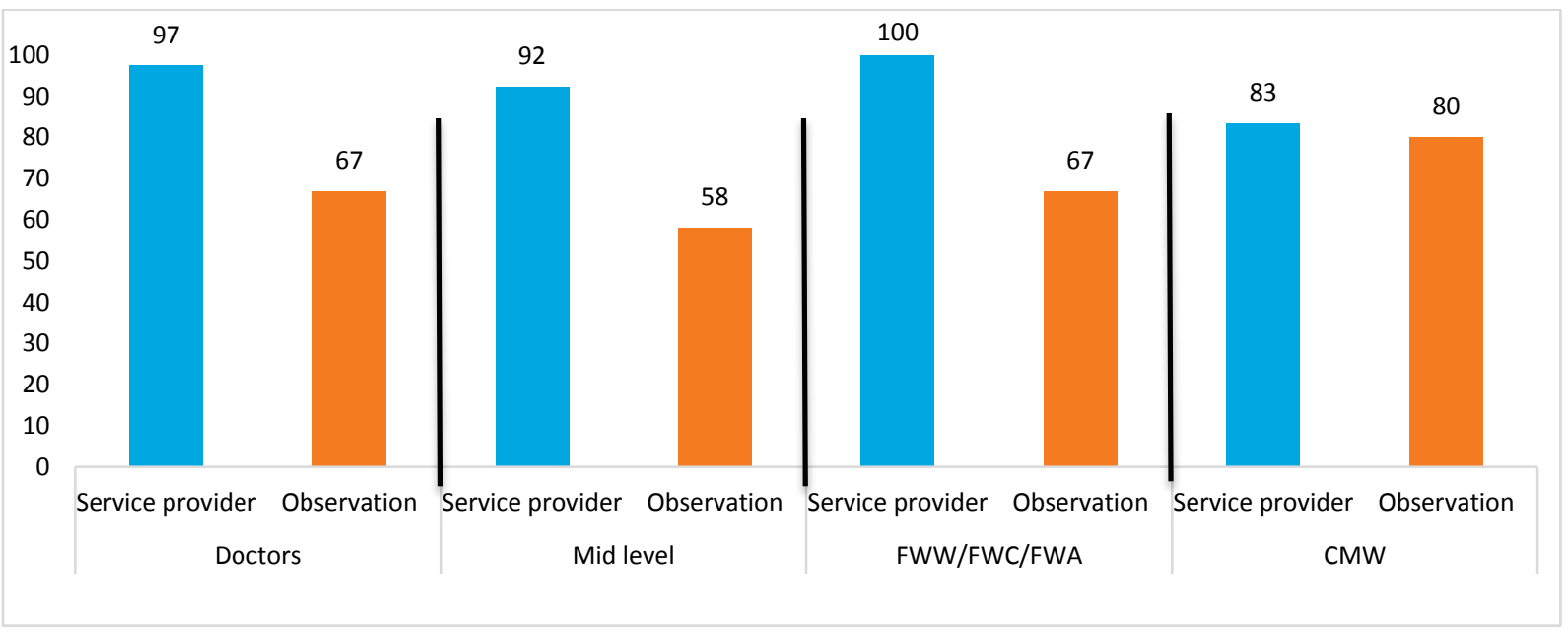

Source: HFA

Giving clients a date for a follow-up visit is very important, especially for ensuring that clients receive timely doses of hormonal methods so that protection is maintained. Yet, as Figure 5.7 shows, although the majority of providers said they give clients a follow-up date, only about two thirds of interviewers and about 50 percent of clients confirmed this. The contrast between client and provider perspectives was greatest in the case of CMWs. 
Figure 5.7: Proportion of Service Providers Who Give a Follow-Up Date as Reported by Cadres of Service Providers, Observers, and Clients, \% ( $\mathrm{n}=125$ service providers, 195 clients)

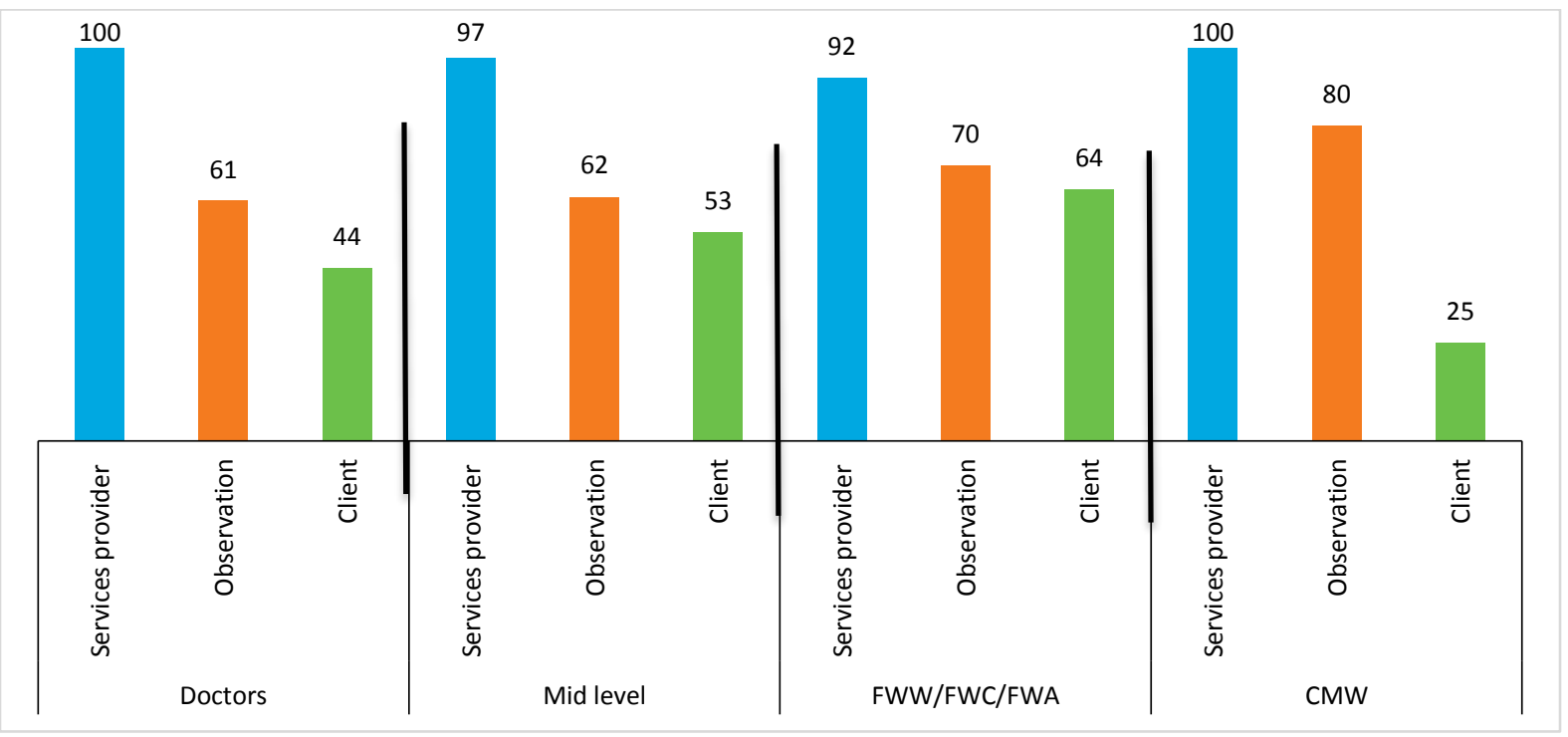

Source: HFA

It is essential that providers ask clients to repeat the instructions given to them to ensure that they have understood. Again, Figure 5.8 shows a large gap between the reports of providers, observers, and clients in this matter. About 85 percent of all cadres of providers reported that they asked their clients to repeat their instructions; in stark contrast, only about a quarter of clients (except those visiting doctors) and observers reported this was the case. Notably, observations and clients' reports are more in concurrence.

Figure 5.8: Proportion of Service Providers Who Ask Clients to Repeat Instructions as Reported by Cadres of Service Providers, Observers, and Clients, \% ( $n=125$ service providers, 195 clients)

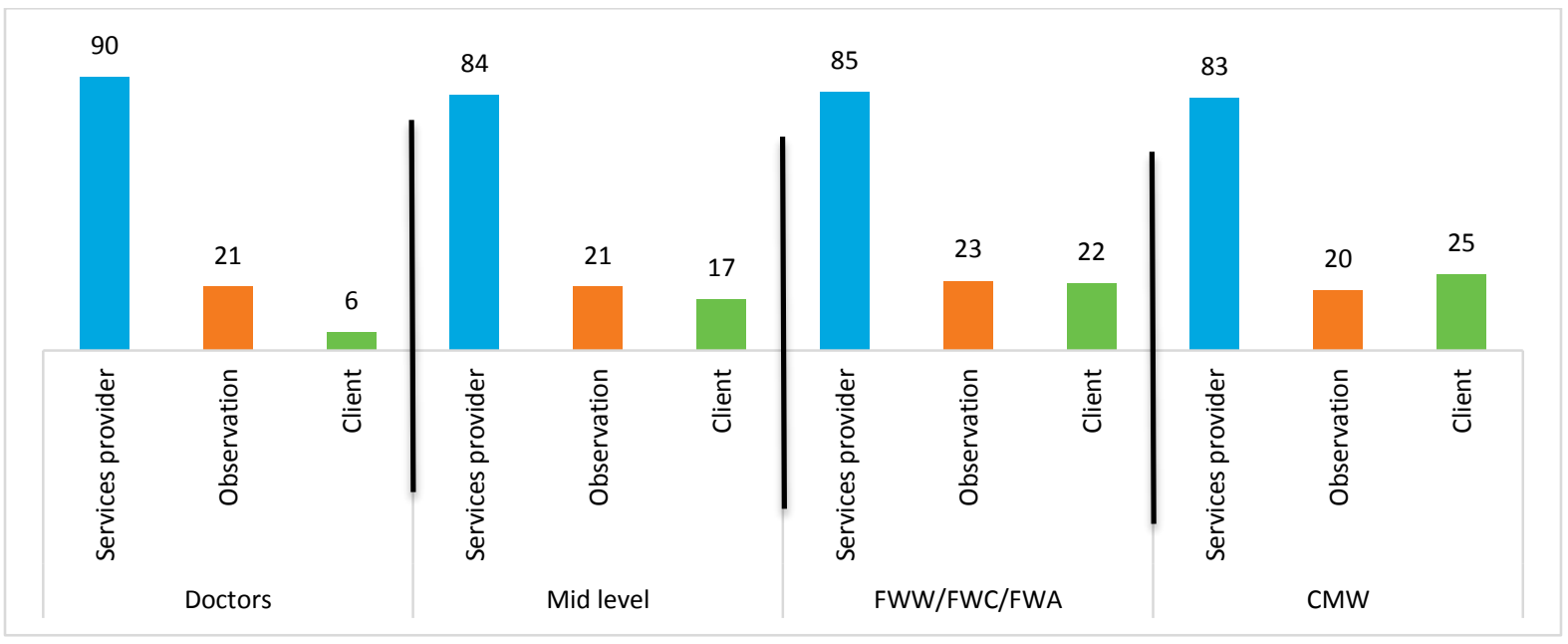

Source: HFA

Findings from FGDs provide further perspectives of men and women regarding the communication practices of service providers. The majority of people who participated in the discussions were visiting public facilities for family planning. Their major concerns were the attitudes of the service providers and the long time they had to wait before they were served. Participants complained that service providers do not listen deeply enough to their patients. 
"A patient feels better simply if a doctor talks to him or her in a good way. If a patient goes to a government facility, he can't even talk with the doctor properly. If he can't do even that, how can he trust him? Doctors should listen to patients. They don't listen. That's why people go to private facilities." FGD Urban men, Faisalabad

A majority of the respondents also observed that service providers at public facilities seemed to be overburdened, and were less attentive and at times even rude to clients.

"Another issue in the government hospital is that doctors get fed up after continuous duties and hard work and they become butchers." FGD Urban women, Rahim Yar Khan

"Doctors often misbehave with patients in government centers but not in private clinics. It should not be like this because if a woman visits, she does so due to some problem. They should not misbehave with her." FGD Urban women, Bahawalpur

Providers' ability to communicate well affects the effectiveness of their interactions with clients, especially whether their clients can trust them and discuss their problems freely. The above community perceptions indicate that while service providers communicate respectfully with clients in the private sector, this is often not the case in the public sector. Notably, data collected at health facilities shows no difference in the attitudes of public and private providers. This could be because the presence of an observer at the time of client-provider interaction influenced providers' behaviors and the question asked was for the day of the visit, while FGD respondents were giving their general opinion about public and private providers.

\section{Client's Autonomy and Privacy}

One of the most important and basic principles in providing family planning services is to involve the client in decision making regarding whether to use a contraceptive method and which one. The client should be enabled to make a voluntary and informed choice, both as a principle and to ensure satisfaction. For this, clients must be offered different options, and through discussion and mutual agreement, a suitable method should be selected based on their choice.

Almost all service providers interviewed in this study reported that they involve their clients in decision making. Clients also confirmed this, especially concerning CMWs and FWWs/FWCs (97 percent; data not shown). However, observations of provider-client interactions indicate that, while 90 percent of FWWs/FWCs do discuss options with clients, relatively fewer providers of other cadres are ensuring their clients' autonomy in this matter ( $71 \%$ of doctors and $76 \%$ of midlevel providers). Clients' relatively high satisfaction in this respect may be because they are not fully aware of their right to free and informed choice and depend on the provider to choose the method for them.

The principles of autonomy and privacy also demand that certain protocols be followed by the provider when conducting a physical examination of a client. Before conducting the examination, permission should be sought from the client and the procedure explained sufficiently for the client to know what to expect. After the examination, the client should be informed of the results of the check-up. During the interviews, respondents were asked whether the provider asked for clients' permission before examining them. As shown in Figure 5.9, more than 90 percent of providers responded in the affirmative. However, observation data tell a different story: less than 50 percent providers asked for permission among most cadres except for FWWs/FWCs, where the proportion was only slightly higher. Only a few of the clients agreed that providers requested their permission before examining them. 
Figure 5.9: Proportion of Service Providers Who ASK for Clients' Permission before Conducting Physical Examinations as Reported by Cadres of Providers, Observers, and Clients, \% ( $n=125$ service providers, 195 clients)

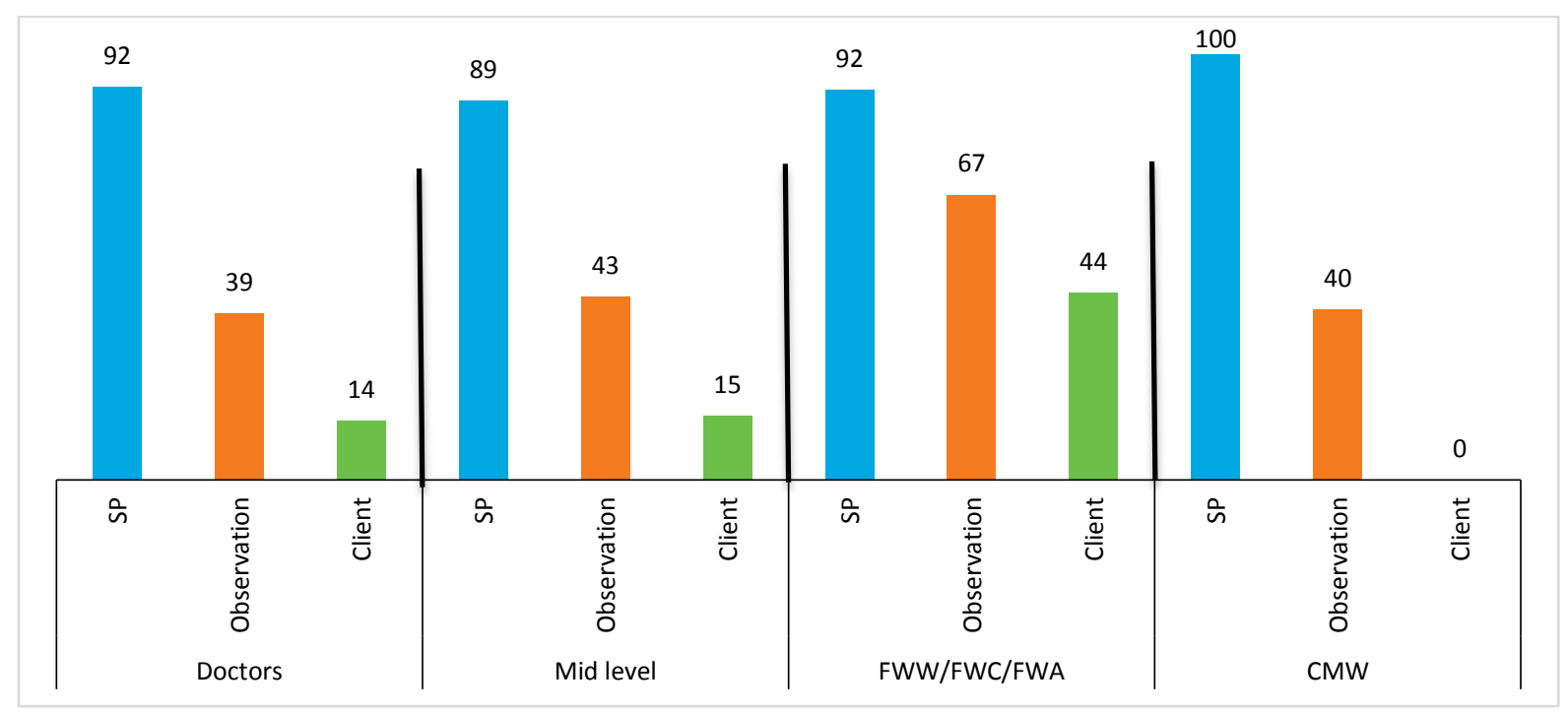

Source: HFA

Ensuring privacy while talking to a client or examining them is a key element in family planning service delivery and one of the important rights of the client. All service providers reported that they maintain privacy during examinations. Almost all clients and about 90 percent of observers confirmed this, as shown in Table 5.5 above. All providers also said they ensured privacy during consultations and observation data also confirms this in about 80 percent of cases, but only two thirds of clients agreed with the statement.

\section{Adequacy of Information Provided to Clients}

Provision of inadequate information to clients is in some ways tantamount to missing an opportunity to recruit or retain FP users. A client who does not receive adequate information about the method she adopts would be vulnerable to method failure as well as shock from unexpected side effects, and may lose the motivation to continue to obtain FP services. Similarly, clients who are referred to other facilities for services must be provided sufficient information and documentation to be able to go there. This is particularly important for poorer and less educated clients, who may have less access to other sources of information and can least afford to lose resources in unsuccessful attempts to reach the referred services.

\section{Method-Specific Details}

An important element of quality of FP services is that clients be provided comprehensible and adequate information about contraceptive methods, especially the method they have selected for use. Figure 5.10 shows the types of information that should be provided, and the proportions of providers and clients interviewed who reported that the what information is being provided. Most of the providers report giving information regarding the pros and cons of the method (73\%) and duration of use (61\%). However, very few providers inform clients about all the other important aspects about selected methods, such as how to use them, how effective they are, and what possible side effects can be expected. Moreover, the data show considerable differences in the responses of service providers and of clients for most components, underscoring the need for providers to ask clients to repeat instructions as a routine communication practice. The findings show that very few clients know how to use the method they have selected, how often it needs to be used, how effective it will be, what the side effects might be and how they are to be managed or when 
to return to the provider for a follow-up visit. It is likely that these omissions have a strong negative effect on clients' ability to use the methods safely, effectively, and on a sustained basis. Inadequate information provision could be contributing to the current high discontinuation rate.

\section{Figure 5.10: Proportion of Providers and Clients Reporting that Specific Information was Provided about the FP Method Selected by the Client, \% ( $n=399$ service providers, 416 clients)}

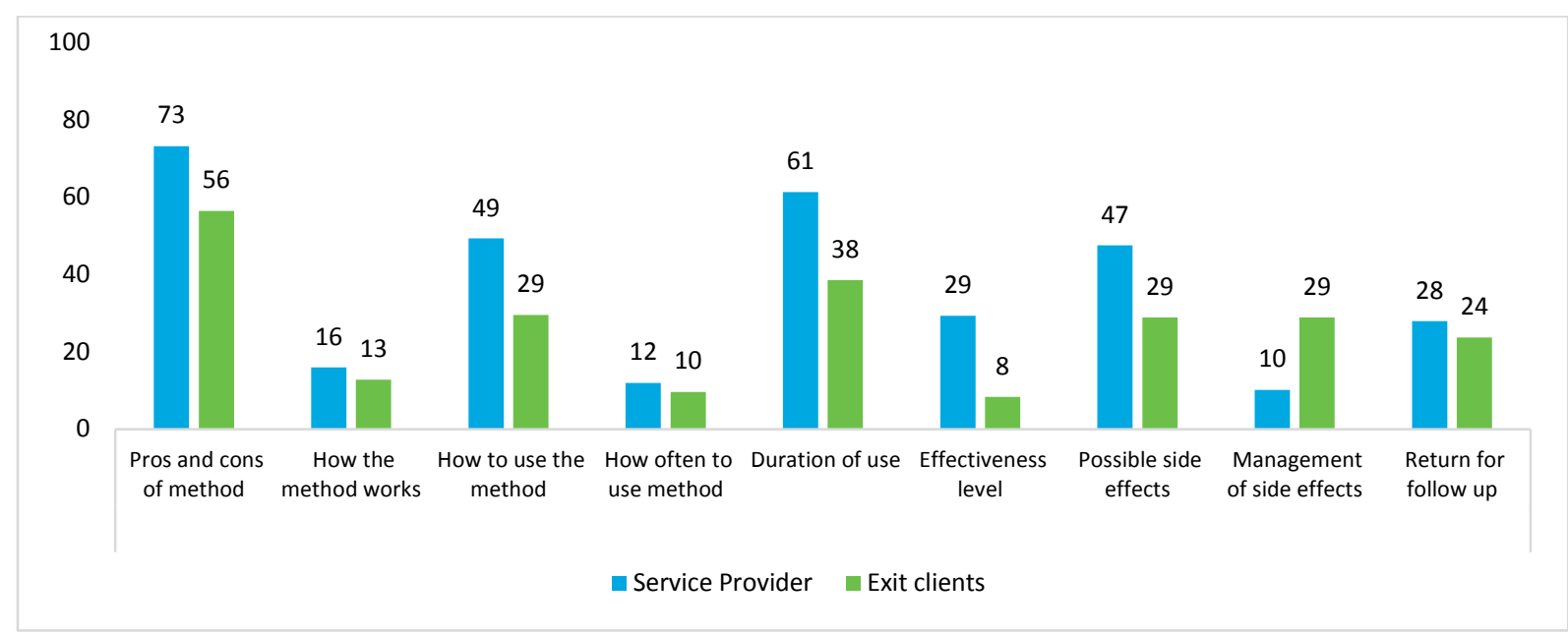

Source: HFA

\section{Referral}

Referral is an integral part of a health system-when the services required by a client are not available at a facility, it should ensure timely referral of the client to an appropriate facility where those services can be accessed. However, to ensure that the client reaches the referral facility, she needs specific information such as its location and timings, what mode of transportation is available to reach it, travel cost and time, and expected expenses for fees and medicines, as well as a referral slip. This is especially important where clients are less educated or poor, and do not have access to online sources of information.

During the study, two questions were asked about referral, specifically, whether providers refer clients to other facilities, and if so, what specific information is provided to clients when they are referred. Overall, 82 percent of service providers said they do refer clients for different reproductive health needs, including family planning, when they do not have the method requested by the client.

Figure 5.11 shows that slightly more than half of the service providers give information to clients regarding the location and address of the referral facility and 54 percent are also providing a referral slip. However, fewer than 20 percent of service providers are providing the other information listed in the figure. There are no differences in the practices of public and private sector providers in this respect (data not shown). 


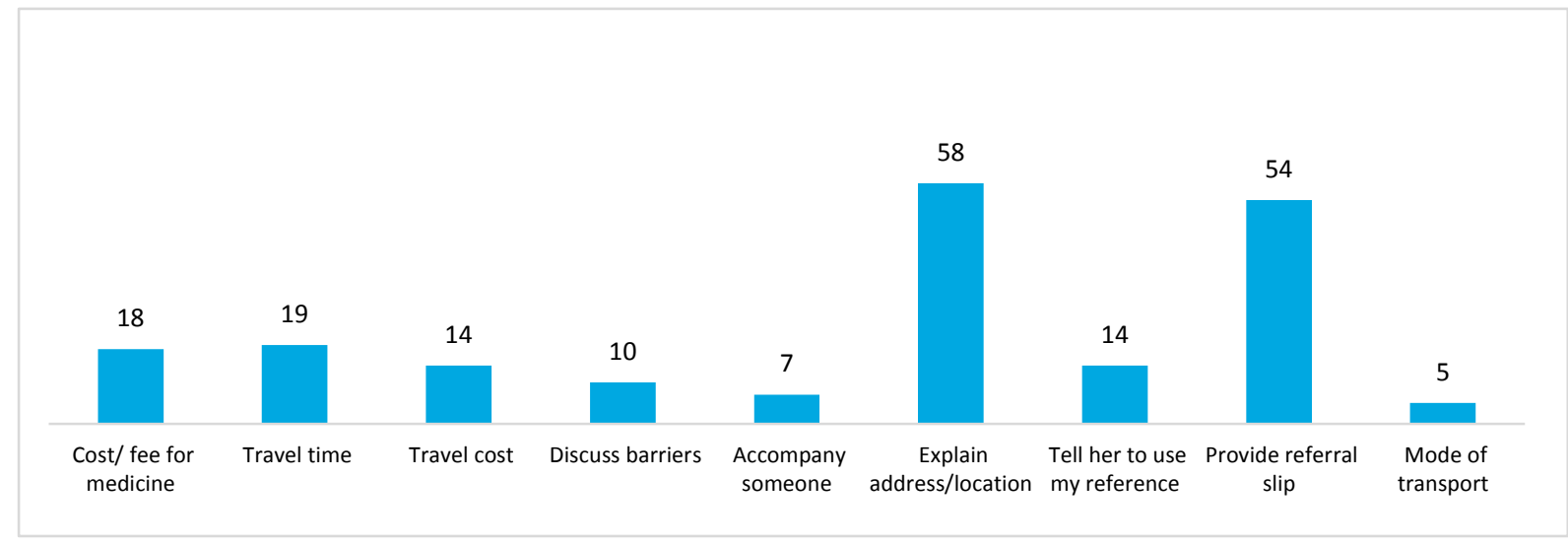

Source: HFA

The fact that clients are being sent home with incomplete information reflects a crucial gap in the knowledge and practices of service providers, which could be contributing to the prevailing high levels of discontinuation.

Overall, this study's findings about the training, knowledge, and practices of service providers indicate that there is a great need to improve their capacities to provide quality family planning services. The fact that only 26 percent of providers have been imparted any related training within the last three years is a serious issue that must be addressed.

\section{General Readiness of Health Facilities}

Aside from the capacity and practices of service providers, and the availability of specific FP methods, the quality of health services is also affected readiness of health facilities. In this study, the readiness of health facilities within the 16 clusters for providing FP services was assessed in terms of the availability of female staff, IUD insertion kits, infection prevention measures, general equipment, privacy measures and contraceptive stocks, as outlined below. The data on readiness of health facilities is for 323 health facilities excluding dispenser, homeopath and hakeem clinics

\section{Availability of Female Staff}

If a health facility is providing family planning services, the presence of a female service provider is very important. As mentioned in Section 4, over 70 percent of interviewed clients as well as household survey respondents prefer that family planning services be provided by female service providers; the non-availability of female providers at a health facility would thus be a major barrier in accessing FP services. Moreover, female providers should ideally be available in both the morning and the evening, as this extends the effective working time of a facility and is necessary for those who cannot avail services in the morning, such as women who must wait for their husbands to get off from work to accompany them to a distant health center.

Table 5.5 shows that in teaching hospitals, DHQ, THQs and in RHCs, a female service provider is available in both the morning and the evening shift. About 80 percent of BHUs have a female provider available in the morning shift and 43 percent in the evening shift, although most of the BHUs are not mandated to function round-the-clock. The PWD facilities are also not mandated to be open in the evening; in the morning shift, 100 percent of RHSC-A Centers and 97 percent of FWCs have a female provider present. 
Table 5.5: Availability of At Least One Female Provider in the Morning and Evening Shift, by Type of Facility

\begin{tabular}{|c|c|c|c|}
\hline & 8 am to 2 pm & 2 to $8 \mathrm{pm}$ & Total \\
\hline & $\%$ & $\%$ & $n$ \\
\hline \multicolumn{4}{|l|}{ Public sector } \\
\hline Teaching hospital & 100 & 100 & 3 \\
\hline $\mathrm{DHQ}$ & 100 & 100 & 4 \\
\hline THQ & 100 & 100 & 14 \\
\hline $\mathrm{RHC}$ & 100 & 100 & 13 \\
\hline $\mathrm{BHU}$ & 80 & 43 & 30 \\
\hline $\begin{array}{l}\text { MCH center/Govt. } \\
\text { dispensary }\end{array}$ & 33 & NA & 15 \\
\hline RHSC-A/FHC & 100 & NA & 8 \\
\hline FWC & 97 & NA & 39 \\
\hline \multicolumn{4}{|l|}{ Private sector } \\
\hline Community midwife clinic & 65 & 55 & 20 \\
\hline Private hospital & 65 & 48 & 40 \\
\hline Doctor's clinic & 29 & 25 & 72 \\
\hline Nurse clinic/LHV clinic & 61 & 64 & 44 \\
\hline Maternity home & 33 & 33 & 3 \\
\hline NGO clinic & 83 & 56 & 18 \\
\hline Total & 53 & 33 & 323 \\
\hline
\end{tabular}

Source: HFA

District level data, presented in Figure 5.12, shows that almost all DoH facilities have at least one female provider present in the morning shift in Rawalpindi and Faisalabad, whereas 78 percent of facilities in Rawalpindi and 55 percent in Faisalabad have a female provider present in the evening. However, only 50 percent of DoH facilities in Bahawalpur and Rahim Yar Khan have at least one female provider present in both the morning and the evening shift. The situation of the private sector in Rawalpindi and Faisalabad is better-about two thirds of facilities have a female provider in both shifts-compared to Bahawalpur and Rahim Yar Khan, where only about a fourth of facilities have a female provider in both shifts.

Figure 5.12: Proportion of Facilities with At Least One Female Provider Present in Morning and Evening Shift, by Sector and District, \%

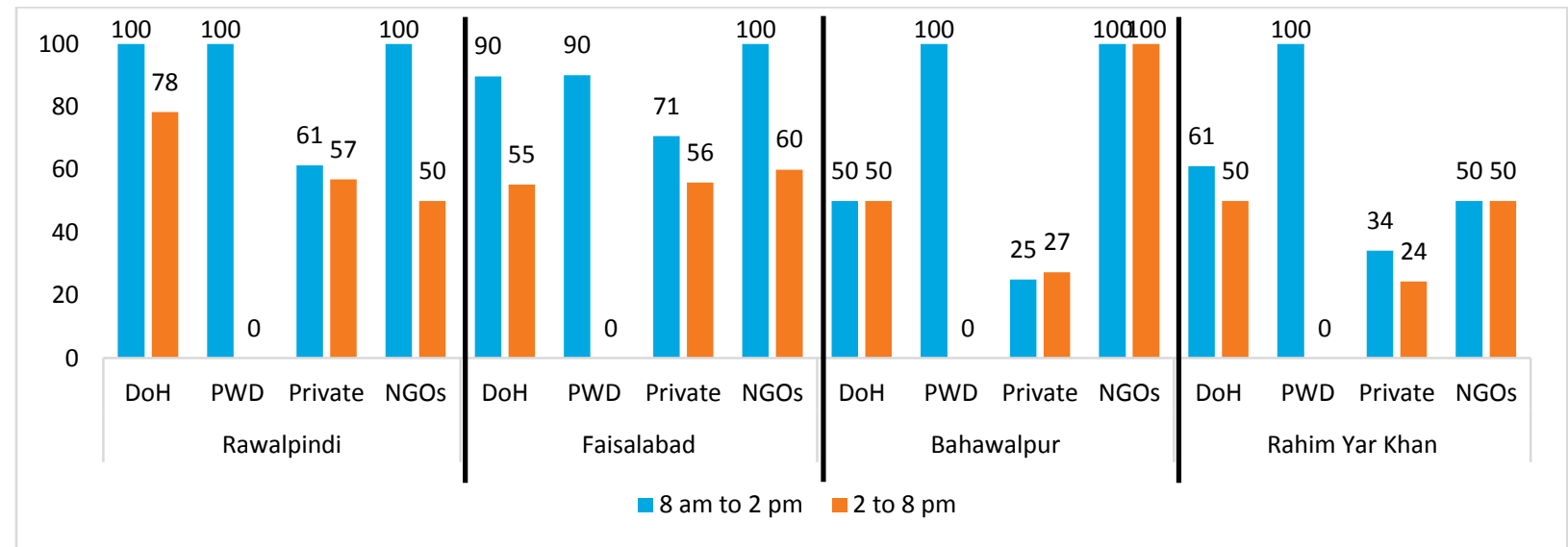

Source: HFA 


\section{Availability of IUD Insertion Kits}

Proper IUD insertion requires a complete IUD kit, including an examination lamp on a stand, straight dressing scissors, a vaginal speculum, vulsellum forcep, uterine sound, sponge-holding forceps, bowls, tenaculum, kidney tray, and sterilizers. Where a family planning services facility does not have the complete kit, it should at the very least have the "essential" kit, consisting of the seven of the above-listed items (i.e., all the above except bowls, a tenaculum, and a kidney tray).

However, Figure 5.13 shows that only 20 percent of public health facilities and a mere 15 percent of private health facilities have a complete IUD kit. Moreover, one fourth of public facilities and 51 percent of private facilities do not have a complete or essential kit, which is a worrying situation.

\section{Figure 5.13: Availability of Functional Essential and Complete IUD Insertion Kits at Public and Private Health} Facilities, \% ( $n=142$ public facilities, 181 private facilities)

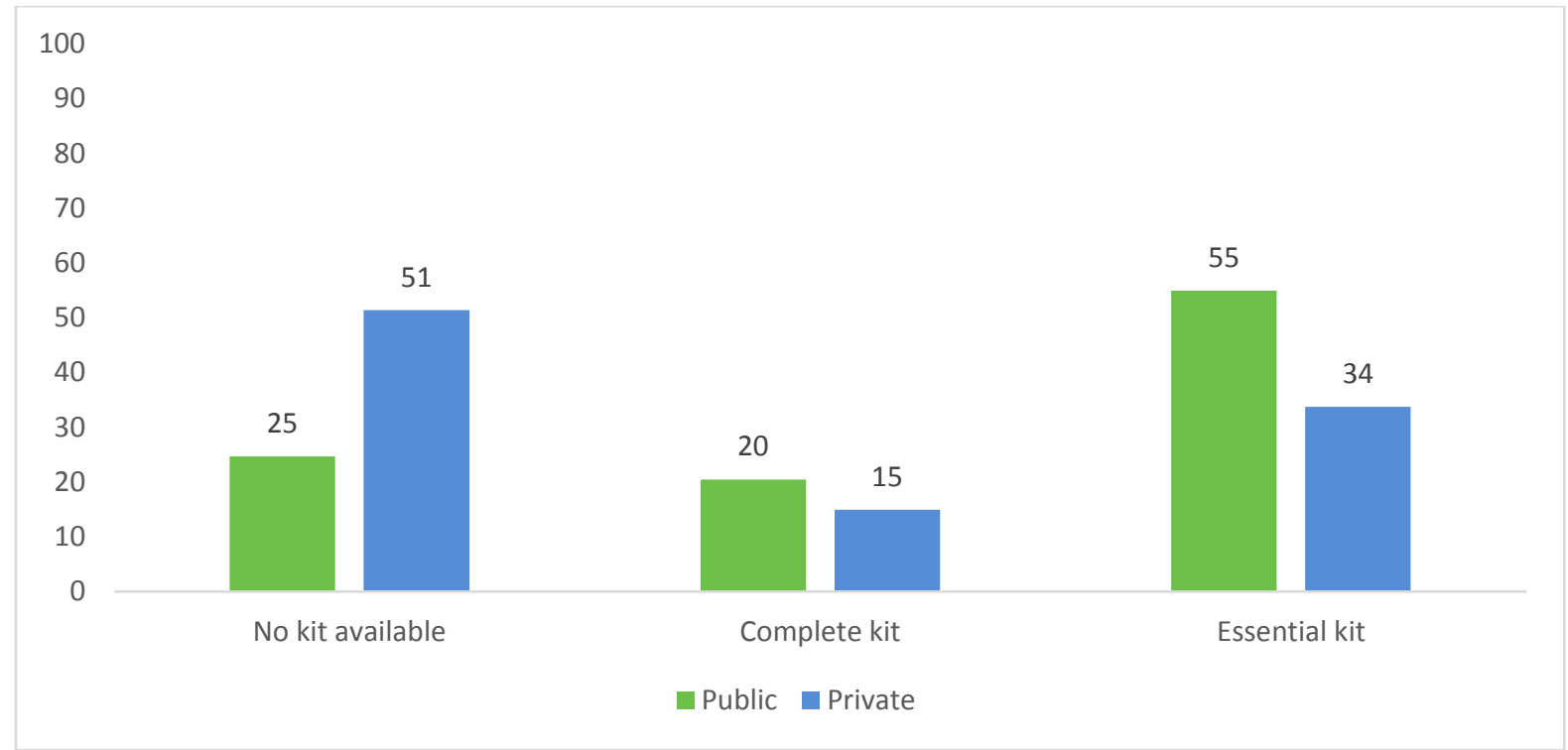

Source: HFA

Table 5.6 shows the availability of IUD kits across the districts and departments. All facilities of the Population Welfare Department have either a complete IUD kit or at least the essential kit in three districts except Bahawalpur, where about 60 percent have one of these kits. However, availability is lower at DoH facilities, being highest in Rahim Yar Khan, where 33 percent of facilities have the complete IUD kit and 61 percent have essential equipment, followed by Faisalabad where 24 percent have the complete kit and 38 percent have essential equipment.

In the private sector, however, more than 55 percent of facilities do not have any IUD kits in three districts except Bahawalpur, where a lower proportion (37\%) lack any kit. Clearly, if providers in the private sector are to be mobilized for a greater role in IUD provision, they will not only require training in insertion and removal technique of IUDs but will also need to be given complete IUD kits, otherwise theory will not lead to practice. A substantial number of NGO clinics (about 80\%) have either the complete IUD kit or essential equipment in three districts except Rahim Yar Khan, where 67 percent of NGO facilities do not have an IUD kit. 
Table 5.6: Availability of Functional Complete and Essential IUD Insertion kits, by Sector and District

\begin{tabular}{|c|c|c|c|c|c|}
\hline & & No kit available & Complete kit & Essential kit & Total \\
\hline & & $\%$ & $\%$ & $\%$ & $\mathrm{n}$ \\
\hline \multirow{4}{*}{ Rawalpindi } & DoH & 26 & 13 & 61 & 23 \\
\hline & PWD & 0 & 14 & 86 & 14 \\
\hline & Private & 55 & 9 & 36 & 44 \\
\hline & NGOs & 17 & 50 & 33 & 6 \\
\hline \multirow{4}{*}{ Faisalabad } & DoH & 38 & 24 & 38 & 29 \\
\hline & PWD & 0 & 30 & 70 & 10 \\
\hline & Private & 37 & 14 & 49 & 35 \\
\hline & NGOs & 20 & 0 & 80 & 5 \\
\hline \multirow{4}{*}{ Bahawalpur } & $\mathrm{DoH}$ & 54 & 13 & 33 & 24 \\
\hline & PWD & 36 & 18 & 45 & 11 \\
\hline & Private & 61 & 18 & 20 & 44 \\
\hline & NGOs & 0 & 0 & 100 & 1 \\
\hline \multirow{4}{*}{ Rahim Yar Khan } & DoH & 6 & 33 & 61 & 18 \\
\hline & PWD & 0 & 25 & 75 & 12 \\
\hline & Private & 56 & 15 & 29 & 41 \\
\hline & NGOs & 67 & 17 & 16 & 6 \\
\hline Total & & 40 & 17 & 43 & 323 \\
\hline
\end{tabular}

Source: HFA

\section{Infection Prevention Measures}

Infection prevention measures are very important for providing safe family planning services. These measures include availability of chlorine solution, a container for the solution, and sterilizer. If the facility is providing tubal ligation or vasectomy services, the availability of an autoclave is also a must.

Table 5.7 shows that arrangements for infection prevention are better at public facilities than at private facilities. Nearly all teaching hospitals, DHQs, and THQs have arrangements for infection prevention while about 90 percent of big hospitals in the private sector have disinfection (chlorine) solution and 80 percent have a sterilizer. Among doctors' clinics, 43 percent have a sterilizer and 78 percent have disinfection solution, while 89 percent of LHV clinics have chlorine solution and 75 percent have a sterilizer. 
Table 5.7: Availability of Functional Infection Prevention Arrangements, by Type of Facility

\begin{tabular}{|c|c|c|c|c|}
\hline & Autoclave & $\begin{array}{l}\text { Chlorine } \\
\text { solution }\end{array}$ & Sterilizer & Total \\
\hline & $\%$ & $\%$ & $\%$ & $\mathbf{n}$ \\
\hline \multicolumn{5}{|l|}{ Public sector } \\
\hline Teaching hospital & 100 & 100 & 100 & 3 \\
\hline $\mathrm{DHQ}$ & 100 & 100 & 75 & 4 \\
\hline THQ & 86 & 100 & 86 & 14 \\
\hline $\mathrm{RHC}$ & 85 & 92 & 92 & 13 \\
\hline $\mathrm{BHU}$ & 63 & 93 & 90 & 30 \\
\hline $\mathrm{MCH}$ center/Govt. dispensary & 0 & 53 & 13 & 15 \\
\hline RHSC-A/FHC & 88 & 100 & 88 & 8 \\
\hline FWC & 13 & 87 & 100 & 39 \\
\hline \multicolumn{5}{|l|}{ Private sector } \\
\hline Community midwife clinic & 15 & 85 & 95 & 20 \\
\hline Private hospital & 68 & 90 & 80 & 40 \\
\hline Doctor's clinic & 28 & 78 & 43 & 72 \\
\hline Nurse clinic/LHV clinic & 20 & 89 & 75 & 44 \\
\hline Maternity home & 67 & 100 & 67 & 3 \\
\hline NGO clinic & 50 & 100 & 89 & 18 \\
\hline Total & 41 & 87 & 74 & 323 \\
\hline
\end{tabular}

Source: HFA

Table 5.8 shows the availability of infection prevention measures by sector and district. Overall, in none of the districts are all or even most health facilities observing all basic infection prevention measures. Most of the facilities of both public and private sector have chlorine solution and a sterilizer. Relatively higher proportions of health facilities report availability of infection prevention measures in Rahim Yar Khan, especially at DOH and PWD facilities. NGO facilities are also better equipped with regard to infection prevention compared to other private facilities in all four districts. 
Table 5.8: Availability of Functional Infection Prevention Arrangements, by Sector and District

\begin{tabular}{|c|c|c|c|c|c|}
\hline & & Auto clave & Chlorine solution & Sterilizer & Total number \\
\hline & & $\%$ & $\%$ & $\%$ & $n$ \\
\hline \multirow{4}{*}{ Rawal } & $\mathrm{DoH}$ & 57 & 78 & 87 & 23 \\
\hline & PWD & 14 & 100 & 100 & 14 \\
\hline & Private & 30 & 82 & 55 & 44 \\
\hline & NGOs & 50 & 100 & 83 & 6 \\
\hline \multirow{4}{*}{ Faisal } & DoH & 62 & 86 & 79 & 29 \\
\hline & PWD & 30 & 80 & 90 & 10 \\
\hline & Private & 56 & 91 & 71 & 34 \\
\hline & NGOs & 80 & 100 & 100 & 5 \\
\hline & DoH & 42 & 83 & 54 & 24 \\
\hline & PWD & 18 & 82 & 100 & 11 \\
\hline & Private & 34 & 77 & 59 & 44 \\
\hline & NGOs & 0 & 100 & 100 & 1 \\
\hline & DoH & 56 & 100 & 100 & 18 \\
\hline & PWD & 42 & 92 & 100 & 12 \\
\hline & Private & 27 & 90 & 66 & 41 \\
\hline & NGOs & 33 & 100 & 83 & 6 \\
\hline \multicolumn{2}{|l|}{ Total } & 41 & 87 & 74 & 323 \\
\hline
\end{tabular}

Source: HFA

\section{Availability of General Equipment and Arrangements for Privacy}

General equipment that must be available and functional for examination of clients includes a weighing scale, stethoscope, blood pressure (BP) measuring apparatus, and an examination table or couch for providing family planning services. In particular, BP apparatus is necessary to identify contraindications before dispensing some of the methods, and for supporting continuous use, especially of hormonal contraceptives.

Table 5.9 shows that, generally, most facilities in both the public and private sector are well equipped with this basic equipment. The table also shows the proportion of facilities that have arrangements in place for maintaining auditory and visual privacy of clients. Privacy is a basic right of clients and a prerequisite for providing quality services. It is therefore very surprising that most of the $\mathrm{DoH}$ facilities are not giving much weightage to privacy (except teaching hospitals and BHUs); private facilities are performing better in this respect. More than three fourths of PWD clinics are also maintaining auditory and visual privacy when dealing with clients. 
Table 5.9: Availability of Functional General Equipment and Arrangement for Privacy, by Type of Facility

\begin{tabular}{|c|c|c|c|c|c|c|}
\hline & $\begin{array}{l}\text { Adult weighing } \\
\text { scale }\end{array}$ & Stethoscope & $\begin{array}{c}\text { BP } \\
\text { apparatus }\end{array}$ & $\begin{array}{l}\text { Examination } \\
\text { table/couch }\end{array}$ & $\begin{array}{c}\text { Auditory/visual } \\
\text { privacy }\end{array}$ & Total \\
\hline & $\%$ & $\%$ & $\%$ & $\%$ & $\%$ & $n$ \\
\hline \multicolumn{7}{|l|}{ Public sector } \\
\hline Teaching hospital & 100 & 100 & 100 & 100 & 100 & 3 \\
\hline $\mathrm{DHQ}$ & 100 & 100 & 100 & 100 & 25 & 4 \\
\hline THQ & 100 & 100 & 100 & 100 & 43 & 14 \\
\hline $\mathrm{RHC}$ & 100 & 100 & 100 & 100 & 62 & 13 \\
\hline $\mathrm{BHU}$ & 100 & 100 & 100 & 100 & 80 & 30 \\
\hline $\begin{array}{l}\text { MCH center/ Govt. } \\
\text { dispensary }\end{array}$ & 47 & 93 & 87 & 67 & 20 & 15 \\
\hline RHSC-A/FHC & 100 & 100 & 100 & 100 & 75 & 8 \\
\hline FWC & 100 & 100 & 100 & 100 & 77 & 39 \\
\hline \multicolumn{7}{|l|}{ Private sector } \\
\hline $\begin{array}{l}\text { Community } \\
\text { midwife clinic }\end{array}$ & 95 & 100 & 100 & 75 & 60 & 20 \\
\hline Private hospital & 88 & 100 & 100 & 93 & 78 & 40 \\
\hline Doctor's clinic & 63 & 96 & 97 & 79 & 56 & 72 \\
\hline $\begin{array}{l}\text { Nurse clinic/LHV } \\
\text { clinic }\end{array}$ & 80 & 93 & 98 & 98 & 84 & 44 \\
\hline Maternity home & 100 & 100 & 100 & 100 & 67 & 3 \\
\hline NGO clinic & 89 & 100 & 100 & 100 & 78 & 18 \\
\hline Total & 73 & 93 & 93 & 77 & 57 & 323 \\
\hline
\end{tabular}

Source: HFA

Table 5.10 shows the availability of general equipment and privacy arrangements across districts. Overall, most of the facilities of DoH and PWD have general equipment available in all districts. The NGO sector is also fully equipped in all four districts, as are most commercial private facilities.

Arrangements for auditory and visual privacy are in place at all NGO clinics and about 78 percent of facilities in all other departments in district Rawalpindi. Most public and private facilities are also ensuring privacy in the other districts, except in Bahawalpur, where only 29 percent of DoH facilities have privacy arrangements in place. 
Table 5.10: Proportion of Facilities having Functional General Equipment by Sector and District

\begin{tabular}{|c|c|c|c|c|c|c|c|}
\hline & Tyne of & $\begin{array}{c}\text { Adult } \\
\text { weighing } \\
\text { scale }\end{array}$ & Stethoscope & $\begin{array}{c}\text { BP } \\
\text { apparatus }\end{array}$ & $\begin{array}{l}\text { Examination } \\
\text { table/couch }\end{array}$ & $\begin{array}{c}\text { Auditory/visual } \\
\text { privacy }\end{array}$ & Total \\
\hline & facility & $\%$ & $\%$ & $\%$ & $\%$ & $\%$ & $n$ \\
\hline \multirow{4}{*}{ Rawalpindi } & $\mathrm{DoH}$ & 100 & 100 & 100 & 100 & 78 & 23 \\
\hline & PWD & 100 & 100 & 100 & 100 & 79 & 14 \\
\hline & Private & 84 & 100 & 100 & 100 & 82 & 44 \\
\hline & NGOs & 100 & 100 & 100 & 100 & 100 & 6 \\
\hline \multirow{4}{*}{ Faisalabad } & $\mathrm{DoH}$ & 97 & 97 & 97 & 83 & 62 & 29 \\
\hline & PWD & 100 & 100 & 100 & 100 & 70 & 10 \\
\hline & Private & 71 & 94 & 100 & 91 & 69 & 35 \\
\hline & NGOs & 100 & 100 & 100 & 100 & 60 & 5 \\
\hline \multirow{4}{*}{ Bahawalpur } & $\mathrm{DoH}$ & 71 & 100 & 96 & 83 & 29 & 24 \\
\hline & PWD & 100 & 100 & 100 & 100 & 82 & 11 \\
\hline & Private & 80 & 93 & 93 & 91 & 64 & 44 \\
\hline & NGOs & 100 & 100 & 100 & 100 & 0 & 1 \\
\hline \multirow{4}{*}{ Rahim Yar Khan } & $\mathrm{DoH}$ & 100 & 100 & 100 & 100 & 61 & 18 \\
\hline & PWD & 100 & 100 & 100 & 100 & 75 & 12 \\
\hline & Private & 61 & 98 & 100 & 71 & 61 & 41 \\
\hline & NGOs & 67 & 100 & 100 & 100 & 83 & 6 \\
\hline Total & & 84 & 98 & 98 & 91 & 67 & 323 \\
\hline
\end{tabular}

Source: HFA

\section{Availability of Contraceptive Stock}

For health facilities to provide the specific family planning methods they are mandated to provide, it is important that sufficient stocks of contraceptives be available. As the discussion in Section 4 shows, clients in the public sector in particular expect contraceptive methods to be provided by the facility at no or nominal cost.

During the survey of health facilities, availability of specific contraceptive methods at each facility on the day of the visit was assessed. The findings, shown in Figure 5.14, indicate that availability of contraceptives is better at public sector facilities as compared to those in the private sector. Over 80 percent of public sector facilities had condoms, oral pills and IUDs but injectables were available at slightly fewer (77\%) facilities. In comparison, only about 30 percent of private sector facilities had oral pills and injectables while about a third had condoms and IUDs in stock. However, emergency contraceptive pills were available at relatively more private health facilities $(17 \%)$ than public facilities $(6 \%)$, where the provision of this method seems to be negligible. 
Moreover, only a few facilities had implants, which is expected given that most facilities do not provide this method. Mostly, RHS-A centers of the Population Welfare Department are providing implants.

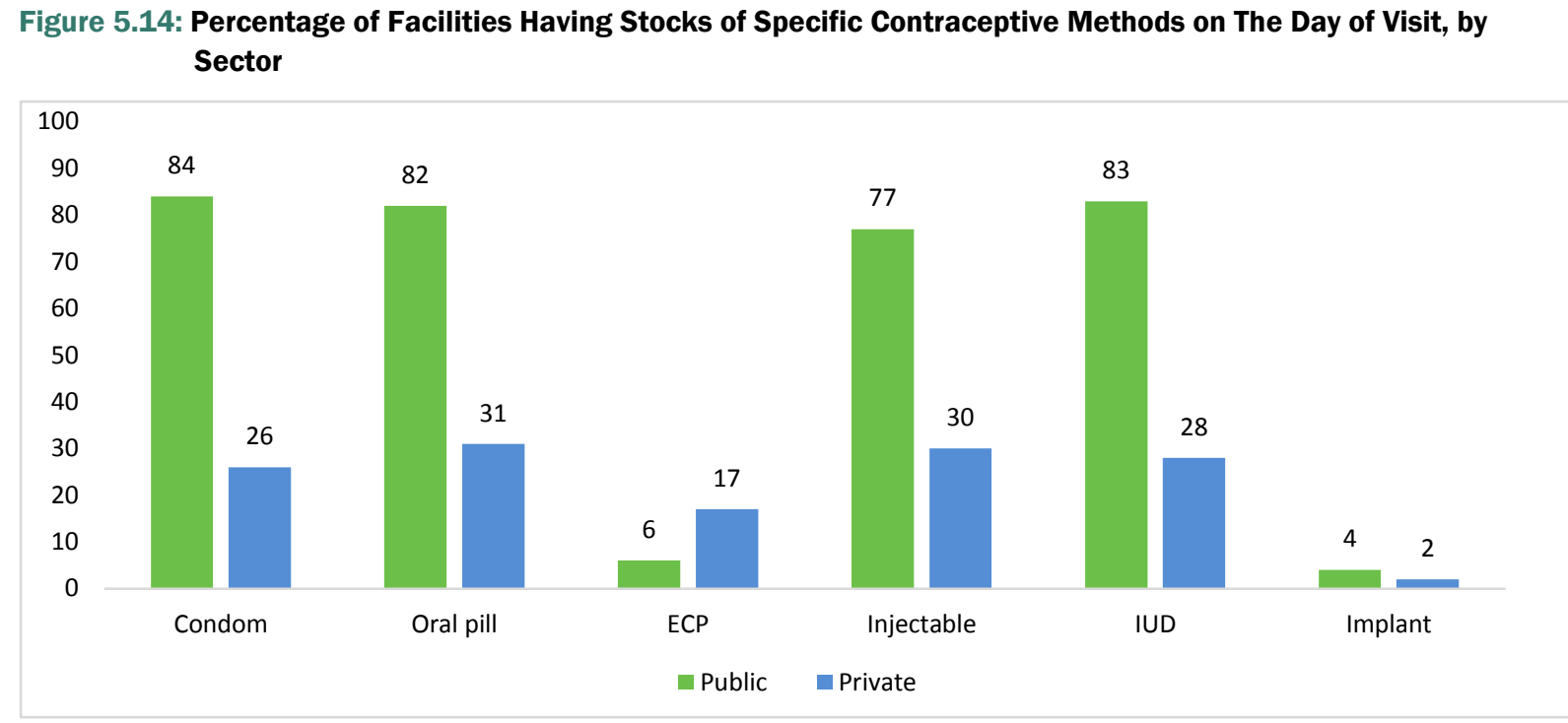

Source: HFA

\section{District Comparison}

The above discussion has presented a detailed analysis of SDPs in the study districts in terms of all the important factors-both at the facility level and the provider level-that enable a facility to provide quality family planning services. To compare the study districts in terms of health facilities' readiness to provide quality FP services, an index was developed based on the proportion of facilities with key capacities at facility and provider level. The 14 indicators included in the index concern availability of basic equipment, amenities, and contraceptive stocks; capacity of service providers; and availability of female providers at the facility, as shown in Table 5.11. For each district, each indicator was assigned a score of 1 to 4 , reflecting the proportion of facilities meeting the criterion expressed in the indicator. The scores of each district for each indicator were summed up for ranking. This analysis was also conducted separately for public and private sector facilities in each district.

Table 5.11 shows the district ranking for capacity of public sector facilities to provide quality FP services. Rawalpindi ranks at the top with Faisalabad second, Rahim Yar Khan third, and Bahawalpur scoring lowest among the four districts. Overall, the districts of North and Central Punjab are performing better compared to the two Southern districts. However, a closer look at performance against indicators shows that in terms of physical readiness, i.e., availability of equipment, amenities, and contraceptives, Rahim Yar Khan is actually better equipped than all the other districts. Its main weaknesses are low availability of female providers and weaker capacity of providers. Thus, while CFP data suggests Rahim Yar Khan has the highest proportion of public facilities offering FP services (about 95\%), the quality of those services has much room for improvement. 
Table 5.11: Ranking of Districts - Capacity of Public Health Facilities to Provide Quality FP Services

\begin{tabular}{|c|c|c|c|c|}
\hline & Rawalpindi & Faisalabad & Bahawalpur & Rahim Yar Khan \\
\hline \multicolumn{5}{|l|}{ Readiness: \% of facilities } \\
\hline Complete IUD kit available & 14 & 25 & 14 & 30 \\
\hline All 5 elements general equipment available & 95 & 88 & 74 & 100 \\
\hline All 6 amenities available & 5 & 10 & 0 & 13 \\
\hline Providing at least 4 contraceptive methods & 86 & 87 & 76 & 93 \\
\hline At least 4 contraceptive methods in stock & 39 & 39 & 38 & 73 \\
\hline Section score & 48 & 50 & 40 & 62 \\
\hline \multicolumn{5}{|l|}{ Capacity of providers: $\%$ of providers } \\
\hline Received any training in FP within last 3 years & 59 & 40 & 49 & 53 \\
\hline All 5 answers about IUD correct & 0 & 3 & 3 & 0 \\
\hline All 5 answers about pills correct & 3 & 3 & 0 & 0 \\
\hline All 5 answers about Injectables correct & 11 & 10 & 6 & 13 \\
\hline All 5 counseling skills related communication & 12 & 14 & 26 & 11 \\
\hline All 3 counseling skills related autonomy & 33 & 22 & 36 & 0 \\
\hline Both counseling skills related privacy & 31 & 39 & 43 & 24 \\
\hline Section score & 21 & 19 & 23 & 14 \\
\hline \multicolumn{5}{|l|}{ Availability of female provider: $\%$ of facilities having } \\
\hline At least one female staff available in morning shift & 100 & 90 & 40 & 37 \\
\hline At least one female staff available in evening shift & 49 & 43 & 34 & 30 \\
\hline Section score & 74 & 66 & 37 & 33 \\
\hline Overall score & 38 & 36 & 31 & 34 \\
\hline
\end{tabular}

Source: HFA

When the public sector scores are compared with those for the private sector, shown in Table 5.12, it is evident that the capacity of the private sector is much lower than that of the public sector in all districts, especially Rahim Yar Khan. Rawalpindi has the highest and Rahim Yar Khan the least score for private facilities. The difference in scores are not large across the districts. Scores for availability of IUD equipment and contraceptive stock are generally very low in the private sector. Availability of female providers in both shifts is better in Rawalpindi and Faisalabad as compared to Bahawalpur and Rahim Yar Khan. 
Table 5.12: Ranking of Districts - Capacity of Private Health Facilities to Provide Quality FP Services

\begin{tabular}{|c|c|c|c|c|}
\hline & Rawalpindi & Faisalabad & Bahawalpur & Rahim Yar Khan \\
\hline \multicolumn{5}{|l|}{ Readiness: \% of facilities } \\
\hline Complete IUD kit available & 11 & 8 & 12 & 10 \\
\hline All 5 elements of general equipment available & 68 & 49 & 48 & 43 \\
\hline All 6 amenities available & 2 & 3 & 0 & 6 \\
\hline Providing at least 4 contraceptive methods & 43 & 46 & 52 & 52 \\
\hline At least 4 contraceptive methods in stock & 14 & 11 & 9 & 23 \\
\hline Section score & 28 & 23 & 24 & 27 \\
\hline \multicolumn{5}{|l|}{ Capacity of providers: \% of providers } \\
\hline Received any training in FP within last 3 years & 10 & 10 & 15 & 15 \\
\hline All 5 answers to IUD correct & 2 & 0 & 0 & 6 \\
\hline All 5 answers to pills correct & 0 & 2 & 2 & 1 \\
\hline All 5 answers to Injectables correct & 3 & 5 & 12 & 6 \\
\hline All 5 counseling skills related to communication & 6 & 24 & 30 & 7 \\
\hline All 3 counseling skills related to autonomy & 20 & 36 & 47 & 5 \\
\hline Both counseling skills related privacy & 46 & 43 & 36 & 24 \\
\hline Section score & 12 & 17 & 20 & 9 \\
\hline \multicolumn{5}{|l|}{ Availability of female provider: \% of facilities having } \\
\hline At least one female staff available in morning shift & 54 & 48 & 20 & 25 \\
\hline At least one female staff available in evening shift & 44 & 36 & 20 & 19 \\
\hline Section score & 49 & 42 & 20 & 22 \\
\hline Overall score & 23 & 23 & 22 & 17 \\
\hline
\end{tabular}

Source: HFA

The above analysis suggests that public and private health facilities in the four districts generally have equipment, contraceptives, and a female service provider. The main gap lies in the knowledge and counseling skills of the providers, which is an important barrier in provision of quality family planning services. These deficiencies are likely to be undermining the ability of providers to be proactive, to provide proper counseling and correct and comprehensive information to clients, and to properly manage side effects of the methods they provide, resulting in multiple missed opportunities to recruit new and retain existing family planning clients.

\section{Missed Opportunities to Serve New and Existing FP Clients}

Collectively, data from the census of health facilities and pharmacies and the assessment of health facilities indicate that opportunities to support family planning use are being missed by the health sector at multiple levels.

As Figure 5.15 illustrates, the first tier of missed opportunities is non-provision of family planning services, which is most pronounced in the private sector, where only 18 percent of health facilities are providing FP services. As a result, it is not clinics and hospitals but pharmacies that comprise the most commonly used private sector channel for FP services. However, a fourth of pharmacies are also not selling any contraceptive. Collectively, of the total 7,601 static SDPs, including 329 public health facilities, 4,139 private health facilities, and 3,133 pharmacies, 56 percent are not providing any family planning service.

In this context, the very low involvement of male doctors in FP service provision is especially noteworthy: despite the strong evidence that most men in Pakistan want to be involved in family planning (PDHS 2012 
13), which is confirmed by the findings of this study, male doctors have yet to step up to fill the need for male providers to counsel men. Present in much larger numbers than female doctors, especially in rural areas, non-providing male doctors represent a large missed opportunity to engage men in family planning.

The timings of facilities are also an important facet of their availability, especially where a part of their clientele has to invest considerable time and money to reach them. The presence of a female provider is crucial for dispensing female methods. It was found that more than 80 percent of public (except DHQs) and private health facilities had a female service provider present in the morning shift. However, only 39 percent of public and 42 percent of private facilities had a female provider available in the evenings, implying additional access difficulties for women who cannot travel in the daytime.

The second level of missed opportunities arises from the fact that the vast majority of SDPs only provides FP services if the client specifically asks for them. This study found that 85 percent of clients who visited health facilities with reproductive health needs other than FP were not provided any counseling or information about family planning methods. Providers do not appear to recognize that they should proactively counsel clients regarding their need to space births to maintain maternal and child health. This is an important gap in the practices of providers and in facility management systems, especially since the majority of clients have low educational attainment and rely greatly on their providers to suggest any additional care they might need.

The third stage of missed opportunities relates to lack of choice of family planning methods. Less than 50 percent of public health facilities are providing all the basic methods-condoms, pills, emergency contraceptive pills, injectables, and IUDs or implants. Availability of implants is particularly low in both sectors. Although a high proportion of all public sector facilities offer IUDs, only about a tenth of private sector facilities are providing this method, and its availability at pharmacies is also negligible. Since the LARCs cannot be provided without the services of a skilled provider, it is particularly important that untapped private potential be harnessed for these methods. Non-involvement of private providers may also be a reason why pharmacies are not interested in keeping these methods.

Notably, even where public facilities are mandated to provide a larger range of methods, their capacity to do so can be restricted by stock-outs of contraceptives. On the day of the visit by the study team, about 80 percent of public health facilities had condoms, oral pills, injectables, and IUDs in stock, but only 6 percent had emergency contraceptive pills. Less than a third of private facilities had condoms, pills, and IUDs in stock, while 17 percent had ECPs. Moreover, while a large proportion of public facilities did have IUDs in stock, only 20 percent had the complete equipment for inserting/removing IUDs and a fourth did not have complete or essential kits for this purpose. Among private health facilities, a mere 11 percent had complete IUD kits and 66 percent did not have complete or essential kits. These issues translate into an even narrower range of options for family planning clients than the initial picture suggests, reducing their capacity to adopt new methods that suit their circumstances.

Gaps in the capacities and practices of service providers, linked to deficiencies in their training and knowledge, comprise the next tiers of missed opportunities to support potential and current FP clients. The findings presented earlier in this section reveal large gaps in service providers' knowledge about specific contraceptive methods as well as specific client rights. Only 26 percent have received any type of training related to family planning in the past three years, including only twelve doctors-three male and nine female.

There are also weaknesses in provider practices related to communication with clients and ensuring their autonomy and privacy. It is pertinent to mention that most DoH facilities, except teaching hospitals and BHUs, are not giving much weightage to privacy, which is an important concern of clients. Arrangements for auditory and visual privacy are better at private and PWD facilities. 
Most clients are leaving health facilities with inadequate information about how to use and what to expect while using their chosen contraceptive method. Many clients who are referred to other facilities for FP services are also not provided sufficient information to facilitate their access.

Overall, there is considerable scope for improving the quality of FP services and making the environment more client-centered. Investing in this area is likely to help reduce the current high levels of discontinuation of family planning.

\section{Figure 5.15: Missed Opportunity}

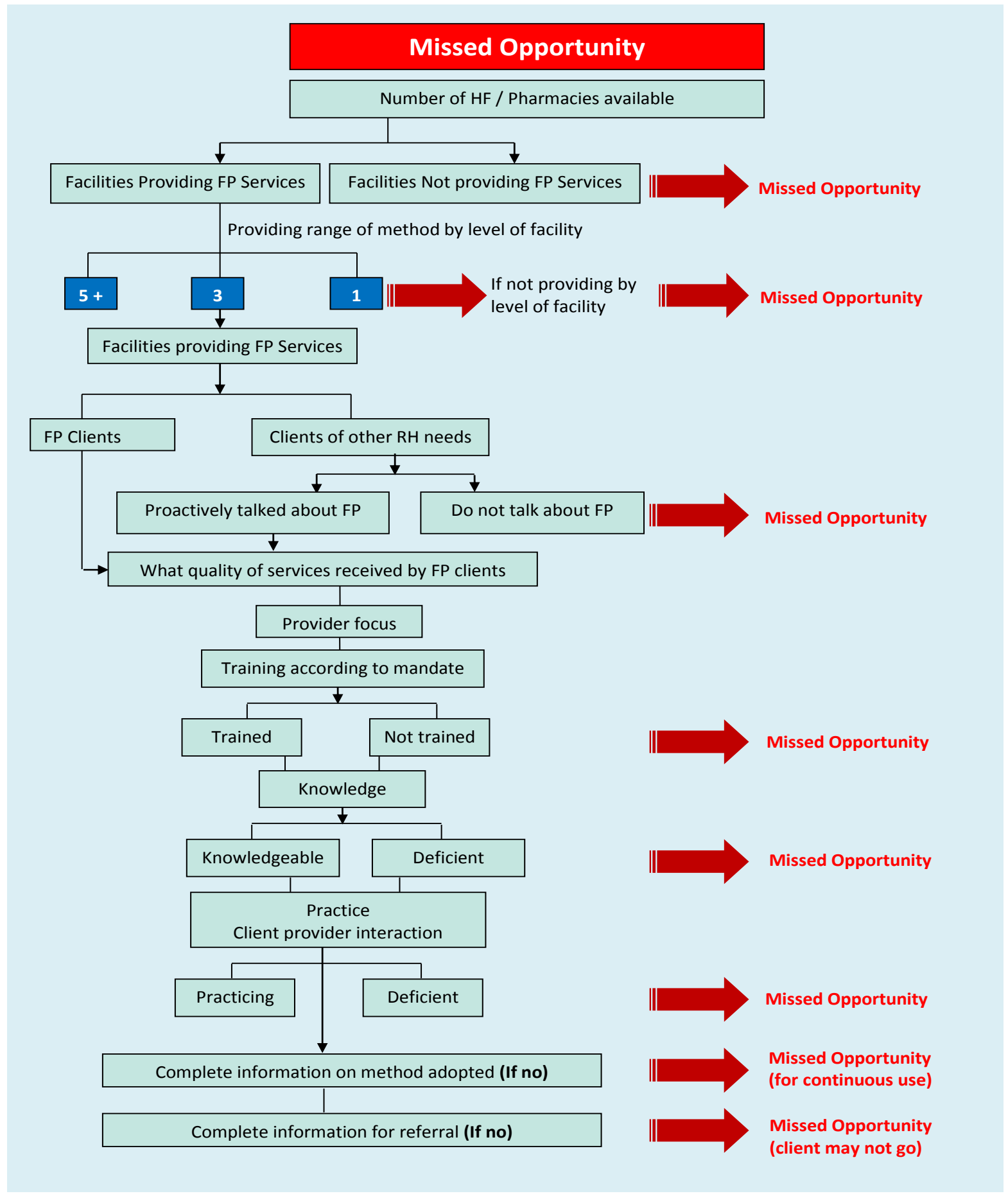



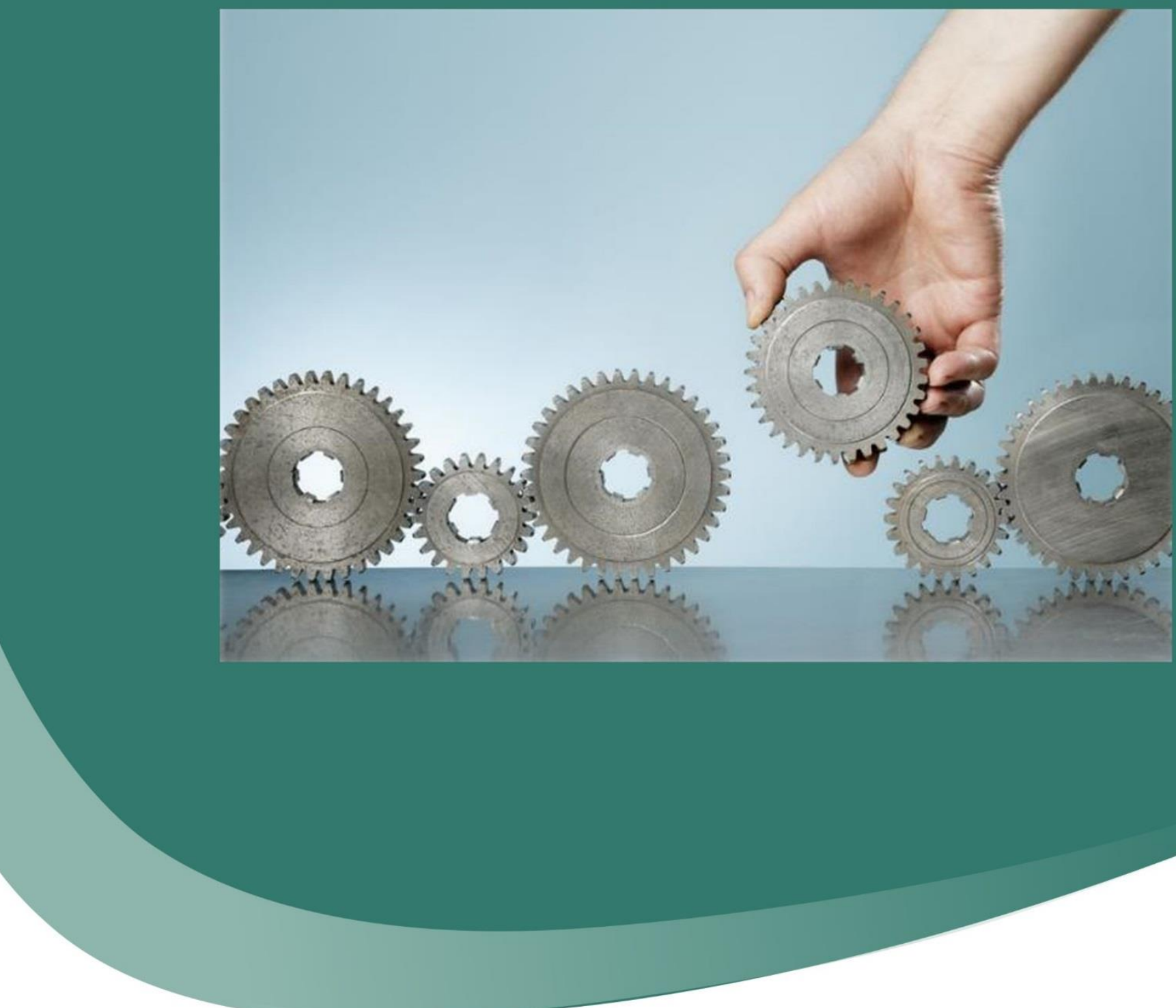



\section{Conclusions and Recommendations}

This study has provided detailed data about the availability and performance of family planning service delivery points in 16 clusters in Punjab, as well as the met and unmet demand for family planning among couples in these clusters, their utilization of existing SDPs, and the motivations and constraints that underlie their choices regarding whether to use contraceptives, which methods to use, and the sources to obtain these methods from. In the following discussion, we synthesize the broad picture of supply and demand that emerges from these data to identify the key gaps that must be addressed as well as the main opportunities for accelerating uptake of family planning in Punjab.

\section{Conclusions}

Demand for family planning is quite high among women with at least one child in the study districts. However, although contraceptive use levels are encouraging among these women-53.3 percent in Rawalpindi and Bahawalpur, 52.3 percent in Rahim Yar Khan, and 50 percent in Faisalabad, unmet need is also quite high, i.e., 23.3 percent in Rawalpindi, 22.9 percent in Bahawalpur, 18 percent in Rahim Yar Khan, and 11.7 percent in Faisalabad. Among women with at least one child, there is no noticeable difference in contraceptive use between the two northern districts, Rawalpindi and Faisalabad (51.7\%) and the southern districts (52.7\%). However, the proportion of past users is relatively higher in the south (24.9\%) compared to the north $(17.5 \%)$, and the situation is reversed for never users, who are present in a larger proportion in the north $(30.8 \%)$ than in the south (22.4\%). Unmet need is slightly higher in the south (20.0\%) than in the north (17.5\%).

Overall, three main methods are being used for family planning, including condoms (21\%), withdrawal (10\%), and female sterilization (9\%). Use of hormonal methods is quite low, especially among women who are urban and of middle or high socioeconomic status; relatively higher proportions of poor rural women use injectables and IUDs.

Affordability and accessibility of FP services is a main concern of men and women in deciding which sector and facilities to utilize and what method to choose. Currently, the most frequently utilized facilities for family planning services include the LHWs, public static facilities, and pharmacies. The main reason for the popularity of these sources is their presence in the vicinity of users and their affordability. Those who opt for private health facilities primarily do so because public facilities are crowded: they have to wait longer to see the service providers, and the providers have less time to attend to them properly. However, the majority of community respondents are not able to afford private services and some also claim that private providers are not adequately qualified.

The mean contraceptive cost is higher in rural than urban areas for all methods except condoms. Respondents in this study feel they are spending too much money on condoms, oral pills, and ECP, but are satisfied with the cost of injectables and IUDs. On the other hand, for implants and tubal ligation, they are willing to pay almost double what they are paying now. This indicates that they recognize that longer acting and permanent methods are more cost-effective over time. We can infer from this that low use of hormonal methods is not as much due to the cost of the methods as to the issues of access and side effects, both of which were frequently cited as reasons for not choosing a method by men and women.

The median distance men and women have to travel to reach facilities offering family planning services is 1 to 5 kilometers; in rural areas, the distance is often much greater. On average, men and women need to travel shorter distances for the short-acting methods than they have to for LARCs or tubal ligation, especially in rural areas. Even for the short-acting methods, access may pose a formidable challenge in areas not yet 
covered by the LHW Programme. With the mobility of most women restricted outside their communities, it is easy to see how large distances can influence decisions about both whether to use modern methods of family planning and which methods to use. Both men and women emphasize the access problem with equal intensity.

Longer acting methods would appear to be the obvious solution for couples who cannot afford to make frequent resupply visits, but here, in addition to greater distances to travel, fear of side effects is a major barrier. Whether based on actual experience or word of mouth, fear of side effects is a main reason why clients do not choose the hormonal methods, especially injectables and IUDs. Women, in particular, are anxious about this risk. Moreover, men and women have limited knowledge about emergency contraceptive pills and implants.

Men express a pronounced preference for male FP service providers to fulfill their growing need for direct access to FP information, counseling, and methods. It is important to address this gap: most women cannot practice family planning or choose a method unless their husbands agree, but men typically cannot consult with female providers and do not know where to go for FP information and services except pharmacies. Men also express a need for evening availability of service providers so they do not have to choose between tending to work and meeting their health needs.

Men and women show a strong preference for provision of FP services via the public sector and in their close vicinity-a third of respondents want doorstep delivery of services, underscoring the importance of the LHWs. Most men and women want FP services to be integrated with $\mathrm{MCH}$ or RH services, but privacy is a major concern and special arrangements will have to be ensured in this regard. Although their knowledge of specific client rights is quite low, men and women do expect service providers to attend properly to them, to be competent, and to provide effective contraceptives. They prefer qualified doctors to less skilled providers, but generally do not identify any specific aspects of quality of care-other than how the provider interacts with them-as reasons for preferring facilities.

In the 16 study clusters, the situation on the supply side greatly explains the constraints and choices of men and women. While the numbers and distribution of major health facilities in the public and private sector in the study areas is quite impressive, the full potential of these facilities is not being utilized to deliver family planning services: of the total 7,601 static SDPs, including 329 public health facilities, 4,139 private health facilities, and 3,133 pharmacies, 56 percent were found to be not providing any family planning service. The public sector, which has the explicit mandate to provide FP services, is generally active in this role in both urban and rural areas, although some gaps are seen among the static facilities of the Department of Health. Three quarters of pharmacies are also providing some FP methods. However, 82 percent of private health facilities are not providing even a single FP method.

In the study clusters, the average number of SDPs per 10,000 population ranges between 1.8 and 2.6 in the public sector (counting both static facilities and LHWs), and between 3.5 and 4.2 in the private sector (including both health facilities and pharmacies). However, when it comes to FP service provision, these ratios drop to 1.7 to 2.5 in the public sector and 1.2 to 2.1 in the private sector.

Availability is further constrained by the absence of female providers in the evening at around 60 percent of public and private facilities providing FP services. Notably, evening availability of female service providers is lower in the two southern districts, Rahim Yar Khan and Bahawalpur, compared to Rawalpindi and Faisalabad. Moreover, while the bulk of private sector providers are male-including hakeems and homeopaths in the largest numbers, followed by dispensers, and male doctors-they currently have very low involvement in FP service provision. 
Male doctors greatly outnumber female doctors, especially in rural areas, and their current non-involvement in FP service provision is a huge missed opportunity to engage men in family planning. Together, nonprovision of FP services by more than half the service delivery points, further reduction in availability of services for women in the evenings, and the dearth of male providers to counsel men greatly reduce sources of FP services for men and women, increasing the distances and costs entailed in accessing these services. Thus, only a small fraction of SDPs are effectively delivering FP services and, that too, mainly for women, excluding men.

Another major source of missed opportunities is the fact that the vast majority of health facilities only provide FP services if the client specifically asks for them. This study found that 87 percent of clients who visited health facilities with reproductive health needs other than FP were not provided any counseling or information about family planning methods. When this approach prevails in settings where most clients are less educated and rely on providers to holistically assess their needs, latent unmet need, for instance among mothers of infants, is bound to be ignored.

There is a huge variation in the availability of specific FP methods, with condoms being provided at the largest number of FP service delivery points, and LARCs, especially implants, available at far fewer facilities. The resulting differences in the accessibility of specific FP methods are clearly skewing method choices and largely explain the pronounced reliance on condoms and low use of LARCs.

Less than 50 percent of public health facilities are providing all the five basic methods-condoms, pills, emergency contraceptive pills, injectables, and IUDs or implants. Among the short-acting methods, condoms, oral pills, and injectables are available at nearly all public health facilities as well as with LHWs, with a slightly lower involvement of DoH facilities. Most pharmacies carry condoms and, to a lesser extent, oral pills, but relatively fewer stock injectables. The proportion of private facilities offering a family planning method is highest for these three methods. Among the long-acting reversible contraceptives (LARCs), availability of implants is quite low, and primarily restricted to public sector facilities. Although high proportions of all public health facilities offer IUDs, only about 12 percent of private health facilities are providing this method, and its availability at pharmacies is also negligible. Availability of male and female sterilization services is clearly very low, with only a few facilities providing this method.

Gaps are observed in the availability of contraceptive stocks and equipment for administering some methods, which could also be contributing to non-availability of these methods. In terms of physical readiness, public sector facilities in Rahim Yar Khan score much higher than those in the other three districts; in the private sector, Rawalpindi scores highest, followed closely by Rahim Yar Khan.

Gaps in the capacities and practices of service providers comprise the next-and arguably one of the most insidious-tiers of missed opportunities to support potential and current FP clients. Only 26 percent have received any type of training related to family planning in the past three years, including only twelve doctorsthree male and nine female. Service providers' knowledge about specific FP methods, especially the hormonal methods, is weak, and they are not clear about basic information regarding contraindications and side effects, or the frequency with which methods should be administered. There are also weaknesses in providers' practices related to communication with clients and ensuring their autonomy and privacy. Among the districts, Bahawalpur scored the highest for provider capacity in both the public and the private sector, while Rahim Yar Khan scored lowest, but in each district, public sector providers scored better than private sector providers.

Currently, most clients are leaving the health facility with inadequate information about how to use and what to expect while using their chosen contraceptive method. Given these gaps in the training and knowledge of service providers, and the resulting lack of capacity to counsel, reassure, and confidently help clients, 
women's fears about side effects are not entirely unfounded. The fact that providers are not proactively offering FP services also underscores the need to highlight the links between FP and $\mathrm{MCH}$ within the medical community.

Furthermore, most DoH facilities, except teaching hospitals and BHUs, are not giving much weightage to privacy, which is an important concern of clients. This issue must be addressed if the Department of Health is to play its role in integrated provision of $\mathrm{RH} / \mathrm{MCH}$ and FP services. Moreover, referral systems must be more cognizant of client needs. Overall, there is considerable scope for improving the quality of FP services and making the environment more client-centered. Investing in this area is likely to help reduce the current high levels of discontinuation of family planning.

\section{Recommendations}

The existence of unmet need for family planning and a skewed method mix in Punjab despite rising levels of use indicates that access to services must be improved. This should be seen not only as an important health intervention for preserving maternal and child health, but also as an opportunity to slow down the treadmill of population growth, enabling progress towards non-health development goals such as education, reduction of poverty and unemployment, and environmental preservation. The findings of the study suggest that there is scope for improving delivery of FP services and methods through all four major sectors, i.e., the public health facilities, the private health facilities, Lady Health Workers, and the pharmacies. Moreover, the agency of current and potential users can be enhanced to improve utilization. Recommendations in this regard are outlined below.

1. Build solid commitment to family planning across the health sector. Lack of relevant training among providers, the fact that public health facilities do not proactively offer FP services to clients, and private providers' disinterest in FP service provision are all telling signs that the medical community does not yet see family planning as a priority.

Male and female doctors, mid-level providers, and community health workers must be aware of the importance of Healthy Timing and Spacing of Pregnancies (HTSP), and this should reflect in the protocols they observe while dealing with clients at health facilities and in communities. Moreover, the institutions involved in health policy making and governance; shaping the health discourse and communications; and educating, training, and organizing health professionals must be fully on board. Unless all of these stakeholders play their due roles in helping women space and limit births, the health infrastructure will remain underutilized and dependent on external interventions to improve responsiveness to the needs of current and potential contraceptive users.

Notably, in recent years, the leadership of the Government of Punjab, including the Chief Minister himself, has expressed its unequivocal commitment and demonstrated this through enhanced funding for expanding access to FP services. But for the effects of this policy focus to permeate through the health infrastructure, it is critical that the cause of family planning be embraced by the health and medical community as part and parcel of mainstream health services, especially maternal and child health services. A broad range of champions have been identified representing all key institutions shaping Punjab's health sector, as well as the population sector, and the champions need to be facilitated over the next few years in identifying necessary modifications in Punjab's existing health strategy so that family planning may be prioritized in service delivery; health systems; health policy, governance and management; education and training of health staff; and research and communications. Assistance of international organizations could also be channeled and synergized more efficiently under the aegis of such a strategy. 
2. Tailor specific interventions to local supply and demand realities. As this study shows, the coverage of health facilities is not uniform across Punjab. Urban areas have a higher concentration of all types of facilities, while some rural communities do not have access to any public facility or even a Lady Health Worker. The availability and quality of health services also varies across districts. Likewise, the CPR, unmet need, and capacity of communities to access facilities varies, especially between rural and urban areas and by socioeconomic status. These variations call for localized strategies based on a sound understanding of indigenous needs and potentials. Thus, while the measures recommended below for improving service delivery and empowering clients are broadly applicable to all settings, the weightage given to each must be calibrated carefully, based on ground realities, in designing interventions for specific areas. Strategies must be designed in consultation with relevant authorities at the district and Union Council (UC) level, which would also ensure that the planned measures are practicable and locally supported.

3. Ensure that all public facilities are equipped to provide all FP services as per their mandate. It should be ensured that each health facility is providing the full range of family planning services in its mandate, especially emergency contraceptive pills and, to the extent possible, implants, which are especially lacking. Among other measures, this requires a regular and adequate supply of contraceptives to all health facilities. Moreover, all facilities should have a female provider present, including during the evening shift at facilities mandated to be open round-the-clock. Availability of necessary equipment for providing FP services, such as blood pressure measurement apparatus and IUD kit, must also be ensured.

4. Train public health service providers and enforce appropriate standards to provide quality FP services. There are large gaps in the knowledge of service providers which must be addressed urgently through training in counseling and all aspects of provision of the specific methods in their mandate, including how to manage any side effects that might arise. Skill-based training and relevant equipment should be provided. Providers should also be oriented to the importance of family planning for Healthy Timing and Spacing of Pregnancies and trained to offer FP counsel and information to patients even when they do not ask for it specifically. Moreover, they should be oriented to client rights and trained to modify their practices to preserve these rights, even in the busy environment of crowded facilities.

The following training is recommended for specific cadres:

- Female doctors and LHVs should be trained in contraceptive technology, counseling, IUD insertion and removal, and implant insertion and removal;

- Male doctors should be trained in contraceptive technology and counseling, including implant insertion and removal; and

- LHWs should be trained to manage the side effects of the methods they provide, as well as to provide additional methods, such as the Standard Days Method (SDM), emergency contraceptive

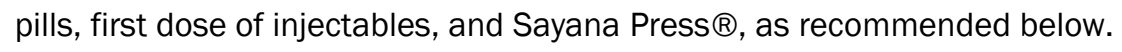

The training of service providers should be complemented by appropriate management measures to ensure impact, including supportive supervision at all levels, enforcement of quality standards and checklists, and regular refresher trainings as needed. For LHWs, who are the major source of FP services at the community level, the scope of work should be refocused on family planning, especially with waning polio responsibilities. 
5. Reach out actively to clients of public health facilities. All relevant service providers should be officially assigned as part of their regular duties to offer FP counsel to clients who visit for other services, and this task should be added in the discharge slip of obstetrics/gynecology in-patients at all levels of public health facilities, i.e., DHQ, THQ and RHCs and BHUs with 24/7 services, to ensure that all patients receive FP counseling as a mandatory part of their maternal care.

To attract clients, signboards should be prominently displayed at each health facility announcing the specific types of health services it offers, highlighting family planning, in the local language. Separate family planning counseling desks for men and women should be set up in each health facility to provide information to clients, especially men, regarding specific contraceptives and other possible sources where they can obtain FP services. These facilities should be situated close to the waiting area, to interest clients awaiting their consultation. Since use of contraceptives is considered a very private matter, arrangements for ensuring auditory and visual privacy must be ensured, especially at DoH facilities, where they are most lacking.

Moreover, a system should be established to send SMS messages from health facilities to clients reminding them of follow-up or resupply visits and sharing information about FP methods and benefits. Such systems are in use to support immunization elsewhere.

6. Increase provision by private health facilities, especially in less well-served areas. Despite their huge presence and spread in both urban and rural areas, as well as their frequent utilization for maternal and child health care, private health facilities are playing a very limited role in providing FP services. This should change, especially in areas that are not adequately served by public health facilities. Mobilizing private provision will require a number of interventions including training of male and female providers; incentivization of FP service provision, for example through vouchers; facilitating supply of contraceptives to providers, for example, by linking them with local pharmacies, pharmaceutical distributors and wholesalers, social marketing organizations, or the public sector supply chain; quality assurance through registration with the Health Care Commission; and possibly also accreditation. To attract clients, signboards in the local language should be installed announcing the FP services offered and any demand-side financing arrangements available at private facilities.

Service providers should be trained to provide all the methods they are permitted to provide by their concerned professional associations. Thus:

- Female doctors, LHVs and midwives should be trained in contraceptive technology, counseling, IUD insertion and removal, and implant insertion and removal, and provided relevant equipment;

- Male doctors should be trained in contraceptive technology and counseling, including provision of implants; and

- Dispensers and homeopaths should be trained in counseling and provision of condoms, pills, emergency contraceptive pills, and the second dose of injectables through task shifting/sharing.

Similarly, at the community level in areas not served by the LHW Programme, tested interventions involving community volunteers and provision of subsidized services should be introduced and rolled out. Since cost has been identified as one of the barriers to FP use, conditional cash transfer (voucher) programs targeting the poor should be considered to facilitate beneficiaries' access to the nearest available public or private health facilities.

7. Build further on pharmacies' role in provision of contraceptives and information. It is common for customers in Pakistan to ask pharmacists for advice about simple health complaints, and to purchase 
medicines recommended by them. In the context of family planning, most pharmacies stock condoms and are one of the largest sources of contraceptives in the study area after public health facilities and LHWs. This role can be enhanced further.

In areas where private FP service provision needs to be increased, linkages can be built between service providers and pharmacists so the latter can procure methods for providers and refer customers for hormonal methods, especially injectables and LARCs. Such linkages would also encourage more pharmacies to maintain stocks of these methods.

Moreover, pharmacists can be trained through detailing to serve as the first point of contact to provide men detailed information about specific FP methods. Signboards indicating that FP services are available, and notices encouraging customers to ask the pharmacist about FP methods can support this role. Free pictorial leaflets showing the range of contraceptive options can also be placed at pharmacies where interested customers can pick them up.

8. Empower users and mobilize communities to increase access to FP services. The increasing potential of mass media and mobile technology-including apps, social media, and voice and pictorial messages-should be tapped to disseminate information and build awareness among men and women about the types of FP services available and where they can be accessed, with a special focus on men's needs. A toll-free telephone or SMS-based helpline for FP related information should be established and widely advertised.

In addition, men's and women's awareness should be built regarding patient rights and the channels of recourse available to them if these rights are neglected. To improve accountability at health facilities, toll-free numbers could be provided and prominently displayed at health facilities for clients to lodge complaints if they experience service quality issues.

At the community level, male and female influential residents, such as religious scholars, councilors, teachers, and health professionals, can be sensitized, linked with the relevant health authorities, and engaged to spread awareness in the community about the benefits of family planning as well as sources of information and services, and also to highlight issues being faced by the community in accessing quality services. Where possible, this role may be played by new or existing village organizations.

9. Enhance the role of LHWs in increasing access to family planning. In the 1990s, the LHW Programme fueled a surge in contraceptive uptake in Pakistan, which was unfortunately not sustained in subsequent decades. This is attributed, among other reasons, to dilution of the LHWs' focus on family planning due to their involvement in a host of additional tasks, especially polio eradication activities. The proven effectiveness of LHWs in increasing contraceptive prevalence must be restored, especially in the southern districts where they are a major source. The following measures may be taken in this regard:

Prioritize family planning in the day-to-day agenda of LHWs - Practical measures must be taken to ensure that LHWs dedicate adequate time to family planning work, visit and ask women concerning family planning needs, and refer them to health facilities for longer term or permanent methods. The score allocated to family planning on the LHWs' performance scorecard should be increased. Checklists could be developed to ensure that LHWs regularly discuss family planning with clients. The program's Management Information System (MIS) should be used to monitor and ensure regular follow-up of family planning clients by LHWs. At the broader level, provincial plans for family planning should specifically mention the role expected from LHWs. 
Improve the supply of contraceptives to LHWs - It must be ensured that LHWs have regular and adequate supplies of all contraceptive methods, which are often out of stock in Punjab. In particular, supply of contraceptives from district stores to facilities must be improved (Population Council 2016). Rather than being rationed, supplies to LHWs should reflect the realistically assessed needs of their family planning clientele.

Train LHWs for a stronger role in family planning - LHWs should be trained with a focus on areas in which their knowledge is low. Specifically, they must be trained to support clients through counseling and management of side effects of various contraceptive methods, especially pills and injectables (Rashida et al. 2015). In addition to technical and client-centered training, the potential of mHealth technology to facilitate decision-making by LHWs should be explored.

Expand the choice of contraceptive methods LHWs can provide - LHWs are willing and have the capacity to provide additional contraceptive methods that they are not currently permitted to provide, including SDM, emergency contraceptive pills, the first dose of injectable contraceptives (Population Council 2016; Mahmood and Nisar 2012), and Sayana Press ${ }^{\circledR}$. These methods should be added to their repertoire. SDM could serve as a side effect-free gateway method for new users. Careful training of LHWs to provide the first dose of injectables could greatly increase the availability and use of this longer-acting method as it is particularly suited to remote communities. 


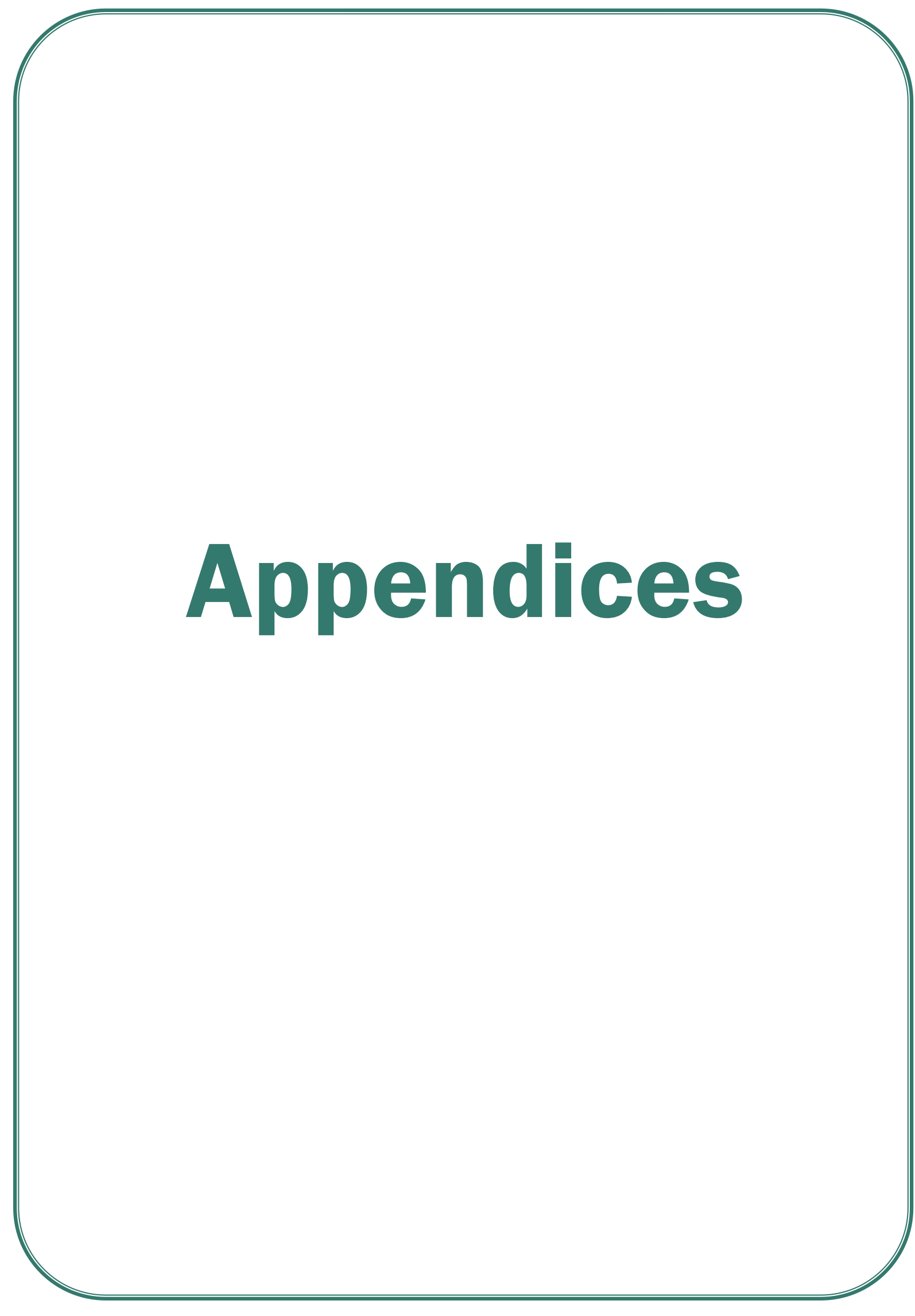




\section{Appendix A}

Table A.1: Currently Married Women with Unmet Need in Punjab, by District - 2017, Population Census

\begin{tabular}{|c|c|c|c|c|c|c|c|}
\hline Division/District & $\begin{array}{l}\text { Population } \\
\text { Census- } \\
2017(000)\end{array}$ & $\begin{array}{l}\text { \%age of } \\
\text { CMWA }\end{array}$ & $\begin{array}{c}\text { Number } \\
(000) \\
\text { CMWA }\end{array}$ & TFR & CPR (\%) & $\begin{array}{l}\text { Unmet need } \\
(\%)\end{array}$ & $\begin{array}{c}\text { Number } \\
(000) \\
\text { CMWA with } \\
\text { Unmet need }\end{array}$ \\
\hline The Punjab & 110,006 & 16.24 & 17,865 & 3.5 & 38.7 & 17.5 & 3,126 \\
\hline Bahawalpur Div. & 11,463 & 16.26 & 1,864 & 3.5 & 29.0 & 19.4 & 362 \\
\hline Bahawalpur & 3,668 & 17.01 & 624 & 3.8 & 25.7 & 21.5 & 134 \\
\hline Bahawalnagar & 2,982 & 15.66 & 467 & 3.4 & 35.2 & 16.4 & 77 \\
\hline R.Y.Khan & 4,814 & 16.07 & 774 & 3.3 & 27.9 & 19.5 & 151 \\
\hline D.G. Khan Div. & 11,014 & 16.03 & 1,766 & 4.8 & 25.3 & 25.3 & 447 \\
\hline D.G.Khan & 2,872 & 16.79 & 482 & 4.9 & 22.1 & 27.3 & 132 \\
\hline Layyah & 1,824 & 15.08 & 275 & 3.5 & 30.6 & 21.2 & 58 \\
\hline Muzaffargarh & 4,322 & 16.14 & 698 & 4.6 & 27.1 & 26.2 & 183 \\
\hline Rajanpur & 1,996 & 15.44 & 308 & 6.2 & 21.8 & 24.0 & 74 \\
\hline Faisalabad Div. & 14,176 & 16.03 & 2,272 & 3.4 & 36.0 & 17.7 & 402 \\
\hline Faisalabad & 7,873 & 15.66 & 1,233 & 3.4 & 37.8 & 17.6 & 217 \\
\hline Chiniot & 1,370 & 16.08 & 220 & 3.2 & 28.3 & 16.9 & 37 \\
\hline Jhang & 2,743 & 16.48 & 452 & 3.7 & 31.7 & 20.1 & 91 \\
\hline T.T.Singh & 2,190 & 16.73 & 366 & 3.3 & 40.0 & 15.7 & 58 \\
\hline Gujranwala Div. & 16,123 & 16.31 & 2,630 & 3.3 & 46.9 & 14.9 & 392 \\
\hline Gujranwala & 5,014 & 15.69 & 787 & 3.3 & 46.9 & 17.7 & 139 \\
\hline Gujrat & 2,756 & 15.44 & 426 & 2.9 & 46.1 & 14.5 & 62 \\
\hline Hafizabad & 1,157 & 16.44 & 190 & 3.3 & 50.3 & 12.6 & 24 \\
\hline $\begin{array}{l}\text { Mandi Baha-ud- } \\
\text { Din }\end{array}$ & 1,593 & 17.08 & 272 & 3.1 & 40.6 & 14.8 & 40 \\
\hline Narowal & 1,710 & 15.99 & 273 & 4.3 & 51.0 & 15.0 & 41 \\
\hline Sialkot & 3,893 & 17.49 & 681 & 3.1 & 47.6 & 12.4 & 84 \\
\hline Lahore Div. & 19,396 & 15.76 & 3,057 & 3.5 & 45.6 & 16.4 & 501 \\
\hline Lahore & 11,125 & 15.86 & 1,764 & 3.1 & 47.3 & 15.9 & 281 \\
\hline Kasur & 3,455 & 15.39 & 532 & 4.5 & 42.3 & 14.9 & 79 \\
\hline Nankana Sahib & 1,356 & 16.17 & 219 & 3.5 & 45.7 & 17.0 & 37 \\
\hline Sheikhupura & 3,460 & 15.68 & 543 & 3.5 & 43.4 & 18.8 & 102 \\
\hline Multan Div. & 12,265 & 16.88 & 2,070 & 3.4 & 39.4 & 16.2 & 335 \\
\hline Multan & 4,745 & 16.99 & 806 & 3.6 & 39.0 & 16.6 & 134 \\
\hline Khanewal & 2,922 & 16.62 & 486 & 3.4 & 39.5 & 15.7 & 76 \\
\hline Lodhran & 1,701 & 17.05 & 290 & 3.9 & 39.2 & 15.7 & 46 \\
\hline Vehari & 2,897 & 16.87 & 489 & 2.8 & 40.4 & 16.6 & 81 \\
\hline Rawalpindi Div. & 10,007 & 16.43 & 1,644 & 2.9 & 44.4 & 14.5 & 238 \\
\hline Rawalpindi & 5,405 & 15.88 & 858 & 3.1 & 43.2 & 15.8 & 136 \\
\hline
\end{tabular}




\begin{tabular}{|c|c|c|c|c|c|c|c|}
\hline Division/District & $\begin{array}{l}\text { Population } \\
\text { Census- } \\
2017(000)\end{array}$ & $\begin{array}{l}\text { \%age of } \\
\text { CMWA }\end{array}$ & $\begin{array}{c}\text { Number } \\
(000) \\
\text { CMWA }\end{array}$ & TFR & CPR (\%) & $\begin{array}{l}\text { Unmet need } \\
\text { (\%) }\end{array}$ & $\begin{array}{c}\text { Number } \\
(000) \\
\text { CMWA with } \\
\text { Unmet need }\end{array}$ \\
\hline Attock & 1,883 & 17.03 & 321 & 3.0 & 48.2 & 12.5 & 40 \\
\hline Chakwal & 1,496 & 17.62 & 264 & 2.7 & 44.9 & 12.8 & 34 \\
\hline Jhelum & 1,223 & 16.96 & 207 & 2.3 & 42.7 & 14.3 & 30 \\
\hline Sahiwal Div. & 7,380 & 16.55 & 1,221 & 3.8 & 37.7 & 17.4 & 213 \\
\hline Sahiwal & 2,517 & 16.52 & 416 & 3.9 & 37.6 & 15.6 & 65 \\
\hline Okara & 3,039 & 16.51 & 502 & 3.8 & 37.4 & 20.3 & 102 \\
\hline Pakpattan & 1,824 & 16.66 & 304 & 3.7 & 38.6 & 15.0 & 46 \\
\hline Sargodha Div. & 8,181 & 16.41 & 1,343 & 3.1 & 33.3 & 18.0 & 242 \\
\hline Sargodha & 3,703 & 16.70 & 618 & 2.6 & 34.6 & 19.1 & 118 \\
\hline Bhakkar & 1,650 & 15.56 & 257 & 3.9 & 31.9 & 17.6 & 45 \\
\hline Khushab & 1,281 & 16.60 & 213 & 3.3 & 32.2 & 18.2 & 39 \\
\hline Mianwali & 1,546 & 16.56 & 256 & 3.3 & 32.9 & 15.8 & 40 \\
\hline
\end{tabular}

Population and Housing Census 2017

\%age of CMWA from PSLM 2014-15

TFR, CPR and Unmet need from Punjab MICS 2014 


\section{Appendix B}

Data Collection Activities, by Study Component and District

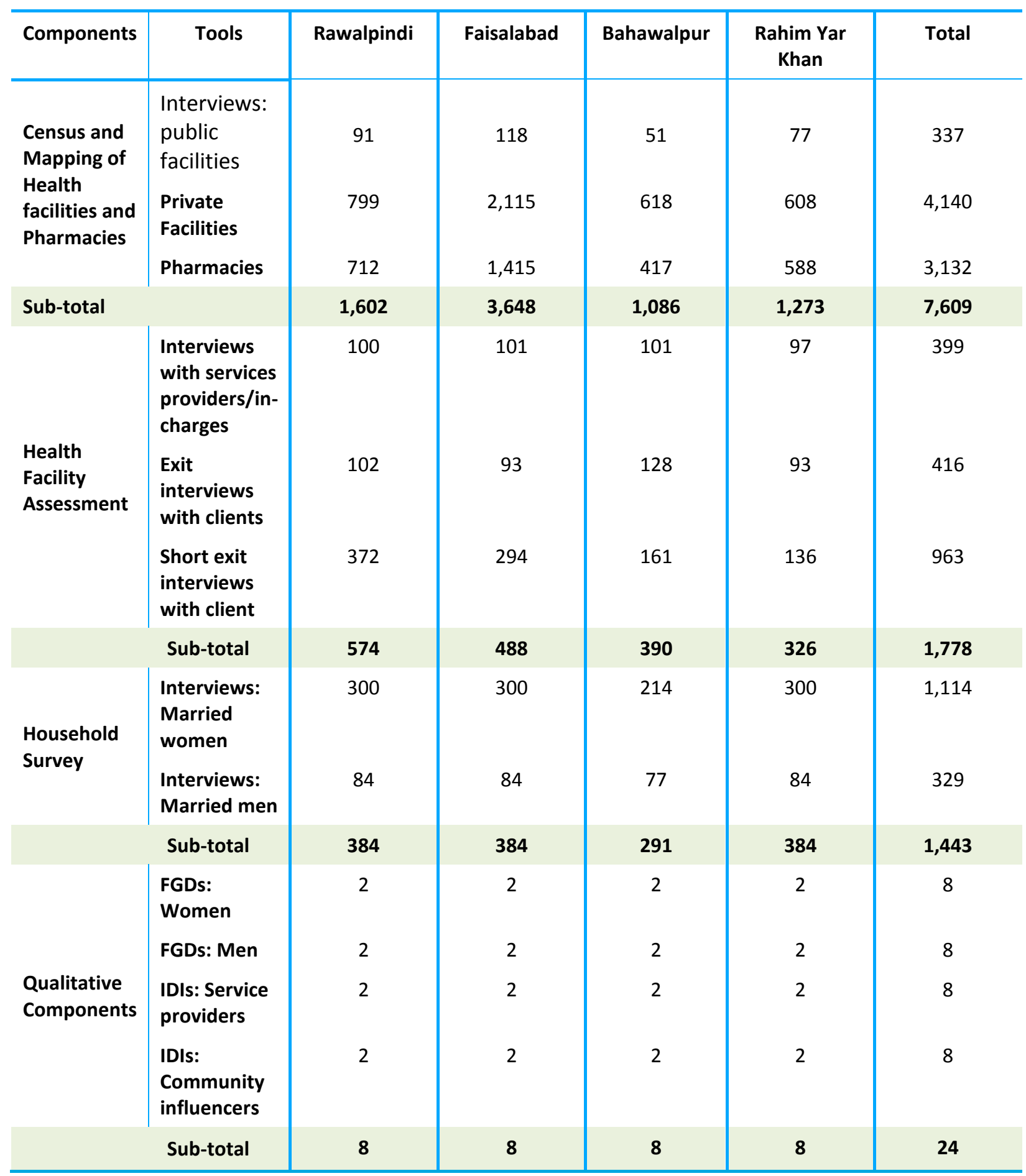




\section{Appendix C}

\section{Consent Form for Structured Interview with In-charge of Health Facility and Health Care Provider}

My name is and I have come from the Population Council, an international non-profit organization working for improving the maternal and reproductive health of the marginalized populations. We are conducting a survey to assess gaps in service delivery and clients' choices when seeking family planning (FP) services in Pakistan.

You are invited to take part in this research study. Before you decide whether to participate, you need to understand why the research is being done and what it will involve. Please take the time to read, or to listen as I read, the following information. You may talk to others about the study if you wish. Please ask me if there is anything that is not clear or if you would like more information. When all of your questions have been answered and you feel that you understand this study, you will be asked if you wish to participate in the study. If your answer is yes, you will be asked to sign this Informed Consent Form. You may be given a signed copy to keep, if you require.

\section{PURPOSE OF THIS RESEARCH STUDY}

The purpose of this study is to assess gaps in services delivery and to see what drives clients' choices when seeking FP services with regards to choice of provider, location and contraceptive method in Pakistan.

The study is being conducted by the Population Council and funded by the Department for International Development (DFID).

\section{PROCEDURES}

You are invited to participate in an interview because you are knowledgeable and understand the provision of FP services at your facility and in general. We will also assess the client load of your facility. The interview will take 60-90 minutes. The duration of the entire study is 12 months. We may need to contact you again to clarify a point made earlier, and you may agree or disagree to participate.

\section{POSSIBLE RISKS OR DISCOMFORT}

If this is not a convenient time for you, we can come back later. Since the interview will be conducted in privacy, the risks of other people learning about what you say are very minimal. Another possible inconvenience may be the time and effort you take to be an informant. You are free to not respond to any question that makes you uncomfortable or that you do not want to answer. You may end your participation at any time without any penalty.

\section{POSSIBLE BENEFITS}

There are no direct benefits to you for participating in the study. You may find an indirect benefit in knowing that you have participated in an important study that will help achieve the goal of universal access to FP services for Punjab in Pakistan.

\section{VOLUNTARINESS}

Your participation in this study is completely voluntary and you will not be paid any compensation for your time. There is no penalty for refusing to take part. If you agree to participate in this study, you may end your participation at any time without penalty and leave. If you decide to take part, you are free to not respond to any questions. You are free to withdraw at any time without affecting your relationship with the study team and community. There is no penalty for refusing to take part.

\section{CONFIDENTIALITY}

Your responses to this interview will be completely confidential and will be used for research purposes only. No personal reference will be made to your participation in this study. We will combine your responses with those of other participants to describe the general picture in Pakistan. Data will be stored in a locked cabinet dedicated to this study. This information will only be accessible to the authorized study team. All records and related documents will be destroyed after 3 years.

The national and international regulatory agencies and sponsoring agencies may request access to confidential records of participating subjects, but the identity of subjects will remain confidential.

As part of the sponsor's monitoring program, you may be requested for an interview by a representative of the sponsor of the study to determine whether informed consent was given. If such a request is made, you will have the option of accepting/declining the interview.

\section{ADDITIONAL SOURCES OF INFORMATION}

The results of the study will be published in a report and discussed at national meetings and conferences. This study has been reviewed by the Population Council's Internal Review Board in New York.

If you have any concern about any aspect of the study, you should ask to speak to the researchers, who will do their best to answer your questions. 
Any complaint about the way you have been treated during the study or any possible harm you might suffer will be addressed. You may call Ms. Zeba Tasneem at 0092-51-8445566 (Ext. 127) for any complaints.

For information about your rights or in case of violation of rights you may contact Ms. Iram Kamran at 0092-51-8445566 (Ext. 129).

\section{AUTHORIZATION}

I have read/heard the Informed Consent for this study. I have received an explanation of the planned interview and its procedure, risks and benefits and confidentiality of my personal information. I agree to take part in this study. I understand that my participation in this study is voluntary. I understand that information obtained in this study will be transmitted only in a form that cannot be identified with me.

Your name:

Your signature:

Date:

Investigator or person who conducted Informed Consent discussion: I confirm that I have personally explained, in the language he/she understands, the nature and extent of the study, potential risks and benefits, and confidentiality of personal information.

Name of person obtaining consent:

Signature of person obtaining consent:

Date: 


\section{Consent Form for Structured Interview with Family Planning Client}

My name is and I have come from the Population Council, an international non-profit organization working for improving the maternal and reproductive health of the marginalized populations. We are conducting a survey to assess gaps in service delivery and clients' choices when seeking family planning (FP) services in Pakistan.

You are invited to take part in this research study. Before you decide whether to participate, you need to understand why the research is being done and what it would involve. Please take the time to read, or to listen as I read, the following information. You may talk to others about the study if you wish. Please ask me if there is anything that is not clear or if you would like more information. When all of your questions have been answered and you feel that you understand this study, you will be asked if you wish to participate in the study. If your answer is yes, you will be asked to sign this Informed Consent Form. You may be given a signed copy to keep, if you require.

\section{PURPOSE OF THIS RESEARCH STUDY}

The purpose of this study is to assess gaps in services delivery and to see what drives clients' choices when seeking FP services with regard to choice of provider, location and contraceptive method in Pakistan.

The study is being conducted by the Population Council and is funded by the Department for International Development (DFID).

\section{PROCEDURES}

You are invited to participate in an interview because you are knowledgeable and understand about FP services being provided in your community. The interview will take 30 minutes. The duration of the entire study is 12 months. We may need to contact you again to clarify a point made earlier, and you may agree or disagree to participate.

\section{POSSIBLE RISKS OR DISCOMFORT}

If this is not a convenient time for you, we can come back later to your home for the interview. Since the interview will be conducted in privacy, the risks of other people learning about what you have said are very minimal. Another possible inconvenience may be the time and effort you take to be an informant. You are free to not respond to any question that makes you uncomfortable or that you do not want to answer. You may end your participation at any time without any penalty.

\section{POSSIBLE BENEFITS}

There are no direct benefits to you for participating in the study. You may find an indirect benefit in knowing that you have participated in an important study that would help achieve the goal of universal access to FP services for Punjab in Pakistan.

\section{VOLUNTARINESS}

Your participation in this study is completely voluntary and you will not be paid any compensation for your time. There is no penalty for refusing to take part. If you agree to participate in this study, you may end your participation at any time without penalty and leave. If you decide to take part, you are free to not respond to any questions. You are free to withdraw at any time without affecting your relationship with the study team and community. There is no penalty for refusing to take part.

\section{CONFIDENTIALITY}

Your responses to this interview will be completely confidential and will be used for research purposes only. No personal reference will be made to your participation in this study. We will combine your responses with those of other participants to describe the general picture in Pakistan. Data will be stored in a locked cabinet dedicated to this study. This information will only be accessible to the authorized study team. All records and related documents will be destroyed after 3 years.

National and international regulatory agencies and sponsoring agencies may request access to confidential records of participating subjects, but the identity of subjects will remain confidential.

As part of the sponsor's monitoring program, you may be asked for an interview by a representative of the sponsor of the study to determine whether informed consent was given. If an interview is requested, you will have the option of accepting/declining the interview.

\section{ADDITIONAL SOURCES OF INFORMATION}

The results of the study will be published in a report and discussed at national meetings and conferences. This study has been reviewed by the Population Council's Internal Review Board in New York.

If you have any concern about any aspect of the study, you should ask to speak to the researchers, who will do their best to answer your questions. 
Any complaint about the way you have been treated during the study or any possible harm you might suffer will be addressed. You may call Ms. Zeba Tasneem at 0092-51-8445566 (Ext. 127) for any complaints.

For information about your rights or in case of violation of rights you may contact Ms. Iram Kamran at 0092-51-8445566 (Ext. 129).

\section{AUTHORIZATION}

I have read/heard the Informed Consent for this study. I have received an explanation of the planned interview and its procedure, risks and benefits, and privacy of my personal information. I agree to take part in this study. I understand that my participation in this study is voluntary. I understand that information obtained in this study will be transmitted only in a form that cannot be identified with me.

Your name:

Your signature: Date:

Investigator or person who conducted Informed Consent discussion: I confirm that I have personally explained, in the language he/she understands, the nature and extent of the study, potential risks and benefits, and confidentiality of personal information.

Name of person obtaining consent:

Signature of person obtaining consent:

Date: 


\section{Consent Form for Focus Group Discussions with Currently Married Men and Women of Reproductive Age}

My name is and I have come from the Population Council, an international non-profit organization working for improving the maternal and reproductive health of the marginalized populations. We are conducting a survey to assess gaps in services delivery and clients' choices when seeking family planning (FP) services in Pakistan.

You are invited to take part in this research study. Before you decide whether to participate, you need to understand why the research is being done and what it would involve. Please take the time to read, or to listen as I read, the following information. You may talk to others about the study if you wish. Please ask me if there is anything that is not clear or if you would like more information. When all of your questions have been answered and you feel that you understand this study, you will be asked if you wish to participate in the study. If your answer is yes, you will be asked to sign this Informed Consent Form. You may be given a signed copy to keep, if you require.

\section{PURPOSE OF THIS RESEARCH STUDY}

The purpose of this study is to assess gaps in services delivery and to see what drives client's choices when seeking FP services with regards to choice of provider, location, reason for choice of contraceptive method, including discontinuation and switching of a method in Pakistan. The study is being conducted by the Population Council and is funded by the Department for International Development (DFID).

\section{PROCEDURES}

You are invited to participate in a group discussion (FGD) because you are knowledgeable and have an understanding about FP services being provided and what particular cadre of providers/facility is preferred in your household or community. The discussion will take 60-90 minutes. The duration of the entire study is 12 months. We may need to contact you again to clarify a point made earlier, and you may agree or disagree to participate.

\section{POSSIBLE RISKS OR DISCOMFORT}

If this is not a convenient time for you, we can come back later. Since the discussion will be conducted in privacy, the risks of other people learning about what you have said are very minimal. However, other people participating in the discussion will hear the experiences and opinions you share. You, along with other participants, will have to pledge that you will not share the information with anyone else outside the group. Another possible inconvenience may be the time and effort you take to be an informant. You are free to not respond to any question that makes you uncomfortable or that you do not want to answer. You may end your participation at any time without any penalty.

\section{POSSIBLE BENEFITS}

There are no direct benefits to you for participating in the study. You may find an indirect benefit in knowing that you have participated in an important study that will help achieve the goal of universal access to FP services for Punjab in Pakistan.

\section{VOLUNTARINESS}

Your participation in this study is completely voluntary and you will not be paid any compensation for your time. There is no penalty for refusing to take part. If you agree to participate in this study, you may end your participation at any time without penalty and leave. If you decide to take part, you are free to skip any questions. You are free to withdraw at any time without affecting your relationship with the study team and community. There is no penalty for refusing to take part.

\section{CONFIDENTIALITY}

Your responses to this interview will be completely confidential and will be used for research purposes only. No personal reference will be made to your participation in this study. We will combine your responses with those of other participants to describe the general picture in Pakistan. If you give permission, this discussion will be audio recorded to ensure that the information provided by you is accurately captured. The study team will write down the whole discussion on paper after listening to this recording. The recording will be stored in the computer and protected by a password and accessible only to the study team. Written material will be stored in a locked cabinet dedicated to this study. This information will only be accessible to the study team. All records will be destroyed after 3 years.

\section{ADDITIONAL SOURCES OF INFORMATION}

The results of the study will be published in a report and discussed at national meetings and conferences. This study has been reviewed by the Population Council's Internal Review Board in New York.

If you have any concern about any aspect of the study, you should ask to speak to the researchers, who will do their best to answer your questions. 
Any complaint about the way you have been treated during the study or any possible harm you might suffer will be addressed. You may call Ms. Zeba Tasneem at 0092-51-8445566 (Ext. 127) for any complaints.

For information about your rights or in case of violation of rights you may contact Ms. Iram Kamran at 0092-51-8445566 (Ext. 129).

\section{AUTHORIZATION}

I have read/heard the Informed Consent for this study. I have received an explanation of the planned discussion and its procedure, risks and benefits, and confidentiality of my personal information. I agree to take part in this study. I understand that my participation in this study is voluntary. I understand that information obtained in this study will be transmitted only in a form that cannot be identified with me.

Your name:

Your signature:

Date:

Investigator or person who conducted Informed Consent discussion: I confirm that I have personally explained, in the language he/she understands, the nature and extent of the study, potential risks and benefits, and confidentiality of personal information.

Name of person obtaining consent: 


\section{Appendix D}

Table D1 shows the number of public and private health facilities and pharmacies present in each of the 16 study clusters. Cluster 1 is based in the main city area in each district, while the other clusters are situated in less densely populated settings. As expected, the presence of most types of health facilities as well as pharmacies is highest in Cluster 1 in each district, the only exception being BHUs, which are more spread out across the clusters. Department of Health (DoH) and Population Welfare Department (PWD) facilities are quite heavily concentrated in the most urban setting, and likewise the LHWs. However, the disparity in availability between the main city and other parts of the district is greatest for the private sector: the combined numbers of health facilities and pharmacies in Clusters 3 to 4 are much lower than the numbers present in Cluster 1.

Table D1: Distribution of Health Facilities and Pharmacies in the Study Areas

\begin{tabular}{|c|c|c|c|c|c|c|}
\hline Sector & Cluster & Rawalpindi & Faisalabad & Bahawalpur & $\begin{array}{l}\text { Rahimyar } \\
\text { Khan }\end{array}$ & Total \\
\hline \multirow[t]{5}{*}{ Department of Health } & Cluster 1 & 14 & 25 & 9 & 2 & 50 \\
\hline & Cluster 2 & 6 & 6 & 6 & 7 & 25 \\
\hline & Cluster 3 & 9 & 3 & 3 & 2 & 17 \\
\hline & Cluster 4 & 7 & 2 & 1 & 7 & 17 \\
\hline & Sub-Total & 36 & 36 & 19 & 18 & 109 \\
\hline \multirow{5}{*}{$\begin{array}{l}\text { Basic Health Unites } \\
\text { (BHUs) }\end{array}$} & Cluster 1 & 2 & 12 & 3 & 6 & 23 \\
\hline & Cluster 2 & 15 & 13 & 6 & 4 & 38 \\
\hline & Cluster 3 & 3 & 9 & 4 & 6 & 22 \\
\hline & Cluster 4 & 10 & 9 & 5 & 12 & 36 \\
\hline & Sub-Total & 30 & 43 & 18 & 28 & 119 \\
\hline \multirow{5}{*}{$\begin{array}{l}\text { Population Welfare } \\
\text { Department }\end{array}$} & Cluster 1 & 7 & 28 & 7 & 10 & 52 \\
\hline & Cluster 2 & 5 & 4 & 3 & 7 & 19 \\
\hline & Cluster 3 & 6 & 1 & 2 & 3 & 12 \\
\hline & Cluster 4 & 2 & 1 & 3 & 12 & 18 \\
\hline & Sub-Total & 20 & 34 & 15 & 32 & 101 \\
\hline \multirow{4}{*}{$\begin{array}{l}\text { Total Public Static } \\
\text { Facilities }\end{array}$} & Cluster 1 & 23 & 65 & 19 & 18 & 125 \\
\hline & Cluster 2 & 26 & 23 & 15 & 18 & 82 \\
\hline & Cluster 3 & 18 & 13 & 9 & 11 & 51 \\
\hline & Cluster 4 & 19 & 12 & 9 & 31 & 71 \\
\hline \multicolumn{2}{|l|}{$\begin{array}{l}\text { Total Public Static } \\
\text { Facilities }\end{array}$} & 86 & 113 & 52 & 78 & 329 \\
\hline \multirow[t]{5}{*}{ Lady Health Workers } & Cluster 1 & 574 & 815 & 183 & 177 & 1749 \\
\hline & Cluster 2 & 169 & 198 & 115 & 124 & 606 \\
\hline & Cluster 3 & 60 & 89 & 99 & 117 & 365 \\
\hline & Cluster 4 & 45 & 84 & 58 & 70 & 257 \\
\hline & Sub-Total & 848 & 1186 & 455 & 488 & 2977 \\
\hline \multirow[t]{4}{*}{ Private Health Facilities } & Cluster 1 & 532 & 1582 & 328 & 211 & 2653 \\
\hline & Cluster 2 & 153 & 308 & 131 & 226 & 818 \\
\hline & Cluster 3 & 78 & 128 & 77 & 95 & 378 \\
\hline & Cluster 4 & 38 & 88 & 88 & 76 & 290 \\
\hline \multicolumn{2}{|c|}{ Total Private Health Facilities } & 801 & 2106 & 624 & 608 & 4,139 \\
\hline \multirow[t]{4}{*}{ Pharmacies } & Cluster 1 & 497 & 1150 & 228 & 235 & 2,110 \\
\hline & Cluster 2 & 80 & 142 & 97 & 150 & 469 \\
\hline & Cluster 3 & 108 & 33 & 34 & 95 & 270 \\
\hline & Cluster 4 & 28 & 90 & 59 & 107 & 284 \\
\hline \multicolumn{2}{|l|}{ Pharmacies } & 713 & 1415 & 418 & 587 & 3,133 \\
\hline \multicolumn{2}{|l|}{ Overall Total } & 2448 & 4820 & 1549 & 1761 & 10578 \\
\hline
\end{tabular}

Source: CFP and PC-Landscape 


\section{District-wise Distribution of Facilities and Pharmacies}

A closer look at the distribution of static public facilities, shown in Figure D1, reveals that BHUs comprise nearly 35 percent of the public facilities in the study districts while the proportions of other types of facilities vary. Dispensaries comprise a greater share in Rawalpindi and Faisalabad and only a small share in Rahim Yar Khan. On the other hand, the proportion of public hospitals, which include the district and tehsil headquarters hospitals (DHQs and THQs) and rural health centers (RHCs), is largest in Bahawalpur and smallest in Faisalabad, while facilities of PWD comprise the largest share of public health facilities in Rahimyar Khan.

In Rawalpindi there are 86 public static facilities in the four clusters which are serving a population of 1.9 million. In Faisalabad, the population covered is highest (4.4 million) than other districts but total public static facilities are only 113. In Bahawalpur and Rahim Yar Khan the population is 1.3 million and 1.6 million but total public facilities are 52 and 78 , respectively.

Figure D1: Distribution of Public Static Health Facilities, by District $(\mathrm{N}=329)$

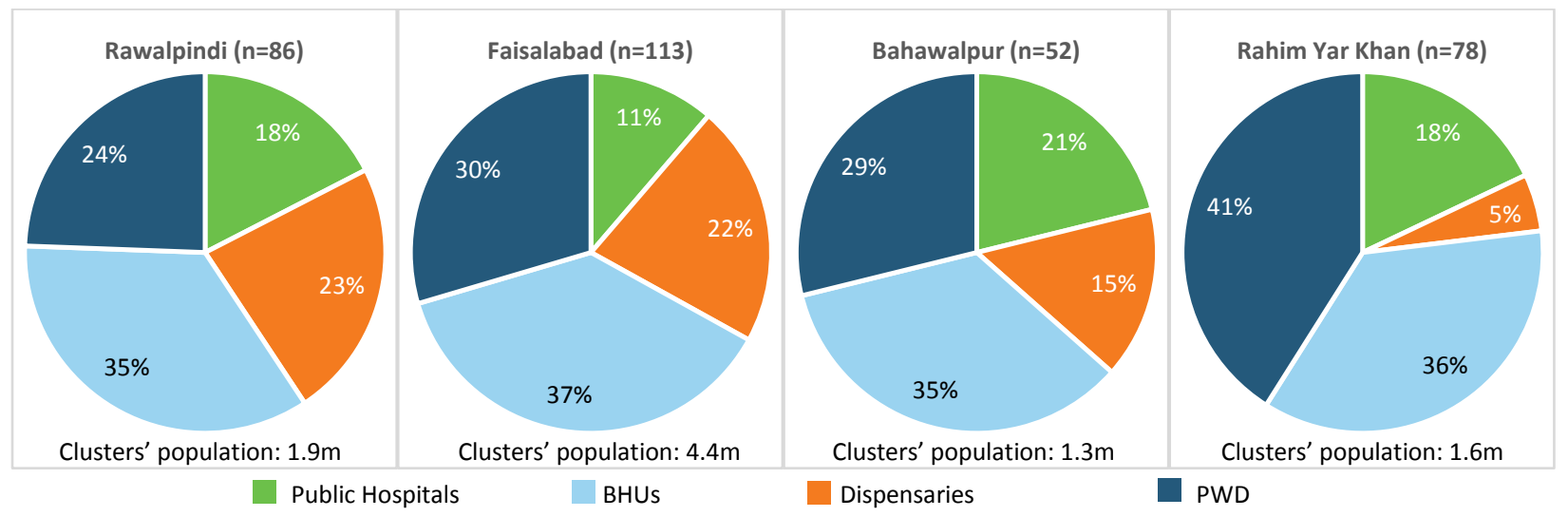

Source: CFP and PC-Landscape

Figure D2 shows that clinics of homeopaths and hakeems comprise the largest proportion of private health facilities in Rawalpindi (44\%), Faisalabad (52\%), and Bahawalpur (50\%), and the second largest (only marginally) in Rahim Yar Khan. Clinics of dispensers comprise the largest proportion of private health facilities in Rahim Yar Khan and are the second most common type of facility in Bahawalpur and Faisalabad but have a negligible presence in Rawalpindi. The next most common type of facility is the male doctor's clinic, followed by private hospitals in all districts except Bahawalpur; these facilities comprise a conspicuously larger share of facilities in Rawalpindi than in other districts. Clinics of female providers comprise relatively small shares in all districts, with mid-level providers such as midwives, nurses and Lady Health Visitors (LHVs) outnumbering doctors. Finally, clinics run by NGOs comprise roughly the same low proportion as female doctors in all districts. 
Figure D2: Distribution of Various Types of Private Health Facilities, by District $(\mathrm{N}=4,139)$

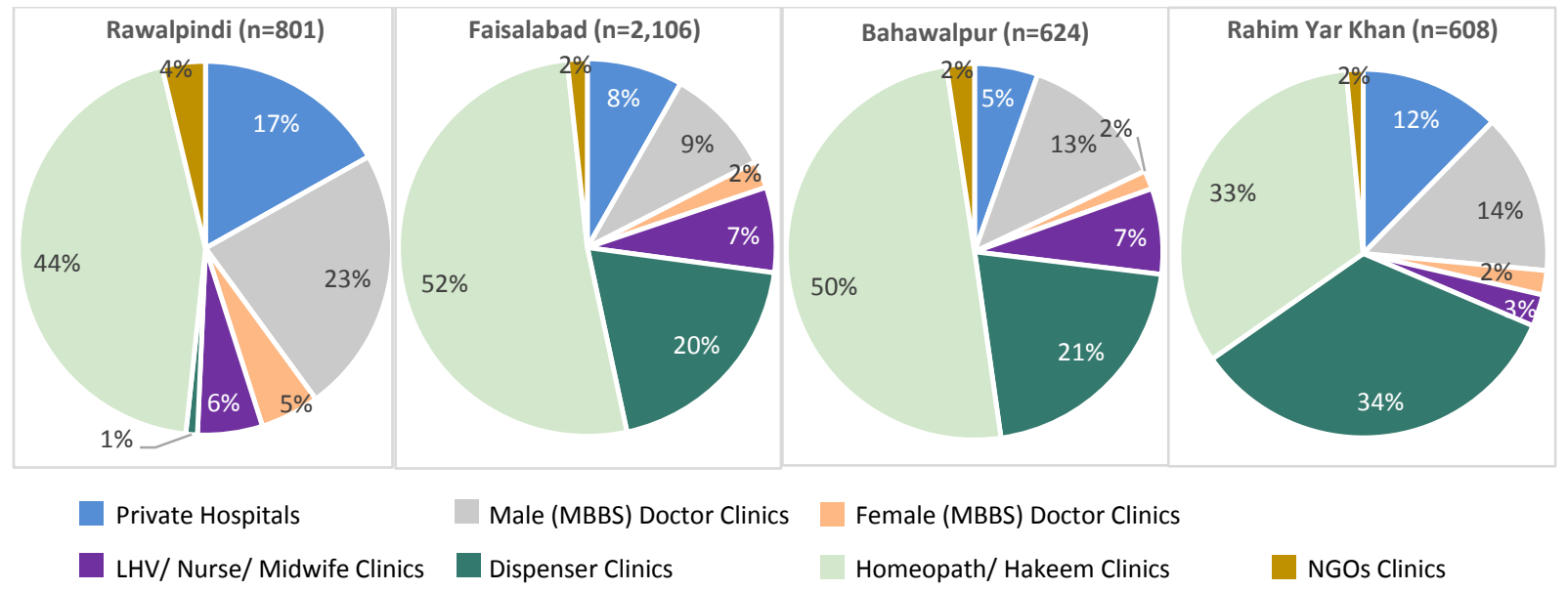

Source: CFP and PC-Landscape

Adding community-based health workers, specifically LHWs, and pharmacies to the pool of service delivery points (SDPs) greatly expands the number of public and private sector facilities. Figure D3 shows that LHWs are easily the largest public health service channel, comprising 86-91 percent of public sector SDPs in all districts.

Figure D3: Distribution of Public Sector Health Facilities, including LHWs, in Study Areas $(\mathrm{N}=3,306)$

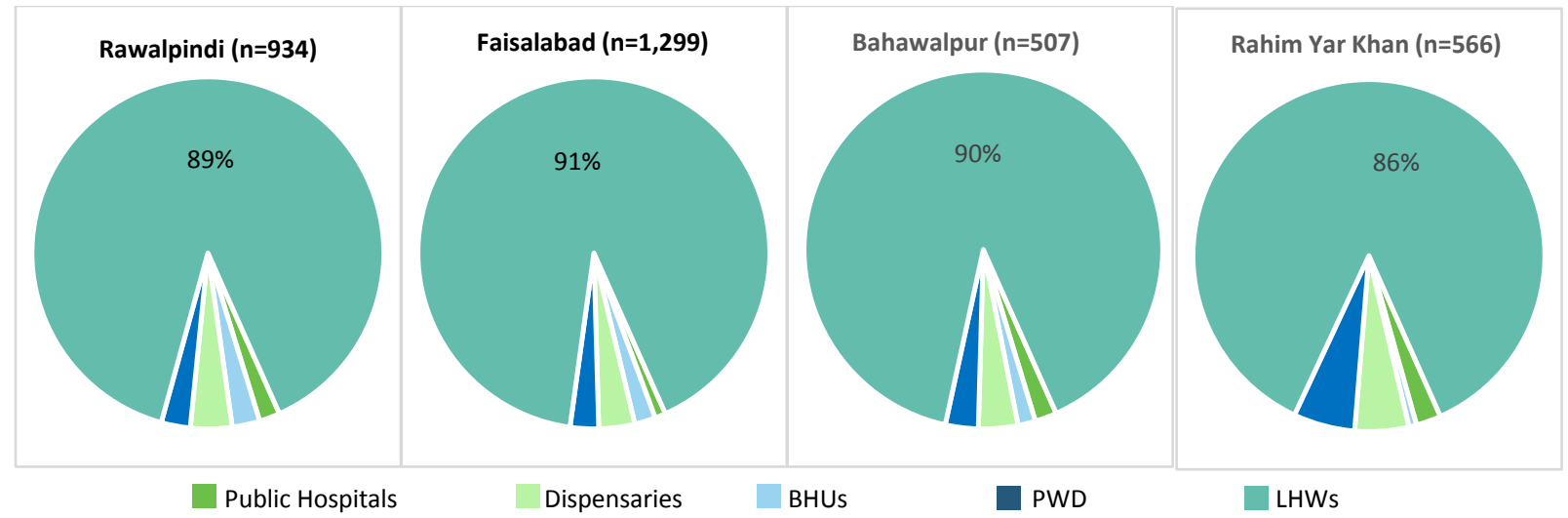

Source: CFP and PC-Landscape

Similarly, as Figure D4 shows, pharmacies make up 40-49 percent of private sector channels in the study districts. 
Figure D4: Distribution of Private Sector Health Facilities and Pharmacies in Study Areas $(\mathrm{N}=7,272)$

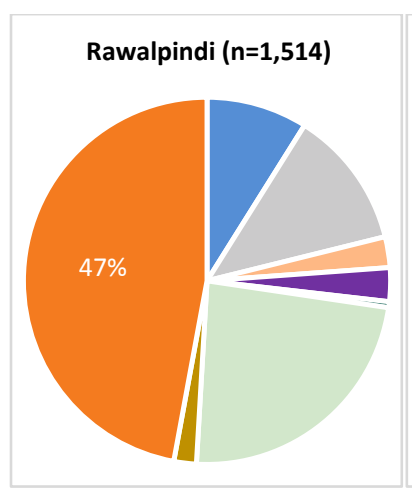

Private Hospitals

LHV/ Nurse/ Midwife Clinics
Faisalabad $(n=3,521)$

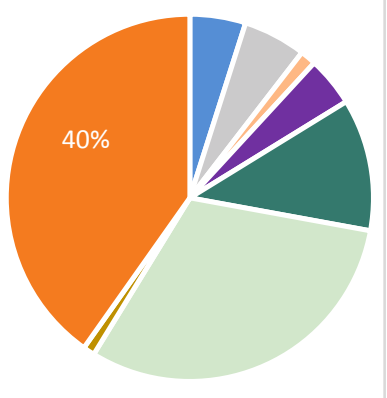

Male (MBBS) Doctor Clinics

Dispenser Clinics
Bahawalpur $(n=1,042)$

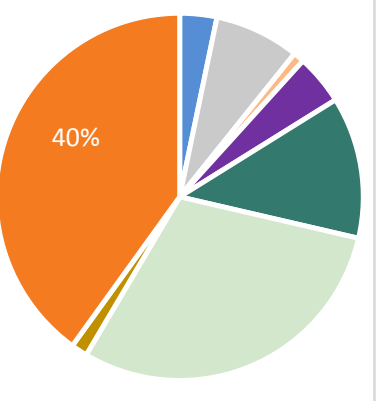

Female (MBBS) Doctor Clinics

Homeopath/ Hakeem Clinics

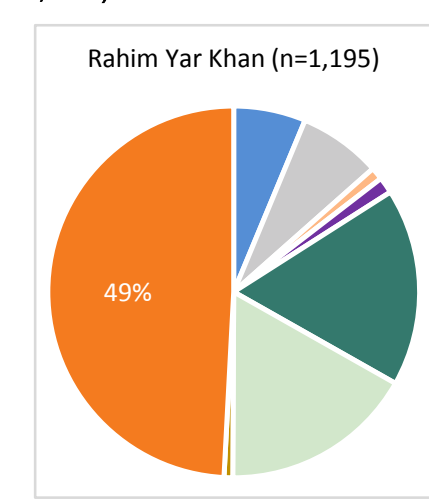

Pharmacies

NGOs Clinics

Source: CFP and PC-Landscape

\section{Urban-rural Distribution of Facilities and Pharmacies}

Table D2 shows the urban-rural distribution of public and private sector health facilities, LHWs, and pharmacies. The data shows that, among public health facilities, more hospitals, including teaching hospitals, DHQs and THQs, are located in the urban areas while basic health units (BHUs) are primarily located in the rural areas. Dispensaries and facilities of the PWD are more concentrated in urban areas in all districts. LHWs, the most numerous channel, are more concentrated in rural areas.

Table also shows that private facilities are significantly more concentrated in urban areas in three districts, especially Faisalabad. However, in other three districts private health facilities are almost equally distributed between urban and rural areas. In all four districts, more pharmacies are located in urban areas, although the proportion, again, varies considerably, being highest in Faisalabad and lowest in Bahawalpur. 
Table D2: Urban-rural Distribution of Health Facilities, LHW, and Pharmacies in the Study Areas

\begin{tabular}{|c|c|c|c|c|c|c|c|c|c|c|c|c|c|c|c|c|c|c|c|c|c|}
\hline \multirow{3}{*}{ Sector and Type of Facility } & \multicolumn{4}{|c|}{ Rawalpindi } & \multicolumn{4}{|c|}{ Faisalabad } & \multicolumn{4}{|c|}{ Bahawalpur } & \multicolumn{4}{|c|}{ Rahimyar Khan } & \multicolumn{4}{|c|}{ Overall } & \multirow{3}{*}{$\begin{array}{c}\text { Total } \\
\mathrm{N} \\
\end{array}$} \\
\hline & \multicolumn{2}{|c|}{ Urban } & \multicolumn{2}{|c|}{ Rural } & \multicolumn{2}{|c|}{ Urban } & \multicolumn{2}{|c|}{ Rural } & \multicolumn{2}{|c|}{ Urban } & \multicolumn{2}{|c|}{ Rural } & \multicolumn{2}{|c|}{ Urban } & \multicolumn{2}{|c|}{ Rural } & \multicolumn{2}{|c|}{ Urban } & \multicolumn{2}{|c|}{ Rural } & \\
\hline & $\%$ & $\mathrm{~N}$ & $\%$ & $\mathrm{~N}$ & $\%$ & $\mathrm{~N}$ & $\%$ & $\mathrm{~N}$ & $\%$ & $\mathrm{~N}$ & $\%$ & $\mathrm{~N}$ & $\%$ & $\mathrm{~N}$ & $\%$ & $\mathrm{~N}$ & $\%$ & $\mathrm{~N}$ & $\%$ & $\mathrm{~N}$ & \\
\hline \multicolumn{22}{|l|}{ Department of Health } \\
\hline \multicolumn{22}{|l|}{ Category I } \\
\hline Teaching Hospitals & 100 & 2 & 0 & 0 & 100 & 4 & 0 & 0 & 100 & 1 & 0 & 0 & 0 & 0 & 0 & 0 & 100 & 7 & 0 & 0 & 7 \\
\hline DHQs & 100 & 1 & 0 & 0 & 100 & 1 & 0 & 0 & 100 & 1 & 0 & 0 & 100 & 1 & 0 & 0 & 100 & 4 & 0 & 0 & 4 \\
\hline \multicolumn{22}{|l|}{ Category II } \\
\hline THQs & 80 & 4 & 20 & 1 & 100 & 2 & 0 & 0 & 100 & 1 & 0 & 0 & 33 & 1 & 67 & 2 & 73 & 8 & 27 & 3 & 11 \\
\hline RHCs & 29 & 2 & 71 & 5 & 50 & 1 & 50 & 1 & 0 & 0 & 100 & 2 & 0 & 0 & 100 & 9 & 15 & 3 & 85 & 17 & 20 \\
\hline BHUs & 27 & 8 & 73 & 22 & 7 & 3 & 93 & 40 & 28 & 5 & 72 & 13 & 14 & 4 & 86 & 24 & 17 & 20 & 83 & 99 & 119 \\
\hline MCH Centers & 100 & 1 & 0 & 0 & 50 & 1 & 50 & 1 & 100 & 6 & 0 & 0 & 0 & 0 & 100 & 1 & 80 & 8 & 20 & 2 & 10 \\
\hline \multicolumn{22}{|l|}{ Category III } \\
\hline Dispensaries & 80 & 16 & 20 & 4 & 64 & 16 & 36 & 9 & 38 & 3 & 63 & 5 & 0 & 0 & 100 & 4 & 61 & 35 & 39 & 22 & 57 \\
\hline Total DoH & 74 & 34 & 26 & 32 & 67 & 28 & 33 & 51 & 66 & 17 & 34 & 20 & 21 & 6 & 65 & 40 & 64 & 85 & 36 & 143 & 228 \\
\hline \multicolumn{22}{|c|}{ Population Welfare Department } \\
\hline FHCs & 100 & 1 & 0 & 0 & 100 & 1 & 0 & 0 & 0 & 0 & 0 & 0 & 75 & 3 & 25 & 1 & 83 & 5 & 17 & 1 & 6 \\
\hline FWCs & 74 & 14 & 26 & 5 & 91 & 30 & 9 & 3 & 53 & 8 & 47 & 7 & 43 & 12 & 57 & 16 & 67 & 64 & 33 & 31 & 95 \\
\hline Total PWD & 87 & 15 & 13 & 5 & 95 & 31 & 5 & 3 & 27 & 8 & 23 & 7 & 59 & 15 & 41 & 17 & 75 & 69 & 25 & 32 & 101 \\
\hline Total Public Static Facilities & 80 & 49 & 20 & 37 & 81 & 59 & 19 & 54 & 47 & 25 & 28 & 27 & 40 & 21 & 53 & 57 & 70 & 154 & 30 & 175 & 329 \\
\hline Community-based Workers & & & & & & & & & & & & & & & & & & & & & \\
\hline LHWs & 100 & 468 & 100 & 380 & 100 & 715 & 100 & 471 & 100 & 174 & 100 & 281 & 100 & 163 & 100 & 325 & 100 & 1520 & 100 & 1457 & 2177 \\
\hline Private Sector & & & & & & & & & & & & & & & & & & & & & \\
\hline NGO Clinics & 47 & 14 & 53 & 16 & 97 & 35 & 3 & 1 & 40 & 6 & 60 & 9 & 33 & 3 & 67 & 6 & 64 & 58 & 36 & 32 & 90 \\
\hline Private Hospitals & 60 & 74 & 40 & 50 & 87 & 148 & 13 & 22 & 67 & 22 & 33 & 11 & 73 & 55 & 27 & 20 & 74 & 299 & 26 & 103 & 402 \\
\hline Male Doctor Clinics & 47 & 87 & 53 & 98 & 87 & 169 & 13 & 26 & 67 & 52 & 33 & 26 & 47 & 40 & 53 & 46 & 64 & 348 & 36 & 196 & 544 \\
\hline Female Doctor Clinics & 54 & 22 & 46 & 19 & 94 & 46 & 6 & 3 & 80 & 8 & 20 & 2 & 46 & 6 & 54 & 7 & 73 & 82 & 27 & 31 & 113 \\
\hline LHV/Nurse/Midwife Clinics & 41 & 23 & 59 & 33 & 69 & 110 & 31 & 49 & 43 & 20 & 57 & 27 & 35 & 6 & 65 & 11 & 57 & 159 & 43 & 120 & 279 \\
\hline Dispenser Clinics & 50 & 4 & 50 & 4 & 42 & 171 & 58 & 239 & 28 & 36 & 72 & 94 & 40 & 82 & 60 & 124 & 39 & 293 & 61 & 461 & 754 \\
\hline Homeopath/Hakeem Clinics & 54 & 194 & 46 & 163 & 83 & 904 & 17 & 183 & 57 & 176 & 43 & 135 & 57 & 115 & 43 & 87 & 71 & 1389 & 29 & 568 & 1957 \\
\hline Total Private Facilities & 52 & 418 & 48 & 383 & 75 & 1583 & 25 & 523 & 51 & 320 & 49 & 304 & 50 & 307 & 50 & 301 & 63 & 2628 & 37 & 1511 & 4139 \\
\hline Pharmacies & 59 & 422 & 41 & 291 & 86 & 1218 & 14 & 197 & 49 & 206 & 51 & 212 & 55 & 325 & 45 & 262 & 62 & 2171 & 38 & 962 & 3133 \\
\hline Overall (without LHWs) & 56 & 889 & 44 & 711 & 79 & 2860 & 21 & 774 & 50 & 551 & 50 & 543 & 51 & 653 & 49 & 620 & 65 & 4953 & 35 & 2648 & 7601 \\
\hline
\end{tabular}

Source: CFP and PC-Landscape

Category I = Facilities with more than 50 beds

Category II = Facilities with 1 to 50 beds

Category III = Facilities not providing inpatient care 


\section{Appendix E}

\section{Provision of FP Services by Sub-categories of Health Facilities}

Table E1 presents a further breakdown of provision of at least one FP service or method by various types of public and private facilities. The data shows that, in the public sector, Category I facilities, including teaching hospitals and DHQs, are all providing FP services. Among Category II facilities, while BHUs and mother and child health centers (MCHs) are all providing at least one FP service, gaps are seen at THQs and RHCs in Rawalpindi. Dispensaries in rural areas of Faisalabad and in urban areas of Bahawalpur are more active than in other districts.

Much more variation is evident across the different types of health facilities in the private sector. Clinics of the mid-level cadres, i.e., Lady Health Visitors (LHVs), nurses, and midwives, are consistently more active in providing FP services in all districts. The other notable types of health facilities in the private sector include hospitals and, to some extent, NGO clinics. Private hospitals are more active in Rawalpindi, Faisalabad and in rural areas of Bahawalpur while NGO clinics show reasonably high involvement in all areas except rural areas of Rawalpindi district. Female private doctors are performing well in Rawalpindi and Rahimyar Khan and in urban areas of Faisalabad and Bahawalpur but data indicates they have no presence in rural areas of Faisalabad and Bahawalpur districts. Clinics of male doctors are present in good numbers but a limited number of these doctors are providing services in Rawalpindi and, to some extent, in rural areas of other districts. Clinics of dispensers and of homeopaths or hakeems are present in far larger numbers than the other types, but generally the proportions providing any FP services are quite low. However, in rural areas of the southern districts, Bahawalpur and Rahimyar Khan, higher proportions of hakeems/homeopaths and especially dispensers are active. Better proportions are also seen in urban Rawalpindi, although the number of dispenser clinics mapped was quite low. It is important to note that hakeems or homeopaths were only recently permitted to dispense fewer methods of family planning services.

Most pharmacies are selling at least one family planning product in all districts, with the proportion of sellers generally much higher in urban areas, except in Bahawalpur. 
Table E1: Proportion of Sub-categories of Health Facilities and Pharmacies Offering any FP Service, by District and Urban/Rural Location in Study Areas

\begin{tabular}{|c|c|c|c|c|c|c|c|c|c|c|c|c|c|c|c|c|}
\hline \multirow{3}{*}{ Type of Facility } & \multicolumn{3}{|c|}{ Rawalpindi } & \multicolumn{3}{|c|}{ Faisalabad } & \multicolumn{3}{|c|}{ Bahawalpur } & \multicolumn{3}{|c|}{ Rahimyar Khan } & \multicolumn{3}{|c|}{ Overall Provision } & \multirow{3}{*}{\begin{tabular}{|c|} 
Total \\
$\mathbf{N}$
\end{tabular}} \\
\hline & Urban & Rural & \multirow{2}{*}{$\mathbf{N}$} & Urban & Rural & \multirow{2}{*}{$\mathbf{N}$} & Urban & Rural & \multirow{2}{*}{$\mathbf{N}$} & Urban & Rural & \multirow{2}{*}{$\mathbf{N}$} & Urban & Rural & \multirow{2}{*}{$\mathbf{N}$} & \\
\hline & $\%$ & $\%$ & & $\%$ & $\%$ & & $\%$ & $\%$ & & $\%$ & $\%$ & & $\%$ & $\%$ & & \\
\hline \multicolumn{17}{|l|}{ Department of Health } \\
\hline \multicolumn{17}{|l|}{ Category I } \\
\hline Teaching Hospitals & 100 & - & 2 & 100 & - & 4 & 100 & - & 1 & - & - & - & 100 & - & 7 & 7 \\
\hline DHQs & 100 & - & 1 & 100 & - & 1 & 100 & - & 1 & 100 & - & 1 & 100 & - & 4 & 4 \\
\hline \multicolumn{17}{|l|}{ Category II } \\
\hline THQs & 75 & 100 & 4 & 100 & - & 2 & 100 & - & 1 & 100 & 100 & 3 & 88 & 100 & 10 & 11 \\
\hline RHCs & 50 & 60 & 4 & 100 & 100 & 2 & - & 100 & 2 & - & 100 & 9 & 67 & 88 & 17 & 20 \\
\hline BHUs & 100 & 100 & 30 & 100 & 100 & 43 & 100 & 100 & 18 & 100 & 100 & 28 & 100 & 100 & 119 & 119 \\
\hline MCH Centers & 100 & - & 1 & 100 & 100 & 2 & 100 & - & 6 & - & 100 & 1 & 100 & 100 & 10 & 10 \\
\hline \multicolumn{17}{|l|}{ Category III } \\
\hline Dispensaries & 38 & 25 & 7 & 44 & 78 & 14 & 67 & 20 & 3 & - & - & - & 43 & 41 & 24 & 57 \\
\hline \multicolumn{17}{|l|}{ Population Welfare Department } \\
\hline FHCs & 100 & - & 1 & 100 & - & 1 & - & - & - & 100 & 100 & 4 & 100 & 100 & 6 & 6 \\
\hline FWCs & 100 & 100 & 19 & 100 & 100 & 33 & 100 & 100 & 15 & 100 & 100 & 28 & 100 & 100 & 95 & 95 \\
\hline \multicolumn{17}{|l|}{ Community-based Workers } \\
\hline LHWs & 100 & 100 & 848 & 100 & 100 & 1186 & 100 & 100 & 455 & 100 & 100 & 488 & 100 & 100 & 2977 & 2977 \\
\hline \multicolumn{17}{|l|}{ Private Sector } \\
\hline NGO Clinics & 64 & 19 & 12 & 57 & 100 & 21 & 50 & 56 & 8 & 100 & 50 & 6 & 60 & 38 & 47 & 90 \\
\hline Private Hospitals & 55 & 54 & 68 & 45 & 45 & 76 & 18 & 27 & 7 & 22 & 20 & 16 & 41 & 43 & 167 & 402 \\
\hline Male Doctor Clinics & 31 & 24 & 51 & 7 & 15 & 15 & 6 & 12 & 6 & 8 & 15 & 10 & 13 & 19 & 82 & 544 \\
\hline Female Doctor Clinics & 73 & 53 & 26 & 50 & - & 23 & 25 & - & 2 & 33 & 43 & 5 & 52 & 42 & 56 & 113 \\
\hline LHV/Nurse/Midwife Clinics & 74 & 52 & 34 & 74 & 61 & 111 & 55 & 48 & 24 & 67 & 45 & 9 & 71 & 54 & 178 & 279 \\
\hline Dispenser Clinics & 25 & 50 & 3 & 6 & 7 & 28 & 6 & 33 & 33 & 4 & 21 & 29 & 6 & 16 & 93 & 754 \\
\hline Homeopath/Hakim Clinics & 22 & 7 & 53 & 3 & 4 & 32 & 1 & 12 & 17 & - & 7 & 6 & 5 & 7 & 108 & $\begin{array}{c}195 \\
7\end{array}$ \\
\hline Pharmacies & 85 & 78 & 586 & 76 & 51 & 1027 & 71 & 63 & 280 & 77 & 61 & 410 & 77 & 65 & 2303 & 3133 \\
\hline
\end{tabular}

Source: CFP and PC-Landscape

Category I = Facilities with more than 50 beds

Category II = Facilities with 1 to 50 beds

Category III = Facilities not providing inpatient car 